US Army Corps

of Engineers ${ }_{\circledast}$

Engineer Research and

Development Center

Rapid Airfield Damage Recovery (RADR) Program

\title{
Evaluation of Airfield Damage Repair Methods for Extreme Cold Temperatures
}

Emily Asenath-Smith, Terry D. Melendy, Jr., Amelia M. Menke,

February 2019

Andrew P. Bernier, and George L. Blaisdell

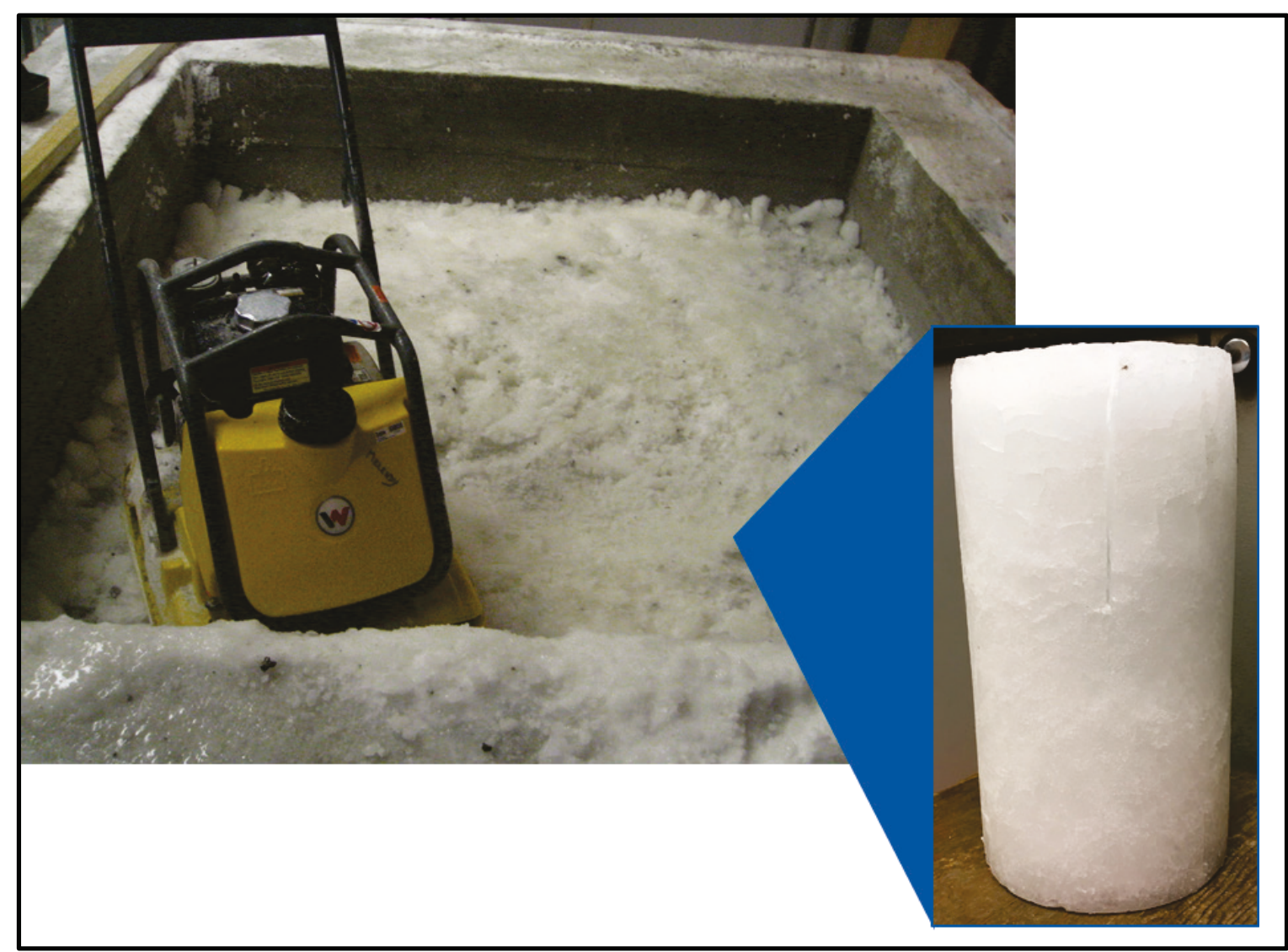


The U.S. Army Engineer Research and Development Center (ERDC) solves the nation's toughest engineering and environmental challenges. ERDC develops innovative solutions in civil and military engineering, geospatial sciences, water resources, and environmental sciences for the Army, the Department of Defense, civilian agencies, and our nation's public good. Find out more at www.erdc.usace.army.mil.

To search for other technical reports published by ERDC, visit the ERDC online library at http://acwc.sdp.sirsi.net/client/default. 


\section{Evaluation of Airfield Damage Repair Methods for Extreme Cold Temperatures}

Emily Asenath-Smith, Terry D. Melendy, Jr., Amelia M. Menke, Andrew P. Bernier, and George L. Blaisdell

Cold Regions Research and Engineering Laboratory

US Army Engineer Research and Development Center 72 Lyme Road

Hanover, NH 03755

Final report

Approved for public release; distribution is unlimited. 


\section{Abstract}

To address the need for expedient repair solutions for paved runways in cold environments, airfield damage repair Rapid Airfield Damage Recovery (RADR) materials were tested at temperatures down to $-40^{\circ} \mathrm{F}$. New materials and methods were developed to fill the identified performance gaps for conventional RADR materials. Simulated crater repairs were performed at -20 and $-40{ }^{\circ} \mathrm{F}$. Folded fiber glass panels and hinges met the published tensile strength, but did not meet the required flexural strength. Fiberglass-reinforced polyester panels retained their $73^{\circ} \mathrm{F}$ tensile and flexural strengths down to $-40^{\circ} \mathrm{F}$. If required, foreign object debris covers can be used at temperatures below freezing, but further experimentation is needed to fully assess matting candidates at temperatures below $\mathrm{O}^{\circ} \mathrm{F}$. Geocell sidewalls and junctions showed an increased maximum force, with a ten-fold decrease in the displacement before failure. Rapid setting flowable fill and polyurethane foam, prepared conventionally, were demonstrated as backfill materials at temperatures as low as $\mathrm{O}^{\circ} \mathrm{F}$. As a cap material, Rapid Set ${ }^{\circledR}$ concrete can be placed using conventional techniques down to $17^{\circ} \mathrm{F}$. Snow and ice materials were demonstrated as backfill materials below freezing and met the strength requirements for capping applications at temperatures down to $-40^{\circ} \mathrm{F}$.

DISCLAIMER: The contents of this report are not to be used for advertising, publication, or promotional purposes. Citation of trade names does not constitute an official endorsement or approval of the use of such commercial products. All product names and trademarks cited are the property of their respective owners. The findings of this report are not to be construed as an official Department of the Army position unless so designated by other authorized documents. 


\section{Contents}

Abstract.............................................................................................................. ii

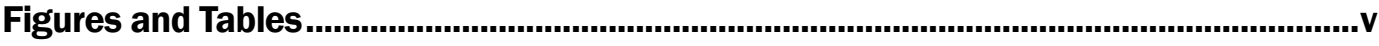

Preface ................................................................................................................. ix

Unit Conversion Factors....................................................................................... $\mathrm{x}$

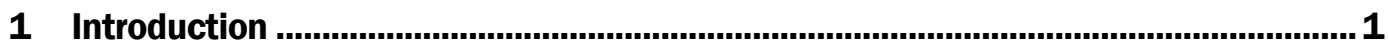

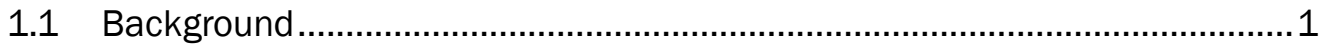

1.1.1 Compacted snow as a runway repair material ....................................................... 2

1.1.2 Additives in snow and ice materials.................................................................. 5

1.2 Objectives..................................................................................... 5

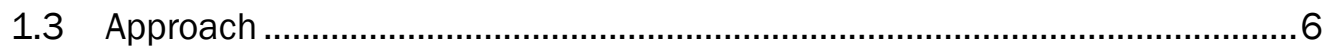

2 Experimental Design .................................................................................. 7

2.1 Materials overview and properties tested ........................................... 7

2.1.1 Laboratory instrumentation................................................................................. 7

2.1.2 Materials and temperatures studied ................................................................ 8

2.1.3 Foreign object debris (FOD) covers ................................................................. 9

2.1.4 Cellular confinement systems (geocells) ............................................................ 12

2.1.5 Polyurethane foam backfill material ............................................................... 14

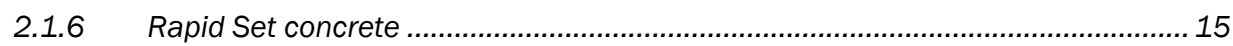

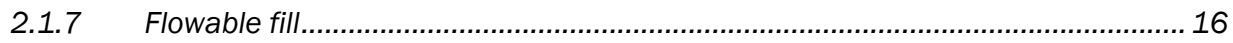

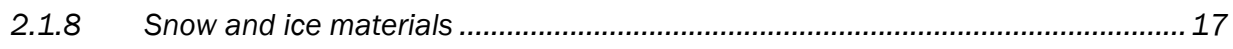

2.1.9 Simulated crater repairs ............................................................................ 18

3 Results and Discussion ...........................................................................22

3.1 Existing RADR Materials ........................................................... 22

3.1.1 Foreign object debris (FOD) covers ................................................................. 22

3.1.2 Cellular confinement systems (geocells) ......................................................... 42

3.1.3 Polyurethane foam backfill material ......................................................................4 49

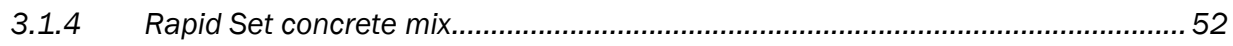

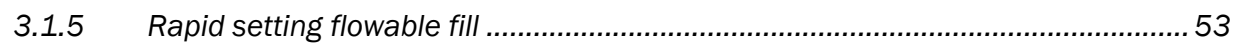

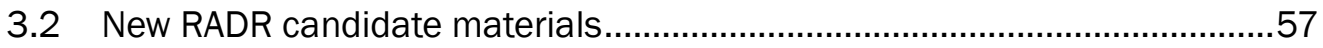

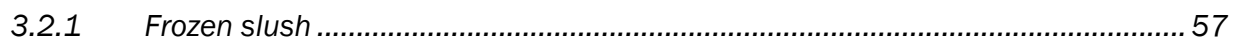

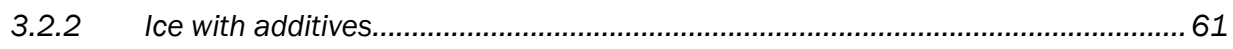

3.2.3 Debris reinforced ice.......................................................................................... 62

3.3 Extreme cold repair of a full-scale crater .......................................... 65

3.3.1 Dry flowable fill (dFF) as a backfill material at $17^{\circ} \mathrm{F}$.............................................65

3.3.2 Rapid Set concrete cap at $17^{\circ} \mathrm{F}$ (over dry flowable fill backfill)............................. 67

3.3.3 Debris-reinforced ice backfill layer at $-20^{\circ} \mathrm{F}$.......................................................6. 69

3.3.4 Frozen slush repair of a full-size crater at $-20^{\circ} \mathrm{F}$................................................ 71

3.3.5 Snow slush with cellulose additive repair of a full-size crater at $-20^{\circ} \mathrm{F} . . . . . . . . . . . . . . .74$ 


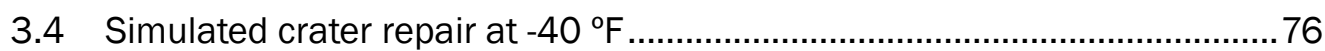

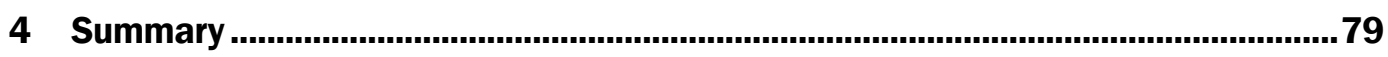

4.1 Existing RADR materials performance …................................................ 79

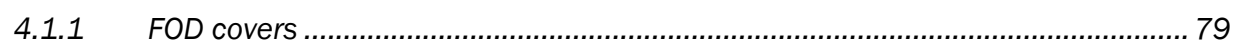

4.1.2 Geocell cellular confinement systems ................................................................... 80

4.1.3 Polyurethane foam backfill...................................................................... 80

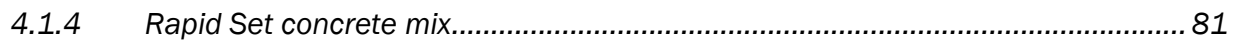

4.1.5 Rapid setting flowable fill (FF) ............................................................................ 81

4.2 Performance of new candidate RADR materials .......................................81

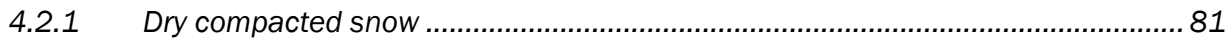

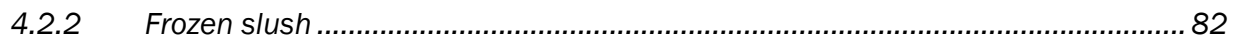

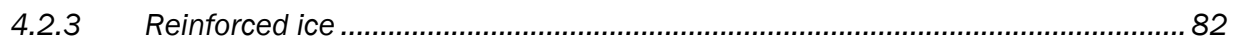

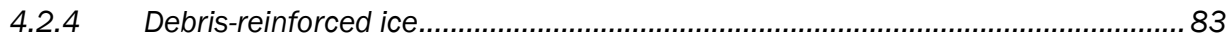

4.3 Performance envelops of materials for RADR ......................................... 83

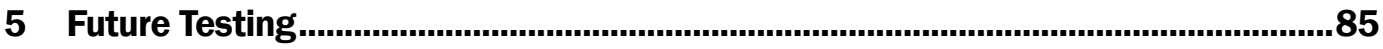

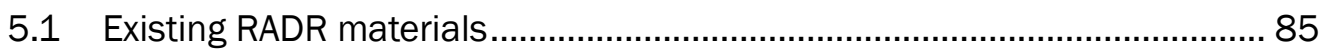

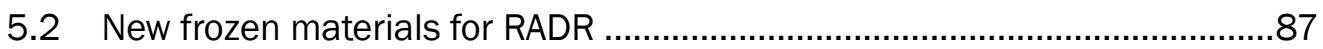

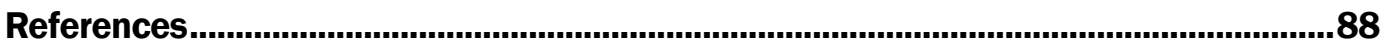

Appendix A: Individual Loading Curves for Mechanical Testing of FOD Covers...........91

Appendix B: Photographs of Polyurethane Foam Samples during Curing at -40

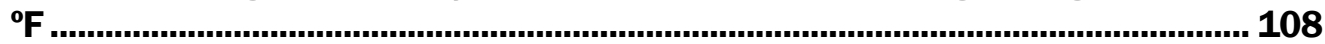

Appendix C: Plots of Compressive Strength versus Temperature for Existing

Cementitious Crater Fill Materials .............................................................. 109

Appendix D: Plots of Compressive Strength versus Temperature for New

Crater Fill Materials for use Below Freezing .................................................... 111

Report Documentation Page 


\section{Figures and Tables}

\section{Figures}

Figure 1. Graphical representation of the cross section of a runway crater.

Figure 2. Patching of damaged area of compacted snow runway near McMurdo Station, Antarctica: a) excavated damaged area, b) fresh, tumbled snow being introduced to cavity, c) initial compaction of lower 8-inch layer, d) continued compaction of lower layer, and e) final compaction of upper 8-in. layer (which was placed and compacted in the same fashion as the lower layer)..

Figure 3. Universal load frame at ERDC-CRREL a) shown with environmental chamber, which allows for temperature control down to $-90^{\circ} \mathrm{F}$ and b) looking inside environmental chamber to loading platens used for uniaxial compression of cylindrical specimens.

Figure 4. Illustration of the different configurations that were used to assess the strength of geocell structures at extreme cold temperatures: a) sidewall tension; b) junction shear; c) junction peel. Content reproduced from content in Cancelli et al (Cancelli et al. 1993).

Figure 5. Gripping assembly used to test the geocell specimens

Figure 6 . The metal form used to simulate a runway section for full scale mock crater repairs in the cold facilities at ERDC-CRREL

Figure 7. Fully assembled simulated crater ready for repairs with select backfill layer and capping materials: a) top view; b) side view.

Figure 8. The circular metal form used to simulate a crater for repair with frozen slush materials at $-40^{\circ} \mathrm{F}$.

Figure 9. FFM specimens after tensile testing at various temperatures: a) 73; b) 25 ; c) 0 ; d) -25 ; e) $-40^{\circ} \mathrm{F}$.

Figure 10. Tensile strength and percent elongation of FFM panel specimens as a function of temperature.

Figure 11. Prepared FFM hinge specimens showing the folded, banded configuration used for temperature conditioning.....

Figure 12. FFM hinge failure modes: a) predominantly, hinges failed at the elastomer-panel junction for the FFM hinges; b) at $-40^{\circ} \mathrm{F}$, failure within the hinge was observed.

Figure 13. Tensile strength and percent elongation for FFM hinges as a function of temperature.

Figure 14. FRP specimens after tensile testing at various temperatures: a) 73; b) 25 ; c) 0 ; d) -25 ; e) $-40^{\circ} \mathrm{F}$.

Figure 15. Tensile strength and percent elongation of FRP panels at various temperatures.

Figure 16. Flexural testing setup used for testing FFM and FRP panel specimens. In this image, the testing of an FRP specimen at $0^{\circ} \mathrm{F}$ is shown. Note the delamination of the specimen into layers, which are evident in the ends also.

Figure 17. FFM specimens after flexural testing at various temperatures: a) 73; b) 25 ; c) 0 ; d) -25 ; e) $-40^{\circ} \mathrm{F}$. 
Figure 18. Flexural strength and percent deflection of FFM panels at various temperatures

Figure 19. FRP panel specimens after flexural testing at various temperatures: a) 73; b) 25 ; c) 0; d) -25; e) $-40^{\circ} \mathrm{F}$.

Figure 20. Flexural strength and percent deflection of FRP panels at various temperatures.

Figure 21. Experimental setup used for the flexural fatigue loading of FRP mats at low temperatures.

Figure 22. A comparison of the delamination characteristics of the FRP specimens subject to flexural testing: upper specimen was subject to single loadto-failure and shows distinct glass fibers between delaminated layers at the right end; the lower specimen was subject to cyclic flexural testing wherein the glass fibers were worn from between the layers as evident at the left end of the specimen.

Figure 23. Flexural fatigue testing of FRP panels showing the decline in flexural strength with cyclic loading for up to 500 cycles. The circled data points denote the initial flexural strength taken by a single load-to-failure.

Figure 24. Flexural strength of FRP panels after 5,000 fatigue load cycles at various temperatures.

Figure 25. Barcol hardness of FOD covers at various temperatures: a) FFM; b) FRP.

Figure 26. Geocell specimens after testing sidewall tension

Figure 27. Force and displacement values measured on geocell sidewalls in tension at all temperatures of interest.

Figure 28. Geocell specimens after testing the junctions in shear.

Figure 29. Force and displacement data for geocell weld junctions subject to shear loading.

Figure 30. Geocell specimens after peel testing the junctions.

Figure 31. Force and displacement behavior of geocell junction welds subject to peel testing.

Figure 32. Extreme cold expansion experiments with geocell grids at various temperatures. Photographic image of 'retracted' geocell after manual expansion: a) at $\left.\left.\left.73^{\circ} \mathrm{F}, \mathrm{b}\right) 25^{\circ} \mathrm{F}, \mathrm{c}\right) 0^{\circ} \mathrm{F}, \mathrm{d}\right)-25^{\circ} \mathrm{F}$, and e) $-40^{\circ} \mathrm{F}$. Note: The geocell panel is displayed in the same orientation in all images.

Figure 33. Plot of volume expansion and density of polyurethane foam as a function of temperature.

Figure 34. Plot of compressive strength of foam as a function of temperature.

Figure 35. Foam samples after uniaxial compression testing at temperatures down to $-25^{\circ} \mathrm{F}$.

Figure 36. A cylindrical specimen formed using the dry flowable fill technique 0 ${ }^{\circ} \mathrm{F}$. a) As formed, the lack of cohesion between lifts is seen as the top of the specimen broke and is placed on top. b) After thawing, the specimens were observed to cure, forming a cohesive cylinder.

Figure 37. Frozen slush testing specimens (a) before and (b) after subjecting to uniaxial compressive loads. 
Figure 38. Comparison of average UCS of current and proposed runway repair materials at a range of temperatures.

Figure 39. Debris-reinforced ice specimens manufactured for uniaxial testing; a) before and b) after testing.

Figure 40. Layer of wetted dry flowable fill being stirred with rake when filling the base of the full scale crater.

Figure 41. RSP index of lightly wetted flowable fill at $17^{\circ} \mathrm{F}$ during first $24 \mathrm{hr}$

Figure 42. Load of Rapid Set concrete in mixer at $17^{\circ} \mathrm{F}$ just prior pouring.

Figure 43. Top surface of mock crater top layer repair with RS concrete after 24-

$\mathrm{hr}$ since completion.

Figure 44. RSP index of Rapid Set concrete at $17^{\circ} \mathrm{F}$ during first $24 \mathrm{hr}$.

Figure 45. Simulated crater repair performed with debris-reinforced ice: a) concrete debris backfill; b) backfill after introduction of water and, c) after complete freeze-up.

Figure 46. Repair of a full sized crater with frozen slush at $-20^{\circ} \mathrm{F}$. a) The top of the backfill layer. b) Filling the cap layer with compacted frozen slush.................................72

Figure 47. RSP index of frozen slush at $-20^{\circ} \mathrm{F}$ during first $24 \mathrm{hr}$........................................73

Figure 48. Cold water used to flood snow and ice filled damaged area of glacial ice runway (temperature approximately $15^{\circ} \mathrm{F}$ )............................................................... 74

Figure 49. Snow slurry mix with cellulose additive on simulated crater. ...........................75

Figure 50. RSP index of frozen slush with additive at $-20^{\circ} \mathrm{F}$ during first $22 \mathrm{hr}$...................75

Figure 51. Top surface of dry snow in simulated crater tamped with garden rake............ 76

Figure 52. Crater repair with frozen slush at $-40^{\circ} \mathrm{F}$ : a) saturated snow surface; b) surface of frozen slush repair. Note: The smooth frozen slush surface in b) is obscured by snow deposition on the top caused by ambient moisture...

Figure 53. Uniaxial unconfined compressive strength of frozen slush at $-40^{\circ} \mathrm{F}$, derived from RSP penetrometer testing.

\section{Tables}

Table 1. Certified values for FOD cover material properties. .................................................. 9

Table 2. Certified specifications for material properties of geocell confinement grids.

Table 3. Certified specifications for polyurethane foam used as ADR backfill material.

Table 4. Target values of average penetrometer values for cap and backfill layers for a compacted snow patch.

Table 5. Average values for tensile strength and percent elongation of FFM panels subject to tensile loading.

Table 6. Tensile strength and elongation of the FFM hinges as a function of temperature.

Table 7. Tensile strength and percent elongation of FRP panels as a function of temperature.

Table 8. Flexural strength and percent deflection of FFM panels. 
Table 9. Flexural strength and percent deflection of FRP panels.

Table 10. Results from flexural fatigue testing of FRP panels loaded to $75 \%$ deflection for up to 500 cyclic loads.

Table 11. Results from flexural fatigue testing of FRP panels loaded to $75 \%$ deflection for up to 5000 cyclic loads.

Table 12. Individual values for Barcol hardness of FOD covers.

Table 13. Force and displacement values for tensile testing of 4 in. geocell (GW20) sidewalls.

Table 14. Force and displacement values for shear testing of 6-in. geocell (GW20)

junction welds.

Table 15. Force and displacement values for peel testing of 4 in. geocell (GW20) junction welds.

Table 16. Summary of data for testing foam as a function of temperature.......................50

Table 17. Uniaxial compressive strength of warm Rapid Set concrete................................53

Table 18. Uniaxial compressive strength of below freezing Rapid Set concrete. .53

Table 19. Uniaxial compressive strength of flowable fill prepared according to traditional methods at $73^{\circ} \mathrm{F}$.

Table 20. Uniaxial compressive strength of flowable fill prepared according to traditional methods at $23^{\circ} \mathrm{F}$.

Table 21. Uniaxial compressive strength of flowable fill prepared according to traditional methods at $\mathrm{O}^{\circ} \mathrm{F}$. 55

Table 22. Performance ranges for traditional and new candidate RADR materials...........59

Table 23. Uniaxial compressive strength of frozen slush.

Table 24. Uniaxial compressive strength of ice composite samples.

Table 25. Uniaxial compressive strength of concrete debris-frozen water samples. .........64

Table 26. Performance ranges for traditional and new candidate RADR materials. 


\section{Preface}

This study was conducted for the U.S. Air Force Civil Engineer Center (AFCEC) under Project 463347, Rapid Airfield Damage Recovery (RADR) Program. The technical monitor was Mr. Craig Mellerski, AFCEC. The Program Manager was Mr. Jeb S. Tingle, U.S. Army Engineer Research and Development Center-Geotechnical and Structures Laboratory (ERDCGSL).

The work was performed by Force Projection and Sustainment Branch (CEERD-RRH) and the Engineering Resources Branch (CEERD-RRE) of the Research and Engineering Division (CEERD-RR), U.S. Army Engineer Research and Development Center, Cold Regions Research and Engineering Laboratory (ERDC-CRREL). At the time of publication, Dr. Harley Cudney was Acting Chief, CEERD-RRH; and Mr. J.D. Horne was Division Chief, CEERD-RR. The Deputy Director of ERDC-CRREL was Mr. David B. Ringelberg, and the Director was Dr. Joseph L. Corriveau.

COL Ivan P. Beckman was the Commander of ERDC, and Dr. David W. Pittman was the Director. 


\section{Unit Conversion Factors}

\begin{tabular}{|c|c|c|}
\hline Multiply & By & To Obtain \\
\hline British thermal units (International Table) & $1,055.056$ & joules \\
\hline cubic feet & 0.02831685 & cubic meters \\
\hline cubic inches & $1.6387064 \mathrm{E}-05$ & cubic meters \\
\hline cubic yards & 0.7645549 & cubic meters \\
\hline degrees Fahrenheit & $(F-32) / 1.8$ & degrees Celsius \\
\hline feet & 0.3048 & meters \\
\hline foot-pounds force & 1.355818 & joules \\
\hline horsepower (550 foot-pounds force per second) & 745.6999 & watts \\
\hline inches & 0.0254 & meters \\
\hline inch-pounds (force) & 0.1129848 & newton meters \\
\hline kilopounds (force) & 4.4482216 & kilonewtons \\
\hline ounces (mass) & 0.02834952 & kilograms \\
\hline ounces (U.S. fluid) & $2.957353 \mathrm{E}-05$ & cubic meters \\
\hline pints (U.S. liquid) & 4.73176 E-04 & cubic meters \\
\hline pints (U.S. liquid) & 0.473176 & liters \\
\hline pounds (force) & 4.448222 & newtons \\
\hline pounds (force) per foot & 14.59390 & newtons per meter \\
\hline pounds (force) per inch & 175.1268 & newtons per meter \\
\hline pounds (force) per square foot & 47.88026 & pascals \\
\hline pounds (force) per square inch & 6.894757 & kilopascals \\
\hline pounds (mass) & 0.45359237 & kilograms \\
\hline pounds (mass) per cubic foot & 16.01846 & kilograms per cubic meter \\
\hline pounds (mass) per cubic inch & $2.757990 \mathrm{E}+04$ & kilograms per cubic meter \\
\hline pounds (mass) per square foot & 4.882428 & kilograms per square meter \\
\hline pounds (mass) per square yard & 0.542492 & kilograms per square meter \\
\hline square feet & 0.09290304 & square meters \\
\hline square inches & $6.4516 \mathrm{E}-04$ & square meters \\
\hline square miles & $2.589998 \mathrm{E}+06$ & square meters \\
\hline square yards & 0.8361274 & square meters \\
\hline yards & 0.9144 & meters \\
\hline
\end{tabular}




\section{Introduction}

\subsection{Background}

The U.S. Air Force (USAF) pavements community has spent considerable effort in the past researching, developing, and testing materials and techniques for airfield damage repair (RADR). These efforts have been concentrated on rapid repair solutions since the time required to return the pavement to service directly affects mission readiness (Priddy 2014). When expedient repairs are required, solutions focus on materials, tools, and techniques to be light, fast, and robust for at least a short time frame (e.g., 100 passes)(Priddy et al. 2007), and low in resources demand (i.e., cost, manpower, equipment required) (Robinson et al. 2016).

In general, the repair process for craters consists of debris removal, cutting, and excavation before backfill and capping as described in Bell et al. (2013). Schematically, the cross section of a crater repair can be envisioned as depicted in Figure 1. The distinction between the backfill and cap layers helps to categorize ADR materials into the two categories. The cap materials typically include cementitious or asphalt materials (Carruth and Howard 2016; Priddy et al. 2016). However, for expedient repairs, a coarse granular material is used to backfill the entire crater, but is surfaced with a composite matting FOD cover (Rushing et al. 2016). Backfill materials can include various soils, stabilized soils, rapid setting flowable fill materials, and expandable foam (Garcia 2017). (Mejias-Santiago et al. 2016; Priddy et al. 2016).

Figure 1. Graphical representation of the cross section of a runway crater.

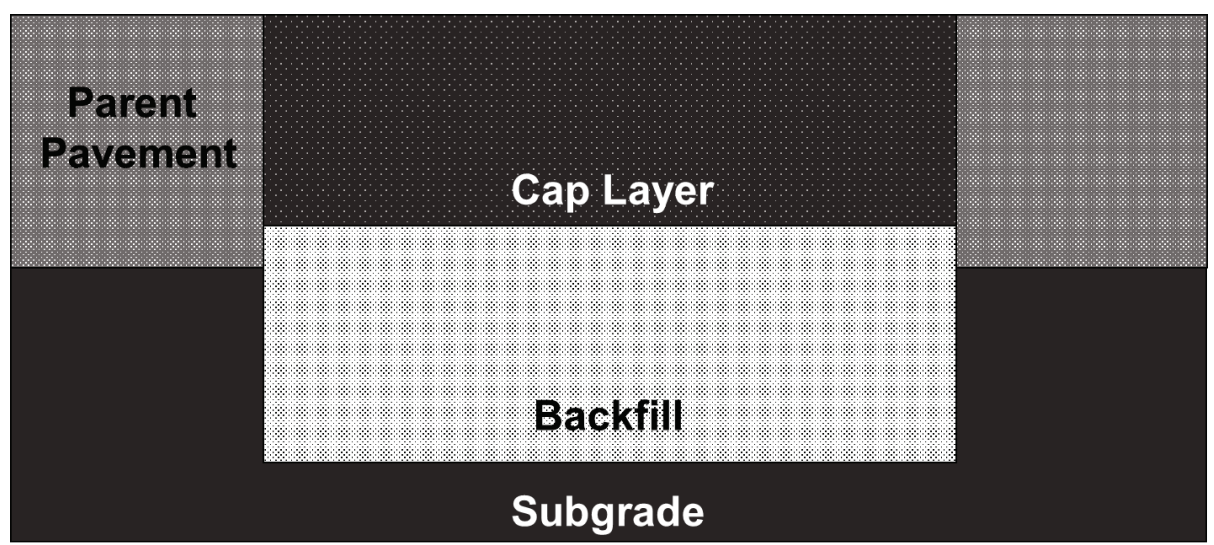




\subsubsection{Compacted snow as a runway repair material}

In Antarctica, the U.S. constructed and maintains a compacted snow runway for heavy cargo aircraft. The USAF routinely operates $\mathrm{C}-17 \mathrm{~s}$ at gross loads of $500,000 \mathrm{lb}$ on this runway. Being founded on a deep snow field (300 ft of glacial snow and ice floating on deep ocean) and constructed entirely of compacted snow, patching of any runway damage caused by aircraft or ground equipment operations (or natural forces like warm temperatures) is naturally achieved by compacting dry native snow.

Dry snow can be used to fill a cavity in a paved runway, but only under limited conditions. In this case, dry means no manually added water; the snow itself may be moist due to solar heating, warm ambient temperatures, or wetting from natural liquid precipitation. This method entails harvesting clean snow from a nearby source, transporting it to the site of the damage, and placing it in a prescribed manner with compaction. Fresh snow (white, not gray; fine grained - snow particles less than 1/8 in.-and not in frozen clumps) is required for a dry snow patch.

Ensuring a good patch is reliant on both the method of placement of the snow in the cavity and near term future weather. Snow is placed and compacted in the cavity in layers of no more than 6-in.-thickness. Snow placed in the cavity should be disaggregated (stirred and manipulated with hand tools or foot-stepping) and the top nominally leveled. Each placed layer must be compacted before placement of the next layer. This can be performed with a walk-behind vibratory plate compactor (set to a low frequency: less than $100 \mathrm{~Hz}$ ), a rammer-style compactor (commonly called a jumping jack), or, if the cavity is not too deep and with gently sloping edges, with a rubber-tired vehicle with tire pressures less than $100 \mathrm{psi}$. Upon consolidation of a given layer, the next layer is placed and the compaction process repeated.

The snow placed and processed from the bottom of the cavity up to about 1 $\mathrm{ft}$ below the original pavement surface can be considered the backfill. The remaining layers added to reach the original pavement surface will constitute the cap. These cap layers must be placed in maximum 4-in. lift thicknesses and care taken to compact the placed snow to the maximum extent possible (determined by there being no more drop in layer surface elevation with repeated compaction efforts). This can be achieved by repeated coverages with the compaction tools being used, in at least three independent directions. Figure 2 shows aspects of such a patch. 
Upon reaching the original pavement surface, the snow patch will need to rest for 24 to $48 \mathrm{hr}$ to allow intergranular bond growth, which, in most situations, will add 50-100 percent strength. A dry, compacted snow patch is likely to only be effective (i.e., have adequate strength) to support aircraft with tire pressures of 200 psi and less when (a) the ground surrounding the cavity is frozen, (b) air temperatures are between 27 and $17^{\circ} \mathrm{F}$ when constructed, and (c) air temperatures remain below $17^{\circ} \mathrm{F}$ during the entire time the patch is required to perform (i.e., support flight operations).

Figure 2. Patching of damaged area of compacted snow runway near McMurdo Station, Antarctica: a) excavated damaged area, b) fresh, tumbled snow being introduced to cavity, c) initial compaction of lower 8-inch layer, d) continued compaction of lower layer, and e) final compaction of upper 8-in. layer (which was placed and compacted in the same fashion as the lower layer).

a)
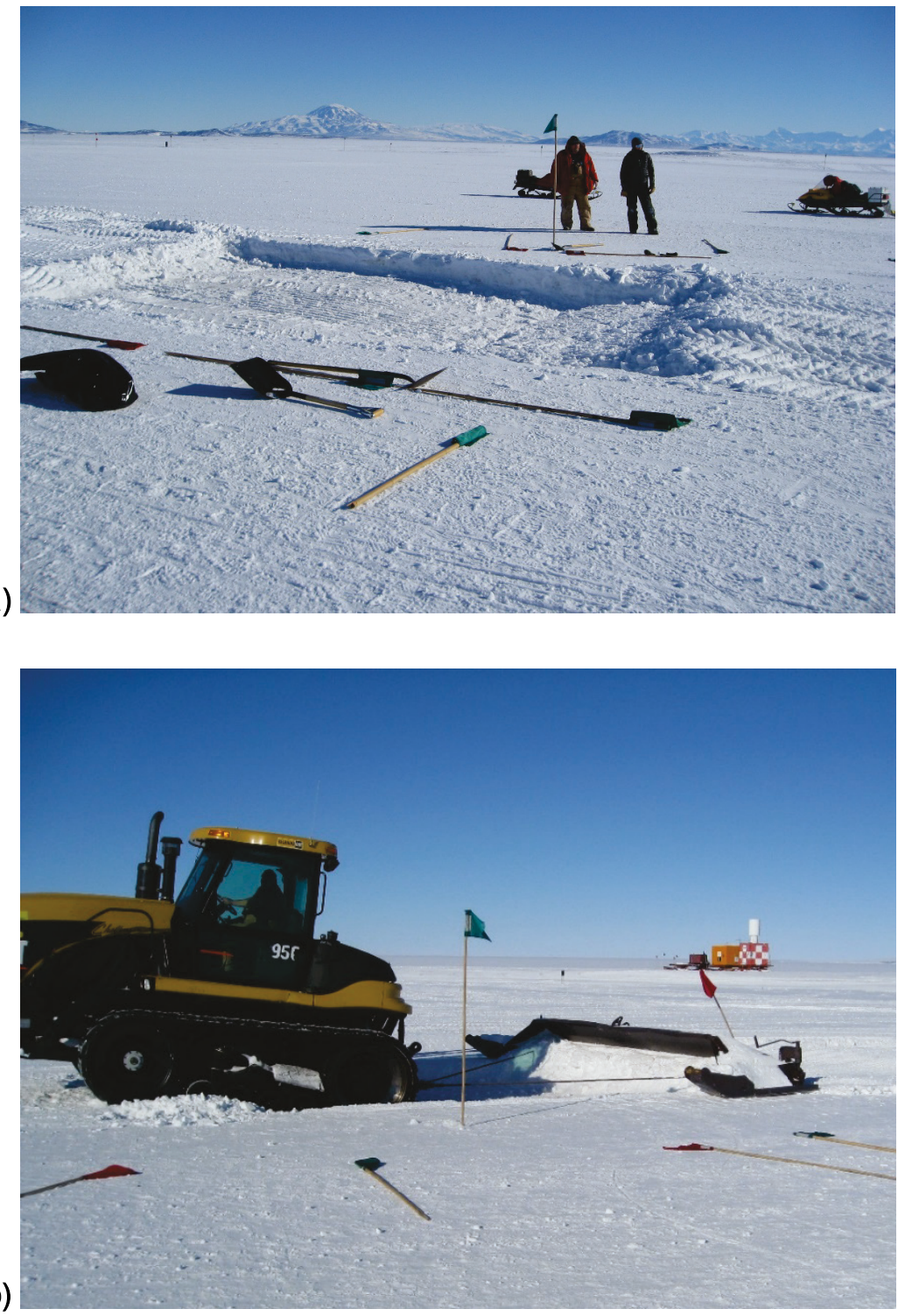
c)

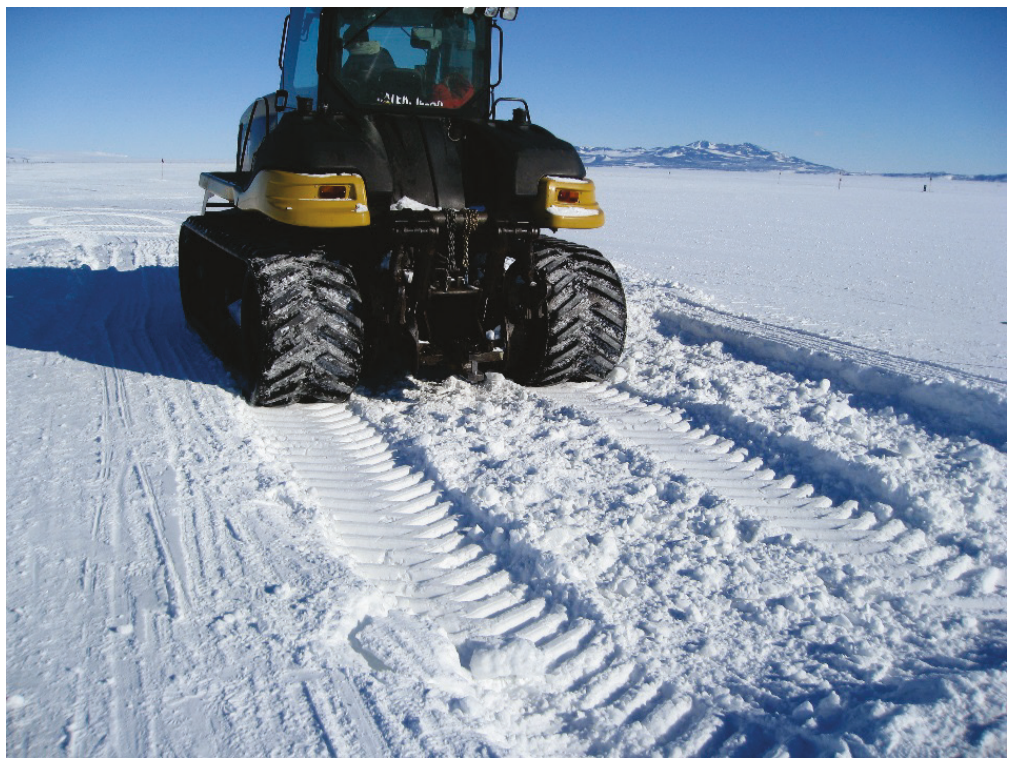

d)

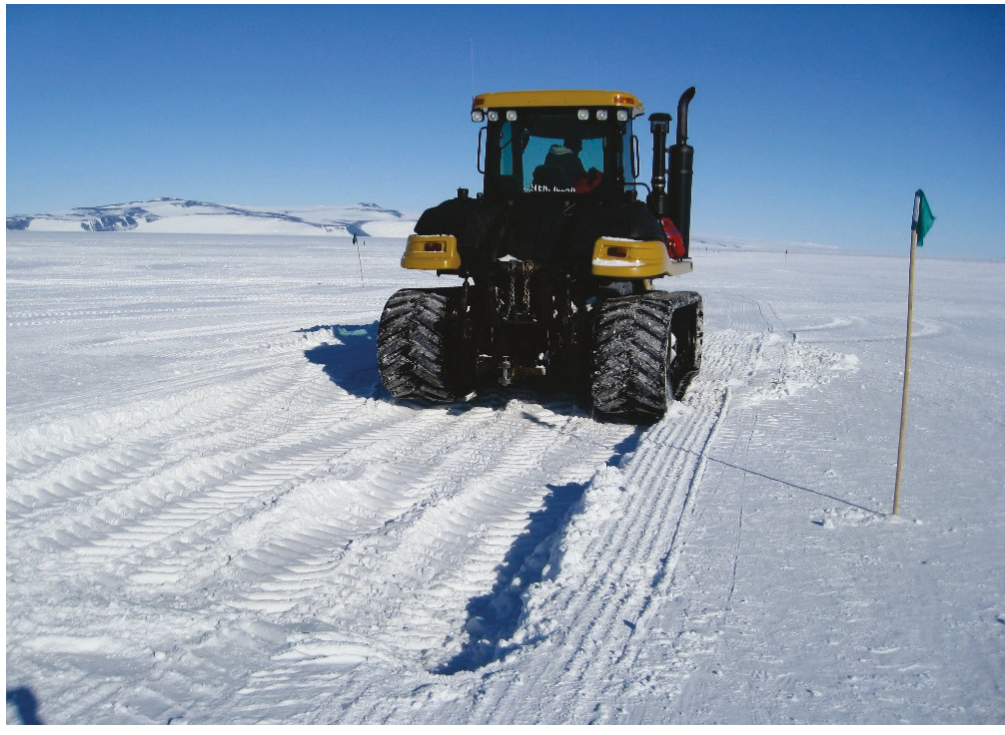

e)

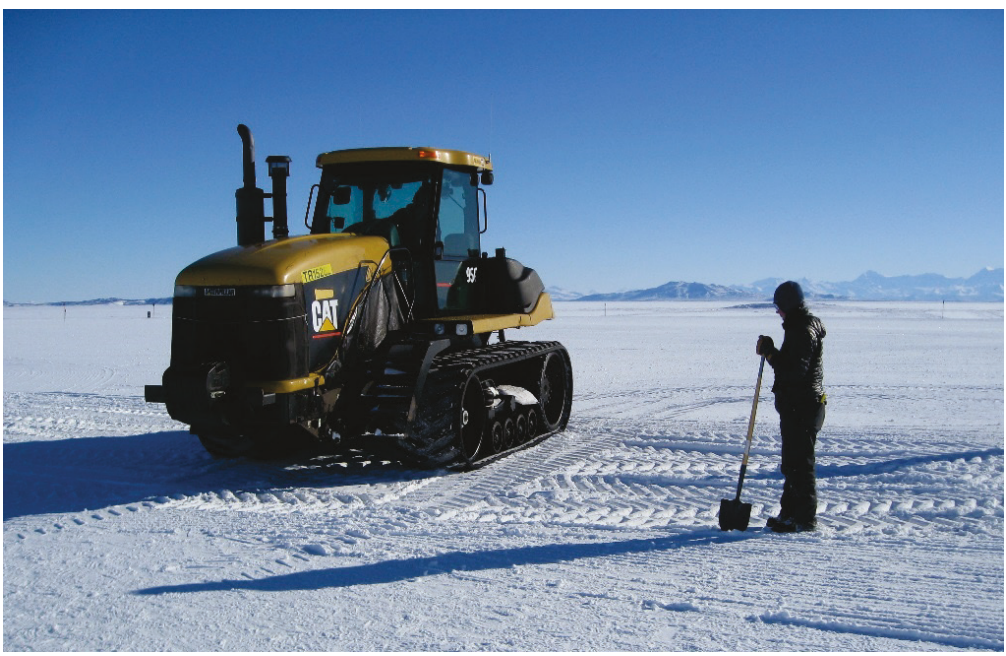




\subsubsection{Additives in snow and ice materials}

The application space for snow and ice materials in roadways and runways has seen implementation only in specific scenarios. As previously discussed, their use in runways composed entirely of snow or ice has been achieved with great success. Their utility in repairing existing concrete and asphalt runways is less widely explored and is one focus of the research reported herein. When translating snow and ice construction techniques to asphalt and concrete runways, the ice and snow properties may need to be modified to allow sufficient bonding and to minimize the differences in strength between the two disparate materials classes.

Motivated by materials shortages in World War II, high performance ice, made from ice reinforced with wood pulp, has been researched for structural applications (Gold 1992). When compared to concrete, such ice-wood composites are reported to have half the weight, while retaining an equivalent flexural strength (Li et al. 2015). When compared to single phase ice, ice-wood composites can have up to a three-fold greater flexural and compressive strength (Vasiliev et al. 2015). U.S. Army Engineer Research and Development Center-Cold Regions Research and Engineering Laboratory (ERDC-CRREL) research and those of others has demonstrated that the incorporation of high aspect ratio $(\mathrm{l} / \mathrm{w}=15)$ fibers is associated with increased load bearing capacity in ice (Vasiliev et al. 2015). In addition, we have discovered that the mechanisms by which fibers strengthen ice stems from their ability to arrest crack propagation during loading. ${ }^{*}$ As a result, cellulose, a fibrous wood-derivative, was used to reinforce snow and ice repairs.

\subsection{Objectives}

The objective of this research project was to assess existing RADR materials at extreme cold temperatures and to develop new innovative materials and methods for rapidly repairing bomb craters at extreme cold temperatures. By first testing existing RADR materials, the performance of existing materials as a function of temperature could be evaluated and technology

\footnotetext{
* Asenath-Smith, E., J. T. D. Melendy, R. Lieb-Lappen, R. Moser, and R. B. Haehnel. 2019. In situ structural and mechanical characterization reveals strengthening mechanism of high aspect ratio materials in ice. (In preparation.)
} 
gaps identified. With a clear description of the gaps, new materials and approaches for runway repairs at temperatures down to $-40{ }^{\circ} \mathrm{F}$ could be developed.

\subsection{Approach}

This research involved laboratory testing and facility-based experiments of alternative repair materials and methods. First, the materials properties of existing RADR materials were tested at select temperatures $(73,25,0,-25$, $-40^{\circ} \mathrm{F}$ ) using instrumentation in laboratories at ERDC-CRREL. The goal of this first set of experiments was to identify the actual (temperature) operational window for existing RADR materials. Next, new materials candidates were identified and tested for use as RADR repair materials at the set temperatures down to $-40^{\circ} \mathrm{F}$. These experiments were designed to fill the performance gaps of existing RADR materials and to provide alternative material options (e.g., indigenous snow/ice) for performing repairs in remote locations. Using the information learned in the first two thrusts of this research, the new methods were used to repair simulated craters at extreme cold temperatures $\left(-20,-40{ }^{\circ} \mathrm{F}\right)$. 


\section{Experimental Design}

\subsection{Materials overview and properties tested}

\subsubsection{Laboratory instrumentation}

Mechanical properties of materials were tested using a hydraulic universal load frame (MTS, Minnesota, USA) equipped with two actuators and three electronically controlled servo-valves. The bottom actuator is capable of reaching 250,000 lbf across a 9-in. loading surface while the top is able to reach 22,000 lbf across a 2.5-in. loading surface. The top actuator has the ability to be controlled by a two-stage or three-stage servo-valve. These features allow the top actuator to have low load, low displacement or highspeed control loadings, respectively.

The system was controlled by an MTS FlexTest SE connected to a computer running MTS 793 software with the Multipurpose Testware Suite (MPT) for test procedure design. The 793 software with MPT allows the user to program ASTM International style testing procedures for repeatable testing and data collection. In addition, standard testing procedures can be modified for unique testing scenarios, and completely custom test procedures can be written and executed.

Temperature control of test samples was achieved using an HVAC environmental chamber (Figure 3) (Bemco, California, USA). The chamber is cooled or heated via closed loop air flow and is capable of reaching temperatures as low as $-90^{\circ} \mathrm{F}$ and as high as $+104^{\circ} \mathrm{F}$. The environmental chamber is designed to reach the desired temperature set point to within $\pm 0.5{ }^{\circ} \mathrm{F}$. 
Figure 3. Universal load frame at ERDC-CRREL a) shown with environmental chamber, which allows for temperature control down to $-90^{\circ} \mathrm{F}$ and $\mathrm{b}$ ) looking inside environmental chamber to loading platens used for uniaxial compression of cylindrical specimens.
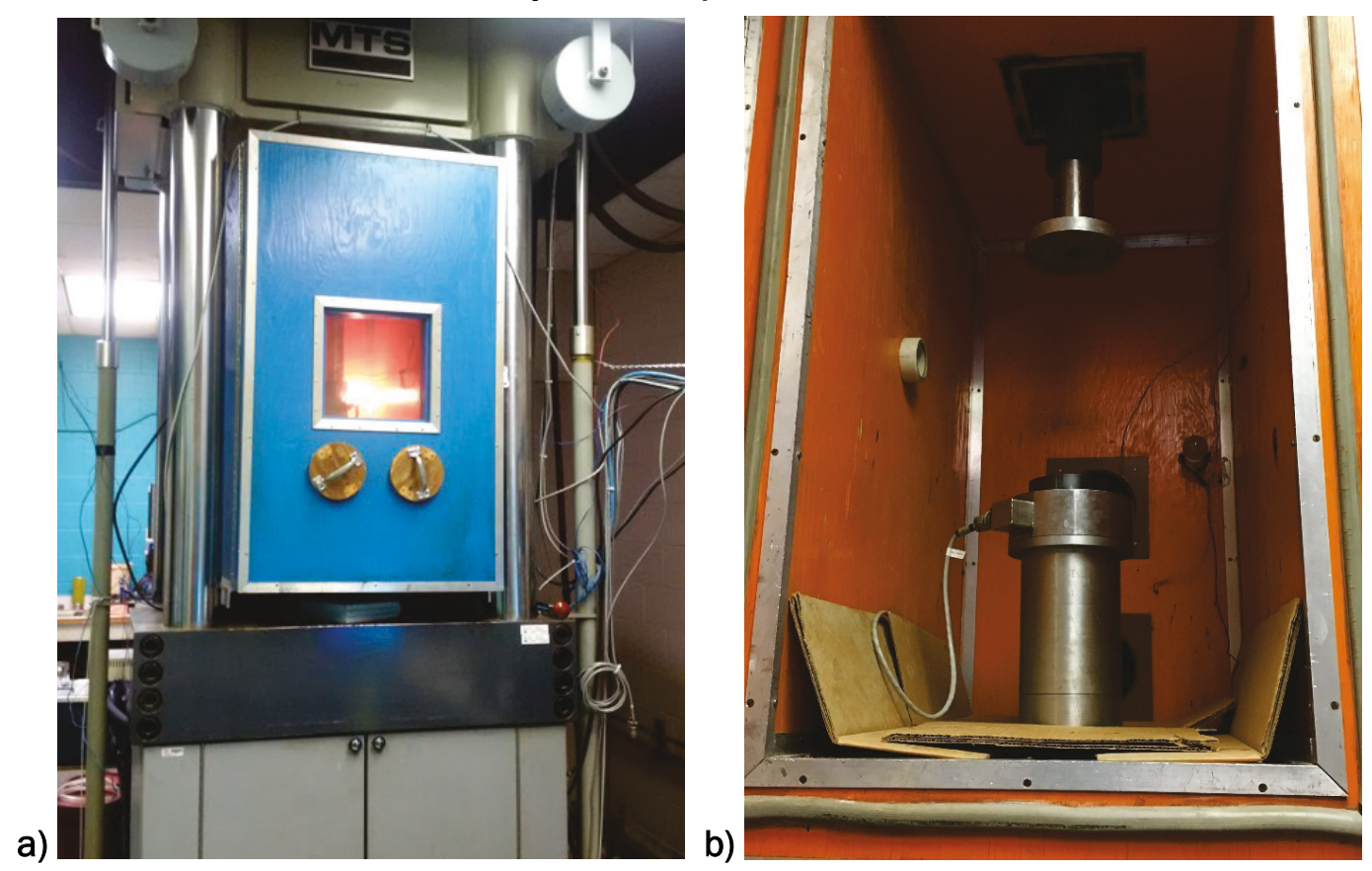

\subsubsection{Materials and temperatures studied}

The existing materials currently used in RADR by the USAF included:

- Foreign object debris (FOD) covers folded fiberglass mat (FFM) and fiberglass-reinforced polyester (FRP)

- Geocell grid confinement systems

- Polyurethane foam

- Rapid Set concrete

- Rapid setting flowable fill.

An incremental approach to testing was applied, whereby the properties of all materials were measured using set points of $25,0,-25$, and $-40^{\circ} \mathrm{F}$, with tests at $73^{\circ} \mathrm{F}$ used as a benchmark. New materials candidates (including snow, ice, and frozen materials) were studied as new RADR materials for use in crater repairs at freezing and extreme cold temperatures. 


\subsubsection{Foreign object debris (FOD) covers}

\subsubsection{Introduction}

Typically used to cover craters that have been backfilled with crushed stone, fiberglass reinforced matting has been used to prevent FOD damage to aircraft during trafficking over repaired craters. Historically, FFM has been the FOD cover used by the USAF and FRP has been used by the U.S. Army. However, FFM covers are not certified for $\mathrm{C}-17$ aircraft. As a result, the FRP mat system was redesigned and certified for $\mathrm{C}-17$ operations as an expedient repair method (Rushing et al. 2016).

Requirements for the material performance of each cover are published (Department of the Air Force. Headquarters, Air Force Civil Engineer Support Agency. 2007, Department of the Air Force. Headquarters, Air Force Civil Engineer Support Agency. 2016) and were used to benchmark the individual properties of each FOD cover over the temperature range of interest. The required values for each FOD cover property studied in this work are summarized in Table 1.

Table 1. Certified values for FOD cover material properties.

\begin{tabular}{|c|c|c|c|c|c|}
\hline FOD Cover & $\begin{array}{l}\text { Tensile } \\
\text { Strength } \\
\text { (psi) }\end{array}$ & $\begin{array}{l}\text { Flexural } \\
\text { Strength } \\
\text { (psi) }\end{array}$ & $\begin{array}{l}\text { Hardness, } \\
\text { top } \\
\left(\mathrm{B}^{1}\right)\end{array}$ & $\begin{array}{l}\text { Hardness, } \\
\text { bottom }\end{array}$ & Reference \\
\hline FFM & $>17,500$ & $>35,000$ & $>45$ & $>25$ & $\begin{array}{l}\text { (Department of } \\
\text { the Air Force. } \\
\text { Headquarters, Air } \\
\text { Force Civil } \\
\text { Engineer Support } \\
\text { Agency. 2007) }\end{array}$ \\
\hline FFM Hinge & $\begin{array}{l}>1600 \\
\text { lbf/linear } \\
\text { inch }\end{array}$ & $n / a$ & $n / a$ & $\mathrm{n} / \mathrm{a}$ & $\begin{array}{l}\text { (Department of } \\
\text { the Air Force. } \\
\text { Headquarters, Air } \\
\text { Force Civil } \\
\text { Engineer Support } \\
\text { Agency. 2007) }\end{array}$ \\
\hline FRP & 45,000 & 65,000 & $>45$ & $>45$ & $\begin{array}{l}\text { (Department of } \\
\text { the Air Force. } \\
\text { Headquarters, Air } \\
\text { Force Civil } \\
\text { Engineer Support } \\
\text { Agency. 2016) }\end{array}$ \\
\hline
\end{tabular}

1Barcol hardness units 


\subsubsection{Mechanical properties testing details}

Specimens of the FFM and FRP covers were cut from 2-ft $\mathrm{x} 2$ - $\mathrm{ft}$ pieces of the composite panels along the y-axis to measure 1-in. x 10-in. The FFM covers contain an elastomer hinge, which was also tested. Hinge specimens were cut along the $\mathrm{x}$-axis to center the elastomer strip in the 1-in. $\mathrm{x}$ 10-in. specimens. The specimens were thermally conditioned at the target temperature for a minimum of $5 \mathrm{hr}$ before test of specimens occurred. Four replicates of each sample type were used for each temperature set point.

The tensile strength of the FFM and FRP covers as well as the FFM hinges were evaluated at all set point temperatures of interest. The flexural strength of the composite matting was also measured at all temperatures. Finally, a flexural fatigue test was performed on the FRP mats, specifically focusing on the cold temperature ranges where trafficability studies are difficult.

Tensile strength. The tensile strength of the FRP and FFM panels and the FFM hinges was tested according to ASTM D3039/M.

The FFM hinge testing was performed after temperature equilibration in the folded position for $5 \mathrm{hr}$. In short, the hinge samples were folded, bound together with rubber bands, and conditioned at the desired testing temperature. In preparation for testing of the hinge samples, the rubber bands were removed and the hinge was opened by hand in the target temperature environment. After opening, the sample was placed in the testing apparatus (e.g., grips) and subjected to tensile loading.

Hydraulic wedge grips (MTS 647, MTS, Minnesota, USA) were used to hold and stabilize all the mat samples during tensile testing, using a gauge length of 6 in. These grips are controlled by a hydraulic power supply (685.10) capable of 10,000 psi. A surrogate bar of aluminum 1-in. x 10-in. $\mathrm{x} 0.5$-in. was used to line up the grips prior to testing to ensure a purely axial tensile loading configuration. An initial grip force of 2,000 psi was applied to hold the sample, but as temperature decreased, the grip pressure was increased up to 4,000 psi.

Tensile loading was applied with an MTS 22-kip actuator and recorded by a 25-kip load cell (BLH, USA). Time, load, displacement, and temperature were recorded during testing. The testing procedure for FRP was created 
based upon the draft specification (Department of the Air Force. Headquarters, Air Force Civil Engineer Support Agency. 2016), and the testing procedure for the FFM was conducted according to the MIL-DTL32265 specification (Department of the Air Force. Headquarters, Air Force Civil Engineer Support Agency. 2007).

Flexural strength. Flexural strength testing was performed on both the FFM and FRP mat specimens, oriented along the y-direction, according to ASTM D790, Method 1, Procedure A. This method used a 3-pt configuration with a support span of 8.0 in., a loading nose radius of 1.0 in., and a support radius of 0.5 in. In the FFM specification (MIL-DTL-32265), only the loading nose is specified at a 1-in. radius. On the other hand, the draft specification for FRP only states a 0.5-in. radius for the supports. Thus, for this experiment, the supports were consistent between the two specimen types, using a 1-in. radius loading nose and 0.5-in. radius for the supports. All specimens were tested at a crosshead movement rate of $0.43 \mathrm{in} . / \mathrm{min}$ according to the MIL-DTL-32265 (Department of the Air Force. Headquarters, Air Force Civil Engineer Support Agency. 2007) and the draft FRP specification (Department of the Air Force. Headquarters, Air Force Civil Engineer Support Agency. 2016). This provided the ability to compare each under similar loadings. A minimum of four replicate tests were performed at each temperature.

Flexural fatigue. Finally, a flexural fatigue test (ASTM D7774) (2017) was used to assess the trafficability of the FRP matting at extreme cold temperatures. These specimens were flexed 75 percent of the deflection at failure at each temperature for a total of 5,000 cycles at $1 \mathrm{~Hz}$ per cycle. The same test apparatus was used as the one used for the flexural testing with a modification allowing the sample to be held in the same place during repeated cycling. This modification is an aluminum plate with the mat sample width notched into it.

\subsubsection{Barcol hardness}

The indentation hardness of the top and bottom of each rigid FOD cover panel was tested according to ASTM D2583(2013) with a Model 943-1 Barcol Impressor (Barcol Impressor, Instrucon, Inc.). Specimens were cut from the FOD cover panels ( 6 in. $\mathrm{x} 10 \mathrm{in}$.) and conditioned at the target set point for $24 \mathrm{hr}$ before measurements were made. A minimum of 24 points distributed over three different locations were sampled on each panel side for each panel type at each temperature. 


\subsubsection{Cellular confinement systems (geocells)}

\subsubsection{Introduction}

Geocellular confinement systems are used to increase load bearing capacity of soils by mechanically stabilizing soils and decreasing erosion (Yadav et al. 2014). Each geocell mesh structure covers nominally $160 \mathrm{ft}^{2}$ when fully opened, with an expanded cell area of 45 in. $^{2}$ (Geosystems 2015). The honeycomb structure of the geocells imposes complex interconnections between cells and thus the performance of the geocell is a function of the different junctions and the wall properties (Figure 4) (Cancelli et al. 1993).

Figure 4. Illustration of the different configurations that were used to assess the strength of geocell structures at extreme cold temperatures: a) sidewall tension; $b$ ) junction shear; c) junction peel. Content reproduced from content in Cancelli et al (Cancelli et al. 1993).

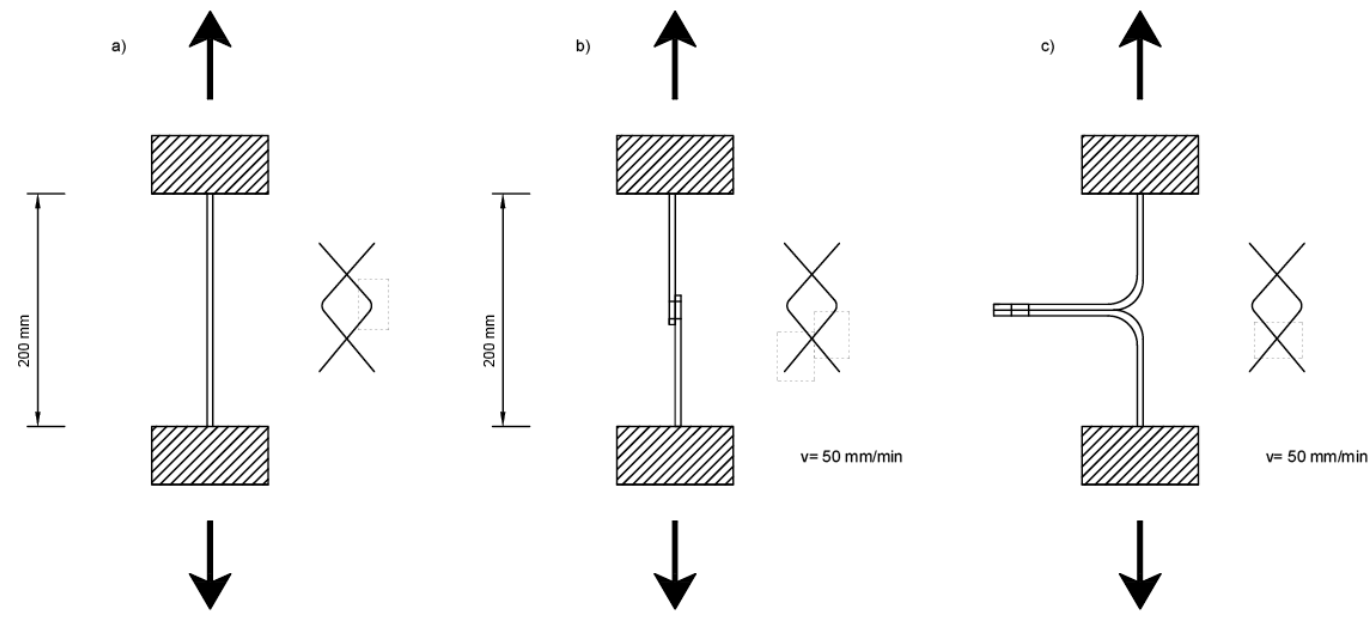

In this work, Geoweb ${ }^{\circledR}$ geocells (GW20, Geosystems, Inc.) composed of polyethylene with a sidewall height of 6 in. were tested. The published specifications for the material properties of the geocells is compiled in Table 2. Tensile testing of the sidewalls, tensile junction peel tests, and junction shear strength were performed to characterize the material behavior at different temperatures (Figure 4). 
Table 2. Certified specifications for material properties of geocell confinement grids.

\begin{tabular}{lccl}
\hline \multicolumn{1}{c}{ Configuration } & $\begin{array}{c}\text { Yield strength } \\
\text { (lbf) }\end{array}$ & \multicolumn{1}{c}{$\begin{array}{c}\text { \% Elongation } \\
\text { (\%) }\end{array}$} & \multicolumn{1}{c}{ Reference } \\
\hline $\begin{array}{l}\text { Sidewall } \\
\text { tension }\end{array}$ & 188 & 8.4 & (Garcia 2017) \\
$\begin{array}{l}\text { Junction shear } \\
\text { Junction peel }\end{array}$ & 211 & $\mathrm{n} / \mathrm{a}$ & (Garcia 2017) \\
\hline
\end{tabular}

\subsubsection{Mechanical properties testing details}

Geocell samples were cut into 10-in.-long strips with any joints aligned in the center of the specimens. Specimens were conditioned at the target temperature for a minimum of $5 \mathrm{hr}$ before testing, and four replicates were tested at each condition. Specimens were secured with manual grips (ADMET, Massachusetts, USA) that were custom modified to allow a grip surface across the full span of the 6-in. sidewall specimens. To ensure even gripping, external C-clamps were used to grip across the whole sample (Figure 5). The length between the gauge length for all specimens was set to 7.87 in. (Cancelli et al. 1993). The rate at which the samples were tested was based upon the ASTM D4595 (2017) and was set to $3 \mathrm{kN} / \mathrm{min}$ (11.24lbf/sec). 
Figure 5. Gripping assembly used to test the geocell specimens.

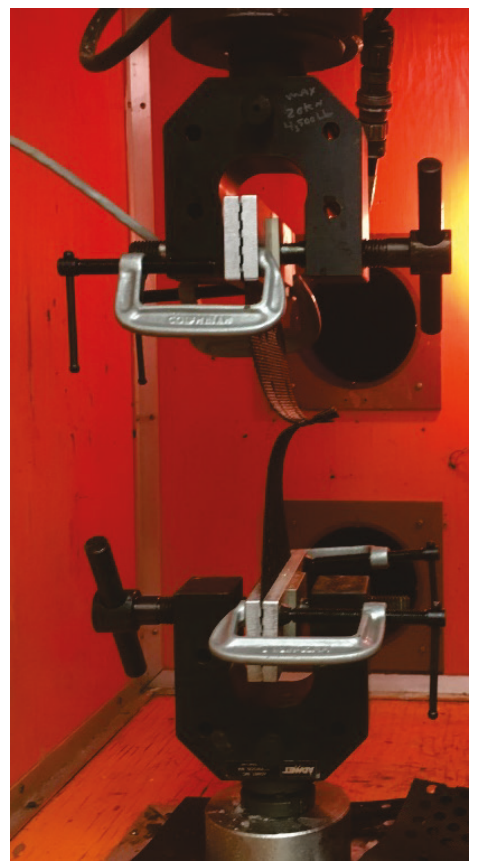

\subsubsection{Extreme cold expansion experiments}

The geocell grids collapse into compressed bundles to facilitate transport. Thus, installation and use of them requires expansion on location. Due to the increase in stiffness of polymeric materials at extreme cold temperatures, experiments were conducted to probe the expansion of the geocell bundles as a means to further assess their usability at extreme cold temperatures.

These experiments were conducted by visual observations. First, at room temperature, a 6-ft-long segment was cut from a geocell panel and opened by stretching the section from either side. Then, it was placed on the floor and allowed to retract. Photographs were taken. Next, the geocell bundle was collapsed, rebanded with zip ties, and allowed to condition for $24 \mathrm{hr}$ at 25, $\mathrm{O},-25$, and $-40^{\circ} \mathrm{F}$. After cold conditioning, the geocell section was opened, pulled to full expansion and released to allow retraction. Photographs and observations were recorded.

\subsubsection{Polyurethane foam backfill material}

Polyurethane foam is a desirable material for crater repair because it can expand to multiples of its packaged volume and can achieve the threshold 
strength for a backfill materials (200 psi). Of the available polyurethane foam materials, the Foam-iT! 10 Slow (Smooth-On, Inc.) has been identified as the best candidate for RADR (Mejias-Santiago et al. 2016). However, it has also been found to undergo uncontrolled expansion when excess moisture is present (Bell et al. 2013), and that it is difficult to dispense and mix at lower temperatures due to increasing viscosity (Kyzar et al. 2010). Benchmark values for the properties of the foam material are listed in Table 3.

Table 3. Certified specifications for polyurethane foam used as ADR backfill material.

\begin{tabular}{|l|l|l|l|l|}
\hline Cure time $(\mathrm{h})$ & \multicolumn{1}{|c|}{$\begin{array}{c}\text { Compressive } \\
\text { strength }(\mathrm{psi})\end{array}$} & Expansion ratio & Density $\left(\mathrm{lb} / \mathrm{ft}^{3}\right)$ & \multicolumn{1}{|c|}{ Reference } \\
\hline 1 & 239 & 5.5 & 11.0 & $\begin{array}{l}\text { (Mejias-Santiago et al. } \\
2016)\end{array}$ \\
\hline 12 & 321 & 5.8 & 11.7 & $\begin{array}{l}\text { (Mejias-Santiago et al. } \\
2016)\end{array}$ \\
\hline
\end{tabular}

All tests were performed on the foam materials at low temperature under the assumption that a heating tank and supply hoses would be accessible in a field scenario. To simulate a heated supply in the lab, target amounts for each foam component (100:87, A:B) were weighed out in the lab and only introduced into the cold environment immediately before mixing. First, Component B was mixed vigorously for $15 \mathrm{sec}$ with an electric drill and metal mixer. Next, the correct amount of Component A was added and both components were vigorously mixed for $30 \mathrm{sec}$. The initial height of each sample was recorded as was the height at 1, 2, and $24 \mathrm{hr}$.

The compressive strength of the cylindrical foam specimens was tested after set times of 2 and $24 \mathrm{hr}$ according to (2004). The cylinders measured 6 in. $\mathrm{x} 6 \pm 0.75 \mathrm{in}$. The rate was set as a function of the height of the sample as specified in the 1621-04a, and is defined in Section 8.3 as $0.1 \pm 0.01$ in./min. In addition, the volume expansion of each sample was determined at $2 \mathrm{hr}$ and $24 \mathrm{hr}$ set times. The final density of each specimen was found from mass and volume measurements on samples that had set for $24 \mathrm{hr}$. At least three replicates of each condition were measured.

\subsubsection{Rapid Set concrete}

Testing of the Rapid Set ${ }^{\circledR}$ (RS) concrete was conducted in accordance with ASTM C39 (2018). This procedure gives a wide range for the application of 
rate. The stress rate shown in $\mathrm{C} 39$ is $0.25 \pm 0.05 \mathrm{MPa} / \mathrm{s}[35 \pm 7 \mathrm{psi} / \mathrm{s}]$. To perform a load-controlled test with a 6-in.-diam sample, units of psi are converted to $989 \pm 197(\mathrm{lbf} / \mathrm{s})$. Due to the high yield of the warmer temperature samples, a 250-kip SensoTec 43/1343-01-02 load cell was used, and when the samples became weaker at increasingly colder temperatures a 100-kip (Thurman TH-CT1) load cell was used. Due to full-scale calibration, the 250-kip load cell accuracy diminishes within the lower 14,500 lbf. This sacrifice guarantees the accuracy of the higher end of the load cell scale. In turn, this requires the use of smaller load cells should the samples have lower resultant yields. A modification to the ASTM test apparatus was made such that the loading was not performed with a spherical bearing block, but rather a rigid mounted one. On either end of the concrete specimens, end caps made from aluminum with a 0.5-in.-thick polypropylene mat were used to level the concrete specimen ends during loading.

The rapid setting concrete used for this study was the CTS Rapid Set concrete mix. As described in ERDC/CRREL TR 14-10 (Oren et al. 2014), aluminum sulfate can be added in bulk to accelerate set times in air temperatures less than $40^{\circ} \mathrm{F}$. However, in this study no additives were used for cold weather testing to determine the limitations of the original material. The pre-measured and manufactured mix was agitated with water in a mortar mixer and commercial-sized rotary mixers then promptly discharged into molds.

For each temperature tested, the material and the rotary mixer were acclimated to the environment for at least $24 \mathrm{hr}$ prior to the test exceeding ASTM-D5229 (2014). This precaution was taken to simulate field conditions that would be experienced. The rapid setting concrete samples produced for the laboratory were 6-in.-x 12-in.-cylinders. According to the Crater Repair ETL 08-3 (2008), an acceptable mix is one that reaches 3,000 psi after $2 \mathrm{hr}$ of cure. Specimens were cured in the representative environments, and the temperature was maintained while being tested.

\subsubsection{Flowable fill}

Rapid setting flowable fill (FF) was sourced from CTS Cement, USA in 5gallon buckets and was tested in accordance with ASTM C39 (2018). This procedure gives a range for the force loading rate. As mentioned previously, the standard gives this range from which the lower end (791 lbf/s) was used as some of the samples would be green. This provided consistent 
testing across all of the specimens. The same modification to the test apparatus as noted in Sec. 2.1.6 was used. Similar to the RS concrete, FF is essentially a two-part mix process of the dry materials and water, combined together in a rotary mixer for these experiments and then placed into the testing molds. The dry method of placing $\mathrm{FF}$ was also tested during the larger-scale demonstrations but excluded from the laboratory experiments due to the lack of structural strength required for uniform results in an unconfined uniaxial loading setup. Temperature equilibration took place in the same manner as the RS concrete; materials and tools were all placed in the testing areas $24 \mathrm{hr}$ prior to testing. Requirements for the strength of this material include an Ultimate Compressive Strength (UCS) of $250 \mathrm{psi}$ after 30 mins of cure time and 750 psi after 3 hours of cure time.

\subsubsection{Snow and ice materials}

Uniaxial compression testing compacted snow and ice reinforced with de-

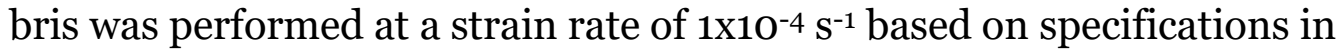
the Frozen Ground Engineering Manual (Andersland and Ladanyi 1994). This rate ensures that the ice is functioning within its brittle regime and deformations due to creep are negligible (Schulson 1990). This rate was recorded and controlled using a MTS 205.60 250-kip load cell. All of the samples were pre-loaded with $50 \mathrm{lbf}$ before the testing procedure was started. Samples varied in height according to the method of growth chosen but were typically 12 in. in length and 6 in. in diameter. The snow utilized in the test samples was manufactured to the sub 1-mm size to simulate natural snow. The water used was deionized. All of the ice samples were broken in similar fashion to concrete samples to ensure comparable test results.

\subsubsection{Manufacturing of ice specimens for laboratory testing}

Polycrystalline ice specimens were made by processing snow through grinders and then sieved to $1 \mathrm{~mm}$ minus grain size. The grain size was chosen at $1 \mathrm{~mm}$ due to common expected natural snow crystal size that would be present in the field. The 12-in. x 6-in. snow slurry specimens were manufactured by adding 3-4 in. of snow in lifts and then saturating with water and mixing. This process was then repeated until the mold was filled and then leveled at the top. This process ensured that the lifts removed as much as possible out of the specimen and was easily repeatable as would be utilized for larger scale testing. 


\subsubsection{Manufacturing of reinforced ice specimens for laboratory testing}

High performance polycrystalline ice was made by reinforcing the ice with a cellulose slurry (University of Maine, Process Development Center, Orono, ME, USA). As received the slurry contains approximately 3 wt percent solids and 90 wt percent fines in water. The slurry was diluted and mixed with ice grains to form a slush containing 10, and 20 wt percent cellulose. The slurry was then poured into the 12-in. x 6-in. molds in 3-4-in. lifts. The lifts were then stirred similar to the snow slurry process and then the process was repeated until the molds were filled. Stirring of the mixture proved to be time sensitive due to rapid freezing that could take place if water was added too slowly or in insufficient quantity.

\subsubsection{Simulated crater repairs}

Craters obviously occur in numerous sizes; with diameter and depth being variable depending on the type of munition and angle of impact on the pavement. Two types of simulated craters were used in this study. One was considered full-scale and measured $6 \mathrm{ft} \times 6 \mathrm{ft}$ in plan dimensions. In addition, it was built over a soil subgrade layer and had a full 18-in.-thick concrete surface. The second simulated crater was based on a 6-ft diameter cylindrical mold without a subgrade layer, but allowed testing of the most promising crater repair technique at $-40^{\circ} \mathrm{F}$.

\subsubsection{Measurement details}

The strength of the snow and/or ice backfill was accomplished using a dynamic cone penetrometer (DCP; common for use in soil strength evaluation) and a Russian Snow Penetrometer (RSP; typically used in snow engineering for strongly compacted snow masses). Use of the DCP and RSP are described in Department of Defense Facilities Criteria (2015). To meet RADR requirements, the necessary index values for each of these devices is listed in Table 4 . 
Table 4. Target values of average penetrometer values for cap and backfill layers for a compacted snow patch.

\begin{tabular}{lll}
\hline Device & $\begin{array}{l}\text { Cap } \\
\text { (Top 2-11 in. layer) }\end{array}$ & $\begin{array}{l}\text { Backfill } \\
\text { (12 in. to } 3 \text { in. above } \\
\text { bottom of cavity) }\end{array}$ \\
\hline DCP & $10 \mathrm{in.}$ & $20 \mathrm{in.}$ \\
\hline RSP & $130 \mathrm{in.}$ & $75 \mathrm{in}$. \\
\hline
\end{tabular}

\subsubsection{Full crater repairs at $-20^{\circ} \mathrm{F}$}

A full-size simulated crater was constructed within the Material Evaluation Facility (MEF) at ERDC-CRREL using a square aluminum metal form (Figure 6). The form was fabricated into an 8.5 - $\mathrm{ft}$ x 8.5 -ft-square that was $4.5 \mathrm{ft}$ tall.

Figure 6. The metal form used to simulate a runway section for full scale mock crater repairs in the cold facilities at ERDC-CRREL.

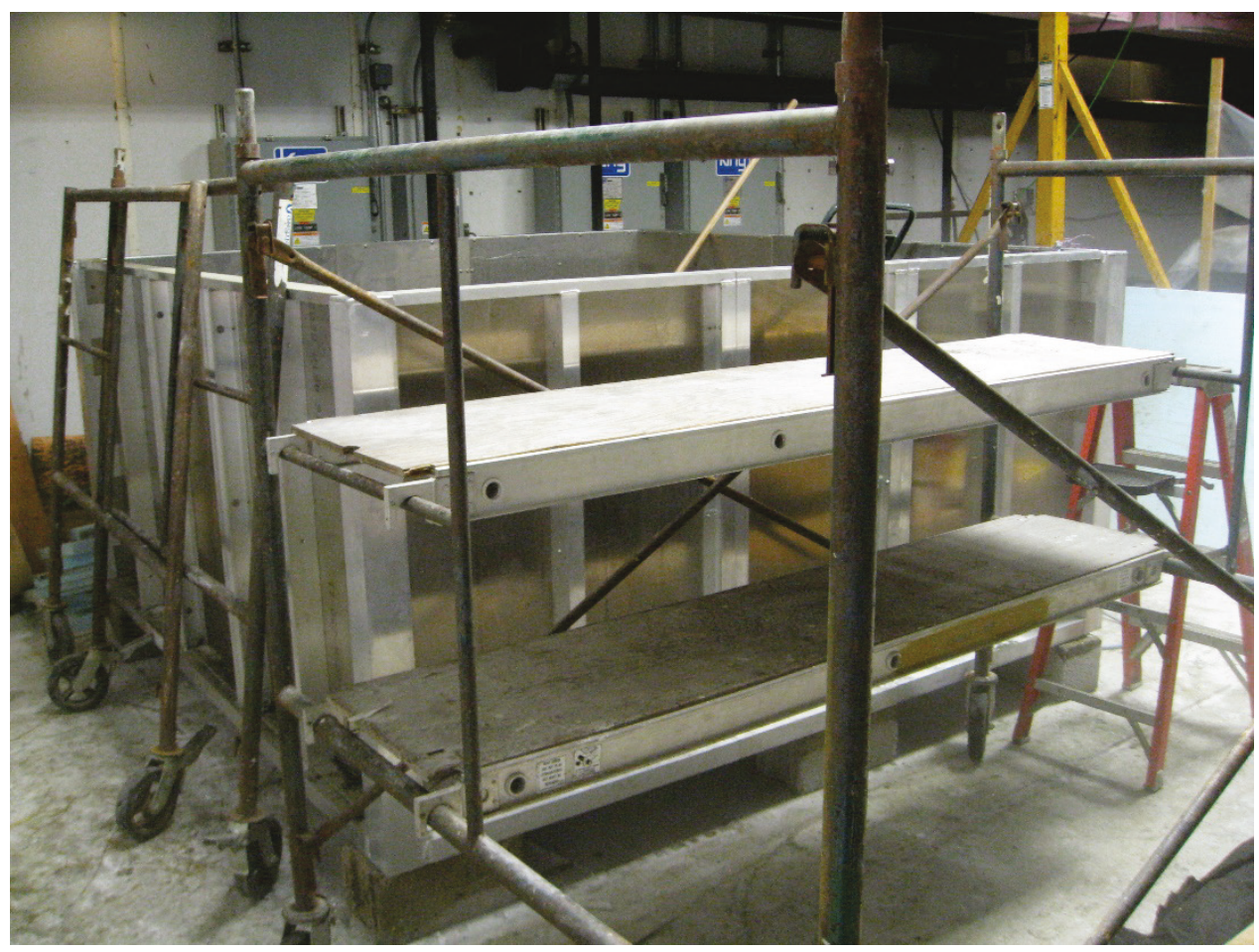

After moving the form into the MEF, the metal form was filled with $2.5 \mathrm{ft}$ of crushed stone and gravel, compacted in 6-in. lifts at optimum moisture content. An 18-in.-thick cap of 3,000 psi concrete was formed on top. The 
crater repair area was formed by retaining a 6 -ft x 6 -ft square section in the center of the simulated runway, replicating a concrete airfield pavement with a crater whose edges had been squared by cutting with a concrete saw. The top of the gravel was excavated in a conical shape to represent the damage to base material that could reasonably be expected in a crater. This resulted in a simulated crater that was 6 - $\mathrm{ft}$ square by $18-$ in. deep at the edges, increasing to $32 \mathrm{in}$. at its center (Figure 7). This simulated crater was constructed inside a large cold room with ample room on all sides so that scaffolding and ladders could be erected adjacent to the sides of the cube allowing easy access to the surface.

Figure 7. Fully assembled simulated crater ready for repairs with select backfill layer and capping materials: a) top view; b) side view.

a)
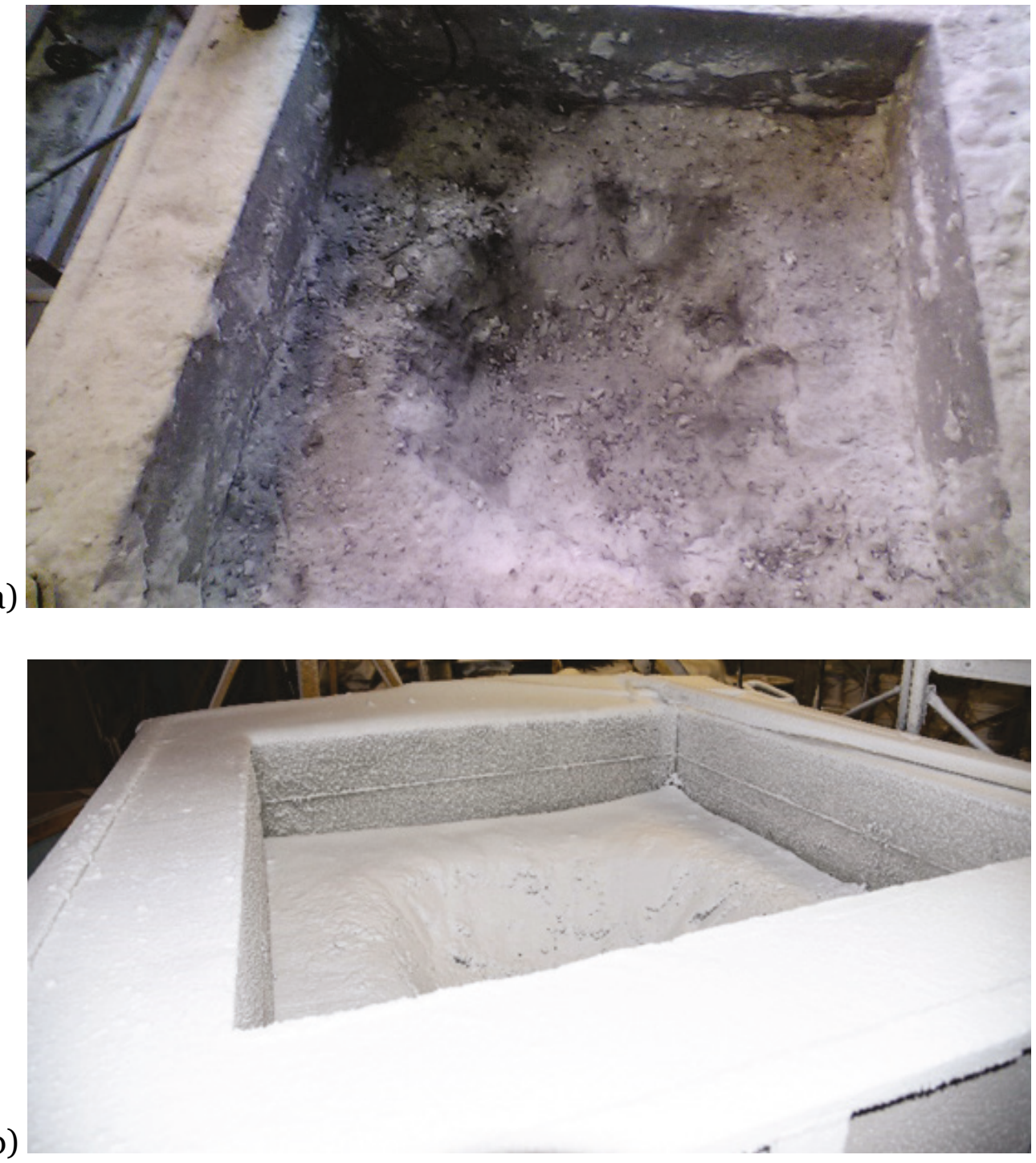


\subsubsection{Simulated crater cap repairs at $-40^{\circ} \mathrm{F}$}

Simulated crater repairs were also performed at $-40^{\circ} \mathrm{F}$ in the Cold Room Complex Facility at ERDC-CRREL using a 6-ft circular metal form supported on a plywood base (Figure 8). The form was composed of galvanized steel and had 2-ft-high sidewalls. The objective of these experiments was to examine the most promising candidates for capping craters at extreme cold temperatures, and to assess the time required to perform such repairs.

Figure 8. The circular metal form used to simulate a crater for repair with frozen slush materials at $-40^{\circ} \mathrm{F}$.

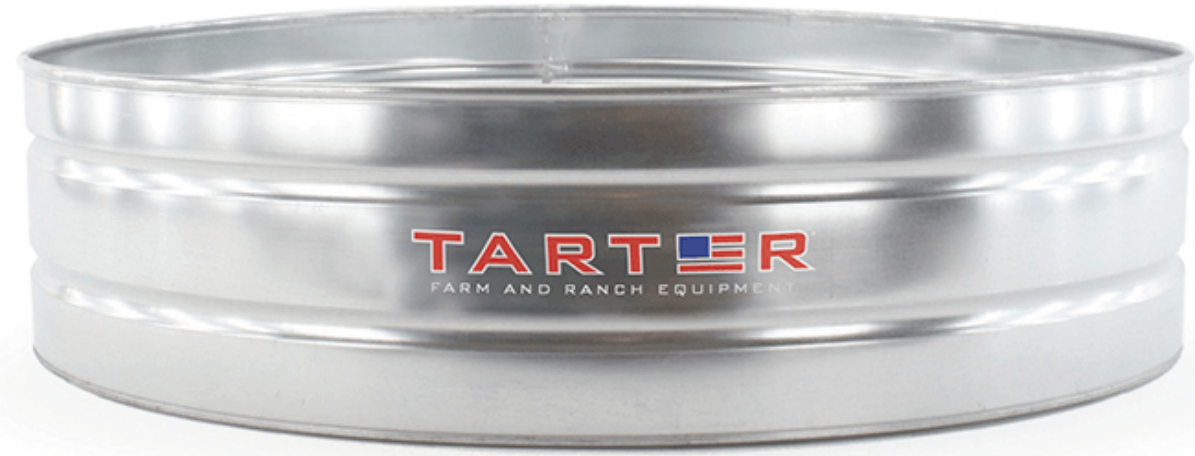




\section{Results and Discussion}

\subsection{Existing RADR Materials}

\subsubsection{Foreign object debris (FOD) covers}

The mechanical properties of FFM and FRP covers were assessed, including the FFM hinges. The foreign object debris (FOD) cover specimens were cut into 1-in. x 10-in. specimens with the elongation along the y-axis. Hinge specimens were cut parallel to the $\mathrm{x}$-axis with the hinge segment isolated in the middle of the test specimens. In particular, the tensile strength, flexural strength, and hardness of the specimens were measured down to $-40{ }^{\circ} \mathrm{F}$, using measurements at $73^{\circ} \mathrm{F}$ as a reference point.

\subsubsection{Tensile strength}

FFM Panels. Under tensile loading, the FFM panel specimens broke consistently within the gauge length (Figure 9). Across all temperatures, the tensile strength increased slightly as the temperature decreased, with no significant difference in elongation (Figure 10). Of note is the discrepancy between the reference measurements at $73^{\circ} \mathrm{F}$ and the value listed in the specification (Table 5). While the tensile strength of the FFM mat specimens were $30,400 \pm 3,318 \mathrm{psi}$, the specification only required $17,500 \mathrm{psi}$. The percent elongation failed to show a significant trend along the range of temperatures studied (Figure 10), with a markedly increase in variability at $\mathrm{O}^{\circ} \mathrm{F}$.

The raw load-displacement curves are compiled in Appendix A (Figure A1). Consistent with the variability in the percent elongation of FFM mats at $\mathrm{o}{ }^{\circ} \mathrm{F}$, the load-displacement curves for this temperature showed unusual behavior. In short, two peaks were observed in the stress-strain curves for the FFM panels for all four samples tested at $\mathrm{o}^{\circ} \mathrm{F}$ only. The two peaks with different maxima occurred as one lower stress peak and low strain with a higher stress peak at higher strain. In the analysis, the tensile strength was taken from the higher stress-strain peak. These results may imply that the polymeric matrix of the matting is undergoing a transition at this temperature and may exhibit inconsistent performance. 
Figure 9. FFM specimens after tensile testing at various temperatures: a) 73; b) 25; c) 0 ; d) -25 ; e) $-40^{\circ} \mathrm{F}$.

a)

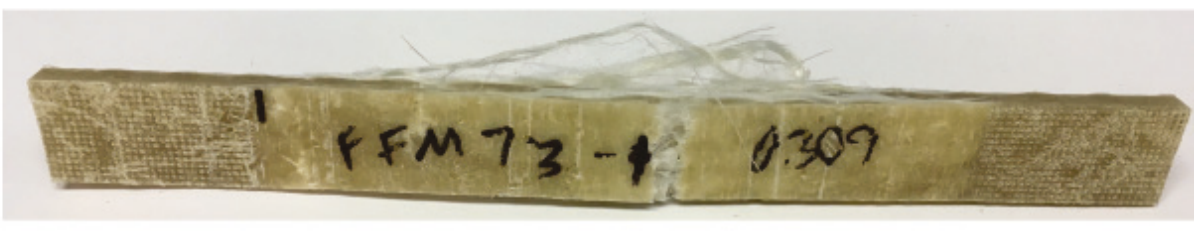

b)
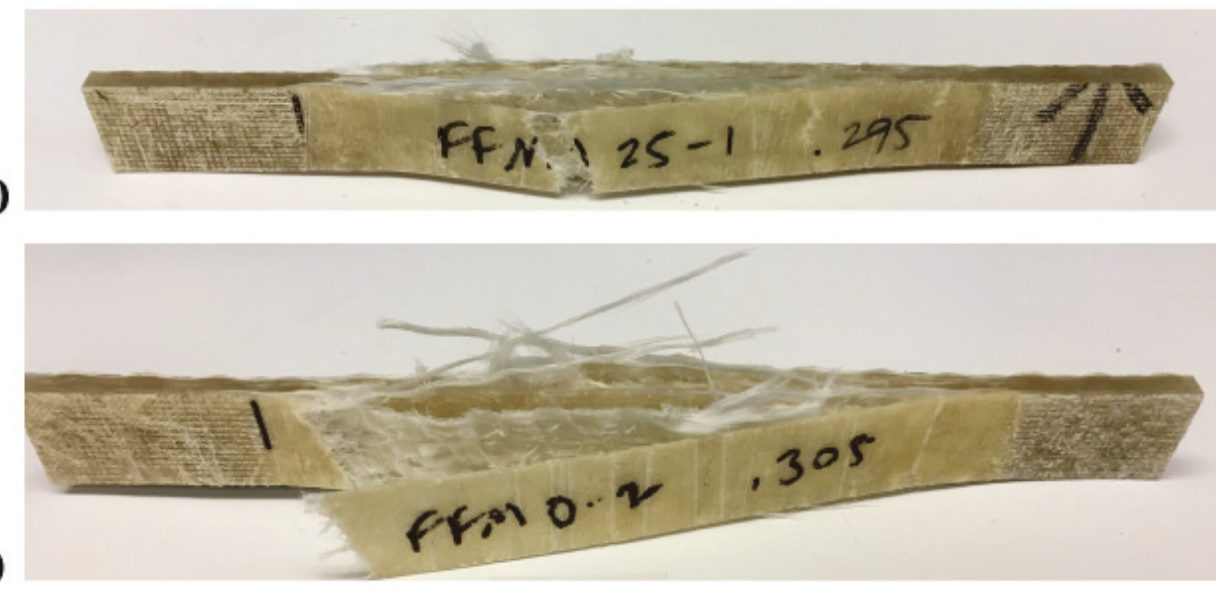

c)

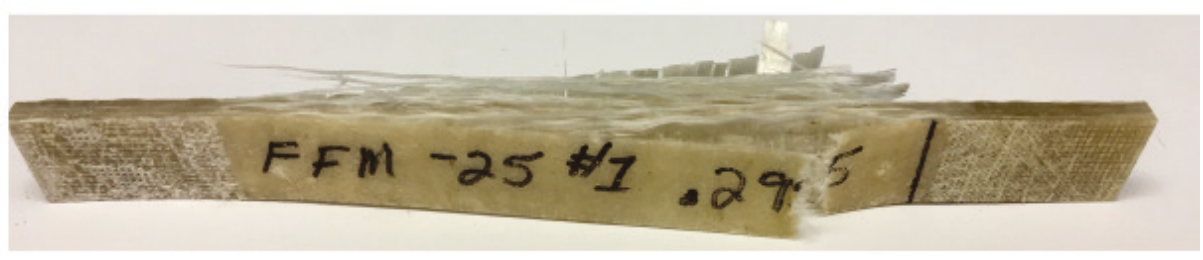

e)

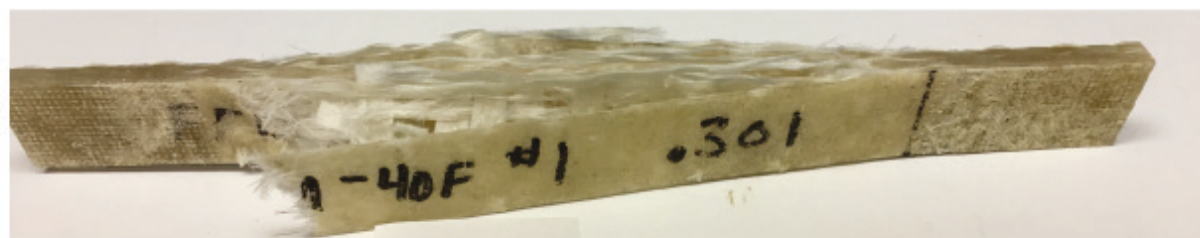


Figure 10. Tensile strength and percent elongation of FFM panel specimens as a function of temperature.

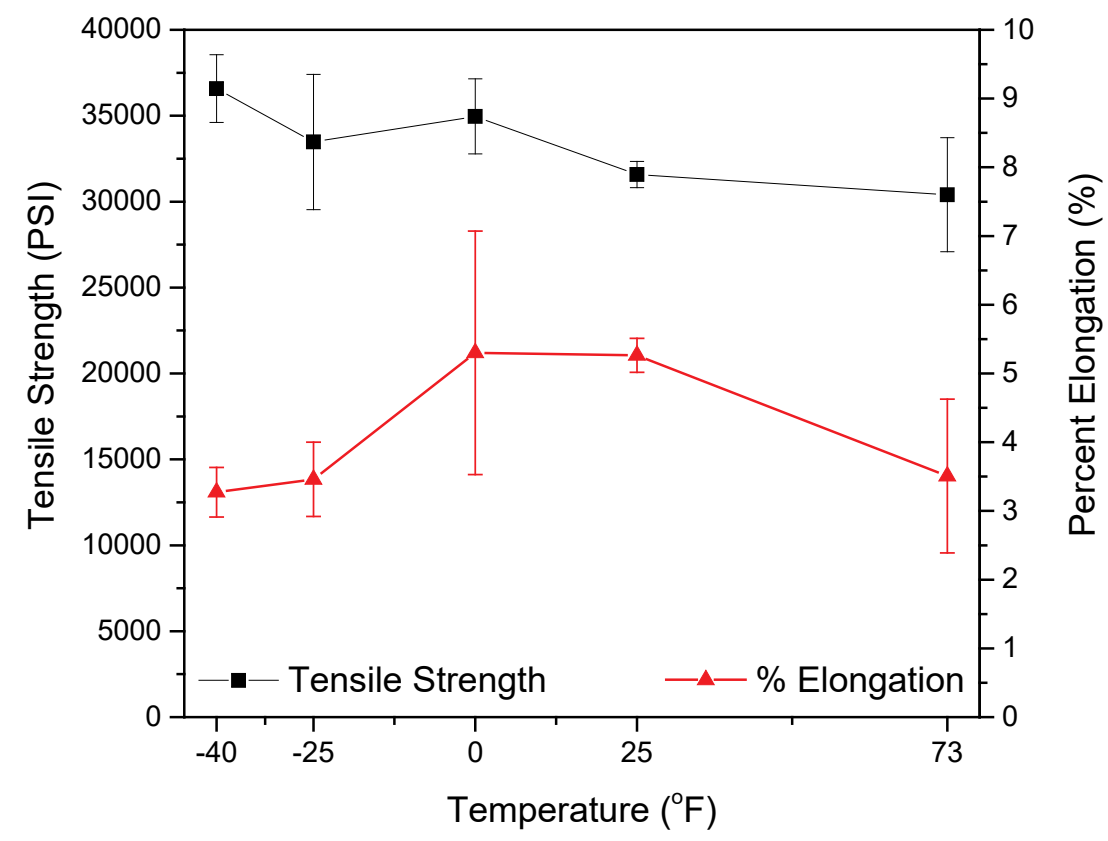

Table 5. Average values for tensile strength and percent elongation of FFM panels subject to tensile loading.

\begin{tabular}{lllll}
\hline $\begin{array}{l}\text { Temperature } \\
\left({ }^{(} \mathrm{F}\right)\end{array}$ & $\begin{array}{l}\text { Tensile strength } \\
(\mathrm{psi})\end{array}$ & $\begin{array}{l}\text { COV} 1 \\
\text { Tensile } \\
\text { strength }\end{array}$ & $\begin{array}{l}\text { Percent } \\
\text { elongation } \\
(\%)\end{array}$ & $\begin{array}{l}\text { COV } \\
(\%) \\
\text { Elongation. }\end{array}$ \\
\hline $73^{2}$ & 17,500 & $\mathrm{n} / \mathrm{a}$ & $\mathrm{n} / \mathrm{a}$ & $\mathrm{n} / \mathrm{a}$ \\
73 & $30,400 \pm 3,318$ & 0.11 & $3.5 \pm 1.1$ & 0.32 \\
25 & $31,578 \pm 768$ & 0.02 & $5.3 \pm 0.3$ & 0.05 \\
0 & $34,962 \pm 21,83$ & 0.06 & $5.3 \pm 1.8$ & 0.33 \\
-25 & $33,470 \pm 3,941$ & 0.12 & $3.5 \pm 0.5$ & 0.16 \\
-40 & $36,580 \pm 1,972$ & 0.05 & $3.3 \pm 0.4$ & 0.11
\end{tabular}

${ }^{1}$ Coefficient of variation found from the ratio of the standard deviation to the average. 2Value from MIL-DTL-32265 (Department of the Air Force. Headquarters, Air Force Civil Engineer Support Agency. 2007). 
FFM hinges. FFM hinge specimens were folded and banded (Figure 11) before temperature equilibration at the temperature set point for at least 5 $\mathrm{hr}$. After temperature equilibration, the specimens were unbanded, and spread open by hand to allow mounting in the tensile loading grips. It was fairly easy to open the hinges by hand at room temperature, and down to $25^{\circ} \mathrm{F}$, but at temperatures $\leq \mathrm{O}^{\circ} \mathrm{F}$, concerted force had to be applied to align the two panel ends axially for mounting in the tensile loading grips.

Figure 11. Prepared FFM hinge specimens showing the folded, banded configuration used for temperature conditioning.

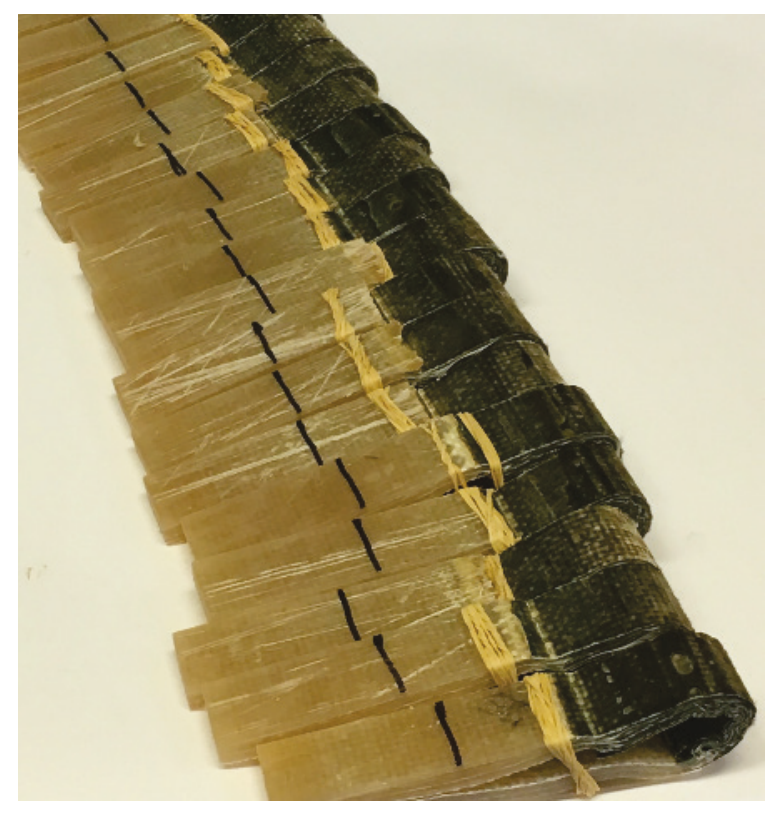

Under tensile loading, almost all of the FFM hinge specimens failed at the elastomer-panel interface (Figure 12a). Only at $-40^{\circ} \mathrm{F}$ were the hinges observed to break within the hinge section (Figure 12b). The tensile strength for the FFM hinge samples was found from the maximum force at breaking divided by the gauge length and was seen to increase as temperature decreased (Figure 13). While the tensile strength of the FFM hinge specimens was $1,990 \pm 215 \mathrm{lbf} / \mathrm{lin}$ in. at $73^{\circ} \mathrm{F}$, the specification only requires $1,600 \mathrm{lbf} /$ lin in. (Table 6). As the temperature was decreased, the tensile strength of the hinges increased to $3,145 \pm 547 \mathrm{lb} / \mathrm{lin}$. in. at $-40^{\circ} \mathrm{F}$. The percent elongation of the hinge specimens was fairly constant as temperature decreased (Figure 13), not varying much outside of the range of 9 percent. 
Figure 12. FFM hinge failure modes: a) predominantly, hinges failed at the elastomerpanel junction for the FFM hinges; b) at $-40^{\circ} \mathrm{F}$, failure within the hinge was observed.

a)

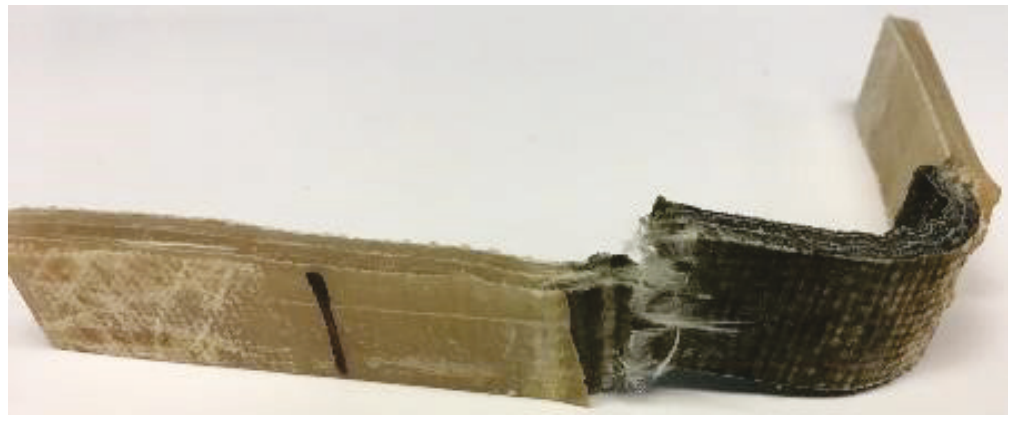

b)

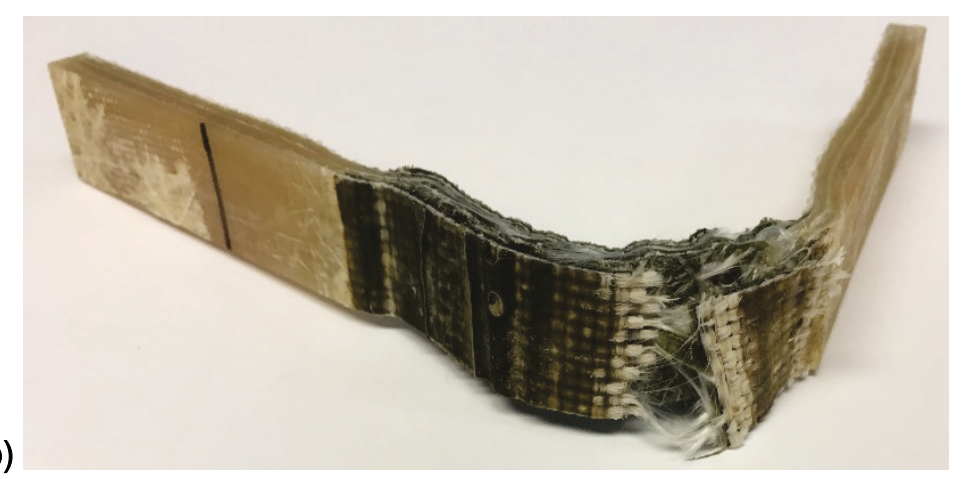

Figure 13. Tensile strength and percent elongation for FFM hinges as a function of temperature.

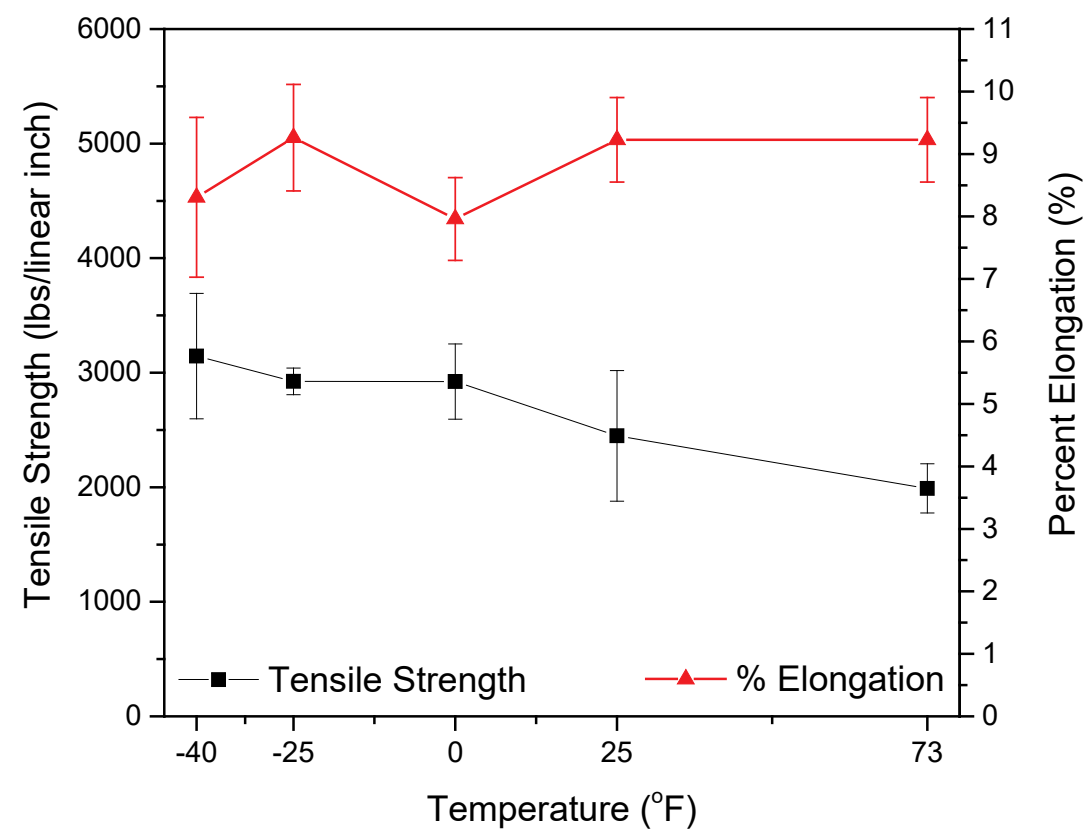


Table 6. Tensile strength and elongation of the FFM hinges as a function of temperature.

\begin{tabular}{lllll}
\hline $\begin{array}{l}\text { Temperature } \\
\left({ }^{\circ} \mathrm{F}\right)\end{array}$ & $\begin{array}{l}\text { Tensile strength } \\
(\text { Ibf/linear inch) }\end{array}$ & $\begin{array}{l}\text { COVa } \\
\text { tensile strength }\end{array}$ & $\begin{array}{l}\text { Percent } \\
\text { elongation }(\%)\end{array}$ & $\begin{array}{l}\text { COV } \\
\text { percent } \\
\text { elongation }\end{array}$ \\
\hline $73^{1}$ & 1,600 & $\mathrm{n} / \mathrm{a}$ & $\mathrm{n} / \mathrm{a}$ & $\mathrm{n} / \mathrm{a}$ \\
73 & $1,990 \pm 215$ & 0.11 & $9.2 \pm 0.7$ & 0.07 \\
25 & $2,449 \pm 570$ & 0.23 & $9.2 \pm 0.7$ & 0.07 \\
0 & $2,923 \pm 328$ & 0.11 & $8.0 \pm 0.7$ & 0.08 \\
-25 & $2,924 \pm 117$ & 0.04 & & 0.09 \\
-40 & $3,145 \pm 547$ & 0.17 & $9.3 \pm 0.9$ & 0.15 \\
\hline
\end{tabular}

1Value from MIL-DTL-32265 (Department of the Air Force. Headquarters, Air Force Civil Engineer Support Agency. 2007).

FRP panels. During tensile loading, the FRP mat specimens all broke within the gauge length (Figure 14). As the temperature was decreased, the tensile strength of the FRP specimens increased from 33,811 $\pm 2,578$ to $46,433 \pm 1,246$ psi with a relatively consistent standard deviation (Table 7). The low coefficient of variation (COV) also corroborates the validity of this trend. 
Figure 14. FRP specimens after tensile testing at various temperatures: a) 73 ; b) 25; c) 0 ; d) -25 ; e) $-40^{\circ} \mathrm{F}$.

a)

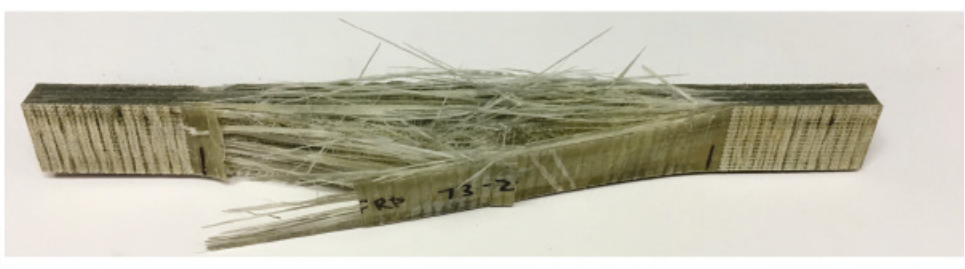

b)
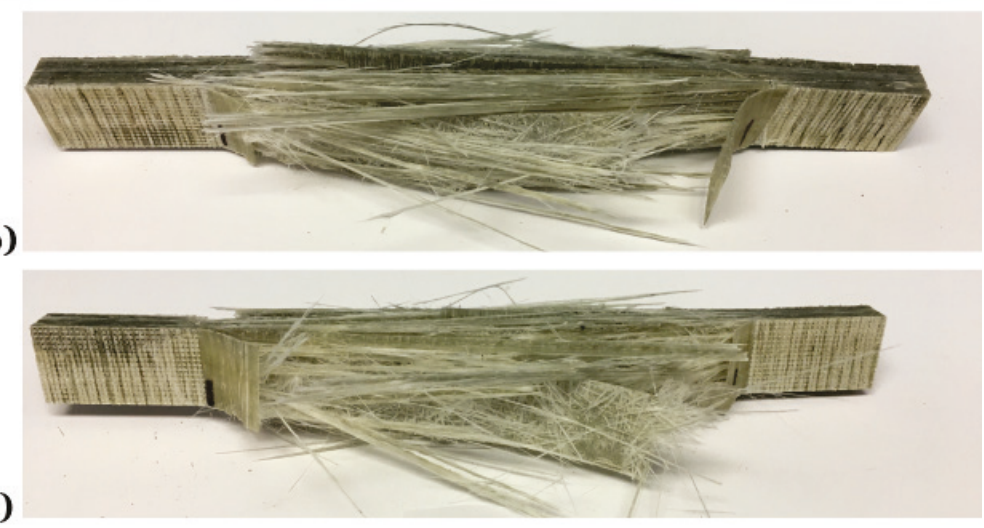

d)

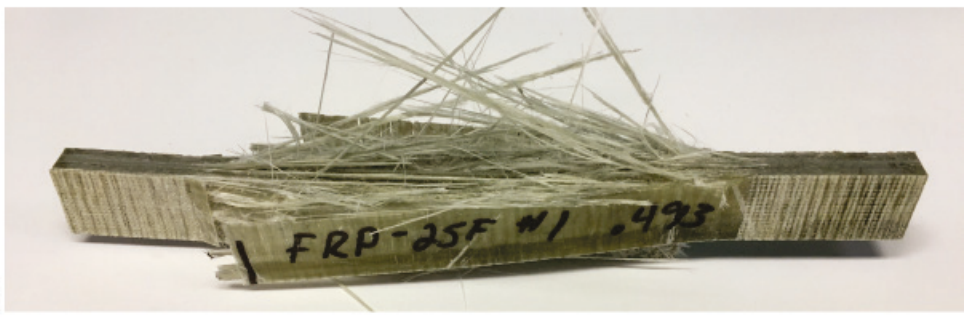

e)

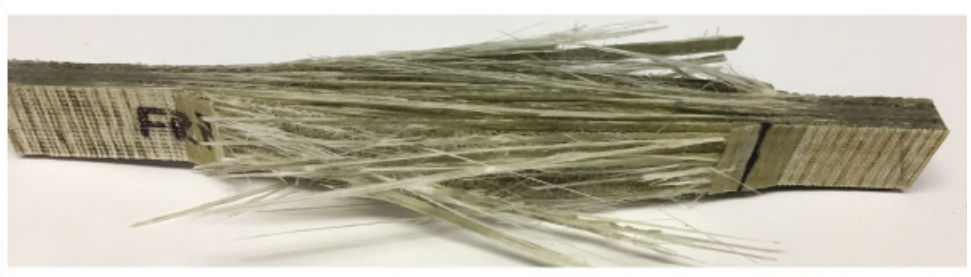


Figure 15. Tensile strength and percent elongation of FRP panels at various temperatures.

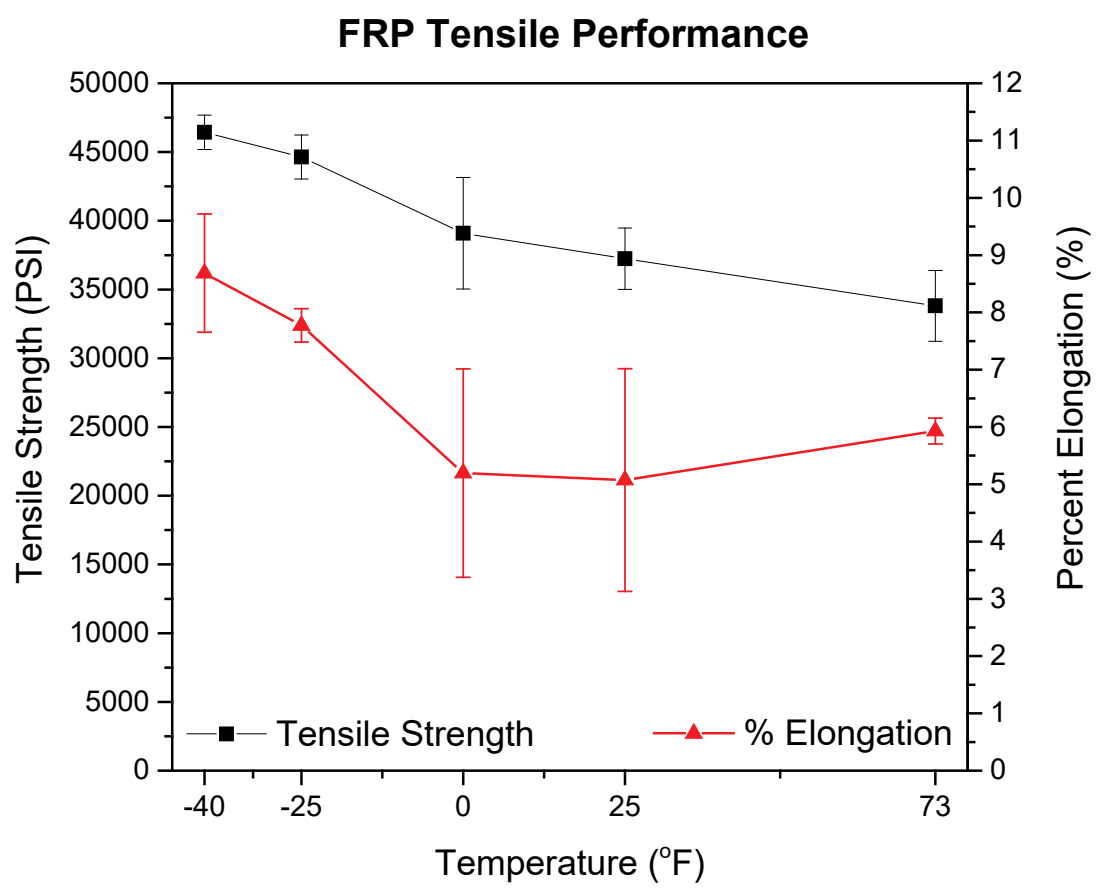

Table 7. Tensile strength and percent elongation of FRP panels as a function of temperature.

\begin{tabular}{lllll}
\hline $\begin{array}{l}\text { Temperature } \\
\left({ }^{\circ} \mathrm{F}\right)\end{array}$ & $\begin{array}{l}\text { Tensile strength } \\
(\mathrm{psi})\end{array}$ & $\begin{array}{l}\text { COV1 } \\
\text { Tensile } \\
\text { strength }\end{array}$ & $\begin{array}{l}\text { Percent } \\
\text { elongation }(\%)\end{array}$ & $\begin{array}{l}\text { COV } \\
\text { Percent } \\
\text { elongation }\end{array}$ \\
\hline $73^{2}$ & 45,000 & $\mathrm{n} / \mathrm{a}$ & $\mathrm{n} / \mathrm{a}$ & $\mathrm{n} / \mathrm{a}$ \\
73 & $33,811 \pm 2,578$ & 0.08 & $5.9 \pm 0.2$ & 0.04 \\
25 & $37,242 \pm 2,230$ & 0.06 & $5.1 \pm 1.9$ & 0.38 \\
0 & $34,962 \pm 21,83$ & 0.10 & $5.2 \pm 1.8$ & 0.35 \\
-25 & $39,089 \pm 4,055$ & 0.04 & & 0.04 \\
-40 & $46,433 \pm 1,246$ & 0.03 & & \\
& & & $8.8 \pm 0.3$ & 0.12 \\
\hline
\end{tabular}

1 Values from draft FRP specification (Department of the Air Force. Headquarters, Air Force Civil Engineer Support Agency. 2016). 
The percent elongation of the FRP mats increased overall, but was highly irregular at 25 and $\mathrm{o}^{\circ} \mathrm{F}$. Similar to the FFM mats, this high variability is manifest in the load-displacement curves (Figure A3). Two different types of curves are observed at $\mathrm{O}^{\circ} \mathrm{F}$; somewhat triangular with a singular peak, and an irregular curve with multiple small maxima atop a single peak. When put in the context of an irregular percent elongation during tensile failure, these mats could also be expected to yield irregular performance around $\mathrm{o}^{\circ} \mathrm{F}$. The tensile strength at cold temperatures increased while the elongation at rupture also increased indicating the mat system may perform well at extreme cold temperatures. Field testing is recommended to address the irregular performance observed.

\subsubsection{Flexural strength}

Flexural testing of both FFM and FRP covers was performed in a threepoint supported beam configuration, with the same radius loading nose (1 in.) and supports (0.5 in.) for both types of specimens (Figure 16).

Figure 16. Flexural testing setup used for testing FFM and FRP panel specimens. In this image, the testing of an FRP specimen at $0^{\circ} \mathrm{F}$ is shown. Note the delamination of the specimen into layers, which are evident in the ends also.

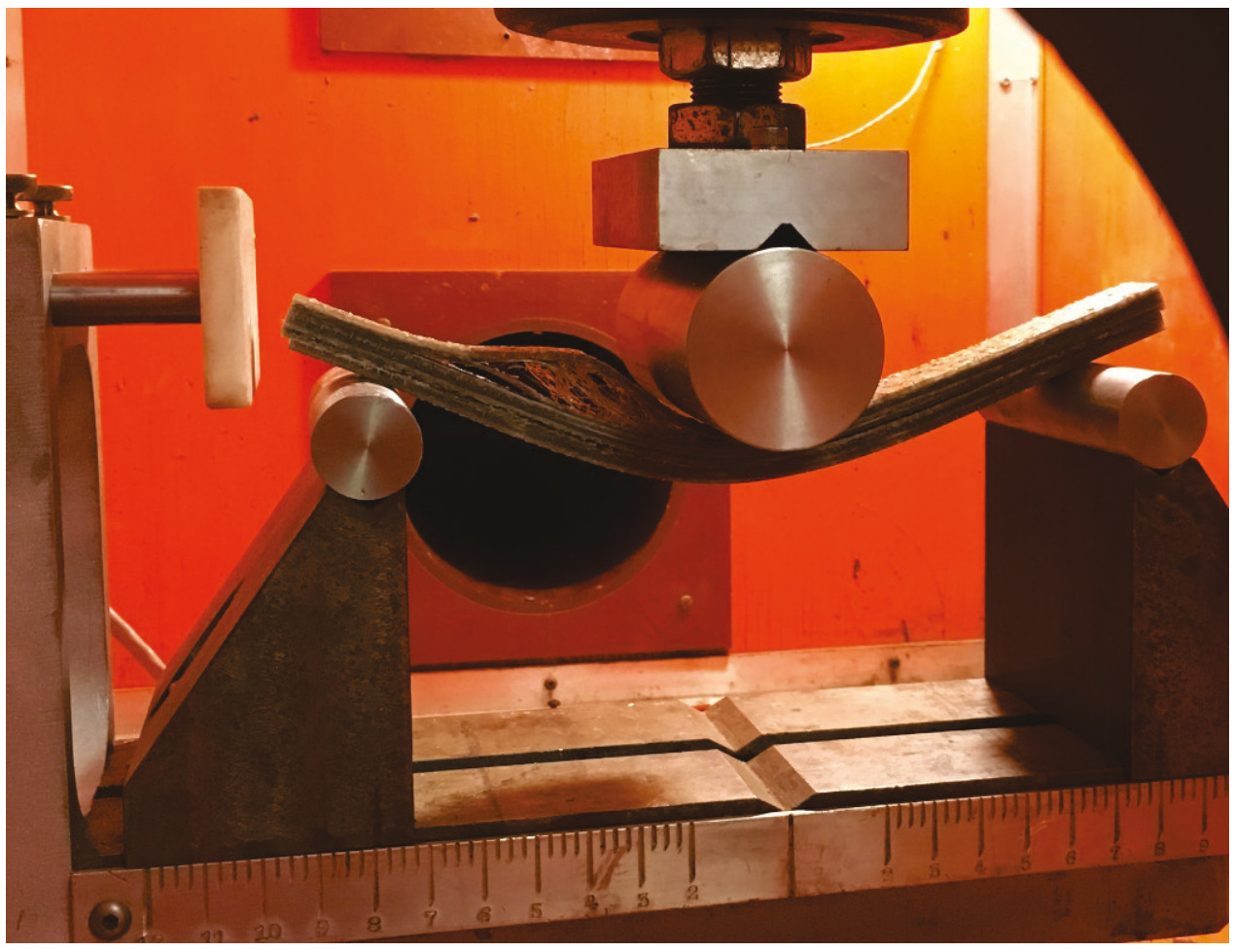

FFM panels. During flexural testing, the FFM specimens appeared to retain less permanent damage as the temperature was decreased (Figure 17). 
Over all temperatures studied, a trend towards increasing flexural strength and percent deflection was observed as temperature was decreased (Figure 18). Plots containing stress versus deflection for each individual FFM specimen is compiled in Figure A4.

While the reference flexural strength of the FFM mat specimens was only $27,579 \pm 1,558$ psi at $73^{\circ} \mathrm{F}$, the specification required 35,000 psi (Table 8). It is noteworthy that these FFM specimens exceeded the specification for tensile strength of the panels and hinges at $73^{\circ} \mathrm{F}$, but fell short of the specification on flexural strength. These results may be a result of aging or weathering of the mats as their age and exposure to wear was not known.

Figure 17. FFM specimens after flexural testing at various temperatures: a) 73; b) 25; c) 0 ; d) -25 ; e) $-40^{\circ} \mathrm{F}$.

a)

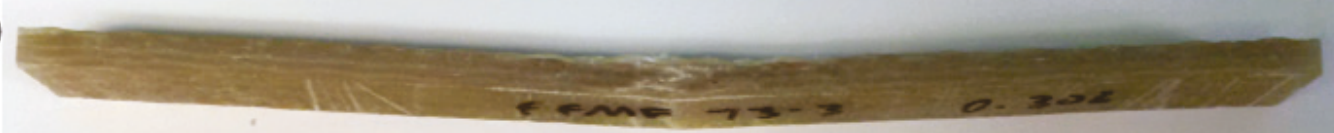

b)

c)

d)

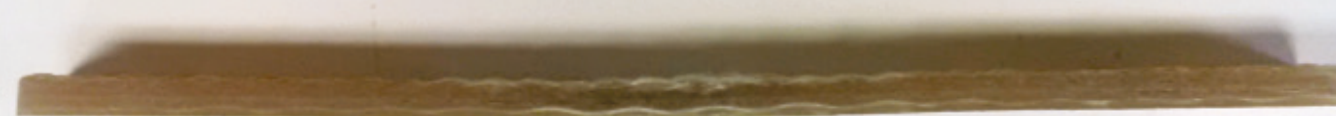

e)

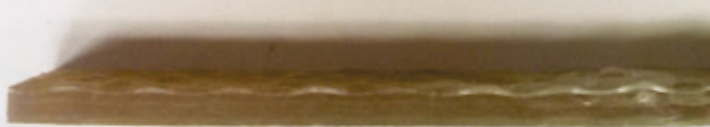


Figure 18. Flexural strength and percent deflection of FFM panels at various temperatures.

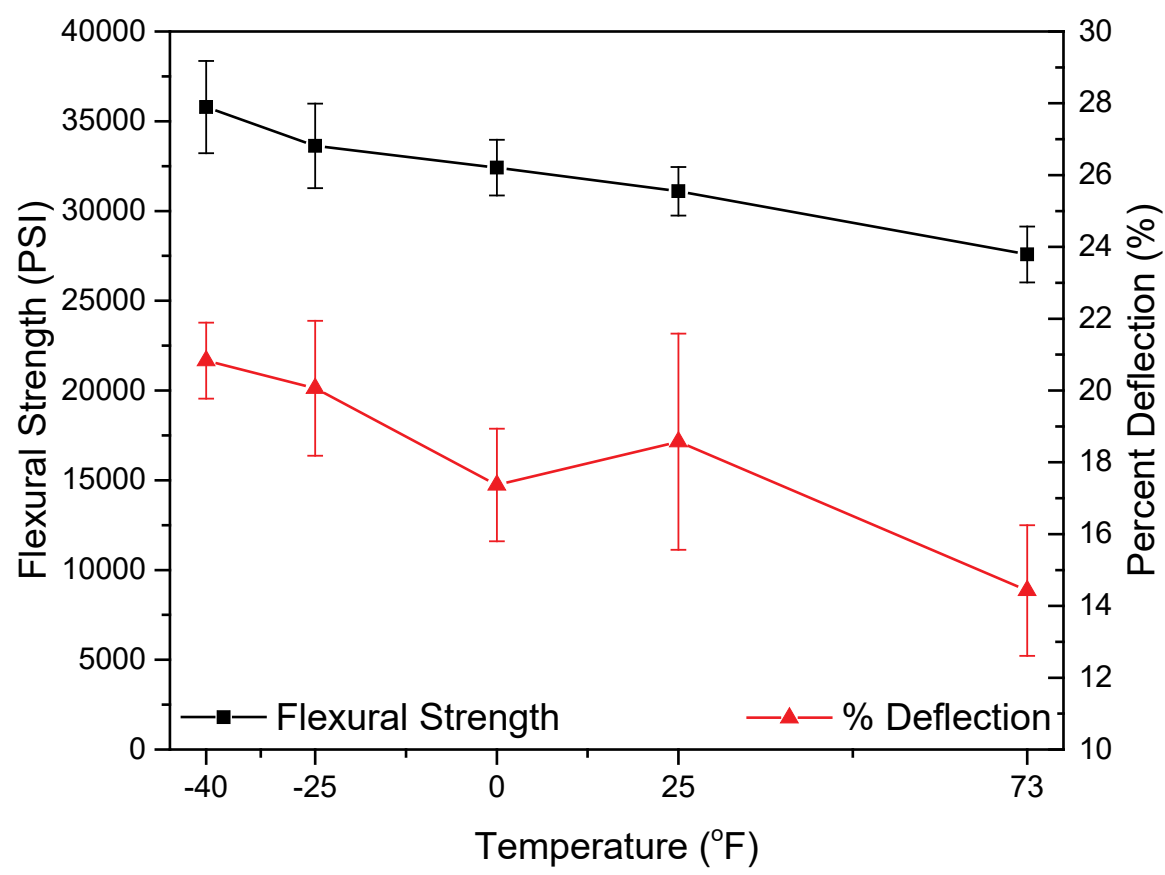

Table 8. Flexural strength and percent deflection of FFM panels.

\begin{tabular}{lllll}
\hline $\begin{array}{l}\text { Temperature } \\
\left({ }^{\circ} \mathrm{F}\right)\end{array}$ & $\begin{array}{l}\text { Flexural strength } \\
(\mathrm{psi})\end{array}$ & $\mathrm{COV}$ & $\begin{array}{l}\text { Percent } \\
\text { deflection (in.) }\end{array}$ & COV \\
\hline $73^{1}$ & 35,000 & $\mathrm{n} / \mathrm{a}$ & $\mathrm{n} / \mathrm{a}$ & $\mathrm{n} / \mathrm{a}$ \\
73 & $27,579 \pm 1,558$ & 0.06 & $14.4 \pm 1.8$ & 0.13 \\
25 & $31,100 \pm 1,349$ & 0.04 & $18.6 \pm 3.0$ & 0.16 \\
0 & $32,413 \pm 1,550$ & 0.05 & $17.4 \pm 1.6$ & 0.09 \\
-25 & $33,360 \pm 2,352$ & 0.07 & $20.1 \pm 1.9$ & 0.09 \\
-40 & $35,790 \pm 2,574$ & 0.07 & $20.8 \pm 1.1$ & 0.05 \\
\hline
\end{tabular}

1Value from MIL-DTL-32265 (Department of the Air Force. Headquarters, Air Force Civil Engineer Support Agency. 2007). 
FRP panels. During flexural testing, the FRP specimens exhibited increasing delamination with decreasing temperature (Figure 19). The flexural strength and percent deflection remained fairly constant across the temperature range of interest (Figure 20) and consistent behavior in the individual stress versus deflection traces was observed (Figure A5). The reference measurements at $73^{\circ} \mathrm{F}$ showed these FRP mats to be weaker than the specified flexural strength of 65,000 psi (Table 9), consistent with their performance in tension.

Figure 19. FRP panel specimens after flexural testing at various temperatures: a) 73; b) 25 ; c) 0 ; d) -25 ; e) $-40^{\circ} \mathrm{F}$.

a)

b)

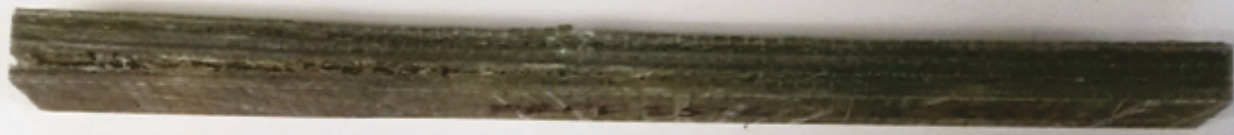

c)

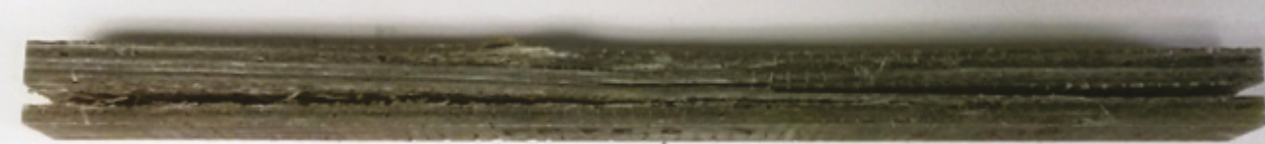

d)

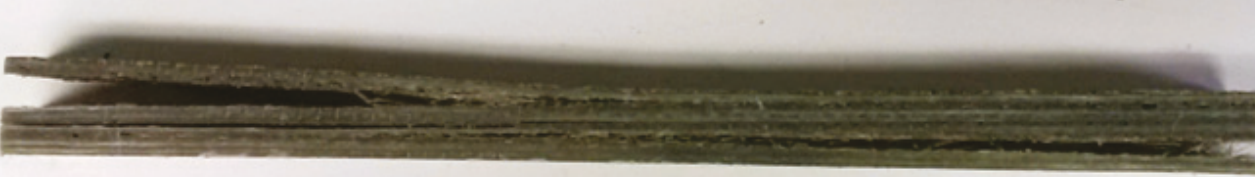

e)

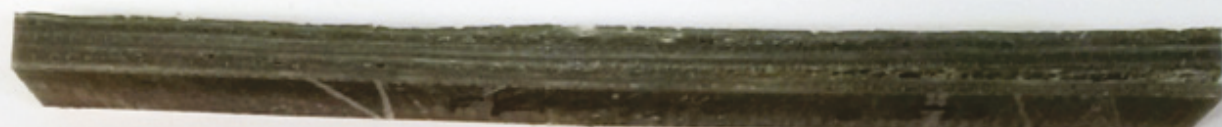


Figure 20. Flexural strength and percent deflection of FRP panels at various temperatures.

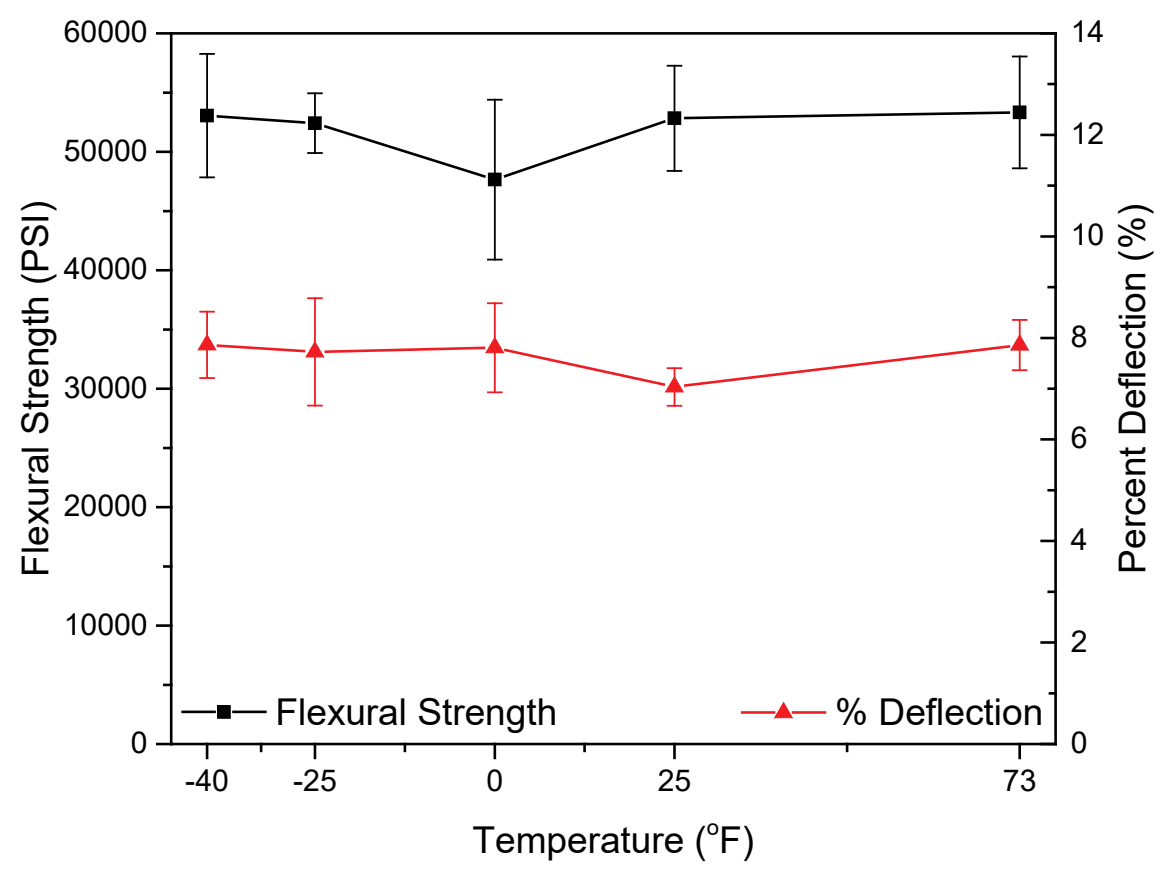

Table 9. Flexural strength and percent deflection of FRP panels.

\begin{tabular}{lllll}
\hline $\begin{array}{l}\text { Temperature } \\
\left({ }^{\circ} \text { F }\right)\end{array}$ & $\begin{array}{l}\text { Flexural strength } \\
\text { (psi) }\end{array}$ & cov & $\begin{array}{l}\text { Percent } \\
\text { deflection (in.) }\end{array}$ & cov \\
\hline 731 & 65,000 & n/a & n/a & n/a \\
73 & $53,326 \pm 4,720$ & 0.09 & $7.9 \pm 0.5$ & 0.06 \\
25 & $52,828 \pm 4,440$ & 0.08 & $7.0 \pm 0.4$ & 0.05 \\
0 & $47,649 \pm 6,755$ & 0.14 & $7.8 \pm 0.9$ & 0.11 \\
-25 & $52,416 \pm 2,526$ & 0.05 & $7.7 \pm 1.1$ & 0.14 \\
-40 & $53,056 \pm 5,217$ & 0.10 & $7.9 \pm 0.7$ & 0.08 \\
\hline
\end{tabular}

1Values from draft FRP specification (Department of the Air Force. Headquarters, Air Force Civil Engineer Support Agency. 2016). 


\subsubsection{Flexural fatigue testing}

Due to the extensive delamination of the FRP panels during flexural testing at low temperatures (Figure 19), the panels were further investigated by carrying out flexural fatigue loading to probe how they would behave during a trafficking scenario. The FRP specimens were loaded with the same apparatus as was used in the single load-to-failure flexural testing, but a simple modification was made to secure the ends of the specimens during cyclic loading (Figure 21). The specimens were tested at temperatures of $\mathrm{O}^{\circ} \mathrm{F},-25^{\circ} \mathrm{F}$ and $-40^{\circ} \mathrm{F}$, with testing at $73^{\circ} \mathrm{F}$ used as a reference. In short, the specimens were loaded to a constant deflection (75 percent of the maximum deflection measured during single load-to-failure at each temperature) for up to 5,000 cycles at a frequency of $1 \mathrm{~Hz}$ while the force was recorded. Individual plots of force versus cycle are compiled in Figure A6.

Figure 21. Experimental setup used for the flexural fatigue loading of FRP mats at low temperatures.

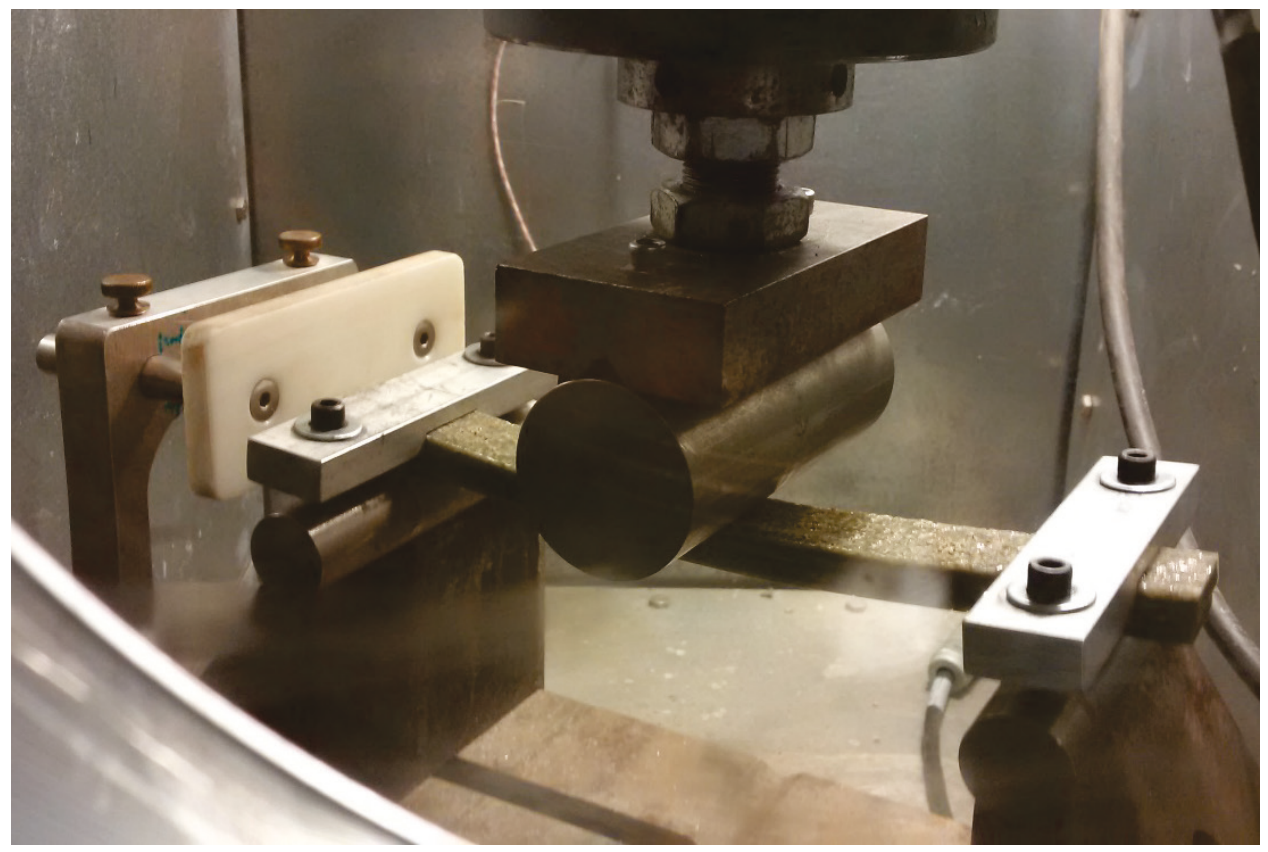

While the glass fiber components of the composite panels were evident between the delaminated layers of the FRP specimens subject to a single load-to-failure flexural testing, the fibers were worn away from between the layers during cyclic flexural testing (Figure 22). 
Figure 22. A comparison of the delamination characteristics of the FRP specimens subject to flexural testing: upper specimen was subject to single load-to-failure and shows distinct glass fibers between delaminated layers at the right end; the lower specimen was subject to cyclic flexural testing wherein the glass fibers were worn from between the layers as evident at the left end of the specimen.

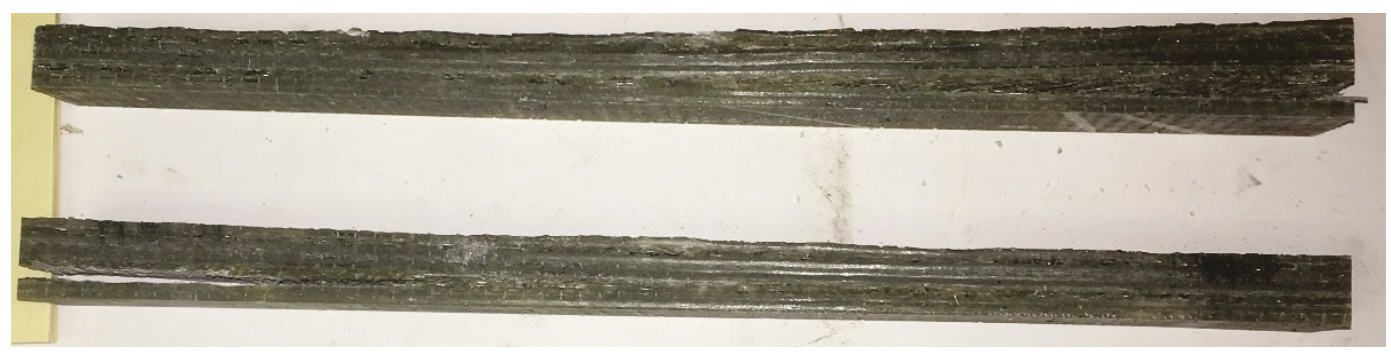

The flexural strength at various temperatures during cyclic loading for up to 500 cycles is shown in Figure 23. The related data are compiled in Table 10. The flexural strength found from the single load-to-failure experiments (Section 3.1.1.2) is included for reference.

The FRP mats showed an initial drop in flexural strength after the first flexural load cycle at $73^{\circ} \mathrm{F}$ and o ${ }^{\circ} \mathrm{F}$, followed by a linear decrease in flexural strength up to 100 cyclic loads. At $-25^{\circ} \mathrm{F}$ and $-40{ }^{\circ} \mathrm{F}$ the FRP specimens did not show an initial drop in strength, but rather a steady linear decline with cycling up to 100 flexural loads. The decrease in flexural strength from 100-500 loads was also linear, but less steep. Overall, the flexural strength of the mats decreased by 4 percent to 24 percent after 100 cycles and by 14 percent to 32 percent after 500 cycles depending on temperature (see Table 10). 
Figure 23. Flexural fatigue testing of FRP panels showing the decline in flexural strength with cyclic loading for up to 500 cycles. The circled data points denote the initial flexural strength taken by a single load-to-failure.

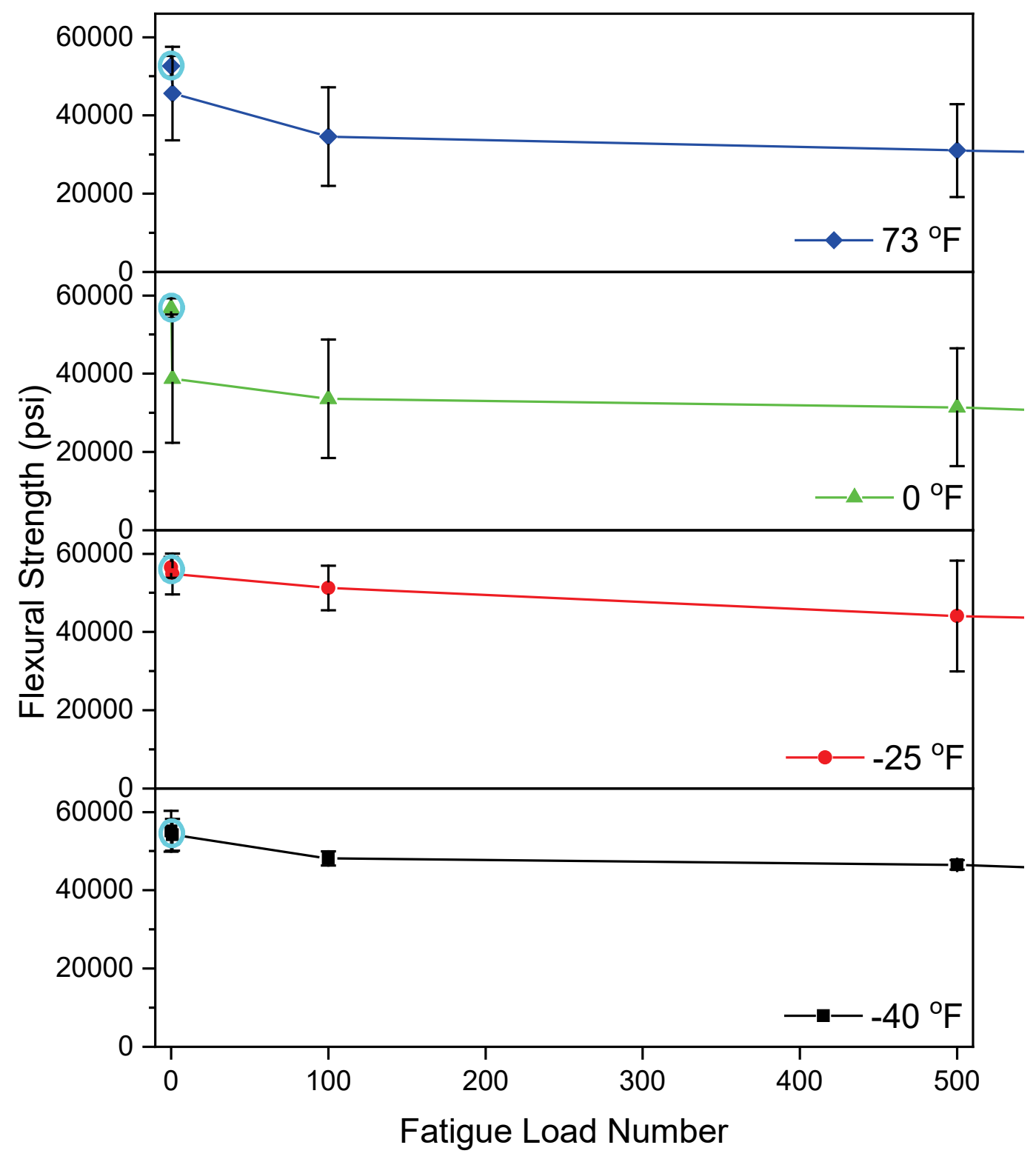


Table 10. Results from flexural fatigue testing of FRP panels loaded to $75 \%$ deflection for up to 500 cyclic loads.

\begin{tabular}{|c|c|c|c|c|c|c|}
\hline $\begin{array}{l}\text { Tempe } \\
\text { rature } \\
\left({ }^{\circ} \mathrm{F}\right)\end{array}$ & $\begin{array}{l}\text { Flexural } \\
\text { strength } 1 \\
\text { (psi) }\end{array}$ & $\begin{array}{l}\text { Flexural } \\
\text { strength, } \\
1 \text { cycle (psi) }\end{array}$ & $\begin{array}{l}\text { Flexural } \\
\text { strength, } \\
100 \text { cycles } \\
\text { (psi) }\end{array}$ & $\begin{array}{l}\text { Average } \\
\text { Flexural } \\
\text { strength } \\
\text { decrease } 2 \\
\text { after } 100 \\
\text { cycles (\%) }\end{array}$ & $\begin{array}{l}\text { Flexural } \\
\text { strength, } \\
500 \text { cycles } \\
\text { (psi) }\end{array}$ & $\begin{array}{l}\text { Average } \\
\text { flexural } \\
\text { strength } \\
\text { decrease }^{3} \\
\text { after } 500 \\
\text { cycles (\%) }\end{array}$ \\
\hline 73 & $\begin{array}{l}52,585 \\
\pm 2,624\end{array}$ & $\begin{array}{l}45,612 \\
\pm 11954\end{array}$ & $\begin{array}{l}34,587 \\
\pm 12,570\end{array}$ & 24 & $\begin{array}{l}31,037 \\
\pm 11881\end{array}$ & 32 \\
\hline 0 & $\begin{array}{l}56,795 \\
\pm 2,516\end{array}$ & $\begin{array}{l}38,723 \\
\pm 16,385\end{array}$ & $\begin{array}{l}33,578 \\
\pm 15,140\end{array}$ & 5 & $\begin{array}{l}31,436 \\
\pm 15,045\end{array}$ & 19 \\
\hline-25 & $\begin{array}{l}56,521 \\
\pm 2,687\end{array}$ & $\begin{array}{l}54,850 \\
\pm 5,210\end{array}$ & $\begin{array}{l}51,238 \\
\pm 5,726\end{array}$ & 18 & $\begin{array}{l}44,117 \\
\pm 14,159\end{array}$ & 20 \\
\hline-40 & $\begin{array}{l}55,097 \\
\pm 5,190\end{array}$ & $\begin{array}{l}54,195 \\
\pm 4,065\end{array}$ & $\begin{array}{l}48,123 \\
\pm 1,835\end{array}$ & 4 & $\begin{array}{l}46,524 \\
\pm 1,198\end{array}$ & 14 \\
\hline
\end{tabular}

${ }_{1}^{1}$ Reference value taken from a single load to failure. Same as data reported in Table 9. 2Decrease between load 1 and 100.

3Decrease between load 1 and 500.

Examining the flexural strength of the FRP panels with longer fatigue loading, the data showed that approximately 25 percent of the flexural strength after the first cycle is retained up to 1,000 cycles (Table 11). By the 2, OOO $^{\text {th }}$ cycle, the FRP composite panels exhibited a decrease in flexural strength of at least 50 percent at $73^{\circ} \mathrm{F}$. 
Table 11. Results from flexural fatigue testing of FRP panels loaded to $75 \%$ deflection for up to 5000 cyclic loads.

\begin{tabular}{|c|c|c|c|c|c|c|c|}
\hline \multirow[t]{2}{*}{$\begin{array}{l}\text { Tempe } \\
\text { rature } \\
\left({ }^{\circ} \mathrm{F}\right)\end{array}$} & $\begin{array}{l}\text { Flexural } \\
\text { strength, } \\
1000\end{array}$ & $\begin{array}{l}\text { Average } \\
\text { flexural } \\
\text { strength } \\
\text { Decrease }{ }^{1}\end{array}$ & $\begin{array}{l}\text { Flexural } \\
\text { strength, } \\
2000\end{array}$ & $\begin{array}{l}\text { Average } \\
\text { flexural } \\
\text { strength } \\
\text { Decrease }^{2}\end{array}$ & $\begin{array}{l}\text { Flexural } \\
\text { strength, } \\
5000\end{array}$ & $\begin{array}{l}\text { Average } \\
\text { flexural } \\
\text { strength } \\
\text { Decrease } \\
\text { After } 5000\end{array}$ & $\begin{array}{l}\% \\
\text { Deflection, } \\
5000\end{array}$ \\
\hline & & Cycles (\%) & & cycles (\%) & & $\begin{array}{l}\text { After b000 } \\
\text { cycles (\%) }\end{array}$ & \\
\hline 73 & $\begin{array}{l}27,650 \\
\pm 13,243\end{array}$ & 24 & $\begin{array}{l}19,847 \\
\pm 10,245\end{array}$ & 57 & $\begin{array}{l}21,626 \\
\pm 7,213\end{array}$ & 57 & $12 \pm 2$ \\
\hline 0 & $\begin{array}{l}24,240 \\
\pm 8,281\end{array}$ & 13 & $\begin{array}{l}20,828 \\
\pm 2,288\end{array}$ & 46 & $\begin{array}{l}21,408 \\
\pm 6,332\end{array}$ & 65 & $10 \pm 2$ \\
\hline-25 & $\begin{array}{l}39,724 \\
\pm 11,096\end{array}$ & 7 & $\begin{array}{l}37,629 \\
\pm 10,179\end{array}$ & 32 & $\begin{array}{l}32,913 \\
\pm 9,161\end{array}$ & 43 & $9 \pm 2$ \\
\hline-40 & $\begin{array}{l}54,195 \\
\pm 4,065\end{array}$ & 11 & $\begin{array}{l}38,017 \\
\pm 10,873\end{array}$ & 30 & $\begin{array}{l}43,712 \\
\pm 14,832\end{array}$ & 14 & $8 \pm 1$ \\
\hline
\end{tabular}

1Decrease between load 1 and 1,000.

2Decrease between load 1 and 2,000.

3Determined from a single load-to-failure test performed after cyclic loading.

4 Decrease calculated from the single load to failure for an unfatigued specimen (Table 9) and single load to failure for specimens which had been subject to 5000 fatigue loading cycles.

After 5,000 flexural loading cycles to the target 75 percent deflection, the specimens were loaded to failure. Plots of the individual strength versus deflection curves are compiled in Figure A7 and the average flexural strength and deflection at failure are compiled in (Figure 24). The results of these tests showed clear trends of increasing strength and decreasing deflection at failure as temperature decreased. These results present a contrast to the single-load-to-failure flexural tests presented in Section 3.1.1.2, wherein the FRP panels maintained a fairly consistent flexural strength and percent deflection across all temperatures examined. These results are consistent with the observed loss of glass fibers during fatigue loading (Figure 17) and the known tendency of polymers to become stiffer at cold temperatures. Essentially, the behavior of the FRP panels is dominated by the polymer matrix at low temperature as the glass reinforcement is worn away. 
Figure 24. Flexural strength of FRP panels after 5,000 fatigue load cycles at various temperatures.

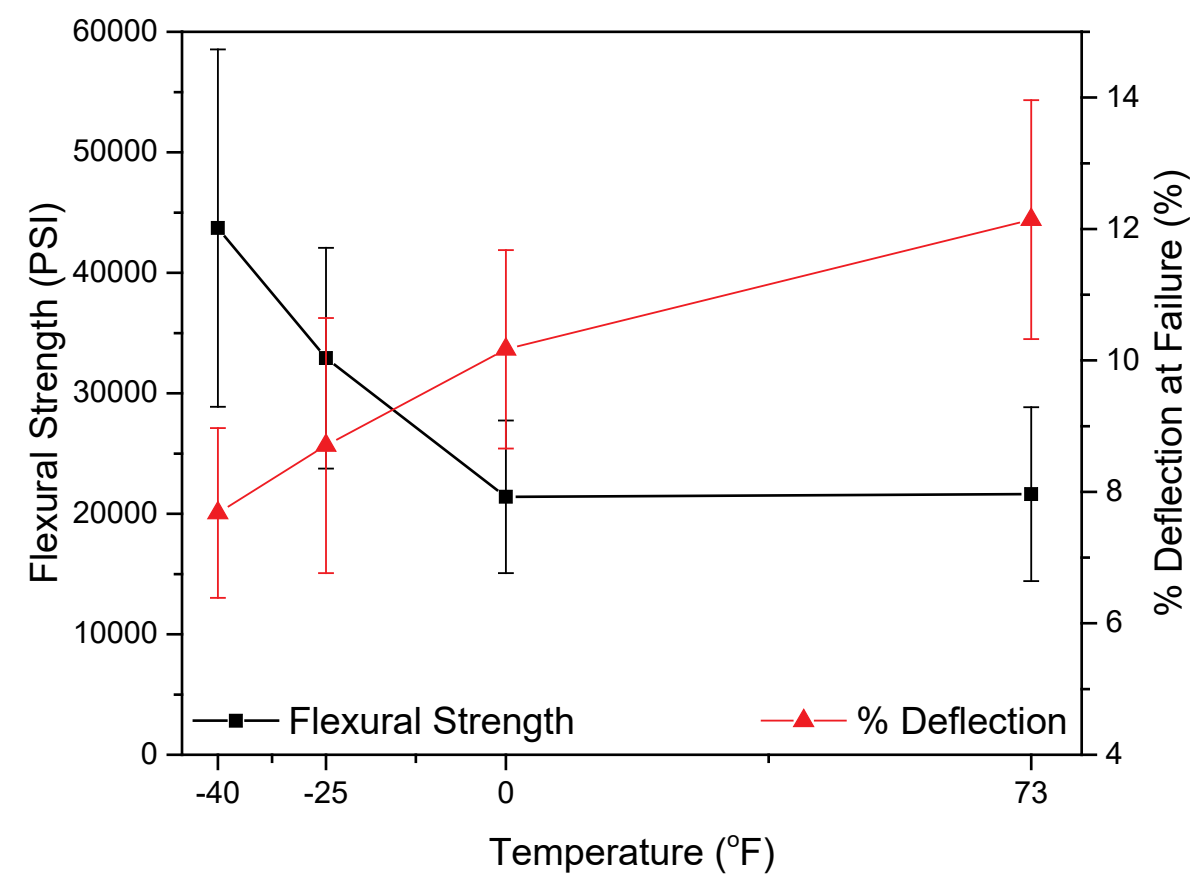

\subsubsection{Barcol hardness}

The hardness of the top and bottom of both the FFM and FRP mat sections was studied across all temperatures with a Barcol Impressor. Small 6-in. $\mathrm{x}$ 10-in. specimens were cut from three different locations in the FOD cover panels. The specimens were conditioned at the set point temperatures for $24 \mathrm{hr}$ before measurements were taken. At least eight replicate measurements were taken on each specimen at all temperatures, leading to a statistical set of at least 24 points per condition.

Neither the FFM panels nor the FRP panels exhibited a clear trend in hardness with temperature (Figure 25). In addition to averages, which don't change consistently, the standard deviation was high for all data points (Table 12). The high variability is likely due to the size of the indenter tip and the composite nature of the panels. The Impressor has a tip diameter of 0.0062 in. (0.157 mm, per ASTM D2583-13a) (2013), which is smaller than the diameter of some of the glass fiber regions in the composite FOD panels. Thus, the data measured for each condition spanned from lower values in the 20s-30s to higher values in the 50 and 6os, representative of the polymer matrix and the glassy fibers, respectively. While the Barcol Impressor is a convenient and easy measurement for field use, 
it was not capable of assessing the temperature response of either type of FOD cover.

Table 12. Individual values for Barcol hardness of FOD covers.

\begin{tabular}{|c|c|c|c|c|}
\hline $\begin{array}{c}\text { Temperature } \\
\left({ }^{\circ} \mathrm{F}\right)\end{array}$ & $\begin{array}{l}\text { Hardness } \\
\text { FFM, top }\end{array}$ & $\begin{array}{l}\text { Hardness FFM, } \\
\text { bottom }\end{array}$ & $\begin{array}{l}\text { Hardness FRP, } \\
\text { top }\end{array}$ & $\begin{array}{l}\text { Hardness FRP } \\
\text { bottom }\end{array}$ \\
\hline $73^{1}$ & $>45$ & $>25$ & 45 & 45 \\
\hline 73 & $34.6 \pm 6.1$ & $38.1 \pm 7.9$ & $55.5 \pm 5.3$ & $47.6 \pm 8.8$ \\
\hline 20 & $39.7 \pm 7.2$ & $39.1 \pm 8.9$ & $63.6 \pm 4.8$ & $50.1 \pm 8.0$ \\
\hline 0 & $39.2 \pm 6.4$ & $38.1 \pm 9.6$ & $58.9 \pm 8.8$ & $47.7 \pm 8.0$ \\
\hline-25 & $43.5 \pm 6.5$ & $44.5 \pm 11.0$ & $65.6 \pm 4.6$ & $54.0 \pm 8.3$ \\
\hline-40 & $40.2 \pm 4.4$ & $36.7 \pm 6.7$ & $55.7 \pm 5.4$ & $44.5 \pm 6.3$ \\
\hline
\end{tabular}


Figure 25. Barcol hardness of FOD covers at various temperatures: a) FFM; b) FRP.

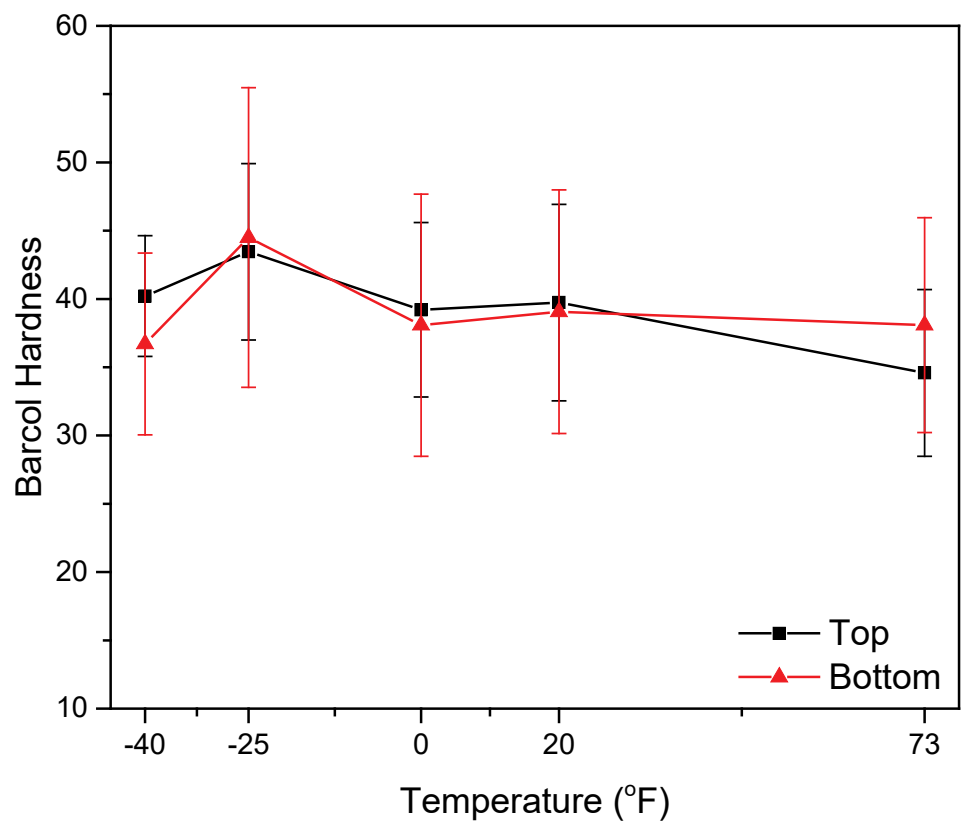

a)

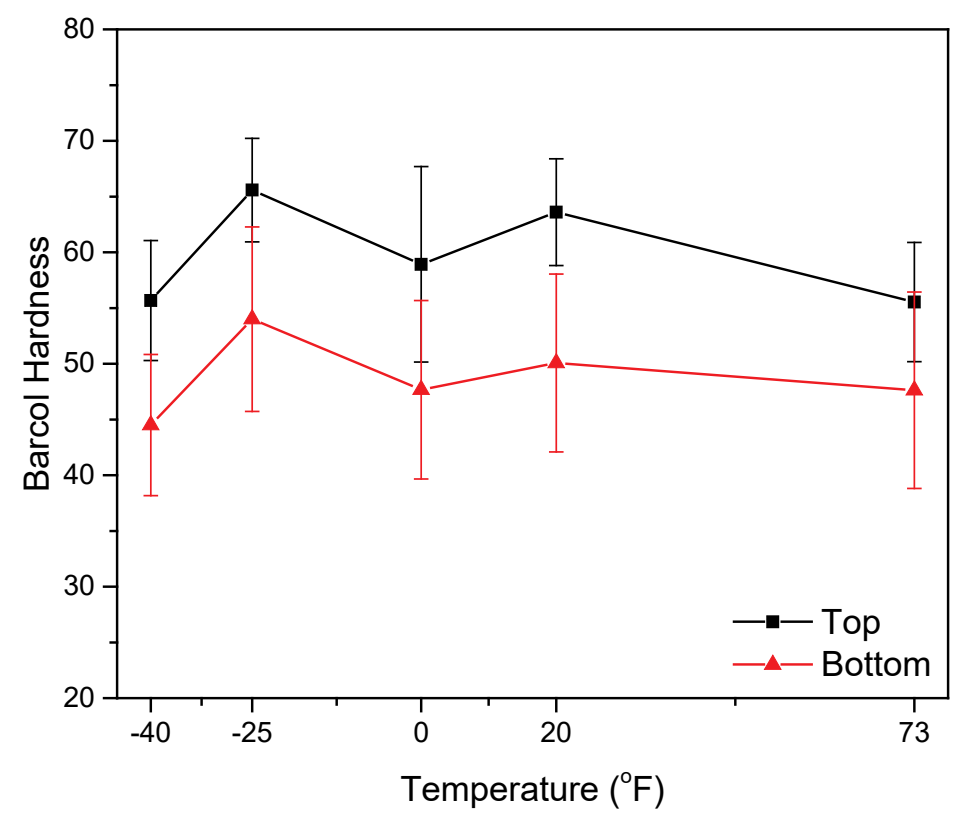

\subsubsection{Cellular confinement systems (geocells)}

As described in Section 2.1.4 and illustrated in Figure 4, three different failure modes of the geocells were assessed; the sidewall tension, junction shear, and junction peel. In general, most of the samples failed near the top of the strip and failure typically initiated at the elongated holes in the geocell. Once the failure started, it would follow the perforations in the material. 


\subsubsection{Sidewall tension}

Across all temperatures studied, the dominant failure mode for the sidewalls under tensile loading was at the perforations (Figure 26). The force at failure and corresponding displacement are shown in Figure 27. Tabulated data are compiled in Table 13.

Figure 26. Geocell specimens after testing sidewall tension.

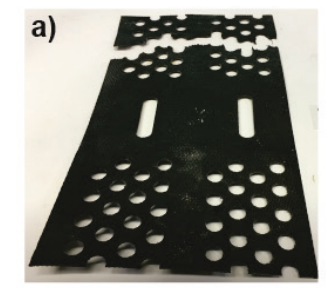

$-40{ }^{\circ} \mathrm{F}$

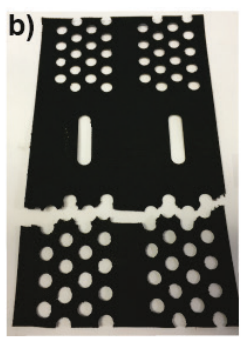

$-25^{\circ} \mathrm{F}$

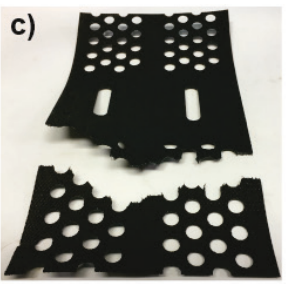

$0{ }^{\circ} \mathrm{F}$ d)

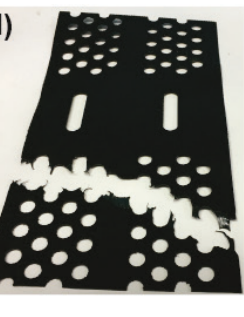

$25^{\circ} \mathrm{F}$ e)

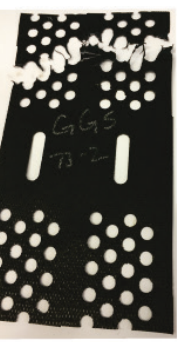

$73^{\circ} \mathrm{F}$

Geocell Sidewall Tensile Test

Figure 27. Force and displacement values measured on geocell sidewalls in tension at all temperatures of interest.

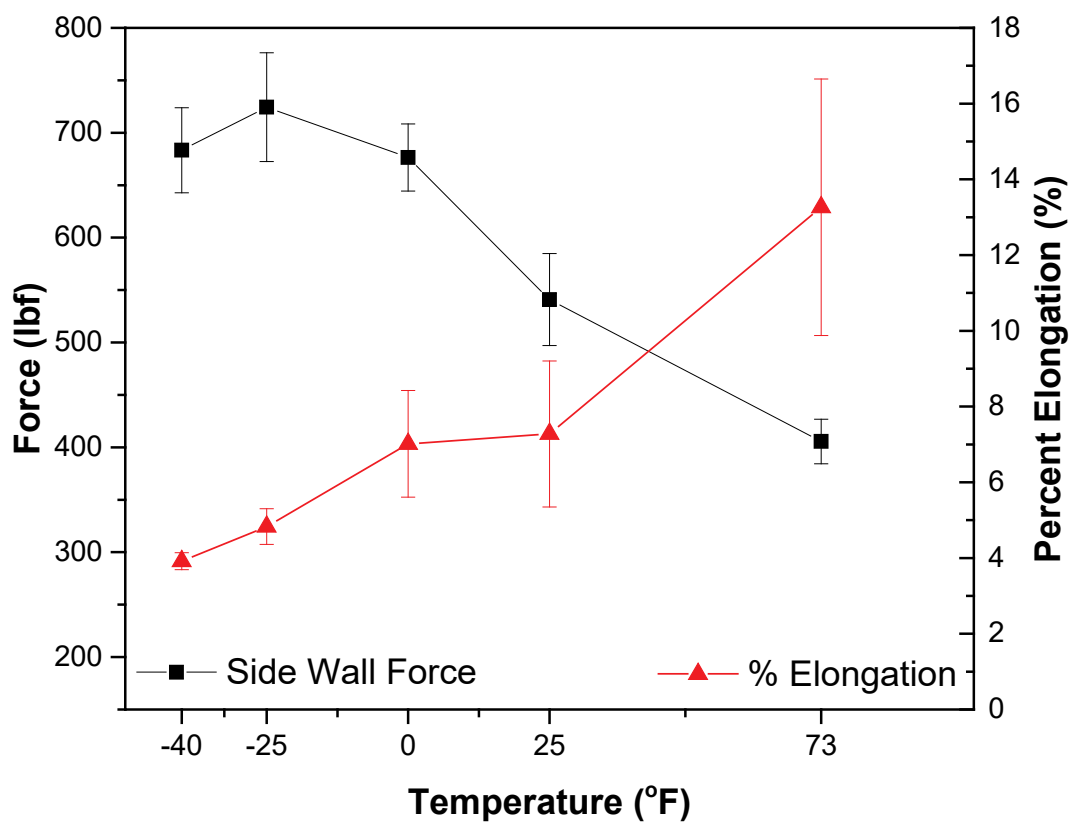


Table 13. Force and displacement values for tensile testing of 4 in. geocell (GW20) sidewalls.

\begin{tabular}{llcl}
\hline $\begin{array}{c}\text { Temperature } \\
\left({ }^{\circ} \mathrm{F}\right)\end{array}$ & $\begin{array}{c}\text { Maximum } \\
\text { force (lbf) }\end{array}$ & $\begin{array}{c}\text { Maximum displacement } \\
\text { (in.) }\end{array}$ & $\begin{array}{c}\text { Percent elongation } \\
(\%)\end{array}$ \\
\hline 73 & $406 \pm 21$ & $1.04 \pm 0.27$ & $13 \pm 3$ \\
25 & $541 \pm 44$ & $0.57 \pm 0.15$ & $7 \pm 2$ \\
0 & $676 \pm 21$ & $0.55 \pm 0.11$ & $7 \pm 1$ \\
-25 & $724 \pm 52$ & $0.38 \pm 0.04$ & $5 \pm 1$ \\
-40 & $683 \pm 41$ & $0.31 \pm 0.02$ & $4 \pm 1$ \\
\hline
\end{tabular}

Under tensile loading, the geocell sidewalls exceeded the specified yield strength (Table 2) over all temperatures studied; however, they did not retain the specified percent elongation at temperatures below $73^{\circ} \mathrm{F}$. Essentially, under tensile loading the geocell sidewalls showed a distinct trend of sustaining increased force with decreasing elongation at failure across the temperature ranges studied. These trends indicate that the geocells become brittle with decreasing temperature and may be more difficult to install at cold temperatures.

\subsubsection{Junction shear}

Geocell junctions were subjected to shear testing. In this test, opposite corners of a joining weld are pulled in tension, thereby subjecting the weld to shear stress (Figure $4 \mathrm{~b}$ ). At all temperatures, the dominant failure mode was at the perforations (Figure 28). The force at failure and corresponding displacement are shown in Figure 29. Tabulated data are compiled in Table 14 .

Figure 28. Geocell specimens after testing the junctions in shear.

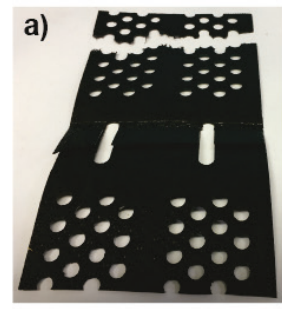

$-40{ }^{\circ} \mathrm{F}$

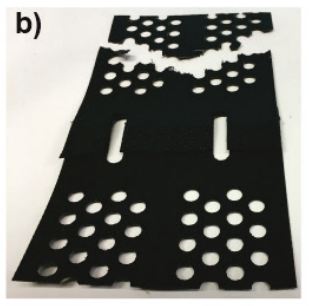

$-25^{\circ} \mathrm{F}$

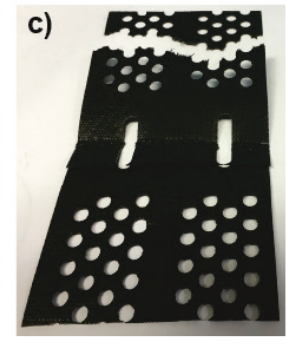

$0{ }^{\circ} \mathrm{F}$

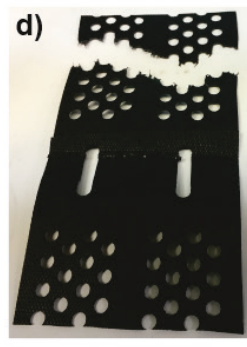

$25^{\circ} \mathrm{F}$

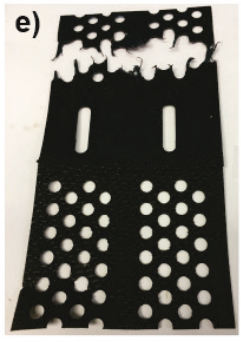

$73^{\circ} \mathrm{F}$

Geocell Junction Shear Test 
Figure 29. Force and displacement data for geocell weld junctions subject to shear loading.

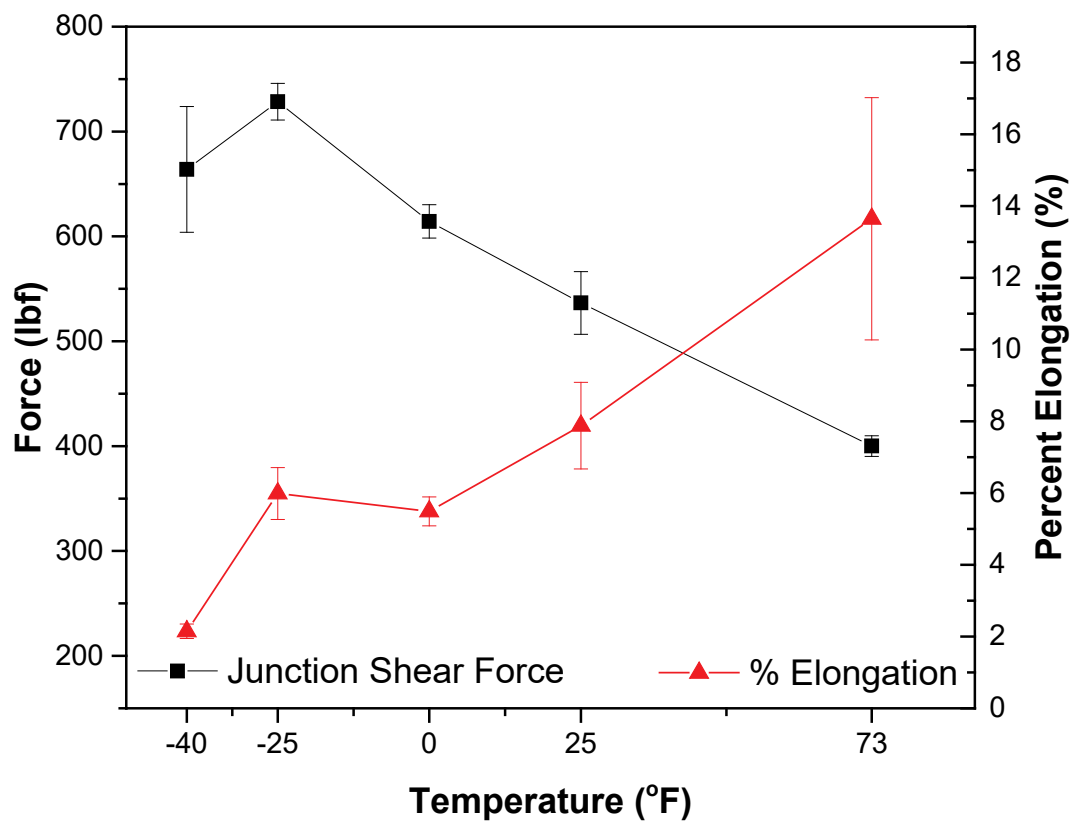

Table 14. Force and displacement values for shear testing of 6-in. geocell (GW20) junction welds.

\begin{tabular}{llll}
\hline $\begin{array}{c}\text { Temperature } \\
\left({ }^{\circ} \mathrm{F}\right)\end{array}$ & \multicolumn{1}{c}{$\begin{array}{c}\text { Max force } \\
\text { (Ibf) }\end{array}$} & $\begin{array}{c}\text { Max displacement } \\
\text { (in.) }\end{array}$ & $\begin{array}{c}\text { Percent elongation } \\
(\%)\end{array}$ \\
\hline 73 & $400 \pm 10$ & $1.07 \pm 0.27$ & $14 \pm 3$ \\
25 & $537 \pm 30$ & $0.62 \pm 0.10$ & $8 \pm 1$ \\
0 & $614 \pm 16$ & $0.43 \pm 0.03$ & $6 \pm 1$ \\
-25 & $728 \pm 18$ & $0.47 \pm 0.06$ & $6 \pm 1$ \\
-40 & $663 \pm 60$ & $0.17 \pm 0.02$ & $2 \pm 1$ \\
\hline
\end{tabular}

Under shear loading, the geocell junctions exceeded the specified yield strength (Table 2) at all temperatures, while exhibiting a general trend to increasing strength with decreasing temperature. While there is no specification for the percent elongation at failure, the geocell junctions underwent decreasing elongation as temperature was reduced. Similar to the sidewalls in tension (Sec. 3.1.2.1), the percent elongation of the junctions decreased by nearly 50 percent between $73^{\circ} \mathrm{F}$ and $25^{\circ} \mathrm{F}$. Overall, these results illustrated the increasing brittleness of the geocell's polymeric composition. 


\subsubsection{Junction peel}

Geocell junctions were subjected to peel strength testing. In this test, opposite sides of a joining weld are subject to tensile loading, causing the weld to peel open (Figure 4c). While the predominant failure mode for the geocells at $73^{\circ} \mathrm{F}$ during the junction peel test was at the perforations, the specimens failed near the welds at all other temperatures (Figure 30). The force at failure and corresponding displacement are shown in Figure 31. Tabulated data are compiled in Table 15

Figure 30. Geocell specimens after peel testing the junctions.

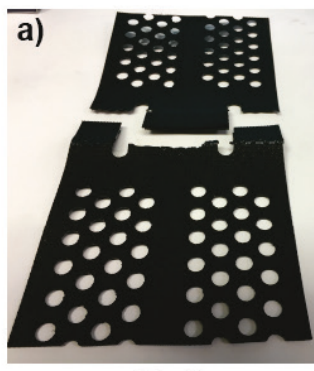

$-40{ }^{\circ} \mathrm{F}$

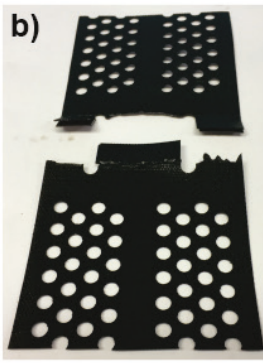

$-25^{\circ} \mathrm{F}$

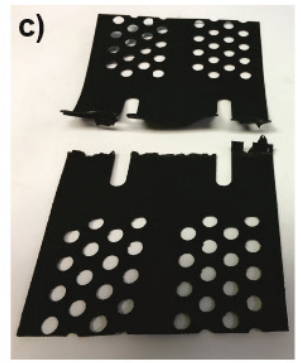

$0^{\circ} \mathrm{F}$

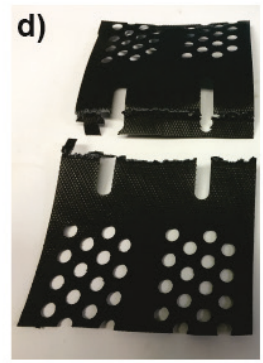

$25^{\circ} \mathrm{F}$

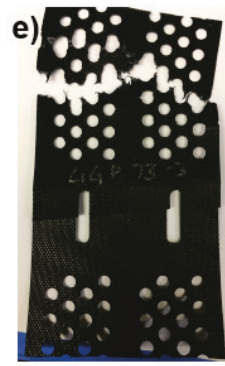

$73^{\circ} \mathrm{F}$

Geocell Junction Peel Test

Figure 31. Force and displacement behavior of geocell junction welds subject to peel testing.

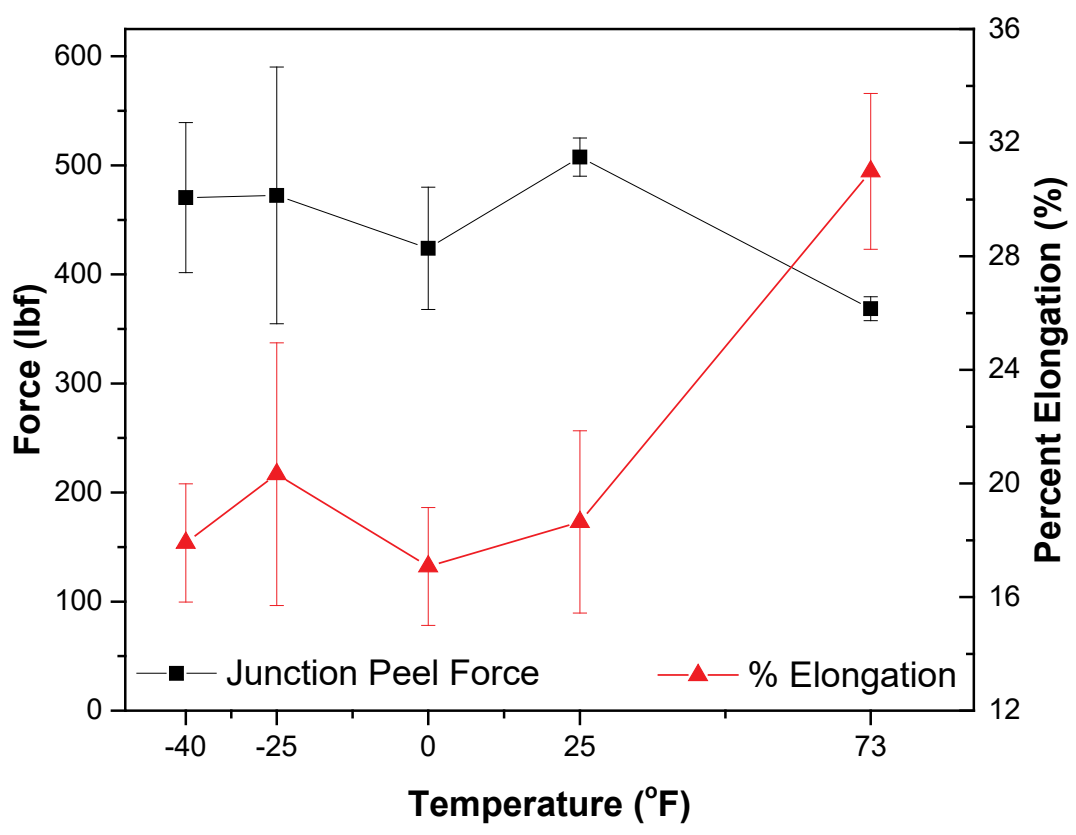


Table 15. Force and displacement values for peel testing of 4 in. geocell (GW20) junction welds.

\begin{tabular}{llll}
\hline $\begin{array}{l}\text { Temperature } \\
\left({ }^{\circ} \mathrm{F}\right)\end{array}$ & $\begin{array}{l}\text { Maximum } \\
\text { force }(\mathrm{lbf})\end{array}$ & $\begin{array}{l}\text { Maximum } \\
\text { displacement (in.) }\end{array}$ & $\begin{array}{l}\text { Percent } \\
\text { elongation (\%) }\end{array}$ \\
\hline 73 & $400 \pm 10$ & $1.07 \pm 0.27$ & $31 \pm 3$ \\
25 & $537 \pm 30$ & $0.62 \pm 0.10$ & $19 \pm 3$ \\
0 & $614 \pm 16$ & $0.43 \pm 0.03$ & $17 \pm 2$ \\
-25 & $728 \pm 18$ & $0.47 \pm 0.06$ & $20 \pm 5$ \\
-40 & $663 \pm 60$ & $0.17 \pm 0.02$ & $18 \pm 2$ \\
\hline
\end{tabular}

In a peel configuration, the geocell junction strength and percent elongation exhibited erratic behavior over the temperatures studied. However, the measured strength values exceeded the specified yield strength (Table 2). The percent elongation at failure did not decrease as drastically as the junctions in shear or the sidewalls under tension.

\subsubsection{Extreme cold expansion experiments}

In order to assess the feasibility of opening and installing the geocell panels, expansion experiments were conducted to evaluate the utility of using a geocell panel at various temperatures. In brief, a 6-ft-long segment of a collapsed geocell panel was opened by stretching to full extension by pulling from opposite sides. Once full extension was achieved, the panel was released from each side simultaneously and allowed to retract. Then the panel was photographed from above (over a white background) to record the open cell area. After expansion experiments at a given temperature, the grid was rebanded with zip ties and conditioned for at least $24 \mathrm{hr}$ at the set point temperature before expanding at the target set point temperature.

At $73{ }^{\circ} \mathrm{F}$, the geocell panel only retracted slightly after releasing, allowing the cells fully opened to almost the published width of 10.2 in. (Figure 32a). As the temperature was decreased, the retraction of the panel became more and more pronounced, to the point that there was only negligible open cell area at $\mathrm{o}^{\circ} \mathrm{F}$, and the panel snapped back to fully closed at -25 and $-40^{\circ} \mathrm{F}$ (Figure $32 \mathrm{~d}, \mathrm{e}$ ). 
Figure 32. Extreme cold expansion experiments with geocell grids at various temperatures. Photographic image of 'retracted' geocell after manual expansion: a) at $73^{\circ} \mathrm{F}$, b) $25^{\circ} \mathrm{F}$, c) $0^{\circ} \mathrm{F}$, d) $-25^{\circ} \mathrm{F}$, and e) $-40^{\circ} \mathrm{F}$. Note: The geocell panel is displayed in the same orientation in all images.

a)

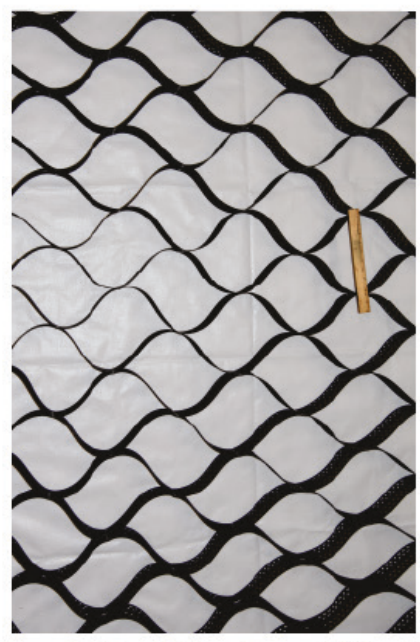

b)

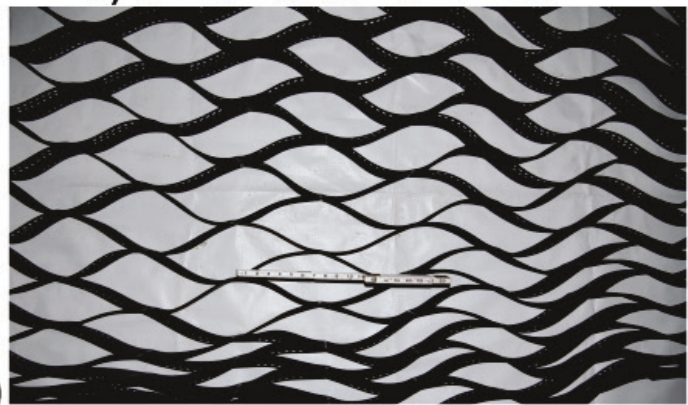

c)
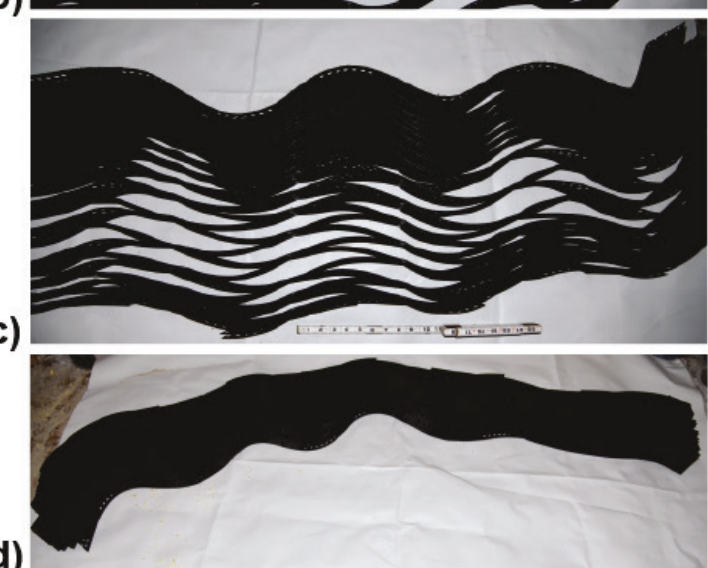

d)

e)

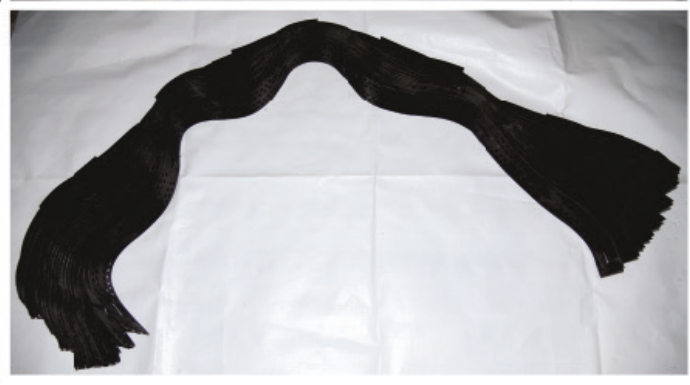




\subsubsection{Geocell discussion points}

The force required to break the geocell sidewalls increased from $406 \pm 21$ $\mathrm{lbf}$ at $73^{\circ} \mathrm{F}$ to a maximum of $724 \pm 52 \mathrm{lbf}$ at $-25^{\circ} \mathrm{F}$, while the percent elongation at failure decreased from $13 \pm 3$ percent to $4 \pm 1$ percent in at $-40^{\circ} \mathrm{F}$. The junctions exhibited a similar trend, with the junction shear force increasing from $400 \pm 10 \mathrm{lbf}$ at $73^{\circ} \mathrm{F}$ to a maximum of $728 \pm 18 \mathrm{lbf}$ at $-25^{\circ} \mathrm{F}$. As temperature decreased from $73^{\circ} \mathrm{F}$ to $-40^{\circ} \mathrm{F}$, the percent elongation decreased from $14 \pm 3$ percent to $2 \pm 1$ percent. The peel loading of the junctions exhibited much greater deviation in the values, but showed an overall similar trend of increasing force and decreasing displacement before yielding as temperature decreased.

All these results are consistent with the increasing brittleness of the polyethylene material at low temperatures. In practice, these results will manifest in the sidewalls of the geocells. Below freezing, the geocell sidewalls have a 66 percent reduction in the amount of stretching they can tolerate before failure, and the junctions have a 90 percent reduction in their tolerance for shearing before failure. When these individual load-to-failure tests are considered in the context of the expansion experiments, it is quite clear that the individual cells may rupture during loading at lower temperatures. In addition, due to the increased force required to open the geocell panels, the individual sidewalls and seams may break during installation.

\subsubsection{Polyurethane foam backfill material}

Polyurethane foam samples were made from Foam-iT! 10 Slow based on a 100:87 ratio (Mejas et al 2016). All components, including the 6-in. x 12in. buckets were kept at room temperature before mixing. This approach was employed as a means to simulate the use of a warm tank supply in a field scenario. Mixing was accomplished with an electric drill mixer, operating at $200 \mathrm{rpm}$. First Component B was mixed for $15 \mathrm{sec}$, then Component $\mathrm{A}$ was added and mixing was continued for an additional $30 \mathrm{sec}$. After transferring Component A, some mass remained coated inside the bucket. After weighing the remains, the actual mass ratio of components was 375:328 in the specimens. All samples remained at the set point temperature during curing, prepping, and testing/analysis. Specimens were analyzed for expansion, density, and compressive strength after 2 and $24 \mathrm{hr}$ of curing. 
As expected, the $73^{\circ} \mathrm{F}$ samples expanded the most (Table 16) and were visibly the most homogeneous. As the temperature was decreased, the expansion ratio decreased and the specimen density increased (Figure 33). An expansion ratio of approximately 5 was retained down to $20^{\circ} \mathrm{F}$ and an expansion ratio of 4.75 was retained down to $\mathrm{o}{ }^{\circ} \mathrm{F}$. Below $\mathrm{O}^{\circ} \mathrm{F}$, the foam specimens exhibited a distinctly different trend, where the density appeared to decrease while expansion remained constant at around 5 (Figure 33).

After the target cure times, foam specimens were cut into approximately 6in. $x$ 6-in. cylinders. Due to flaking and peeling at lower temperatures, smaller diameters were obtained for some specimens. For example, the specimens prepared at $-25^{\circ} \mathrm{F}$ averaged $5.75 \mathrm{in}$. in diameter. While specimens formed at $-40^{\circ} \mathrm{F}$ did expand to approximately $4 \mathrm{x}$ the initial volume, they were brittle (Figure A7). As a result, the $-40^{\circ} \mathrm{F}$ specimens could not be cut into cylinders with the required 1:1 aspect ratio and so they were not subject to uniaxial compression testing.

Consistent with the increasing density at lower temperatures, the uniaxial strength of foam specimens increased with decreasing temperatures down to ${ }^{\circ} \mathrm{F}$ (Table 16, Figure 34). Similar to the trends seen in the expansion and density data, the compressive strength changes dramatically below 0 ${ }^{\circ} \mathrm{F}$, dropping to lower values and showing an increased standard deviation in the specimens that were cured for $24 \mathrm{hr}$.

Table 16. Summary of data for testing foam as a function of temperature.

\begin{tabular}{lllllll}
\hline $\begin{array}{c}\text { Temperature } \\
\left({ }^{\circ} \mathrm{F}\right)\end{array}$ & \multicolumn{2}{c}{$\begin{array}{c}\text { Expansion } \\
\text { ratio }\end{array}$} & \multicolumn{2}{c}{$\begin{array}{c}\text { Density } \\
\left(\mathrm{lbf} / \mathrm{ft}^{3}\right)\end{array}$} & \multicolumn{2}{c}{$\begin{array}{c}\text { Compressive } \\
\text { Strength, (psi) }\end{array}$} \\
\hline $73^{1}$ & $2 \mathrm{hr}$ & $24 \mathrm{hr}$ & $2 \mathrm{hr}$ & $24 \mathrm{hr}$ & $2 \mathrm{hr}$ & $24 \mathrm{hr}$ \\
73 & $\mathrm{n} / \mathrm{a}$ & 5.4 & $\mathrm{n} / \mathrm{a}$ & 11.4 & $\mathrm{n} / \mathrm{a}$ & 240 \\
20 & 5.75 & 5.92 & 11.6 & 11.9 & $257 \pm 13$ & $286 \pm 4$ \\
0 & 5.12 & 4.98 & 12.3 & 12.5 & $349 \pm 8$ & $417 \pm 22$ \\
-25 & 4.86 & 4.75 & 12.6 & 12.9 & $430 \pm 12$ & $475 \pm 18$ \\
-40 & 4.44 & 4.85 & 12.1 & 12.2 & $341 \pm 5$ & $282 \pm 41$ \\
\hline
\end{tabular}

${ }_{1}^{1}$ Reference data taken from (Mejias-Santiago et al. 2016). 
Figure 33. Plot of volume expansion and density of polyurethane foam as a function of temperature.

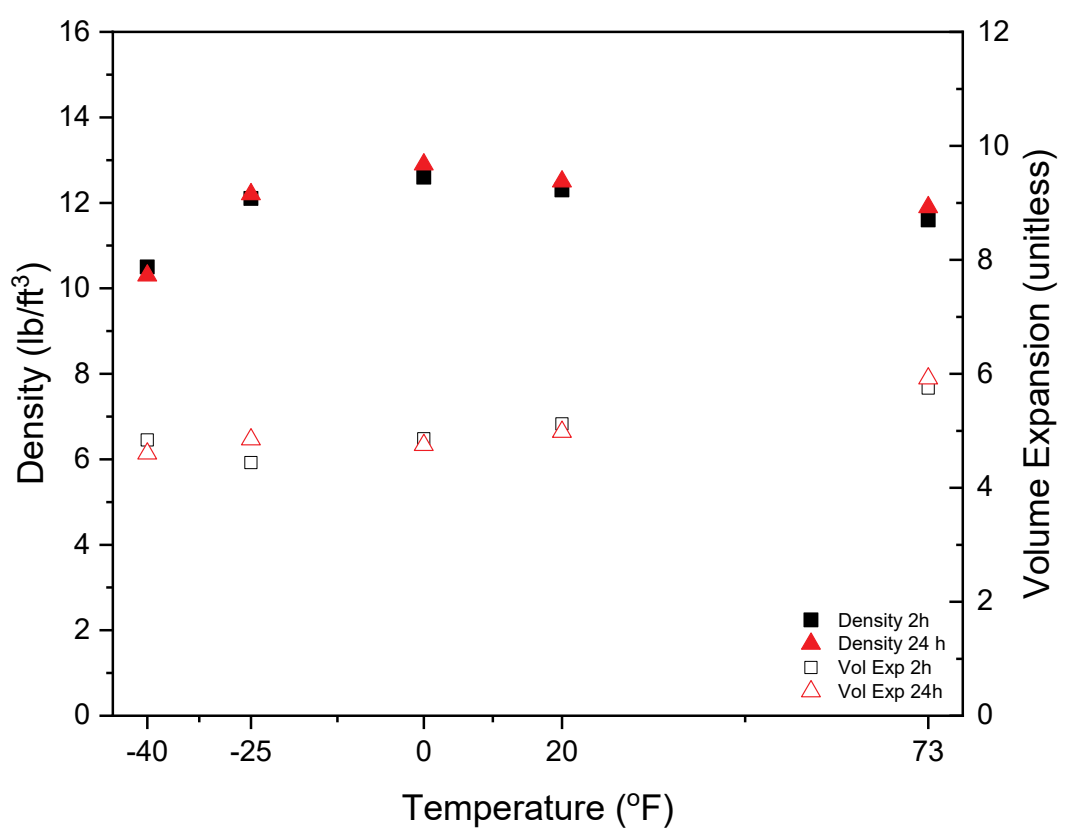

Figure 34. Plot of compressive strength of foam as a function of temperature.

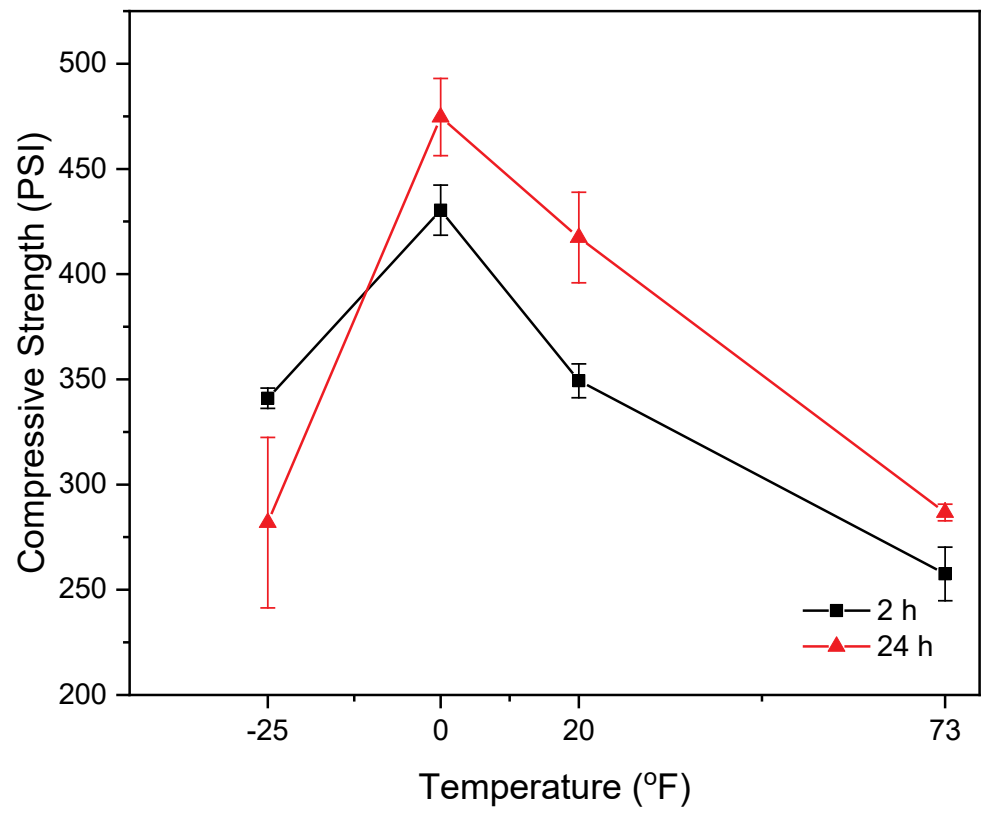

Visual inspections of the specimens after loading under uniaxial compression further corroborates the changing properties as temperature is decreased (Figure 35). While the specimens formed at $73^{\circ} \mathrm{F}$ for both 2 and $24 \mathrm{hr}$ remained smooth and elastic after testing, those formed at lower 
temperatures showed peeling and flaking as temperature decreased. Further, at temperatures $\leq \mathrm{O}^{\circ} \mathrm{F}$, permanent damage was observed in some 24$\mathrm{hr}$ cured samples after testing (Figure 35, $\mathrm{O}$ and $-25^{\circ} \mathrm{F}, 24 \mathrm{~h}$ ).

Figure 35. Foam samples after uniaxial compression testing at temperatures down to $-25^{\circ} \mathrm{F}$.
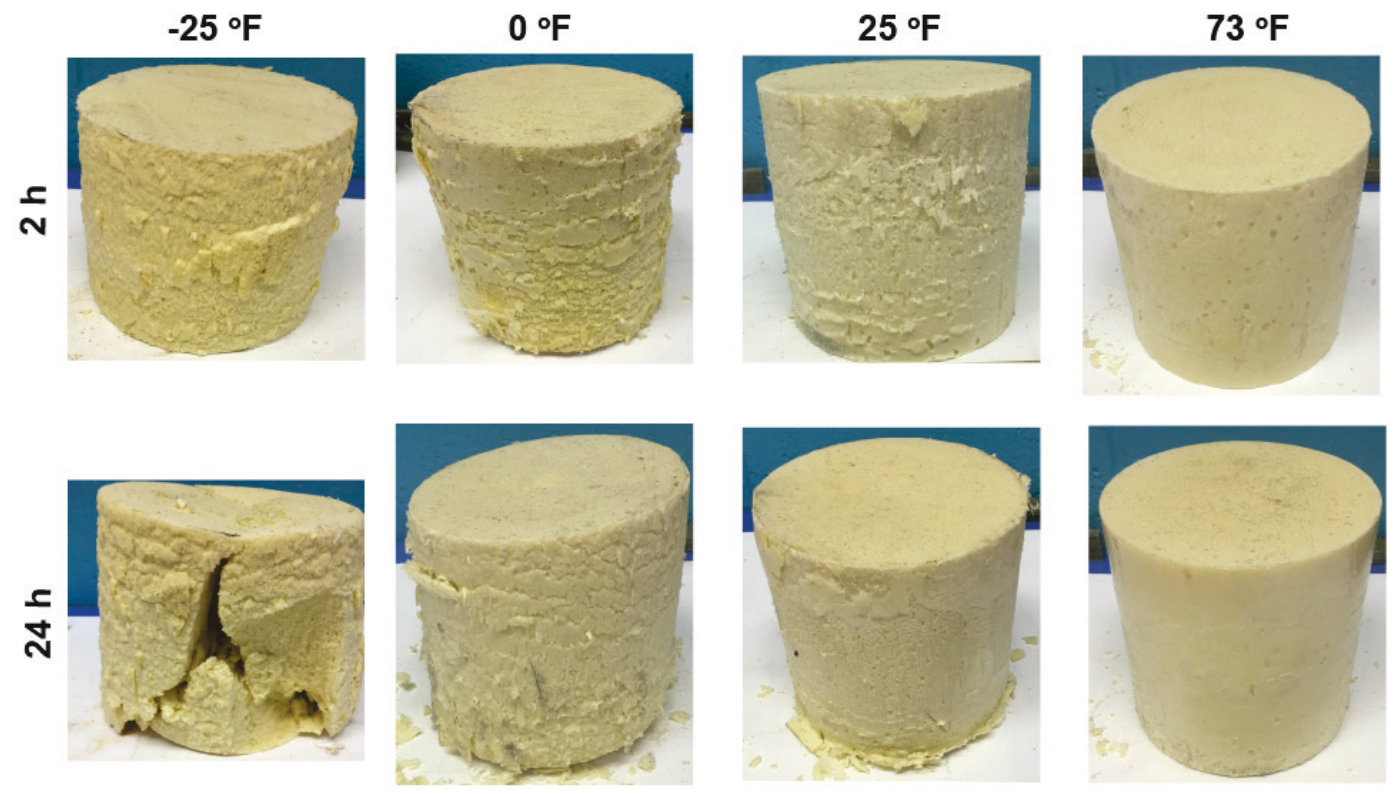

In concert, the results from polyurethane foam testing provide a consistent indication that the foam material can likely be used as a backfill material down to $25^{\circ} \mathrm{F}$, provided the component materials can be supplied at room temperature. These results also indicate that the foam may be an amenable material at lower temperatures, approaching o ${ }^{\circ} \mathrm{F}$; however, further experimentation would be required. Specifically, pilot scale experiments using foam as a backfill and subjecting the full repair to trafficking or other cyclic loading may reveal that the polyurethane foam can be used down to ${ }^{\circ}{ }^{\circ} \mathrm{F}$.

\subsubsection{Rapid Set concrete mix}

The $73^{\circ} \mathrm{F}$ Rapid Set 6-in. $\mathrm{x}$ 12-in. cylindrical samples performed as expected and generated high levels of heat. Using a non-contact temperature gun, the temperature was observed at $180^{\circ} \mathrm{F}$ at the 2 -hr point after the pour. The ultimate strength for the $73^{\circ} \mathrm{F}$ test samples was not less than 6,000 psi after $24 \mathrm{hr}$ and averaged over 7,000 psi (Table 17). 
Table 17. Uniaxial compressive strength of warm Rapid Set concrete.

\begin{tabular}{|l|l|l|l|}
\hline \multicolumn{5}{|c|}{$73^{\circ} \mathrm{F}$ Rapid Set Concrete } \\
\hline Curing time & \multicolumn{1}{|c|}{$\begin{array}{c}\text { Mean UCS } \\
\text { (psi) }\end{array}$} & $\begin{array}{c}\text { Median UCS } \\
\text { (psi) }\end{array}$ & \multicolumn{1}{|c|}{$\begin{array}{c}\text { Standard } \\
\text { deviation (psi) }\end{array}$} \\
\hline $2 \mathrm{hr}$ & 5828 & 5963 & 442 \\
\hline $24 \mathrm{hr}$ & 7137 & 7172 & 57 \\
\hline
\end{tabular}

When cylindrical samples were poured, cured and tested at $23{ }^{\circ} \mathrm{F}$ the results were quite different. Strengths only reached 3,000 and 4,500 psi for two samples, or half the strength when constructed at $73{ }^{\circ} \mathrm{F}$ (Table 18). Further, two samples failed almost immediately.

However, previous experiments at cold temperatures have shown that the mass of the material placed is an important factor. Larger masses generate a sustained exothermic reaction that facilitates the chemical reaction and strength gain. The small mass associated with preparing cylinders for lab testing is likely not representative of the material behavior for mass placements in a crater.

Table 18. Uniaxial compressive strength of below freezing Rapid Set concrete.

\begin{tabular}{|l|l|}
\hline \multicolumn{2}{|c|}{$23^{\circ} \mathrm{F}$ Rapid Set concrete } \\
\hline Curing time & Average UCS (psi) \\
\hline $2 \mathrm{hr}$ & 56 \\
\hline $24 \mathrm{hr}$ & 3830 \\
\hline
\end{tabular}

\subsubsection{Rapid setting flowable fill}

Rapid setting flowable fill is used primarily as a backfill material for crater repairs. It is accepted for use down to $25^{\circ} \mathrm{F}$. In these applications, the water is applied/added as specified by the manufacturer to form a flowable slurry, which is then poured into the crater. The approach to studying FF as a cold weather RADR material was to verify the accepted standards at 73 and $25^{\circ} \mathrm{F}$, while seeking to extend its traditional use to lower temperatures and exploring new ways to apply the material under extreme cold conditions. 


\subsubsection{Traditional rapid setting flowable fill}

Specimens were made according to the manufacturer's specification using a rotary drum mixer and poured into 6 -in. $x$ 12-in. cylindrical concrete molds. The strength was measured under uniaxial compression after 2and 24-hr set times.

The results of testing $\mathrm{FF}$ at 73 and $23^{\circ} \mathrm{F}$ verified the ability to produce the specified strength of 250 psi within 2-3 hr (Table 19 and Table 20). When the temperature was below $25^{\circ} \mathrm{F}$, the mixing of the cementitious FF material with water created issues with water freezing to the drums. Additional water had to be added (above the manufacturer's specification) to reduce clumping and ensure uniform mixing. After $2 \mathrm{hr}$ the $\mathrm{FF}$ formed at $\mathrm{O}^{\circ} \mathrm{F}$ was not set in a state that could be tested in the universal load frame. After 24 $\mathrm{hr}$, the results shown (Table 21) illustrate that the required strength can be met given a longer set period. The set time to be able to remove the cylinder to test was between 19 and $20 \mathrm{hr}$. The strength testing indicated that the $\mathrm{FF}$ material formed at $\mathrm{O}^{\circ} \mathrm{F}$ was more characteristic of ice, indicating that it froze before curing. This state is acceptable and meets the requirements of base material for a crater. Cylinder testing at low temperatures historically has resulted in extended set times in comparison to larger batches of the same material. This is due to the reduced potential of exothermic mass in a small 6 in. $\mathrm{x} 12$ in. cylinder. Larger batches of rapid set flowable fill have a much larger increase in mass resulting in an increase in exothermic potential and decreasing set times. The set times are decreased because of the chemical reaction within the mix is capable of activating due to the increased heat present.

Table 19. Uniaxial compressive strength of flowable fill prepared according to traditional methods at $73^{\circ} \mathrm{F}$.

\begin{tabular}{|l|l|l|l|}
\hline \multicolumn{4}{|c|}{$73^{\circ} \mathrm{F}$ flowable fill } \\
\hline Curing time & \multicolumn{1}{|c|}{$\begin{array}{c}\text { Mean UCS } \\
\text { (psi) }\end{array}$} & \multicolumn{1}{|c|}{$\begin{array}{c}\text { Median UCS } \\
\text { (psi) }\end{array}$} & $\begin{array}{c}\text { Standard } \\
\text { deviation (psi) }\end{array}$ \\
\hline $2 \mathrm{hr}$ & 517 & 513 & 46 \\
\hline $24 \mathrm{hr}$ & 832 & 837 & 37 \\
\hline
\end{tabular}


Table 20. Uniaxial compressive strength of flowable fill prepared according to traditional methods at $23^{\circ} \mathrm{F}$.

\begin{tabular}{|l|l|l|l|}
\hline \multicolumn{5}{|c|}{$23^{\circ} \mathrm{F}$ flowable fill } \\
\hline Curing time & \multicolumn{1}{|c|}{$\begin{array}{c}\text { Mean UCS } \\
\text { (psi) }\end{array}$} & $\begin{array}{c}\text { Median UCS } \\
\text { (psi) }\end{array}$ & $\begin{array}{c}\text { Standard } \\
\text { deviation (psi) }\end{array}$ \\
\hline $2 \mathrm{hr}$ & 144 & 141 & 17 \\
\hline $24 \mathrm{hr}$ & 801 & 811 & 14 \\
\hline
\end{tabular}

Table 21. Uniaxial compressive strength of flowable fill prepared according to traditional methods at $0^{\circ} \mathrm{F}$.

\begin{tabular}{|l|l|}
\hline \multicolumn{2}{|c|}{$0^{\circ} \mathrm{F}$ flowable fill } \\
\hline \multicolumn{1}{|c|}{ Curing time } & \multicolumn{1}{c|}{ Mean UCS (psi) } \\
\hline $2 \mathrm{hr}$ & N/A \\
\hline $24 \mathrm{hr}$ & 1668 \\
\hline
\end{tabular}

\subsubsection{Dry flowable fill (dFF)}

Flowable fill in a dry state was principally utilized in this study. This approach was based on discussions with current RADR researchers. In warmer applications, rapid setting dry flowable fill is placed in 2-3 in. lifts and then saturated with water to ensure water will percolate through the material. In colder environments activation of the cementitious material will not be as fast as when warmer, therefore lifts were increased in thickness to try to reduce required labor in hazardous conditions. In short, to make these samples in the lab, 6-in. $x$ 12-in. cylindrical specimens using $3^{-}$ 4 in. lifts in each cylinder were prepared. Water was added until saturation of each lift ceased. Specimens were made with this approach at $0,-20,-40$ ${ }^{\circ} \mathrm{F}$ using water that was $\sim 55^{\circ} \mathrm{F}$. In warmer temperature testing and accepted practice, water is applied in 2 in. lifts of dry placed material to allow the water to percolate through the material and reduce dry pockets in the mix. In colder environments, water is typically limited in availability due to freezing potential and therefore testing conducted within this study focused on utilizing field capable techniques, which would lead to thicker lifts of dry placed material and decreased water. Standing water in a cold environment could lead to ice lensing between the lifts and would reduce potential strength of the material. Another reason for increasing lift thickness is that procedures take longer to complete in the cold due to material 
and personnel complications. This testing focused on meeting the required metrics at reduced effort levels if possible.

The specimens formed in this way did not have any cohesive strength, and thus, could not be tested in uniaxial compression (Figure 36a). However, after thawing, the cylindrical specimens were found to have cured (Figure $36 \mathrm{~b}$ ). Thus, this technique with $\mathrm{dFF}$ was retained as a potential RADR material for the crater repairs (Section 3.3.1). This process of the cement going into a hibernation state and then activating once melting temperatures were present, should be investigated in greater detail to help illustrate the longevity of the material and its full capabilities. With the single frost thaw cycle pictures being shown below, it is evident that curing took place in the thaw cycle and increased the material strength properties. As with traditional placement of flowable fill 6 in. by 12 in., cylinder testing suffers from the reduced exothermic potential simply due to economy of scale. As the test size increases, so does the exothermic potential, and the chemical reaction set time decreases.

Figure 36. A cylindrical specimen formed using the dry flowable fill technique $0^{\circ} \mathrm{F}$. a) As formed, the lack of cohesion between lifts is seen as the top of the specimen broke and is placed on top. b) After thawing, the specimens were observed to cure, forming a cohesive cylinder.

a)

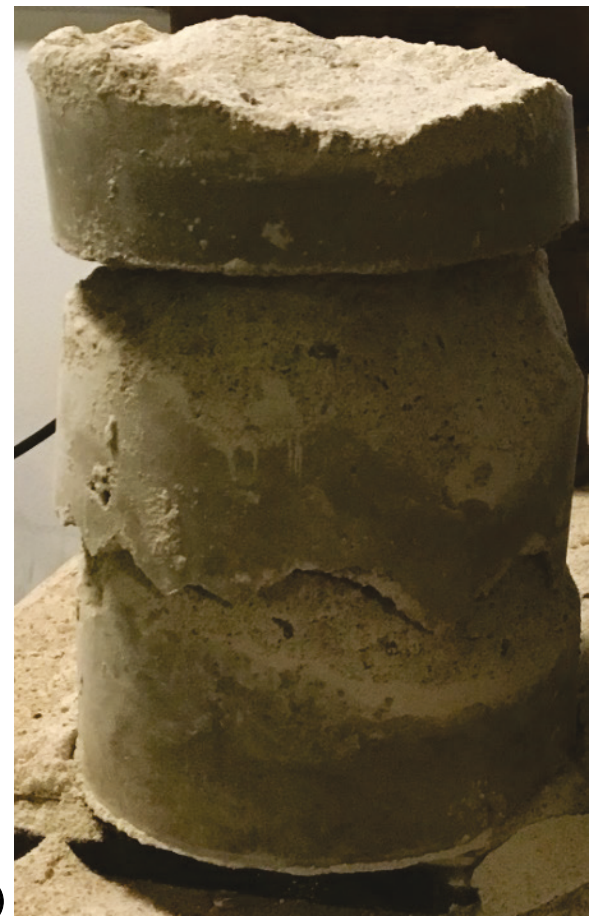

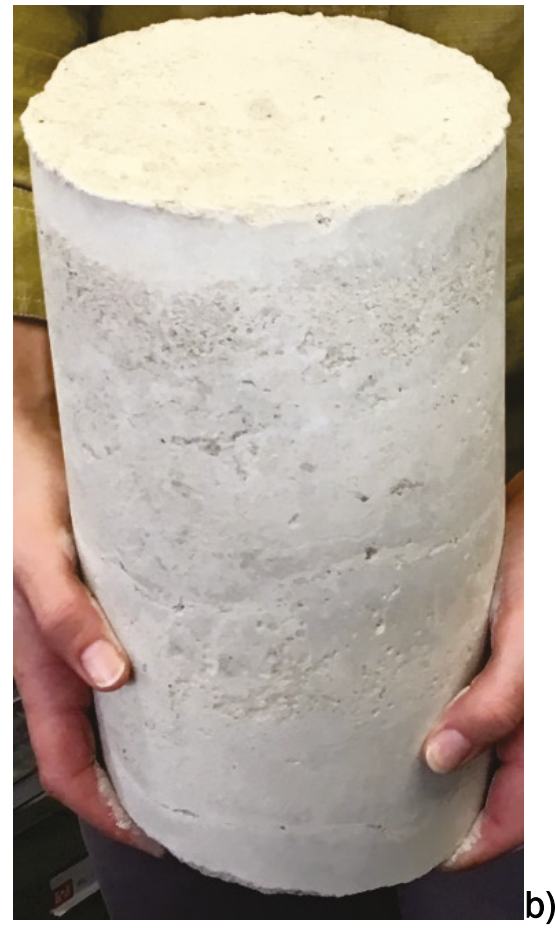




\subsection{New RADR candidate materials}

The USAF pavements community has spent considerable effort in the past researching, developing and testing RADR materials and techniques. These efforts have been concentrated on rapid repair solutions, since the airfield operating surface must be returned to service as quickly as possible to support critical operational missions. When rapid repair is required, solutions focus on materials, tools, and techniques that are light, fast, robust for at least a short time frame, and low in resources demand (i.e., cost, manpower, equipment required).

As discussed in the "Introduction," a family of RADR materials and methods have been developed for normal temperature conditions. While this project addresses the degree to which the existing RADR solutions can be extended into the below-freezing regime, there are new approaches to RADR that can be introduced uniquely for cold climate locations/conditions. These all include the use of water, in liquid and/or solid states, and thus are only applicable for conditions with sustained temperatures below freezing. However, they meet the requirements of being light, fast, robust, and low cost. In general, none of these solutions are appropriate (a) if the near surface soils are above $35^{\circ} \mathrm{F}$ to a depth equal to that of the damage cavity, or (b) if current and predicted air temperatures are/will be above about $25^{\circ} \mathrm{F}$ during the period of time that the patch will be constructed and the patch will be expected to perform (i.e., support aircraft operations). Ideal water temperature for new candidate materials is as low as possible before freezing takes place (as close to $32^{\circ} \mathrm{F}$ ). This is due to the time associated with cooling the materials to their freezing point. Warmer water requires increased bulk thermal energy to cool the material and when freezing is the desired outcome, the time associated achieving freezing is increased if the water is warmer.

\subsubsection{Frozen slush}

If a portable source of clean water is available, a quicker and more robust patch can be created using slush instead of the dry compacted snow described in Section 3.2.1. Slush is a mixture of snow (ice granules) and water. Slush can exist at a range of ice to water volumetric ratios, with ratios at either extreme less desirable as a patching material. Ideally, the ratio of ice to water for this application should be between 50 percent ice/50 percent water to 75 percent ice/ 25 percent water. In most cases, it will be necessary to "manufacture" the slush for a cavity patch. Although a slush can 
be made outside the cavity, it is typically much easier to create within the cavity.

Because water will be used to bond the snow in situ once it is placed in the cavity, it will be necessary to ensure that the cavity is not overly permeable. Any flexible waterproof material can be used to line the cavity before snow placement, but if very cold ambient conditions exist, sprayed water can be used to "ice" the cavity surfaces, creating a relatively impermeable layer. If water is sprayed to reduce permeability, the ice layer should cover all of the cavity's faces, be at least $1 / 2$-inch thick and be allowed to solidify for at least $1 \mathrm{hr}$ before snow is placed in the cavity.

A time gap may be necessary between the placement of each 6 in. layer depending on ambient air and water temperatures and whether the cavity's soil temperatures are above or below freezing. A slush patch manifests its strength from frozen water, meaning that each layer will need to be frozen completely to ensure no weak horizons exist in the finished patch. In a cavity with frozen soil and cold air temperatures (less than $20^{\circ} \mathrm{F}$ ), an hour rest between completion of one layer and placement of the next layer is recommended.

During freeze-up, curing, and upon completion of a patch, strength monitoring can be performed using a DCP or RSP. Ultimate strength for a slush patch will occur when all of the patch (ice granules and water) have reached temperature equilibrium. The lower the equilibrium temperature is, the stronger the patch will be. Strength limits for support of aircraft operations are the same for slush as for compacted snow, and are given in Table 26. Further construction envelope breakdown discussion is provided in Section 4.3. 
Table 22. Performance ranges for traditional and new candidate RADR materials.

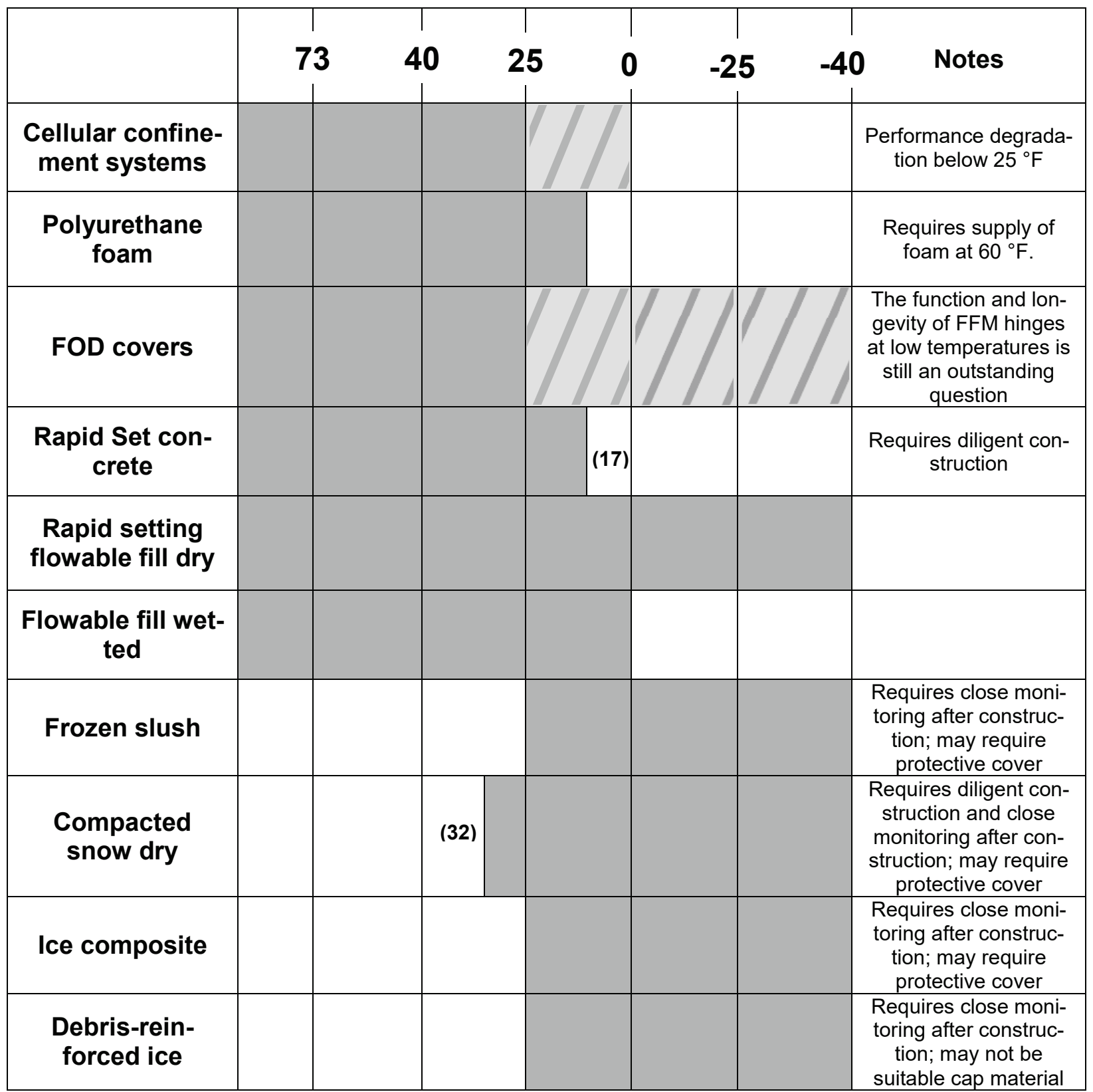

Slush for this project was produced from snow and water slurries and cast into 6-in. x 12-in. cylinders in two- and three-lift applications. The snow used had grain sizes less than $1 / 6$ inch. This technique resulted in polycrystalline ice samples (Figure 37). 
Figure 37. Frozen slush testing specimens (a) before and (b) after subjecting to uniaxial compressive loads.

a)

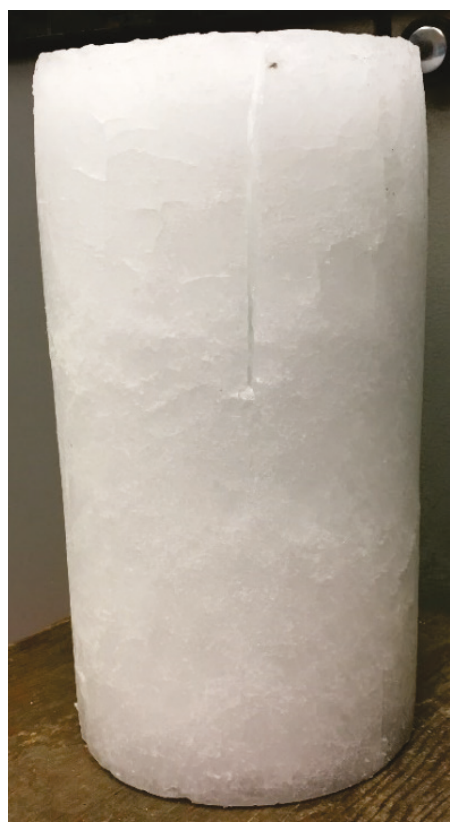

b)

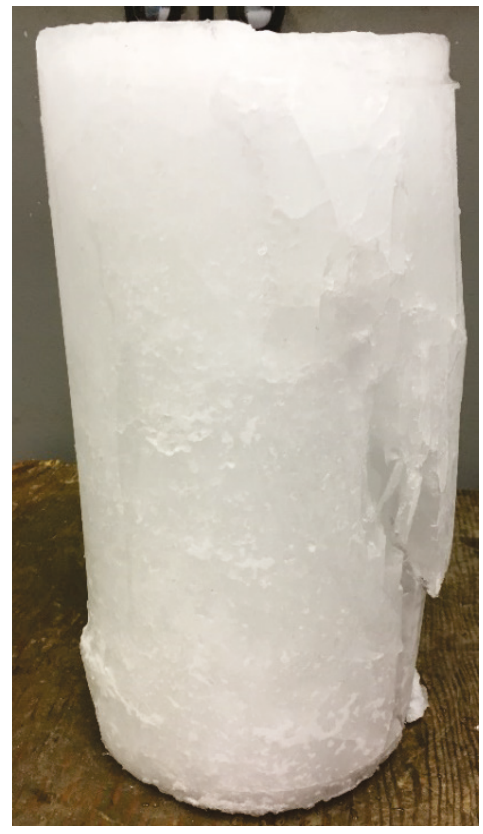

The magnitude of the ultimate strength of frozen slush is suggested by the uniaxial unconfined compression test results summarized in Table 23. These results were from testing described in section 2.1.8, and the samples had varying degrees of internal stress cracking associated with freeze-up. Samples with the least internal cracking showed strengths exceeding 500 psi, while the weakest samples reached between 225 and 325 psi before complete failure. As a patching material, however, frozen slush would exist in a completely confined state, where strengths would be much higher, as would be the case for all backfill materials.

Table 23. Uniaxial compressive strength of frozen slush.

\begin{tabular}{|c|c|c|c|}
\hline \multicolumn{4}{|c|}{$0^{\circ} \mathrm{F}$ snow slurry after $24 \mathrm{hr}$} \\
\hline Method & $\begin{array}{l}\text { Mean UCS } \\
\quad(p s i)\end{array}$ & $\begin{array}{l}\text { Median UCS } \\
\text { (psi) }\end{array}$ & $\begin{array}{c}\text { Standard } \\
\text { deviation (psi) }\end{array}$ \\
\hline 2 Lifts & 432 & 347 & 131 \\
\hline 3 Lifts & 575 & $\mathrm{~N} / \mathrm{A}$ & $\mathrm{N} / \mathrm{A}$ \\
\hline
\end{tabular}




\subsubsection{Ice with additives}

To enhance the strength of ice, cellulose was explored as a reinforcing material in ice due to its ability to increase strength by reducing crack propagation during loading. Specifically, ice-cellulose composite materials was made with 10 wt percent and 20 wt percent cellulose at $0{ }^{\circ} \mathrm{F}$ and $-40{ }^{\circ} \mathrm{F}$ in 6-in. x 12-in. cylinders. After $24 \mathrm{hr}$ of freezing, these samples were tested in uniaxial compression. The results showed strength levels averaging over 900 psi (Table 24). The addition of the additive proved to increase the uniaxial compressive load over snow slurry and ice with debris (Figure 38). The additive is currently being researched on a microscale due to its potential crack reducing properties. The 6 in. $x 12$ in. samples did not expand as water samples did, and freezing took place on a similar time frame to a snow slurry. Increasing the ratio of cellulose in the mix did result in an increase in the uniaxial compressive load, providing evidence that the additive does increase the strength potential of the mix. The 6 in. $\mathrm{x} 12 \mathrm{in}$. cylinder samples were manufactured by mixing snow, cellulose, and water in a bucket and then poured into the molds and allowed to freeze for $24 \mathrm{hr}$. Ice composite performed significantly better than slush alone (Figure 38).

Table 24. Uniaxial compressive strength of ice composite samples.

\begin{tabular}{|l|l|l|l|l|}
\hline \multicolumn{5}{|c|}{ Uniaxial compressive strength of ice composite } \\
\hline Temperature & \multicolumn{1}{|c|}{$\begin{array}{c}\text { Additive } \\
\text { concentration }\end{array}$} & $\begin{array}{c}\text { Mean UCS } \\
(\mathrm{psi})\end{array}$ & $\begin{array}{c}\text { Median UCS } \\
(\mathrm{psi})\end{array}$ & $\begin{array}{c}\text { Standard } \\
\text { deviation (psi) }\end{array}$ \\
\hline $0{ }^{\circ} \mathrm{F}$ & $10 \%$ & 964 & 994 & 69 \\
\cline { 2 - 6 } & $20 \%$ & 1057 & 1039 & 35 \\
\hline$-40^{\circ} \mathrm{F}$ & $10 \%$ & 1293 & 1229 & 171 \\
\hline
\end{tabular}


Figure 38. Comparison of average UCS of current and proposed runway repair materials at a range of temperatures.

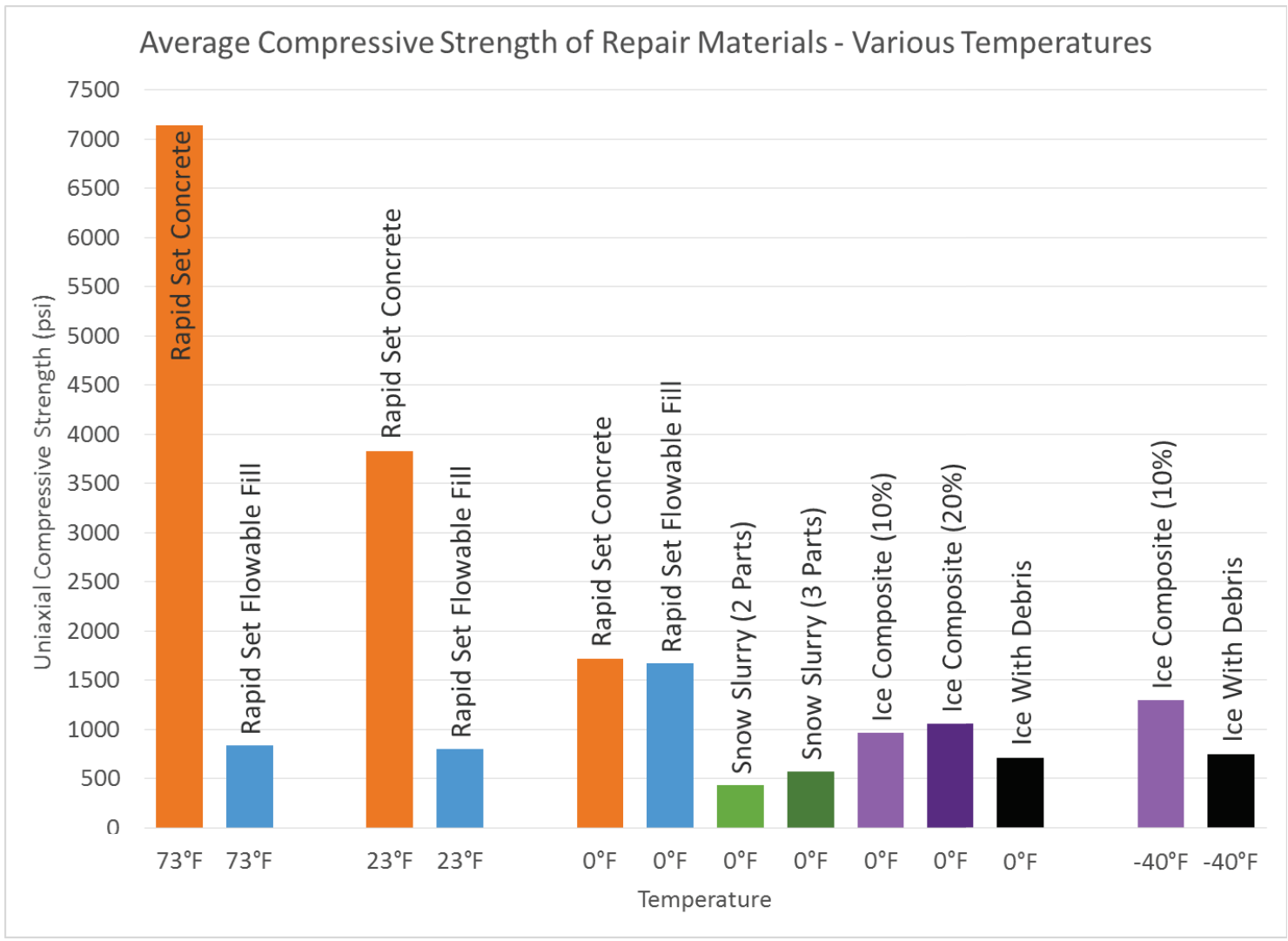

\subsubsection{Debris reinforced ice}

Under ambient temperatures below $25{ }^{\circ} \mathrm{F}$, and cavity soil temperatures less than $35^{\circ} \mathrm{F}$, solid debris of nearly any kind can be used with water and/or snow to create a suitable backfill for a cavity patch. Pieces of concrete, asphalt, and rocks and gravel, as well as ice chunks are ideal debris sources. Pieces should ideally have a range of sizes (to achieve close packing), and no single piece should exceed $1 \mathrm{ft}$ in size. Water, slush or dry snow can be used to stabilize the debris.

If water or slush will be used to fill the voids and immobilize the pieces of debris, the cavity interior surfaces will need to be practically impermeable, as was the case for the solution described in Section 3.2.2.

If water is used to fill the debris voids, the pieces of debris can be placed in the cavity en masse. Debris can be placed in the cavity only as carefully as necessary to eliminate as much as possible "tenting" (i.e., cavities that will close under minimal loading through individual pieces rearranging themselves). The top of the debris pile must not anywhere be higher than $1 \mathrm{ft}$ 
below the original runway surface. Once the debris has filled the base region of the cavity, cold water (between $45^{\circ} \mathrm{F}$ and $32^{\circ} \mathrm{F}$ ) is introduced to flood all of the voids up to the top of the debris pile. The debris can be all placed in one lift and then flooded to reduce wait time. Pouring in lifts could result in poor bonding between the lifts due to the smooth surface created by the frozen water. Total set time would be increased by pouring in lifts as a result as well.

If dry snow or slush will be used for filling the voids between debris pieces, the debris must be placed in the cavity in lifts no greater than $1 \mathrm{ft}$ in nominal thickness. Once the debris is placed, dry, disaggregated snow is cast over the debris pieces with swinging motions with a shovel and a rod or stick used to encourage snow to cascade downward filling the voids. It is not critical that every void be filled; however, greater strength and stability are achieved with a greater percentage of the voids filled. Water is then added to fill the remaining voids.

If making slush, upon finishing filling of the debris layer with dry snow, cold water is introduced around the perimeter, and if necessary in the interior of the cavity, to flood the debris-snow layer. This layer should be allowed to "rest" as described in Section 3.2.2 before placement of the next layer, which will follow the same pattern as the previous layer. In either case, the backfill will be considered complete when the surface of the last layer reaches a level $1 \mathrm{ft}$ below the adjacent runway surface.

Because the solid pieces of debris make up the majority of the cavity backfill, penetrometer testing may not be appropriate. However, drilling, or hand tools can be used to ensure that at least the top 6 in. of the water or slush in voids is frozen, indicating that cap construction can be started. If dry snow is used as the stabilizer, the cap construction can begin immediately upon completion of the backfill.

For a frozen debris backfill, any cap material that is suitable for cold regions application can be installed. However, if a concrete-like material is used, great care must be taken to monitor for melting in the backfill layer, such as an insulator layer. Once melting is detected, no matter how robust the cap appears, the patch must be considered failed or allowed to freeze again to increase lifespan of the patch. 
Ultimate strength for a frozen debris patch is highly dependent on the debris type used as well as the material used to fill the voids. It is unlikely that a cavity filled with frozen debris as described here will not meet minimum strength criteria for the backfill layer of the repair.

On a small scale, a debris/frozen slush fill was created at $\mathrm{o}{ }^{\circ} \mathrm{F}$. In a 6-in. $\mathrm{x}$ 12-in. cylinder, 2-3-in.-long concrete pieces were placed followed by pouring in saturated snow (slush) that was mixed separately in a pail. After 24 $\mathrm{hr}$ of freezing, these samples were tested in uniaxial compression. The results showed strength levels averaging over 700 psi (Table 25), a level more than adequate for a backfill layer in a crater repair. Further, in a confined state, as would be present in a cavity, a concrete debris/frozen slush patch would likely have greater strength than measured here.

Figure 39. Debris-reinforced ice specimens manufactured for uniaxial testing; a) before and b) after testing.

a)

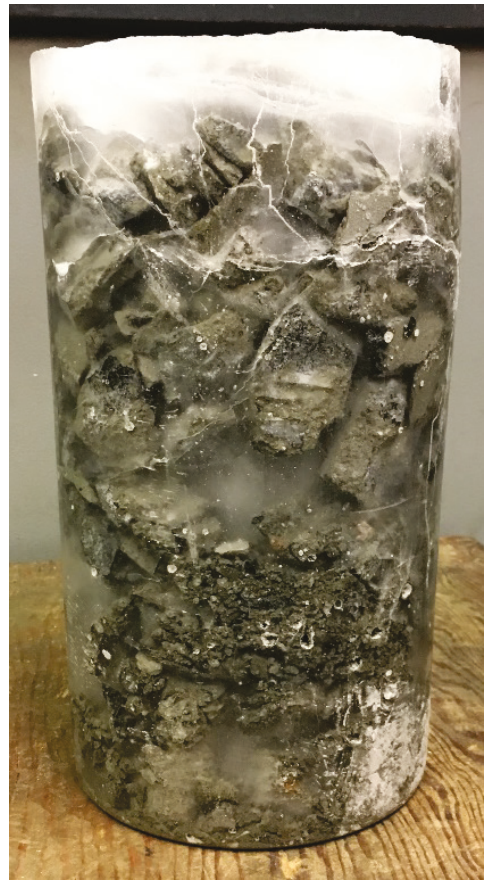

b)

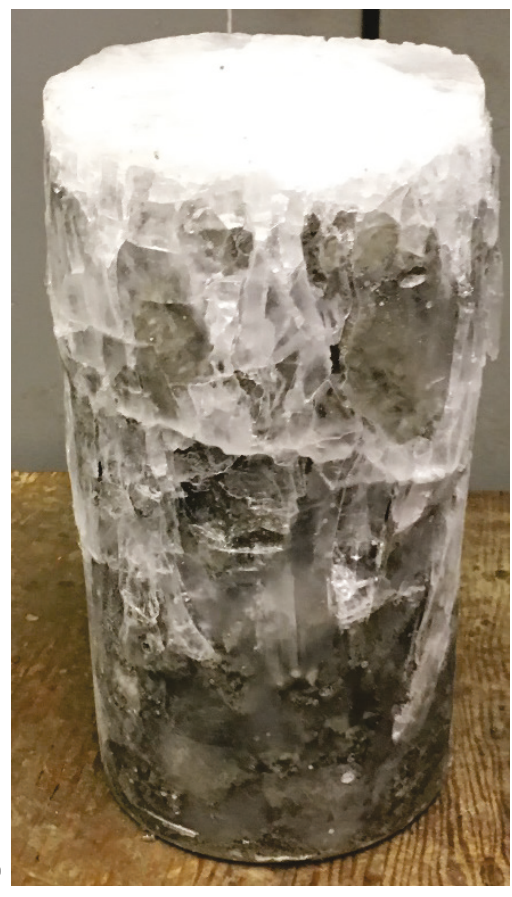

Table 25. Uniaxial compressive strength of concrete debris-frozen water samples.

\begin{tabular}{|l|l|l|l|}
\hline \multicolumn{4}{|c|}{ Uniaxial compressive strength of ice with debris } \\
\hline Temperature & \multicolumn{1}{|c|}{$\begin{array}{c}\text { Mean UCS } \\
(\mathrm{psi})\end{array}$} & $\begin{array}{c}\text { Median UCS } \\
(\mathrm{psi})\end{array}$ & $\begin{array}{c}\text { Standard } \\
\text { Deviation (psi) }\end{array}$ \\
\hline $0^{\circ} \mathrm{F}$ & 712 & 766 & 80 \\
\hline$-40^{\circ} \mathrm{F}$ & 745 & 688 & 139 \\
\hline
\end{tabular}




\subsection{Extreme cold repair of a full-scale crater}

The cold room complex at CRREL provided the facilities necessary to generate conditions mimicking field conditions where an airfield cavity might exist under freezing temperatures. Both traditional and new types of crater repairs were accomplished in cold rooms to evaluate the advantages and challenges of performing expedient patching of an isolated area of damage on a runway.

\subsubsection{Dry flowable fill (dFF) as a backfill material at $17^{\circ} \mathrm{F}$}

With the simulated crater in a large cold room, the test assembly was allowed to stabilize at a temperature of $17^{\circ} \mathrm{F}$. Rapid setting flowable fill (FF) packaged in 50-lb buckets were staged on pallets outdoors directly outside the cold room, to begin filling the cavity. The outdoor temperature at the time of testing ranged between 30 and $35^{\circ} \mathrm{F}$. With three workers, the backfill layer of the cavity was filled manually with $\mathrm{dFF}$, leveled, wetted with tap water spray from a garden hose, and nominally stirred with a rake, (Figure 40) in lifts of 12 in., each 50-lb bucket was mixed with approximately $1 / 2$ gal of water that was between $55^{\circ} \mathrm{F}$ and $40^{\circ} \mathrm{F}$. This process required about $2 \mathrm{hr}$ in this setting (i.e., carrying buckets one at a time through a small exterior doorway and up a ladder to dump into the cavity), but would have been much faster in a real-world situation, even with only three workers. The dFF was allowed to cure (condition at cold temperature) for $24 \mathrm{hr}$ at $17^{\circ} \mathrm{F}$ during which time it was tested for RSP strength at established intervals (Figure 41). 
Figure 40. Layer of wetted dry flowable fill being stirred with rake when filling the base of the full scale crater.

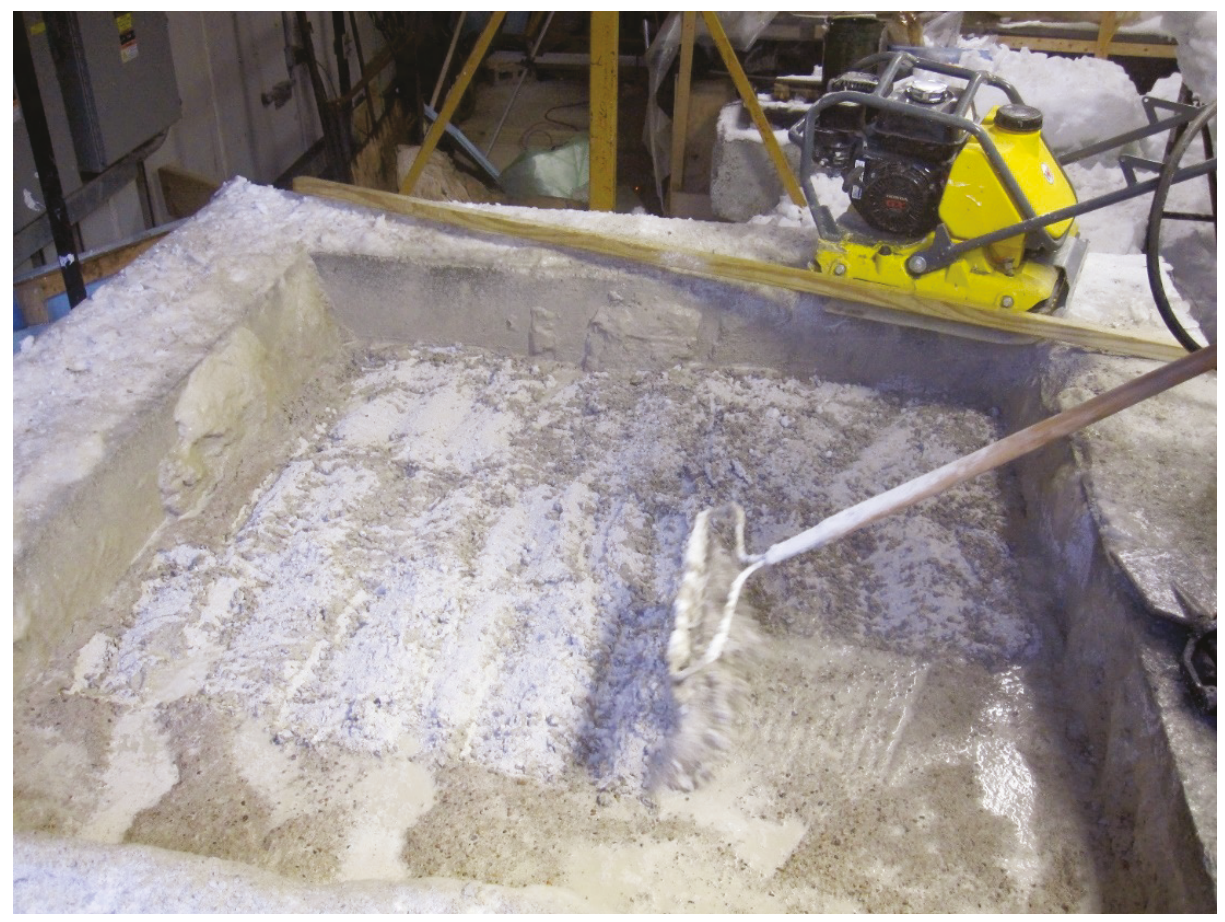

Figure 41. RSP index of lightly wetted flowable fill at $17^{\circ} \mathrm{F}$ during first $24 \mathrm{hr}$.

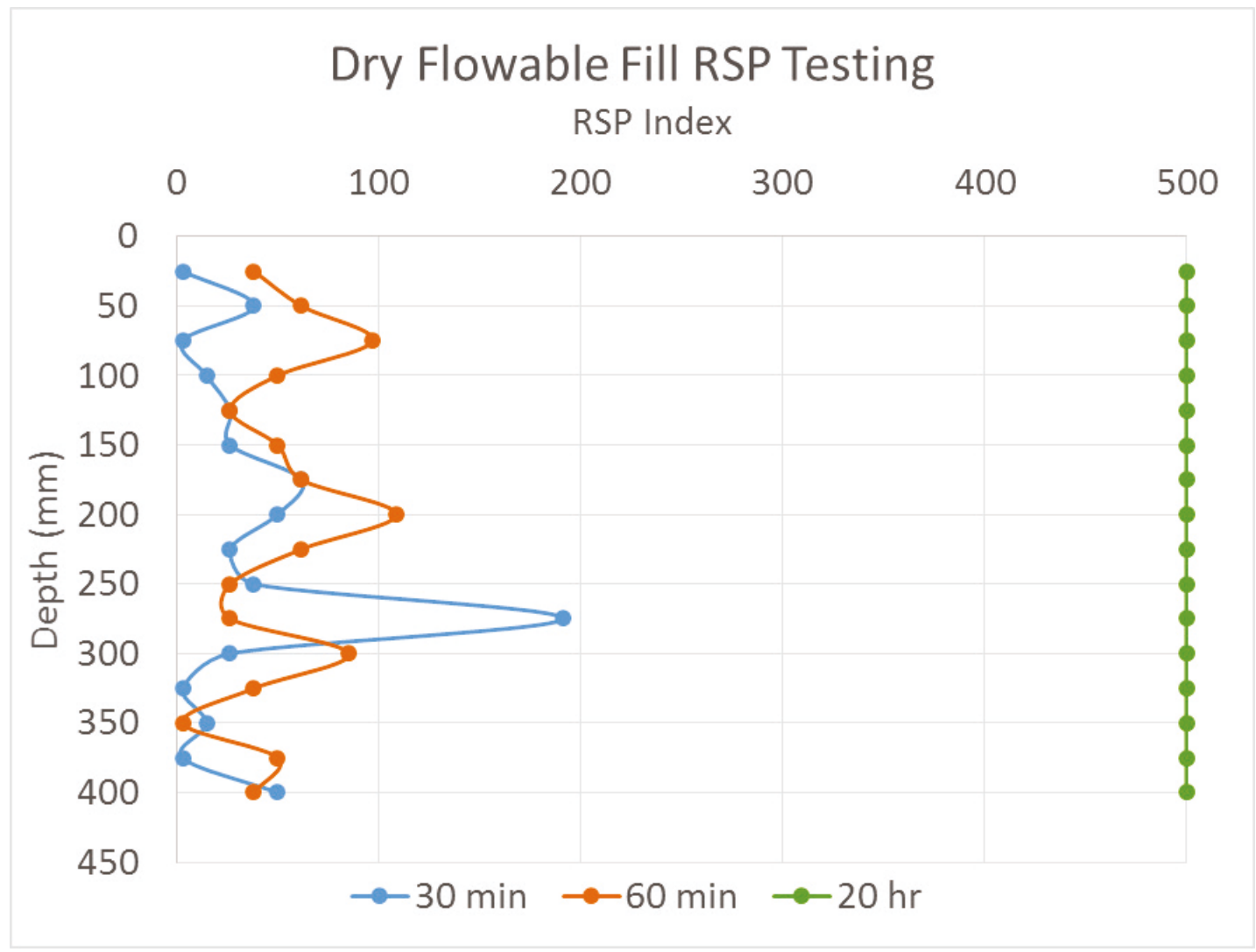




\subsubsection{Rapid Set concrete cap at $\mathbf{1 7}^{\circ} \mathrm{F}$ (over dry flowable fill backfill)}

With the cavity backfilled with $\mathrm{dFF}$, the crater was capped with Rapid Set concrete (RS). The RS was supplied in buckets (5o lb each) and was staged outdoors next to the cold room. An electric-powered portable mixer, resting on scaffolding adjacent to the cavity, was used to combine the RS and tap water between $55^{\circ} \mathrm{F}$ and $40^{\circ} \mathrm{F}$ (garden hose) and to stir it into a uniform mixture (Figure 42). Upon starting the mixer, and before introduction of RS, the interior drum and paddles of the mixer were fully wetted with water from the hose. Once a puddle of 2-3 gal of water was present in the mixer drum, buckets of RS were dumped one at a time into the mixer. Three to five minutes elapsed between the additions of each bucket of RS to ensure that mixing was complete. Water from the hose was sprayed frequently and liberally into the mixer drum to achieve a slurry. The total amount of water determined to be ideal for mixing in the cold weather per 50-lb bucket was approximately 3.5-4 quarts. The manufacturer suggests 2.5-3 quarts per 50-lb bucket, but due to water loss from freezing on the tools and additional clumping present at colder temperatures, additional water was required to manufacture a uniform mix. Too little water allowed clumps of damp cement to form and tumble in the drum rather than mix. Once clumps formed, it was difficult to break them up so mixing could be conducted properly without the addition of significant water and mixing time.

Figure 42. Load of Rapid Set concrete in mixer at $17^{\circ} \mathrm{F}$ just prior pouring.

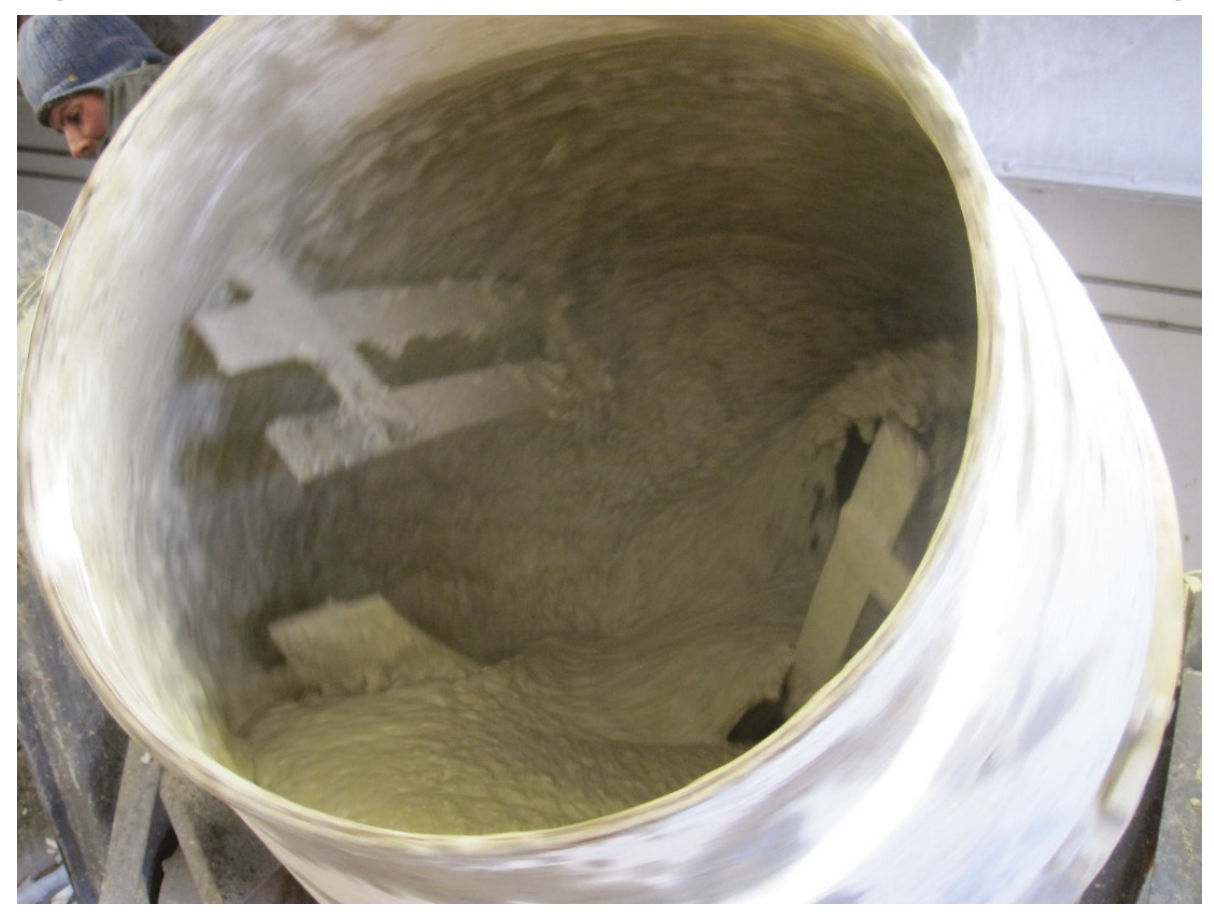


Each mixer drum load consisted of five buckets of RS and 5 gal of water between $55^{\circ} \mathrm{F}$ and $40^{\circ} \mathrm{F}$ temperature. The mixture was deliberately kept wet until the addition of the last two buckets of RS. The amount of mix water was gradually reduced so that almost no added water was required when the last bucket of RS was introduced. Within about 3 min of placing the last bucket of RS into the drum, the concrete mix appeared to have a typical consistency and was immediately dumped out of the drum. Personnel with rakes and shovels moved the fresh concrete to evenly distribute it in the cavity.

As soon as a concrete load was dumped, the mixer drum was replaced in its upward position, and a strong water spray was used to dislodge as much as possible concrete frozen/stuck to the walls and paddles of the drum. This produced the seed water for the next mixing cycle and kept the drum from becoming clogged with built-up concrete. At no time was the drum rotation stopped, even during dumping at the end of each mixing cycle, which also aided in reducing concrete build-up.

It took approximately $6 \mathrm{hr}$ to mix and place the 12-in. cap of RS, whose surface looked entirely similar to poured concrete at above freezing temperatures (Figure 43).

Figure 43. Top surface of mock crater top layer repair with RS concrete after 24-hr since completion.

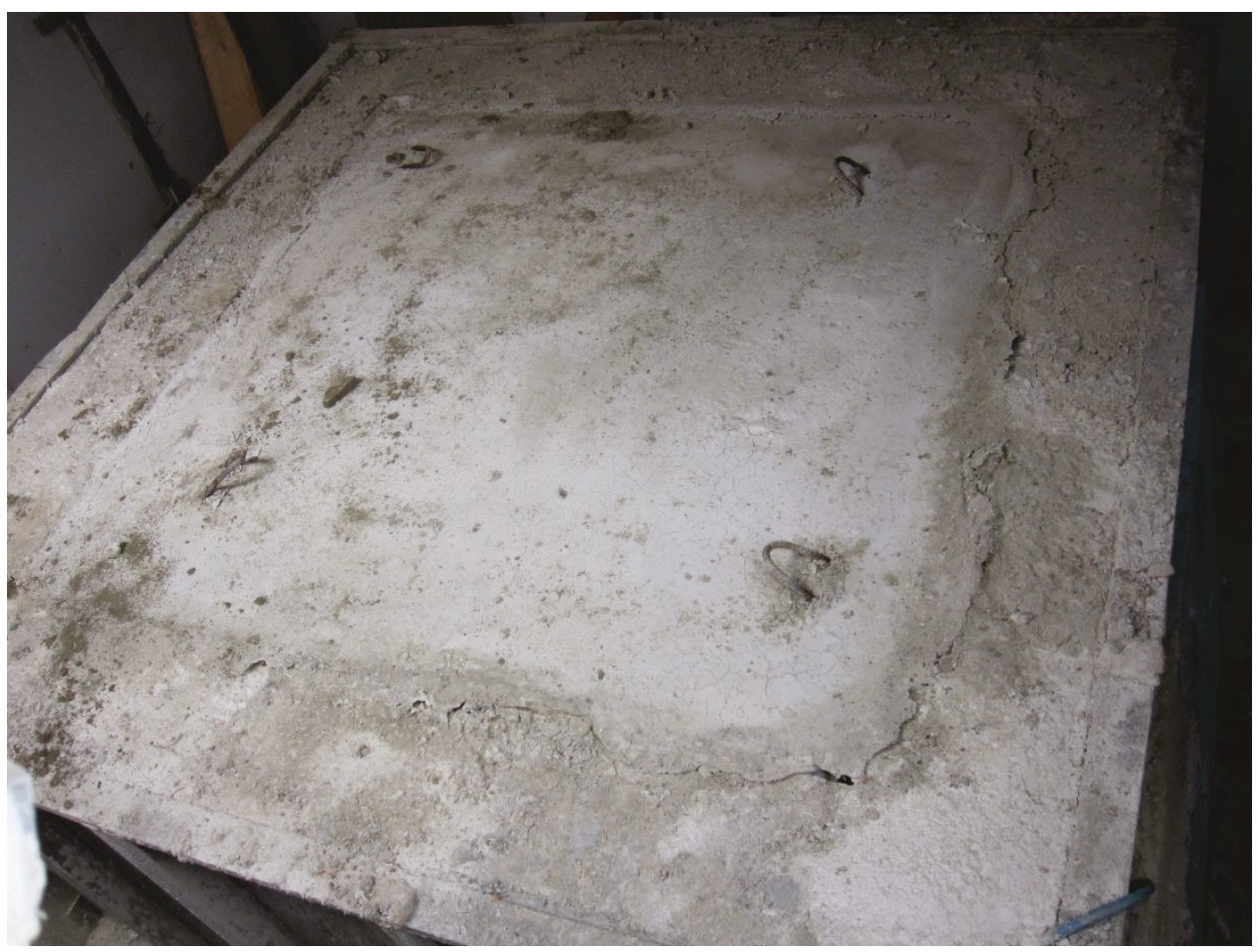


The RSP was used to monitor strength gain in the RS concrete during curing, knowing that after a certain point, the material would be too strong for the RSP. While our sampling interval did not capture when this point occurred, it was clearly more than $2 \mathrm{hr}$ into the cure (Figure 44).

Figure 44. RSP index of Rapid Set concrete at $17^{\circ} \mathrm{F}$ during first $24 \mathrm{hr}$.

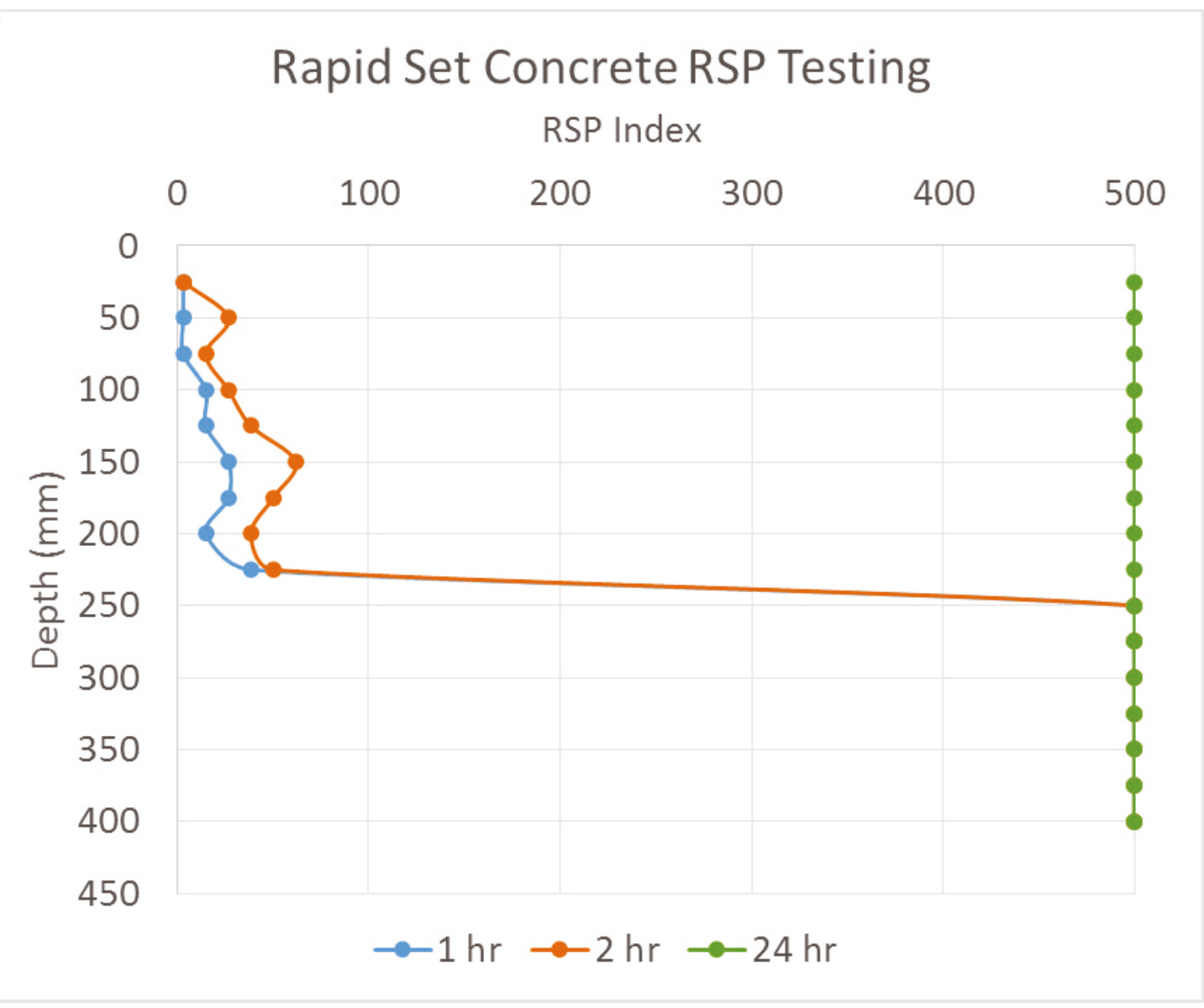

Interestingly, the RS cap, upon curing, appeared to be similar to the two strong cylindrical samples tested rather than the two that failed immediately (Section 3.1.4). This may be associated with there being a larger mass of concrete involved, and thus a much lesser surface-to-volume ratio, allowing the heat of the chemical reaction process to persist longer against the cold boundary conditions and to permeate more of the total mass.

\subsubsection{Debris-reinforced ice backfill layer at -20 ${ }^{\circ} \mathrm{F}$}

A full-scale test was conducted using concrete debris (nominally 6-in. diameter pieces) backfill and water (Figure $45 \mathrm{a}$ ) in a $-20{ }^{\circ} \mathrm{F}$ environment. While freeze-up took longer with straight water than would be the case 
with slush, the result was still satisfactory for the backfill layer of a crater repair (Figure 45b). The ultimate strength of this material would likely be no less than was determined during the compression tests of the small cylindrical samples.

Figure 45. Simulated crater repair performed with debris-reinforced ice: a) concrete debris backfill; b) backfill after introduction of water and, c) after complete freeze-up.

a)
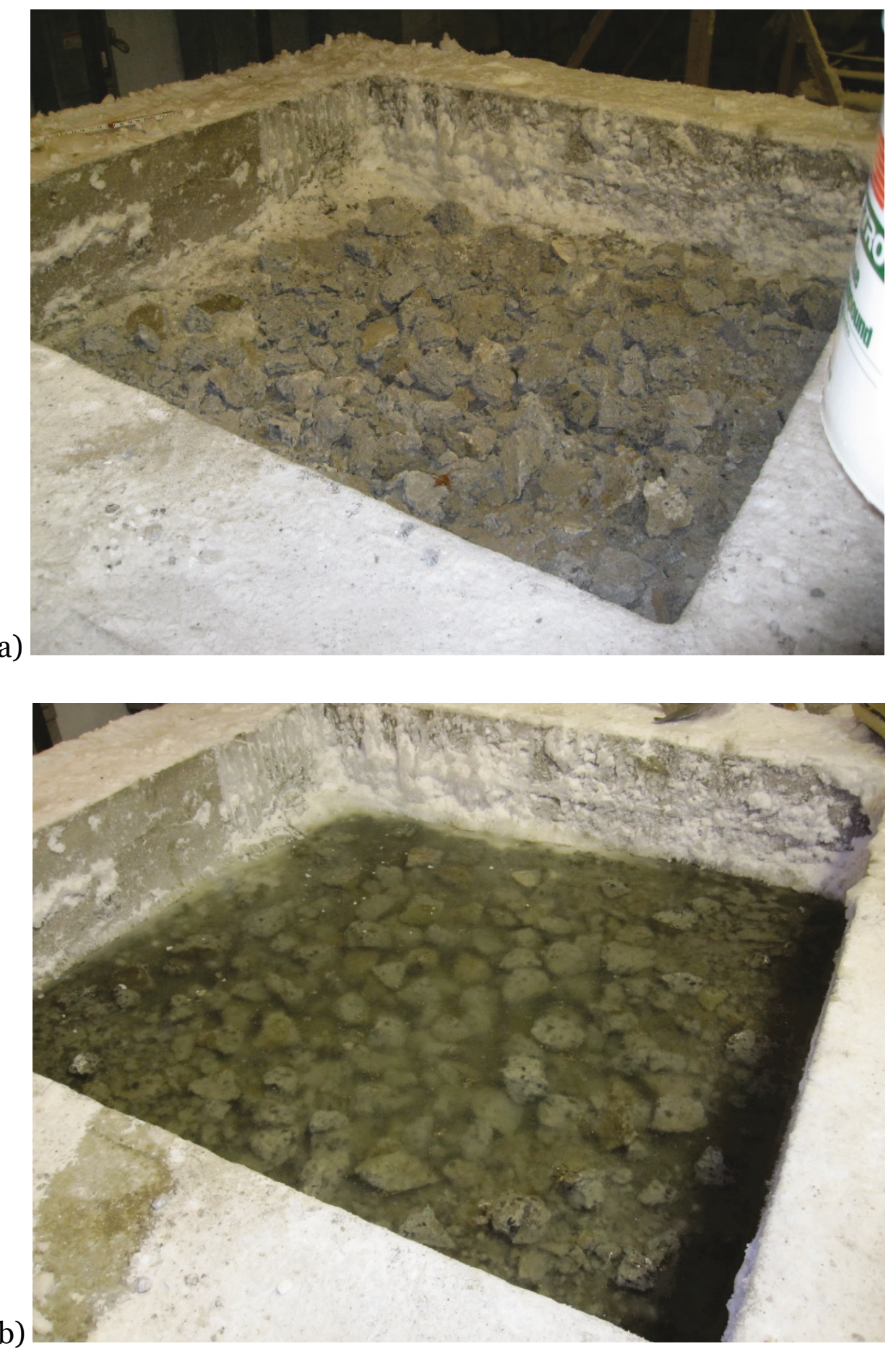


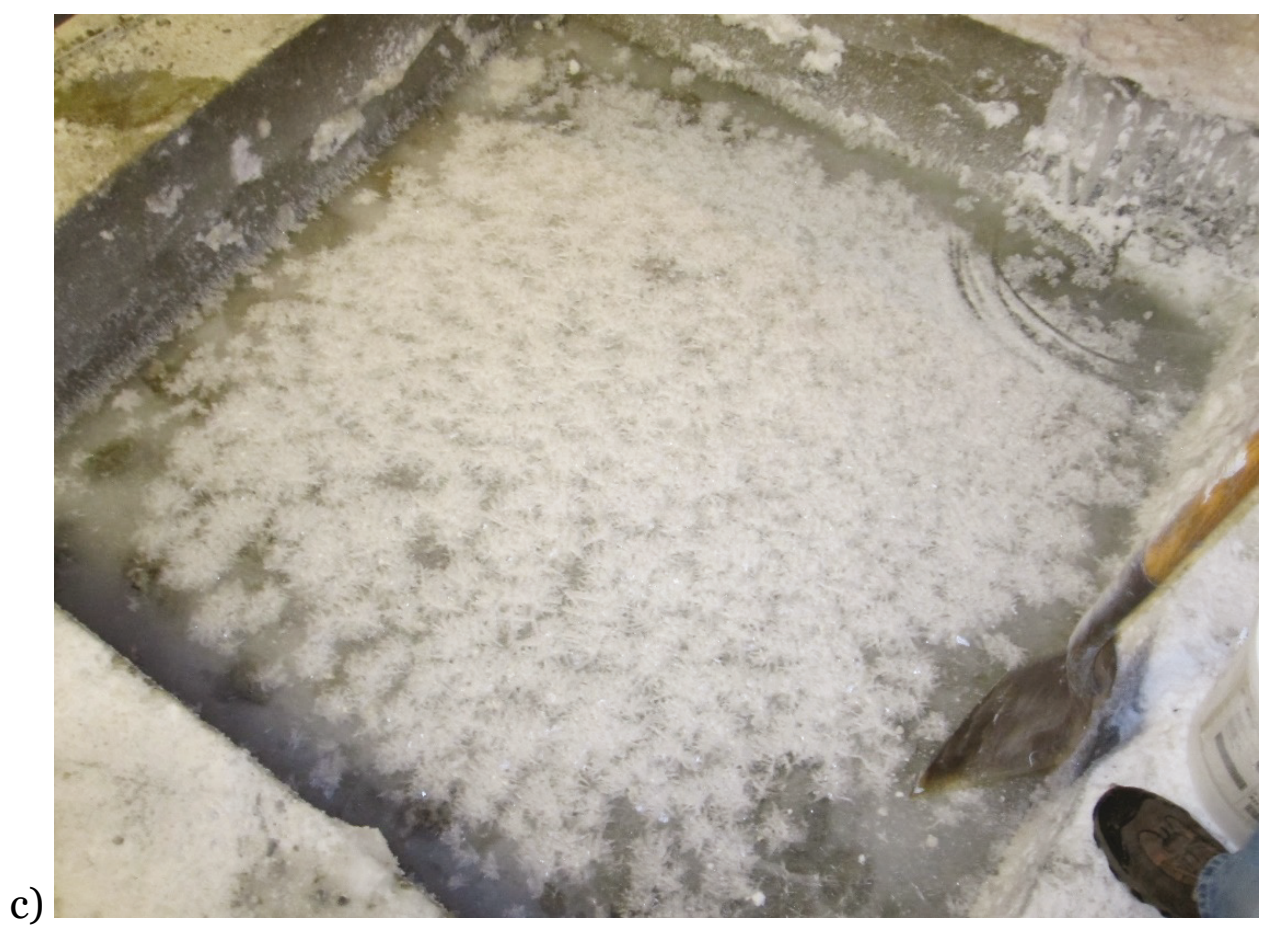

There was no mechanism available for testing the ultimate strength of the resulting patch base. Based on the cylinder test results (Section 3.2.3), it can be concluded that this type of patch would meet the strength requirements for the backfill layer of a crater repair. In future testing, attempts will be made to use the DCP and a medium Clegg hammer.

\subsubsection{Frozen slush repair of a full-size crater at $-20^{\circ} \mathrm{F}$}

In this patching demonstration, a clean snow was placed in the bottom of the crater. A small walk-behind vibratory compactor was used to consolidate the snow in three lifts. The first lift filled the conical portion of the crater (Figure 46a), the second lift extended up to about 12-in. below the crater top (Figure 46b), and the top lift (fill cap) extending up to the original pavement surface. Once each lift was compacted, it was flooded slowly from the edges with tap water $\left(\sim 55^{\circ} \mathrm{F}\right)$ from a garden hose. With the snow particles as freezing nuclei and the below freezing air temperature; the flooded snow (slush) solidified rapidly, meaning each lift could be placed within 30 min of the previous lift being finished with flooding. 
Figure 46. Repair of a full sized crater with frozen slush at $-20^{\circ} \mathrm{F}$. a) The top of the backfill layer. b) Filling the cap layer with compacted frozen slush.

a)

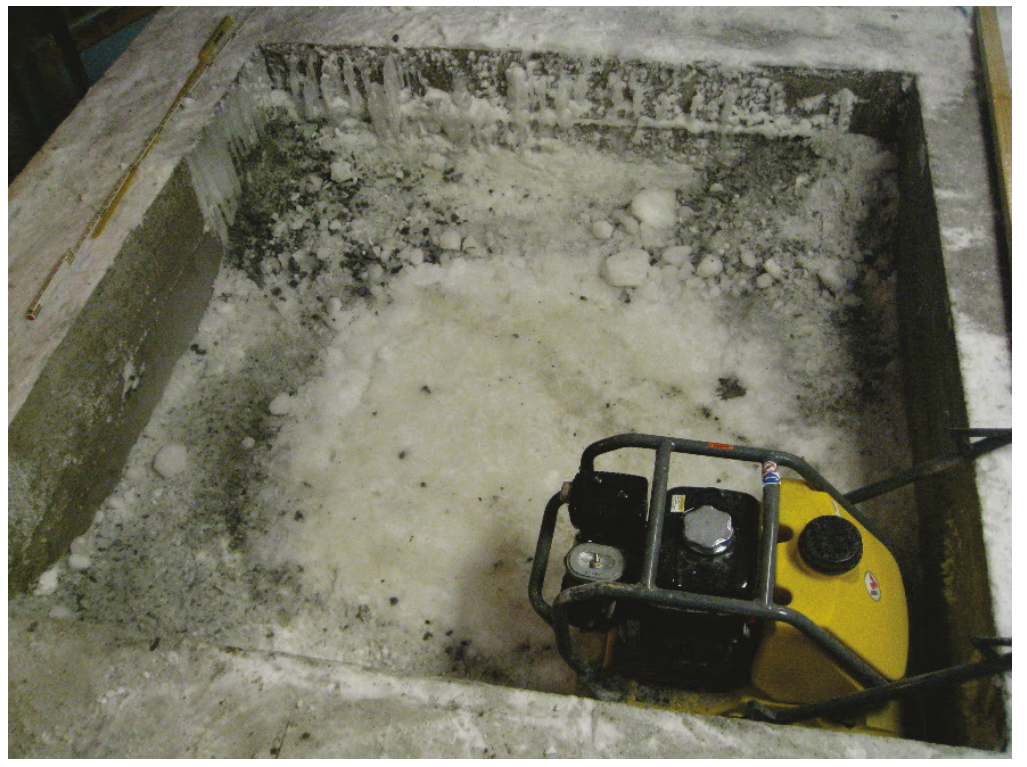

b)

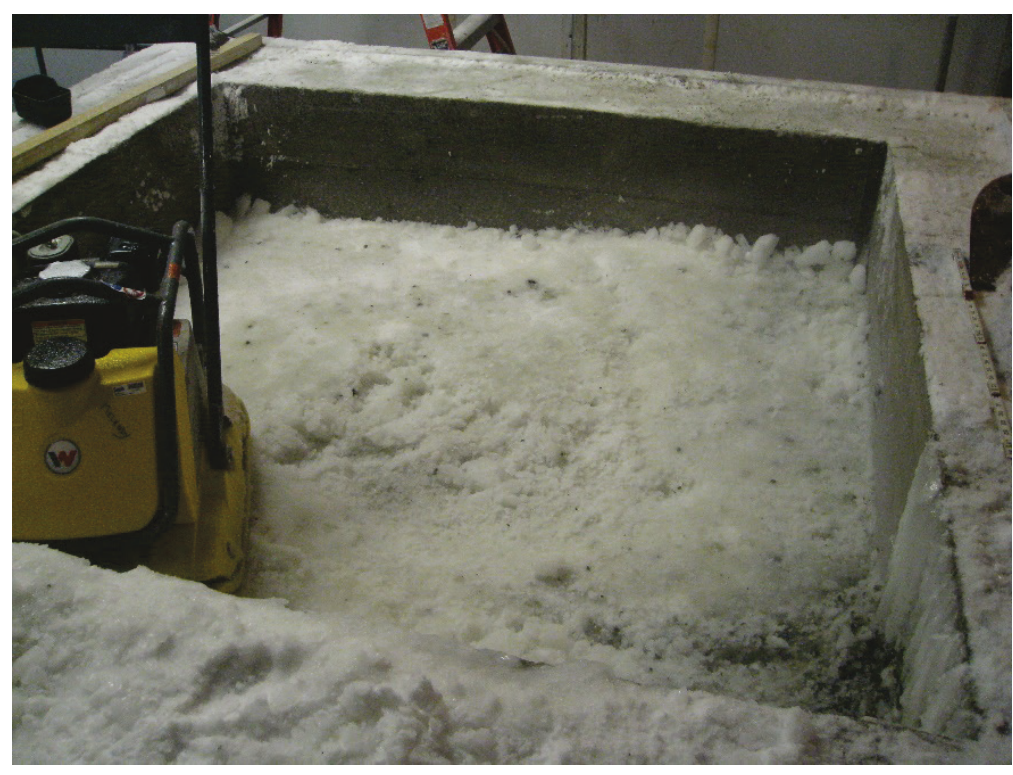

Heat flow associated with the boundary conditions presented by the experimental configuration imply that the freezing front not only progressed from the top down, but also encroached radially (horizontally) inward from the perimeter of the simulated crater frame. Likewise, the cold fill under the crater also extracted heat from the slush mass. This resulted in an ellipsoid of unfrozen slush more or less centered in the crater, which decreased in size as freezing progressed which is clearly demonstrated in the penetrometer strength tests (Figure 47). 
Figure 47. RSP index of frozen slush at $-20^{\circ} \mathrm{F}$ during first $24 \mathrm{hr}$.

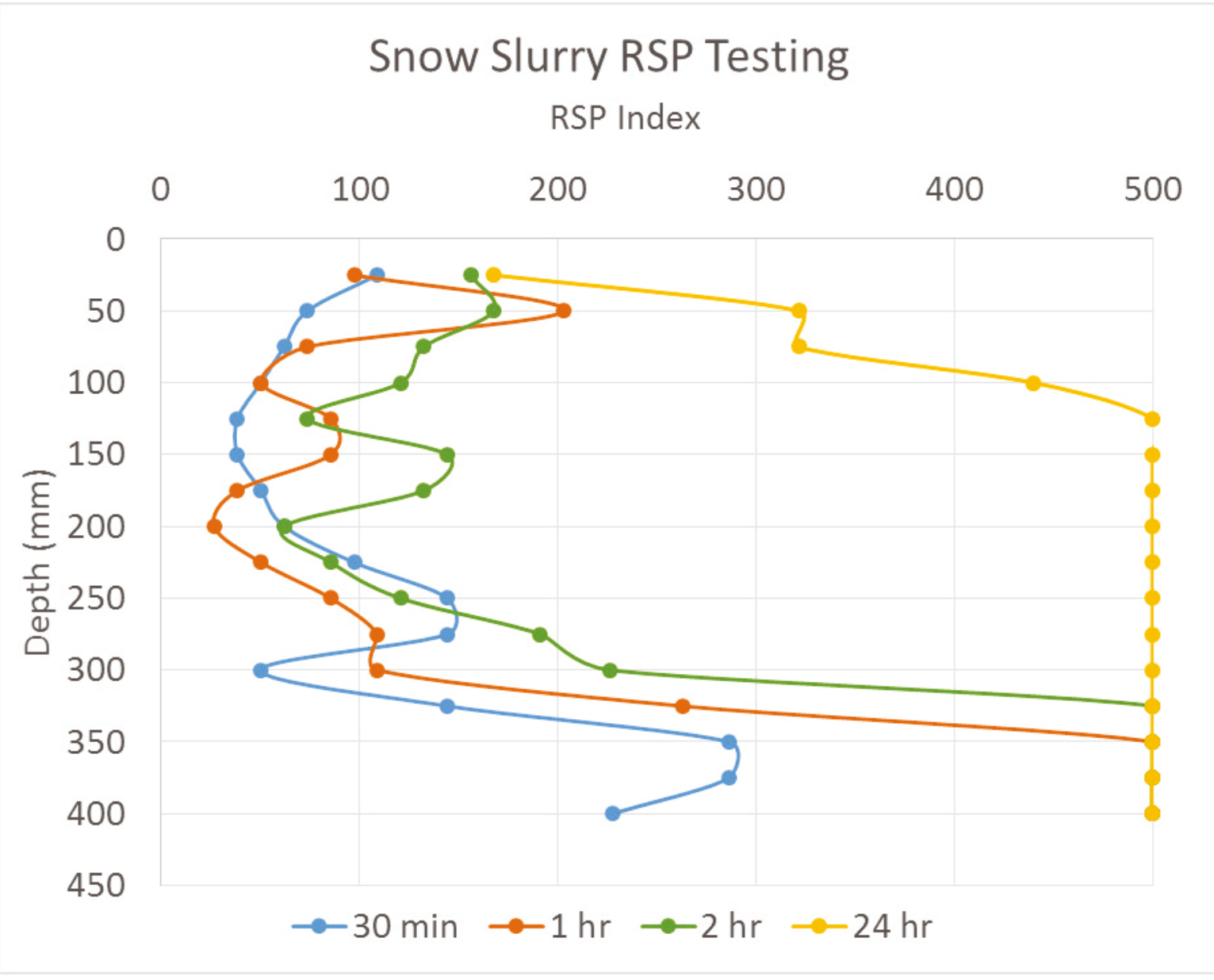

By the time $24 \mathrm{hr}$ had passed, RSP penetrometer tests no longer were possible for assessing patch strength. However, results from the cylinder tests (Section 3.2.2) show that, at a minimum, a frozen slush patch (a confined state) can sustain 600 psi of loading.

In a real-world situation, freeze-up of a patched crater may take longer at a given temperature since the boundaries of the cavity might be warmer than the ambient temperature. Conversely, in some areas at certain times, the opposite may be the case.

Beyond the experiments performed in this study, CRREL has experience using slush, and ice debris with slush filler, as a patch for craters in ice and snow runway systems in Antarctica (Figure 48; Blaisdell, et. al., 1998). These have all demonstrated the ability to support C-141, C-17, B757, and $\mathrm{C}-130$ aircraft operations within 24-48 hr depending upon ambient conditions. 
Figure 48. Cold water used to flood snow and ice filled damaged area of glacial ice runway (temperature approximately $15^{\circ} \mathrm{F}$ ).

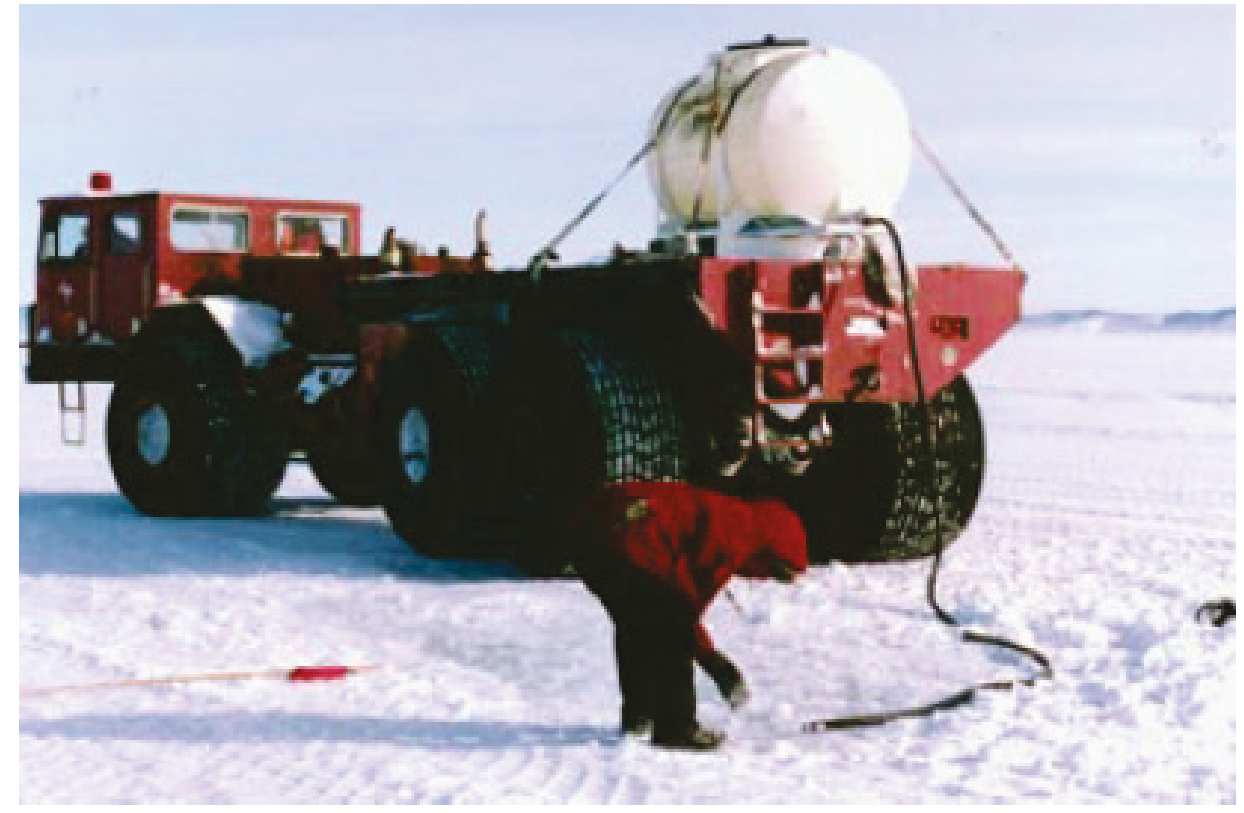

\subsubsection{Snow slush with cellulose additive repair of a full-size crater at $-20^{\circ} \mathrm{F}$}

Simulated crater repair utilizing an additive (cellulose) at 10 percent volume ratio was manufactured as a capping material as part of the testing matrix. The amount of water added was enough to create a slurry saturation without creating standing water. The cellulose was added at the point each snow slurry layer reached 4 in thickness. This was done by dumping a full 50-lb buckets onto the top of the slurry and using hand tools to fully mix the cellulose and snow slurry. The tap water ranged in temperature from $55^{\circ} \mathrm{F}$ to $40^{\circ} \mathrm{F}$. The total cap thickness produced was 19 in. (Figure 49) and resulted in set times (the point where RSP refusal occurred; Figure 50) very similar to that for pure snow slurry. Once set-up, there were no visible cracks in the cap and the patch appeared uniform throughout the repaired area. The entire placement of the cap took place continuously, with no pauses between placement (and cellulose addition) of each lift. 
Figure 49. Snow slurry mix with cellulose additive on simulated crater.

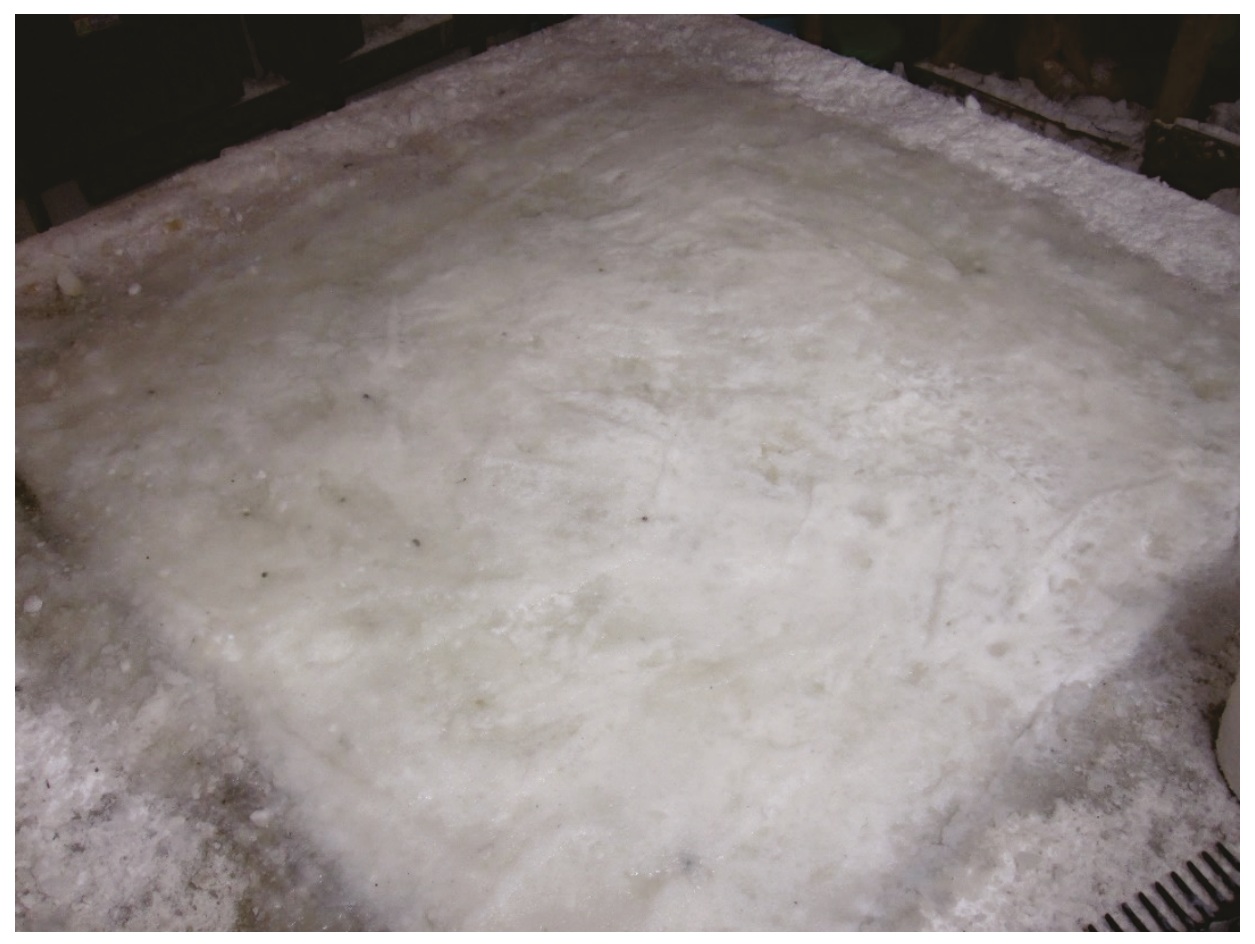

Figure 50. RSP index of frozen slush with additive at $-20^{\circ} \mathrm{F}$ during first $22 \mathrm{hr}$.

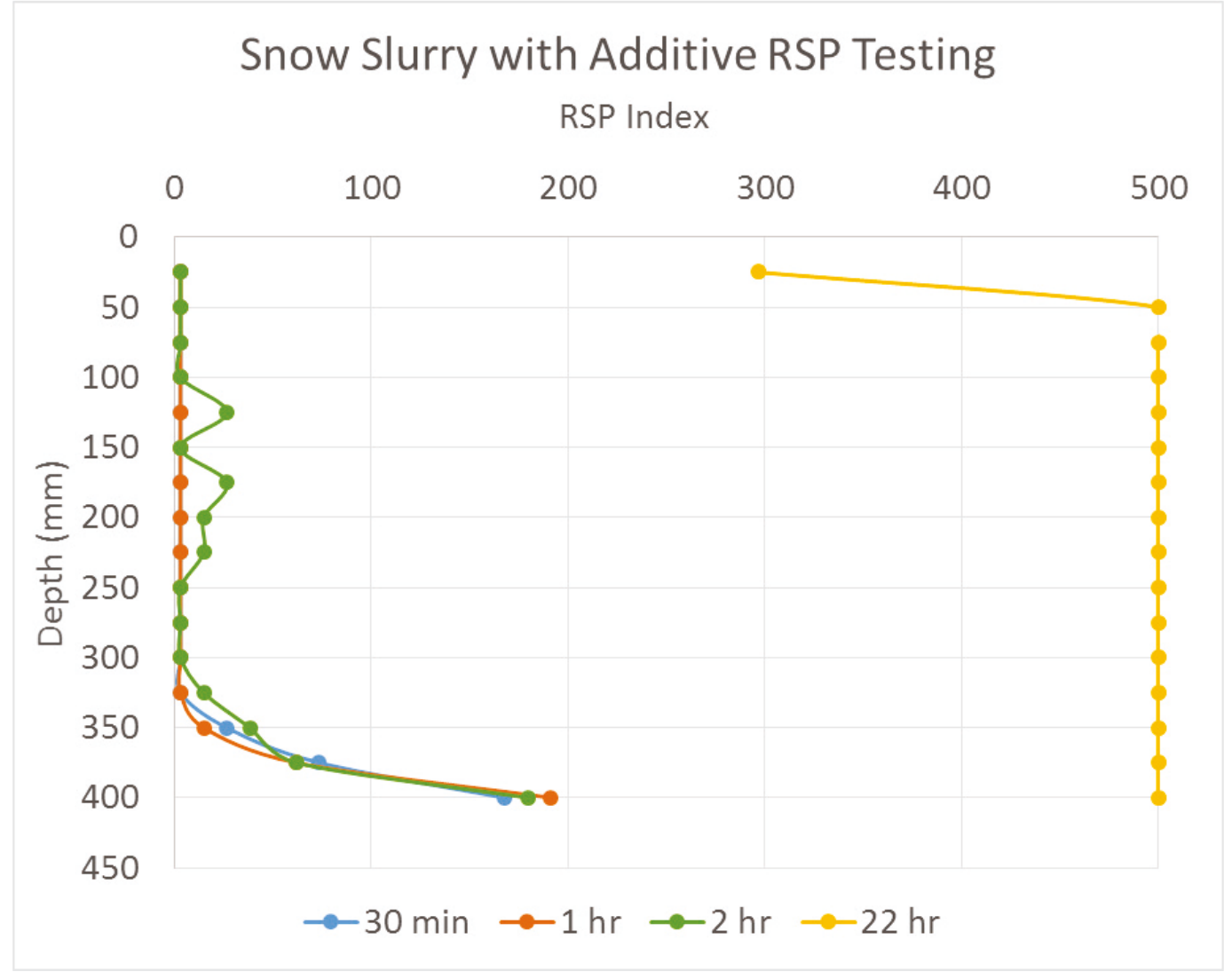




\subsection{Simulated crater repair at $-40^{\circ} \mathrm{F}$}

A circular galvanized steel livestock watering trough (Figure 8) was used as a simulated crater for repairs at $-40^{\circ} \mathrm{F}$. The trough's diameter was $6 \mathrm{ft}$, and its depth was $2 \mathrm{ft}$. This was placed on a plywood base within a cold room. (A cold room was used, rather than the MEF, because the MEF cannot reach $-40^{\circ} \mathrm{F}$.)

Cellulose was used to reinforce ice for a simulated crater repair. With the ambient cold room temperature at $-40{ }^{\circ} \mathrm{F}$, the simulated crater was filled with snow and nominally compacted (tamped with a rake; Figure 51) in a 10-in. layer. A dilution of cellulose slurry was made with $50{ }^{\circ} \mathrm{F}$ tap water in a 50-gal barrel. The cellulose-water mixture was introduced around the perimeter of the trough via gravity feed into the cold room with a garden hose. The cellulose-water mixture was flooded into the snow-filled trough until the snow visually showed saturation at the top surface (Figure 52). With the cellulose-water added, the slush (of cellulose, water, and snow grains) depth in the trough was about 13 in. The slush was left to freeze in the cold room, with strength profiles taken at set intervals using an RSP. The entire mass took approximately $48 \mathrm{hr}$ to fully solidify and sinter (Figure 52b).

Figure 51. Top surface of dry snow in simulated crater tamped with garden rake.

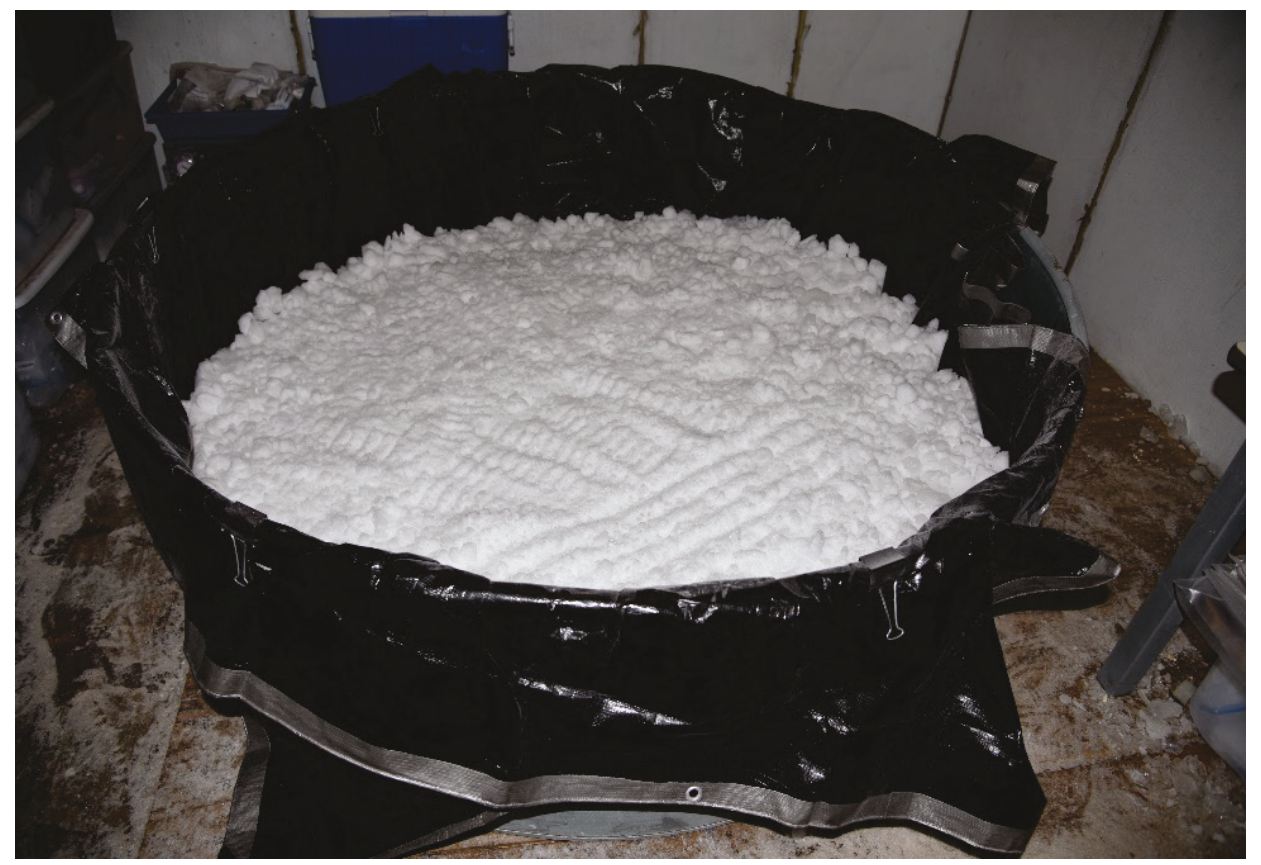


Figure 52. Crater repair with frozen slush at $-40^{\circ} \mathrm{F}$ : a) saturated snow surface; b) surface of frozen slush repair. Note: The smooth frozen slush surface in b) is obscured by snow deposition on the top caused by ambient moisture.

a)

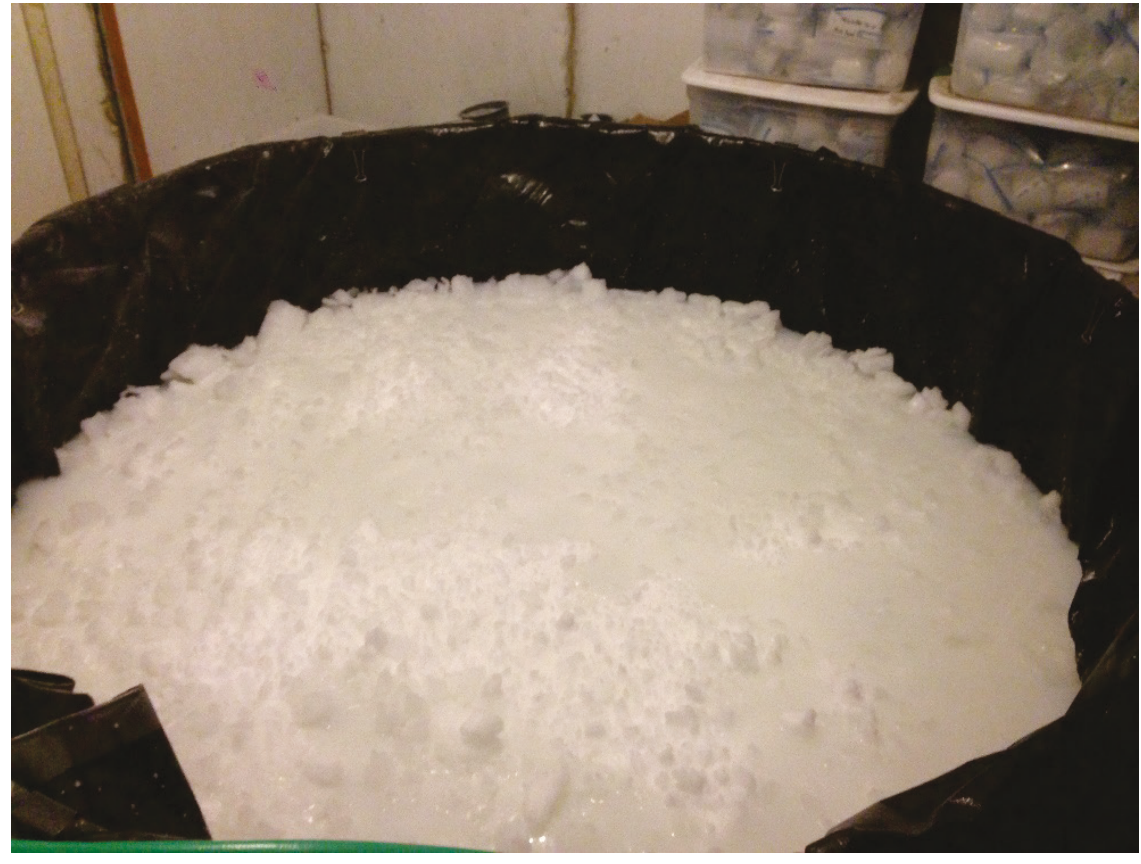

b)

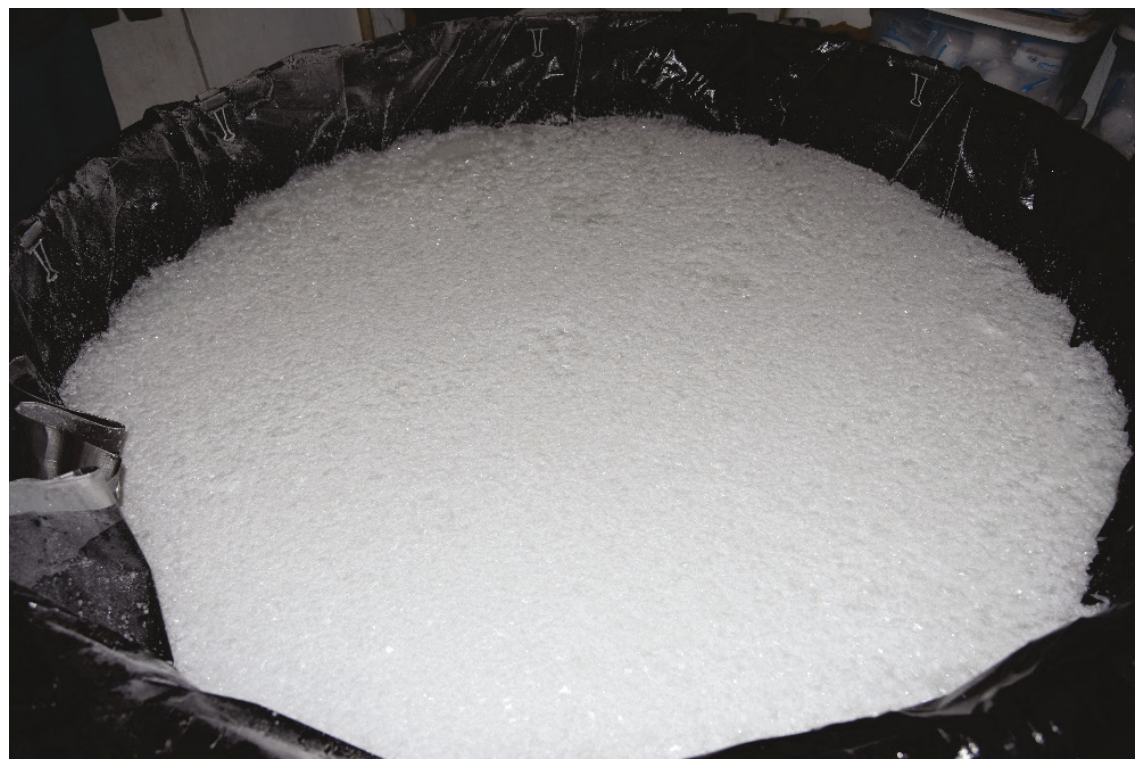

Similar to the frozen slush at $-20^{\circ} \mathrm{F}$ in the full-size simulated crater, the solidification process of the reinforced ice at $-40^{\circ} \mathrm{F}$ may have been influenced by boundary conditions that were different from those present in field settings. In this case at $-40^{\circ} \mathrm{F}$, the heat flow geometry was circular and composed of metal, which readily conducts heat. This could lead to a 
faster solidification time for our experiment as compared to field scenarios. However, the freezing front progressed in a similar geometry and could be witnessed during the early phases of freezing when RSP testing was viable (Figure 53).

Figure 53. Uniaxial unconfined compressive strength of frozen slush at $-40^{\circ} \mathrm{F}$, derived from RSP penetrometer testing.

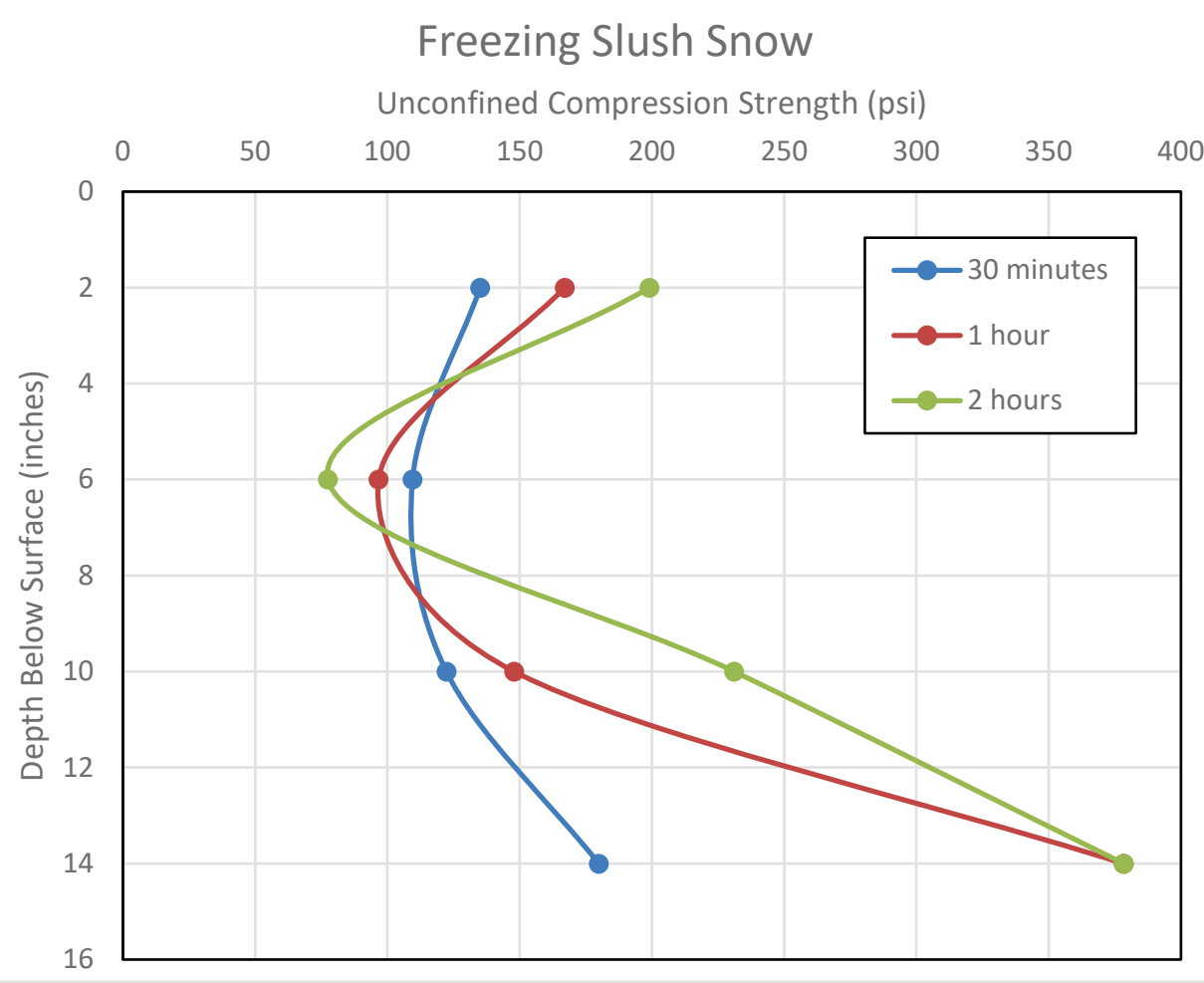




\section{Summary}

\subsection{Existing RADR materials performance}

The testing and assessment of existing RADR materials included both FFM and FRP FOD covers, geocell confinement grids, polyurethane foam, RS concrete and rapid setting FF. In many instances, it was found that these RADR materials could be used at temperatures lower than $73^{\circ} \mathrm{F}$. A summary of those results along with recommendations are presented here.

\subsubsection{FOD covers}

The FFM hinges and panels maintained their specified strength across all temperatures studied. In addition, they retained their $73^{\circ} \mathrm{F}$ flexural strength down to $-40^{\circ} \mathrm{F}$. The failure mechanism of FFM hinges varied with temperature. It was only at $-40 \mathrm{~F}$ that the specimens broke within the hinge region; otherwise the specimens failed at the hinge-panel interface. In addition, the FFM hinges increased with strength at low temperature, but were also very hard to open at $\mathrm{T}<0{ }^{\circ} \mathrm{F}$. It is reasonable to predict that FFM panels would be difficult to open and may experience performance degradation during opening at freezing temperatures.

Both FFM and FRP mats exhibited irregular behavior in tension at $0{ }^{\circ} \mathrm{F}$, indicating that inconsistent performance may result at this temperature.

The FRP panels retained at least their $73^{\circ} \mathrm{F}$ tensile and flexural strength across all temperatures, and even showed an increase in percent elongation during flexural loading as temperature decreased, remaining within their design limits. These surprising results need to be interpreted in the context of the physical observations, wherein the FRP panels were observed to delaminate during flexural loading. This delamination may cause a decrease in the number of passes that an FRP panel can sustain before failing in a field scenario.

Flexural fatigue loading was performed to probe the longevity of FRP mats during trafficking at low temperature. The flexural strength of the mats decreased by 4 percent to 24 percent after 100 cycles and by 14 percent to 32 percent after 500 cycles depending on temperature, implying that they may remain within design limits for limited cycling at these low temperatures. With longer fatigue loading, the data show that approximately 25 
percent of the flexural strength is retained after 1,00o cycles. By the $2, \mathrm{OOO}^{\text {th }}$ cycle, the FRP composite panels exhibit a decrease in flexural strength of at least 50 percent at $73^{\circ} \mathrm{F}$.

During cyclic loading at $\mathrm{T} \leq \mathrm{O}^{\circ} \mathrm{F}$, the reinforcing glass fibers were observed to degrade causing the performance of FRP panels to be dominated by the polymer alone, exhibiting brittle behavior with decreasing elongation at failure. Additional field studies with FRP mats would be of great utility to fully characterizing the conditions under which FRP mats can function at extreme cold temperatures.

While the hardness measurement with a Barcol impressor is convenient and simple, it does not provide a rigorous measurement capable of predicting FOD cover wear, performance, and remaining life span in real settings. A more robust measurement for hardness is recommended.

\subsubsection{Geocell cellular confinement systems}

Geocell sidewalls will only tolerate one-third of the elongation they could at $73{ }^{\circ} \mathrm{F}$ before breaking at $-25^{\circ} \mathrm{F}$ and below. The junctions can only tolerate $1 / 10^{\text {th }}$ of the shear displacement at $-40^{\circ} \mathrm{F}$. In practice, these results that will manifest in the sidewalls of the geocells have a 66 percent reduction in the amount of elongation they can tolerate before failure, and the junctions have a 90 percent reduction in their tolerance for shearing before failure at extreme low temperatures. However, the loading regime within the repaired surface may not induce loads or deformation near the ultimate strength of the material. Thus, material performance will be degraded at extreme cold temperatures, but a detailed load analysis would be required to determine if the expected load conditions will be close to failure limits.

\subsubsection{Polyurethane foam backfill}

If a cost-effective means can be developed for heated supply of foam components, this may be a viable backfill material at temperatures below freezing. Results show that pre-heated foam retains a density of near 11 $\mathrm{lb} / \mathrm{ft}^{3}$, an expansion ratio of at least 5 , and a compressive strength of at least 300 psi down to ${ }^{\circ}{ }^{\circ}$. During testing, the specimens formed at 73 and $25{ }^{\circ} \mathrm{F}$ resist cracking or tearing entirely, while some samples formed at $\mathrm{O}^{\circ} \mathrm{F}$ only show small wrinkles after compressive loading. In summary, if a means to deliver foam at $60^{\circ} \mathrm{F}$ can be established, the foam may remain 
a viable RADR material down to at least $25^{\circ} \mathrm{F}$, possibly o ${ }^{\circ} \mathrm{F}$. Below o ${ }^{\circ} \mathrm{F}$, compressive testing results showed a steep downward trend in the strength of laboratory specimens along with signs of brittle failure in the post-test specimens.

\subsubsection{Rapid Set concrete mix}

Concrete of all types requires water (with or without additives to improve cold weather mixing and concrete curing) to hydrate. The standard military RS concrete mix can be combined with $55^{\circ} \mathrm{F}$ tap water at ambient temperatures down to at least $17^{\circ} \mathrm{F}$ and yield a robust concrete. Mixing must be performed with greater care and urgency than when placed in above freezing conditions, and curing times are considerably longer. However, while not ready for loading within $2 \mathrm{hr}$, after $24 \mathrm{hr}$, a crater cap of RS concrete will fulfill RADR requirements well below the currently recommended air temperatures.

\subsubsection{Rapid setting flowable fill (FF)}

Rapid setting flowable fill is intended to be mixed by combining a dry, finely granular cementitious mix with water. The RADR dry placement method for placing rapid setting flowable fill was evaluated in this project. This was done because dry packed flowable fill is quite dense and has good bearing capacity. Further, by not using a typical amount of water and a concrete mixer made placement much easier (no large water supply needed), reduced mixer freezing potential (tools freezing, clothing or body parts), and significantly quicker. The top of each lift of flowable fill was wetted with tap water between 45 and $55^{\circ} \mathrm{F}$ and crudely mixed when filling a simulated crater, and this backfill layer of a finished crater repair showed excellent bearing strength after $24 \mathrm{hr}$ of curing at temperatures as low as $17^{\circ} \mathrm{F}$. These results imply that dry FF can be placed and wetted at all temperatures down to $-40^{\circ} \mathrm{F}$ due to the water being applied either mixing into the material or freezing within the dry material. The dry FF is likely a viable backfill material and expedient capping material in extreme cold conditions.

\subsection{Performance of new candidate RADR materials}

\subsubsection{Dry compacted snow}

Dry compacted snow has been successfully used as a patching material to support aircraft up to 500,000 lb, and with tire pressures as high as 210 
psi. As a patching material in a conventional runway, a dry compacted snow patch should provide reasonable performance under the right set of environmental conditions (construction and operations at ambient and ground temperatures below $25^{\circ} \mathrm{F}$ ). At all temperatures below $25^{\circ} \mathrm{F}$, compacted snow is a viable option and with minimal training requirements to ensure proper bonding of the snow grains.

\subsubsection{Frozen slush}

Frozen slush can be an expedient and high performing crater repair material in areas where frost enters the ground and persists through much of a winter. This provides a cold sink around and below the crater. When air temperatures are below freezing (much of the time in such areas, otherwise there would not be frost in the ground), a crater can be quickly filled with clean dry snow (or ice cubes, or shave ice from a local ice skating rink), slowly flooded, and left to freeze up. Frozen slush can be a backfill layer, or both backfill and cap layers. In the latter case, a mat or other protective surface may be desirable to improve friction and protect the frozen slush from incoming solar radiation. A frozen slush patch can be expected to perform satisfactorily under environmental conditions with ambient and ground temperatures below $25^{\circ} \mathrm{F}$ and all the way down to $-40^{\circ} \mathrm{F}$.

\subsubsection{Reinforced ice}

Ice reinforced with cellulose can also be an expedient crater repair material. Similar to frozen slush and debris-reinforced ice, cellulose reinforced slurry and ice should be utilized when conditions are below $25^{\circ} \mathrm{F}$ and down to $-40^{\circ} \mathrm{F}$. The advantages to using the cellulose as an additive is that in uniaxial compressive tests as shown in Figure 39, the strength is increased by 20 percent over other alternative options previously listed. A second advantage to adding an additive to the snow or ice is that expansion of the frozen material is limited, reducing potential cracking that ice is typically susceptible to. At additive levels of 10 percent, the slurry showed increases in strength as the temperatures dropped from $0^{\circ} \mathrm{F}$ to $-40^{\circ} \mathrm{F}$, proving its performance increases with decreasing temperatures. This is common with cold materials due the change from being ductile to increased brittle material characteristics. 


\subsubsection{Debris-reinforced ice}

A cavity filled with debris (instead of dry snow as in the case of frozen slush) can also be stabilized with frozen water. This RADR technique is at least as fast as using frozen slush, and equally robust. Like frozen slush, the environmental conditions in which this approach can be applied are limited, lower than $25^{\circ} \mathrm{F}$ down to $-40^{\circ} \mathrm{F}$. Nonetheless, using concrete rubble less than 12 in. in maximum dimension, coarse gravel or rocks, or large ice chunks as the fill matrix with flooded water that is allowed to freeze as the void filler, creates a dense mass that is more than strong enough to meet backfill layer RADR requirements. As in the case of compacted snow and frozen slush, a debris-reinforced patch will require ambient and ground temperatures to be below freezing less than $25^{\circ} \mathrm{F}$ and below.

\subsection{Performance envelops of materials for RADR}

Existing and new repair materials were evaluated for environmental conditions typically outside the range specified for application of tradition RADR protocols. While each material was not evaluated in each temperature range, it was discovered that a number of options exist for performing RADR at temperatures currently below those addressed in existing references.

From the suite of tests performed, Table 26 summarizes the findings in a decision support matrix. Many of the existing RADR materials can be safely used down to $25^{\circ} \mathrm{F}$ with minor modifications. New, natural materials are shown to be viable at temperatures below $25^{\circ} \mathrm{F}$ and down to -40 ${ }^{\circ} \mathrm{F}$.

Existing materials are capable of being used down to $25^{\circ} \mathrm{F}$ with set times in the range of 3-4 hrs. As the temperature drops the set time for new materials is increased from conventional existing materials. These set times are on the order of $12-24 \mathrm{hr}$ for materials that can be used at $25^{\circ} \mathrm{F}$ and below. In most cases, a 24-hr waiting period is necessary. Further, while all of the materials tested are adequate for providing the required level of strength to perform as backfill for craters at subfreezing temperatures, only some are assured to reach the level of strength necessary to serve as caps for RADR. 
Table 26. Performance ranges for traditional and new candidate RADR materials.

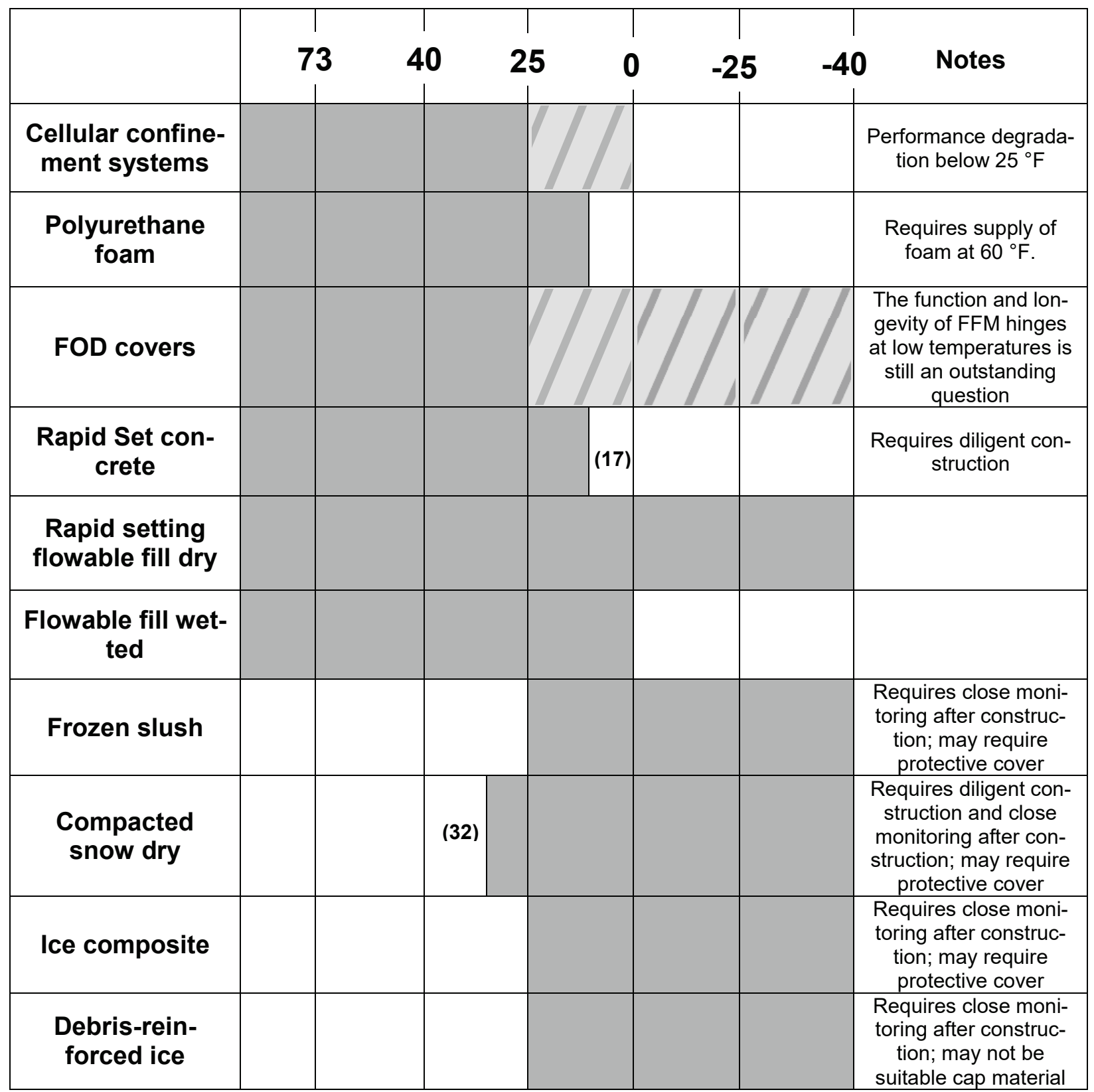




\section{Future Testing}

The test results indicate that existing RADR materials can be deployed effectively at temperatures below what is currently specified. Some can perform quite well down to at least $17^{\circ} \mathrm{F}$ (e.g., Rapid Set concrete). Additionally, new materials/mixtures were identified that are only viable in subfreezing temperatures but were tested in mechanical testing machines, simulated crater repairs in the laboratory, and in a few cases in the field to meet RADR performance requirements.

This study indicates that the Department of Defense may have a number of options available for RADR in temperature ranges that are not currently addressed. And, while these results could be used in an urgent situation to actually effect a runway repair in a cold region, there is much work that can and should be done to establish rigorous protocols for below-freezing RADR.

\subsection{Existing RADR materials}

This study did not test every material at a wide range of temperatures or in both small-scale (confined compression tests) and large-scale (simulated crater repair). A more complete test matrix would establish the true lower temperature limit of viability of various methods. Likewise, the time intervals for strength testing after the patching material was constructed were limited. As for temperature, having a more granular time scale for strength testing would better identify how long various materials take to reach adequate strength at increasingly cold temperatures.

The results of such a study would allow the generation of a three-dimensional matrix (or performance equations) for each RADR material type showing the relationship between ambient temperatures, time since construction and strength level. This family of information would allow repair teams to quickly determine what material would be most suitable for RADR given the existing environmental conditions (current and forecast temperatures) and the time available for repair before resumption of flight operations at a given air facility.

Another factor not addressed in this study is durability. These findings indicate that for a short period of time (days to a week), a material will be successful for RADR as shown in Table 26. However, the deterioration 
with repeated aircraft landing gear loadings and temperature cycling (diurnal as well as multi-day trends) was not studied. With durability results, another dimension could be added to the matrix previously mentioned.

A unique case of temperature cycling is freeze-thaw events. Since many of the existing RADR materials have a water component, temperature fluctuations that travel through the freezing point can have significant impact on strength and integrity of materials. In some cases, the volume may increase with freezing (and vice versa for thawing) and can create internal damage to materials, vastly weakening them over time. However, preliminary data indicate that wetted flowable fill may actually get stronger with exposure to repeated freeze-thaw cycling.

A large body of research has addressed the inclusion of admixtures for lowering freezing point of concrete. This work is mature and in use in the industry to allow traditional concrete work to be done in subfreezing environments with little to no compromise to curing time and ultimate strength. Application of this research to existing RADR materials is likely to show attractive extensions of the temperature performance envelope.

Although there are challenges of construction with traditional RADR materials in cold conditions, this report does not include any practical aspects of performing repairs with these materials in subfreezing conditions. It is well documented that the time to complete a task is increased under cold conditions (human performance, presence of bulky clothing, slower equipment response times). Further, working with water/wet materials in freezing conditions exposes personnel to addition risks for many routing tasks. Thus, while the results presented in this report, and any other results stemming from the studies suggested, may indicate some materials/RADR approaches appear attractive, the time to construct, messiness, and human factors risks should ultimately be a part of the application manual used by troops in the field.

The FRP covers appear to demonstrate unusually good properties at low temperature. While the data show them to have increasing or maintained strength (both tensile and flexural) with decreasing temperature, the percent elongation and percent deflection also increase or are maintained. These results appear to suggest that the FRP mats are great candidates for low temperature RADR. However, the increasing elongation and deflection at low temperatures is consistent with the observed delamination of 
the composite panels -a scenario that may result in catastrophic failure of the mats with high cycling. These outstanding questions on FRP mats would be best addressed by further studies that involve trafficking/cyclic loading of full-sized panels in a cold environment.

The surprising results from testing the polyurethane foam lend promise to further studies of this material at low temperatures. In particular, it would be worthwhile to explore the use of foam as a backfill material, and assess the longevity of repairs performed with various capping materials at low temperatures by trafficking or cyclic loading. In order to attempt this, a mechanism by which to deliver the foam components at room temperature (e.g., $65^{\circ} \mathrm{F}$ ) is required. It may be as simple as keeping the existing foam delivery system in a heated warehouse up until the time that the foam dispensing is needed.

\subsection{New frozen materials for RADR}

Within the U. S. Antarctic Program, considerable experience exists in using snow and slush for construction. Runways, roads, ocean piers, and large building foundations are successfully in use now. The results described above, together with the Antarctic experience, lends confidence that snow and slush (alone or with debris filler) can provide a robust RADR material. However, this has never been demonstrated for a crater in a conventional runway. While there is no reason to believe it won't work, it should be demonstrated on full-scale for validation.

This study utilized fresh water (for both traditional and new RADR materials). In some remote areas (e.g., Polar Regions), fresh water may be more precious than seawater. Again, in Antarctica there is experience using seawater together with natural snow to form robust construction materials. Laboratory tests on the strength or other properties of a snow/salt water slush have not been performed.

To go off from previously completed concrete experimentation, the use of salt water at colder temperatures has not been investigated as part of the mixing procedure. This may prove an area of valuable knowledge for traditional RADR materials. At least one advantage of seawater is it depressed freezing point $\left(28^{\circ} \mathrm{F}\right)$ which clearly extends by a bit the ambient temperature range for working with water-based mixtures. 


\section{References}

Andersland, O. B. and B. Ladanyi. 1994. An introduction to frozen ground engineering. New York: Chapman and Hall.

ASTM International. 2004. Standard test method for compressive properties of rigid cellular plastics. D1621-04a. West Conshohocken, PA: ASTM International.

. 2013. Standard test method for indentation hardness of rigid plastics by means of a barcol impressor. D2583-13a. West Conshohocken, PA: ASTM International.

. 2014. Standard test method for moisture absorption properties and equilibrium conditioning of polymer matrix composite materials. ASTM D5229/D5229M-14. West Conshohocken, PA: ASTM International.

. 2017a. Standard test method for flexural fatigue properties of plastics. ASTM D7774-17. West Conshohocken, PA: ASTM International.

. 2017b. Standard test method for tensile properties of geotextiles by the widewidth strip method. D4595-17. West Conshohocken, PA: ASTM International.

. 2018. Standard test method for compressive strength of cylindrical concrete specimens. ASTM C39/C39M-18. West Conshohocken, PA: ASTM International.

Bell, H. P., L. Edwards, W. D. Carruth, J. S. Tingle and J. R. Griffin. 2013. Wet weather crater repair testing at silver flag exercise site, Tyndall Air Force Base, Florida. ERDC/GSL TR-13-42. Vicksburg, MS: U.S. Army Engineer Research and Development Center.

Blaisdell, G., R. Lang, G. Crist, K. Kurtti, J. Harbin, and D. Flora. 1998. Construction, maintenance, and operation of a glacial runway, McMurdo Station, Antarctica. CRREL M98-1. Hanover, NH: U.S. Army Engineer Cold Regions Research and Engineering Laboratory.

Cancelli, A., P. Rimoldi and F. Montanelli. 1993. Index and performance tests for geocells in different applications. Geosynthetic Soil Reinforcement Testing Procedures. Philadelphia, PA: American Society for Testing and Materials. ASTM STP 1190: 64-75.

Carruth, W. D. and I. L. Howard. 2016. Evaluation of flowble fill surface performance. ERDC/GSL TR 16-33. Vicksburg, MS: U.S. Army Engineer Research and Development Center.

Department of Defense Facilities Criteria. 2015. Air Force; Design, construction, maintenance, and evaluation of snow and ice airfields in Antarctica. FC 3-260o6F, 1 June.

Department of the Air Force. Headquarters, Air Force Civil Engineer Support Agency. 2007. Folded fiberglass mat fabrication and packaging. MIL-DTL-32265. Tyndall, AFB, FL: Air Force Civil Engineering Center. 
Department of the Air Force. Headquarters, Air Force Civil Engineer Support Agency. 2008. Engineering Technical Letter (ETL) 08-03: Crater repair methods using rapid-setting (RS) materials. Tyndall AFB, FL: Department of the Air Force.

Department of the Air Force. Headquarters, Air Force Civil Engineer Support Agency. 2016. Detail specification for fiber-reinforced polymer (frp) mat for airfield damage repair (RADR). MIL-DTL-X. Vicksburg, MS: U.S. Army Engineer Research and Development Center.

Garcia, L. 2017. Laboratory testing results for GEOWEB confinement systems. Personal communication with E. Asenath-Smith. U.S. Army Engineer Cold Regions Research and Engineering Laboratory.

Geosystems, P. 2015. Perforated GEOWEB system performance \& material specification summary. https://www.prestogeo.com/wp-content/uploads/2016/10/GWgeoweb-material-specification.pdf

Gold, L. W. 1992. The Canadian Habbakuk Project: A project of the National Research Council of Canada. Ottawa, Ontario, Canada: National Research Council of Canada.

Kyzar, J. D., L. P. Priddy and J. F. Rowland. 2010. Field evaluation of the navy foam dispenser for threat munition crater repair. ERDC/GSL TR-10-20. Vicksburg, MS: U.S.Army Engineer Research and Development Center.

Li, J. H., Z. Wei and C. Wu. 2015. Preparation and properties of novel building materials at low temperature. Materials \& Design 67: 464-468.

Mejias-Santiago, M., B. Ruiz-Cruz, L. Gurtowski, C. Griggs, J. Johnson and D. Felt. 2016. Refinement of foam backfill technology for expedient airfield damage repair. ERDC/GSL TR-16-16. Vicksburg, MS: U.S. Army Engineer Research and Development Center.

Oren, J. I., R. D. Moser, B. M. Boddu, B. A. Weiss and J. L. Clausen. 2014. Laboratory evaluation of expedient low-temperature admixtures for runway craters in cold weather. ERDC/CRREL-TR 14-10. Hanover, NH: U.S. Army Engineer Cold Regions Research and Engineering Laboratory.

Priddy, L. P. 2014. Development of expedient military concrete airfield pavement repairs. Magazine of Concrete Research 66(1): 25-35.

Priddy, L. P., H. P. Bell, L. Edwards, W. D. Carruth and J. F. Rowland 2016. Evaluation of the structural performance of Rapid Set concrete mix. ERDC/GSL-TR 16-20. Vicksburg, MS: U.S. Army Engineer Research and Development Center.

Priddy, L. P., M. Mejias-Santiago and J. S. Tingle. 2016. Development of foam backfill repair techniques for airfield pavement repairs. Transportation Research Record: J. Trans. Res. Board 2569: 53-61.

Priddy, L. P., J. S. Tingle, T. J. McCaffrey and R. S. Rollings. 2007. Laboratory and field investigations of small crater repair technologies. ERDC/GSL TR-07-27.

Vicksburg, MS: U.S. Army Engineer Research and Development Center. 
Robinson, J. W., J. S. Tingle and C. A. Rutland. 2016. Material handling equipment evaluation for crater repair. ERDC/GSL-TR 16-30. Vicksburg, MS: U.S. Army Engineer Research and Development Center.

Rushing, J. F., W. C. Floyd, T. W. Rushing, L. Garcia, W. D. Carruth, J. S. Tingle and C. A. Rutland. 2016. Validation of FRP matting requirements. ERDC/GSL TR-16-22. Vicksburg, MS: U.S. Army Engineer Research and Development Center.

Schulson, E. (1990). The brittle compressive fracture of ice. Acta Metallurgica et Materialia 38(10): 1963-1976.

Vasiliev, N. K., A. D. C. Pronk, I. N. Shatalina, F. H. M. E. Janssen and R. W. G. Houben. 2015. A review on the development of reinforced ice for use as a building material in cold regions. Cold Regions Science and Technology 115: 56-63.

Yadav, M., A. K. Agnihotri, K. Priyadarshee and G. Dhane. 2014. Application of geocells in refinement of soil: A review. Journal of Civil Engineering and Environmental Technology 1(5): 60-64. 


\section{Appendix A: Individual Loading Curves for Mechanical Testing of FOD Covers}

Figure A1. Individual stress-strain plots for FFM composite panels during tensile loading. a) 73 F, b) 25 F, c) 0 F, d) -25 F, e) -40 F. Notice the dual peaks observed in (c).

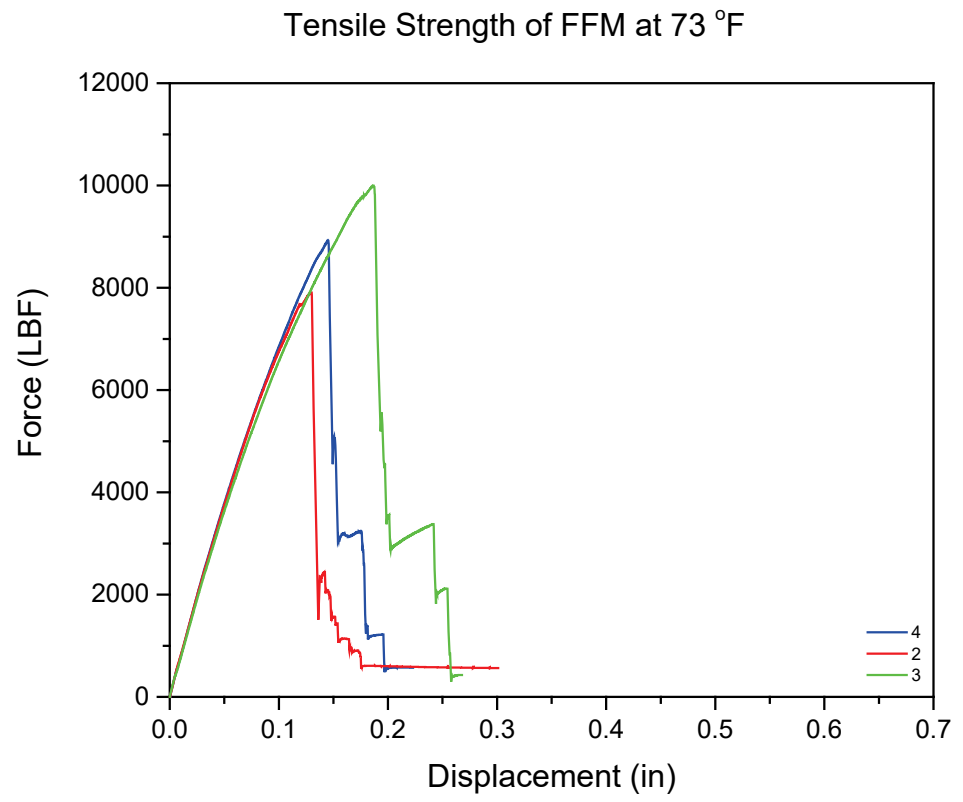

a)

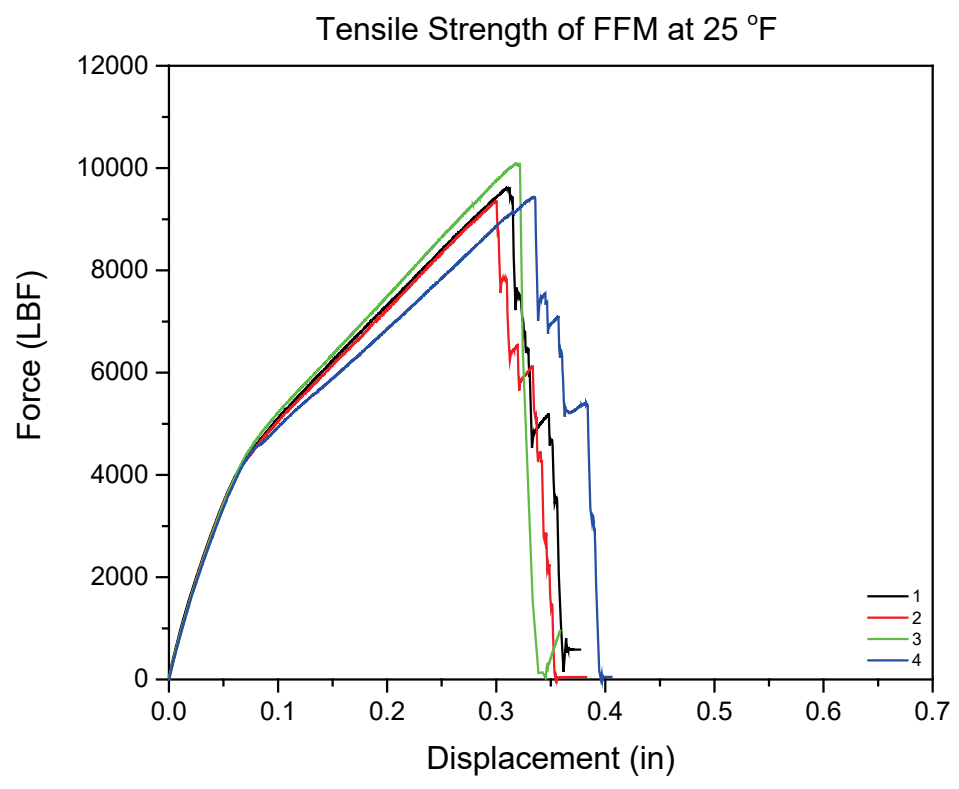

b) 


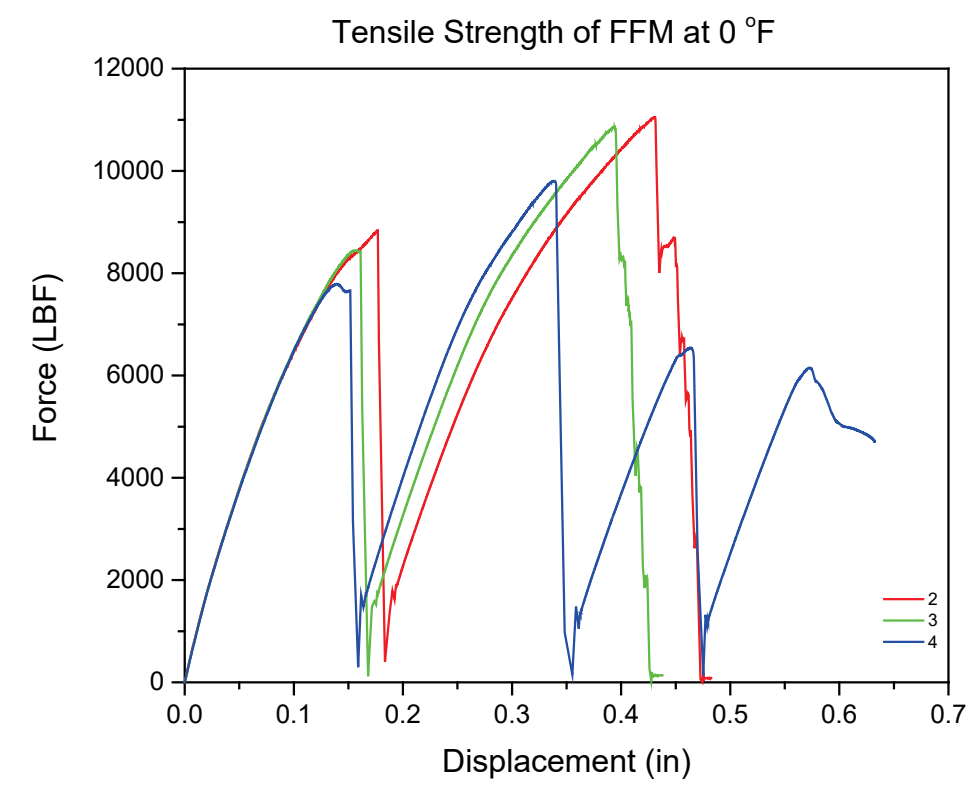

c)

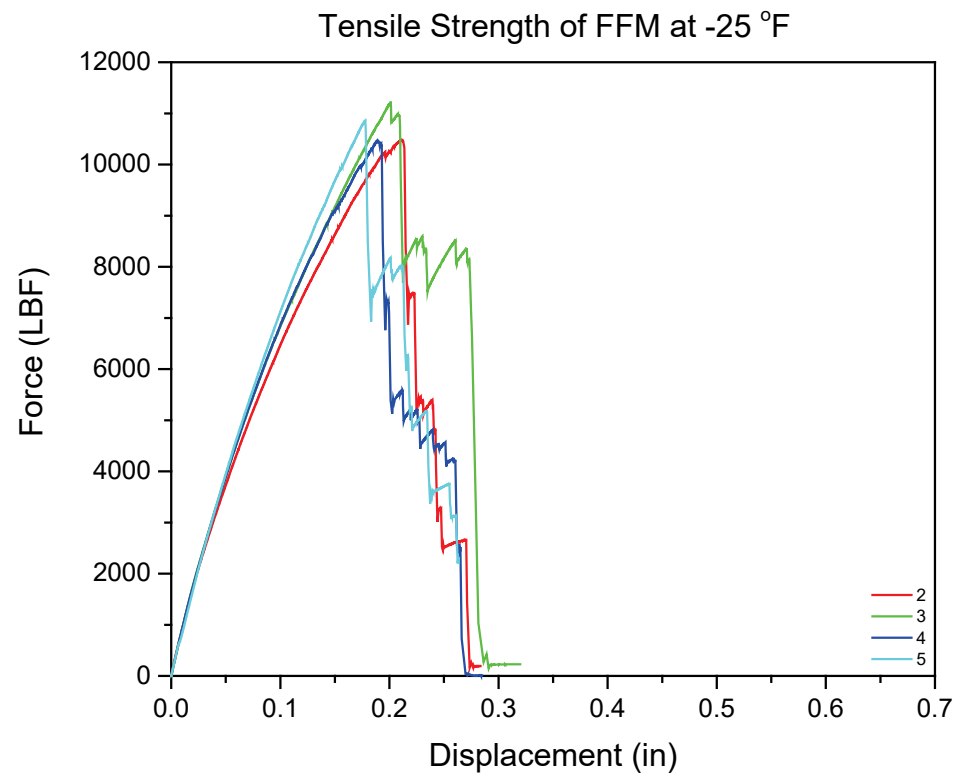

d) 


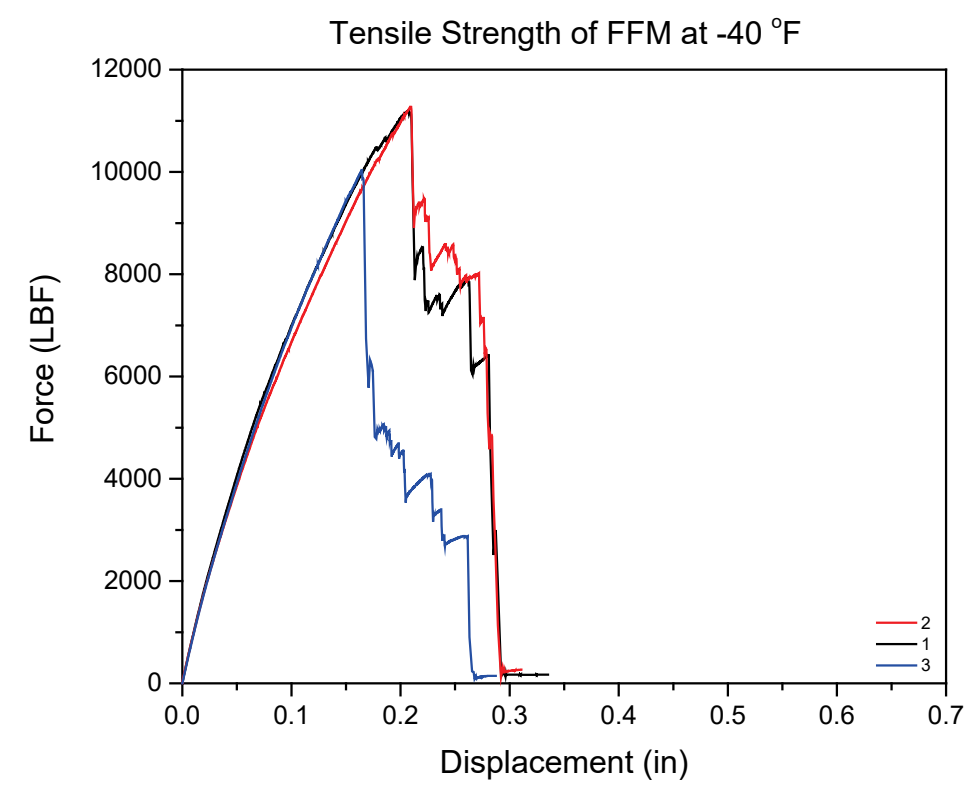

e)

Figure A2. Individual force-displacement curves for tensile testing of FFM hinges at various temperatures: a) 73 ; b) 25 ; c) 0 ; d) -25 ; e) $-40^{\circ} \mathrm{F}$.

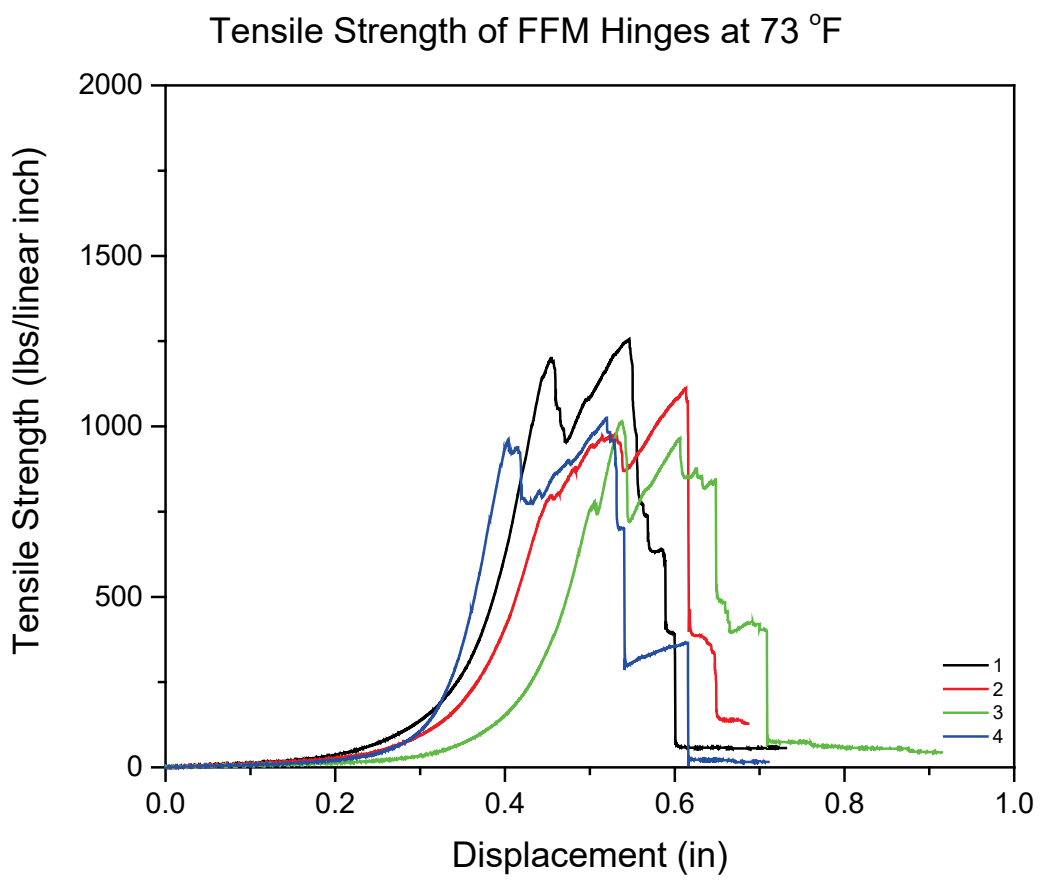

a) 


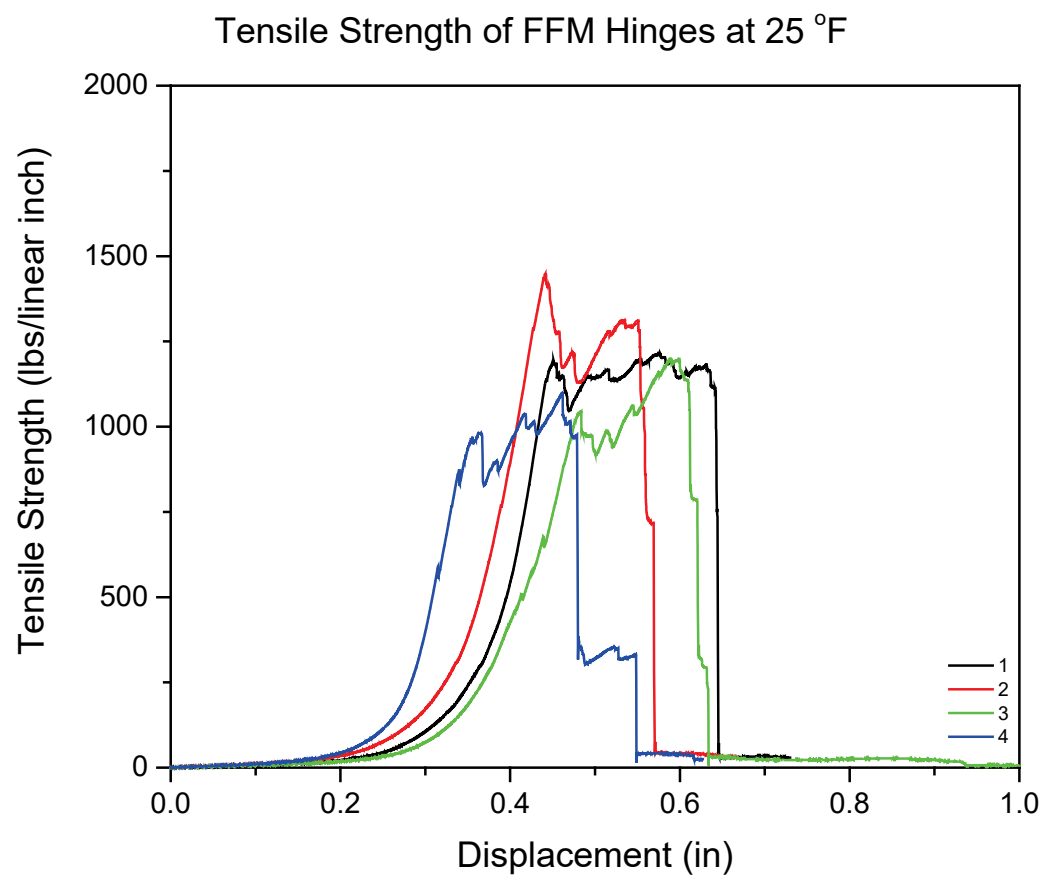

b)

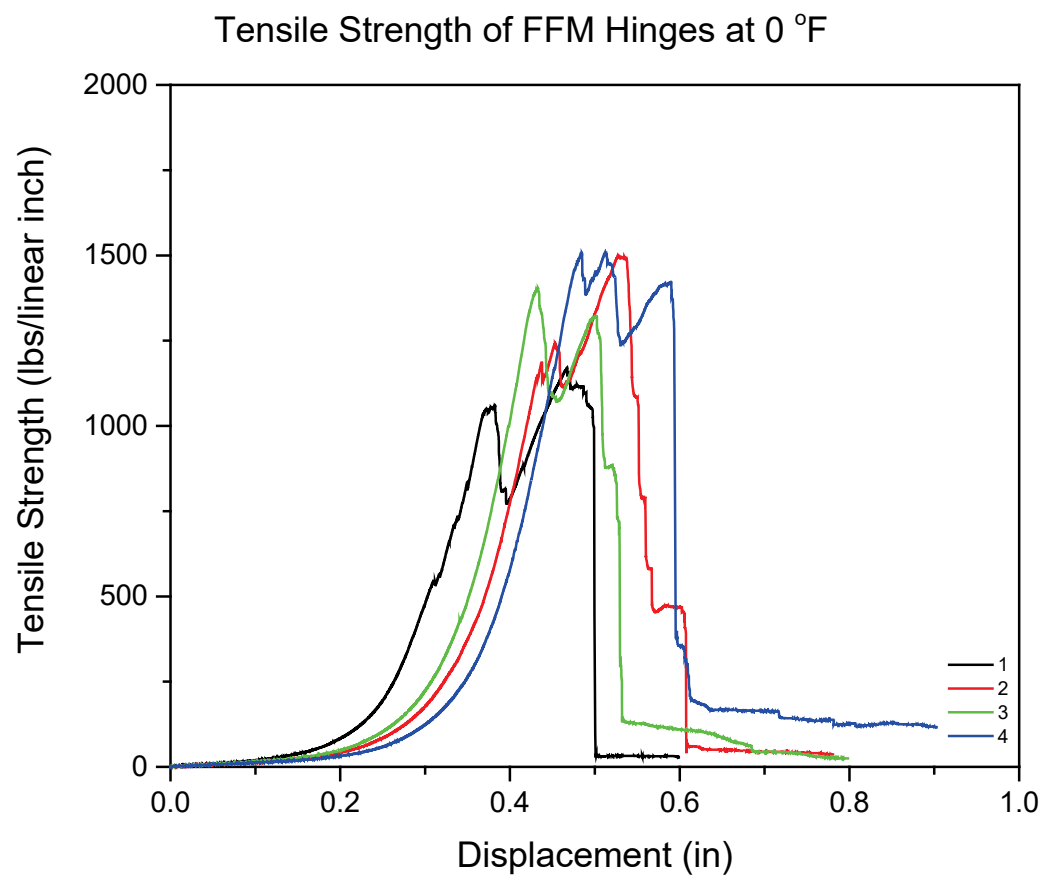

c) 


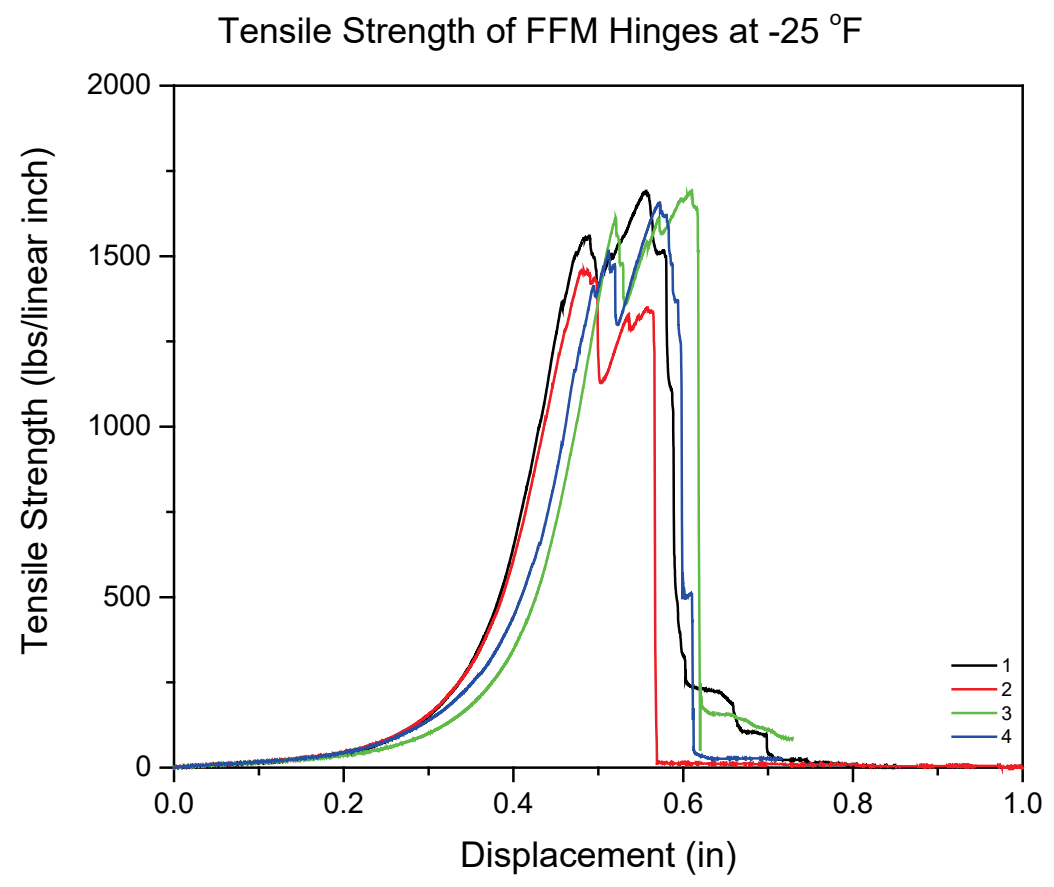

d)

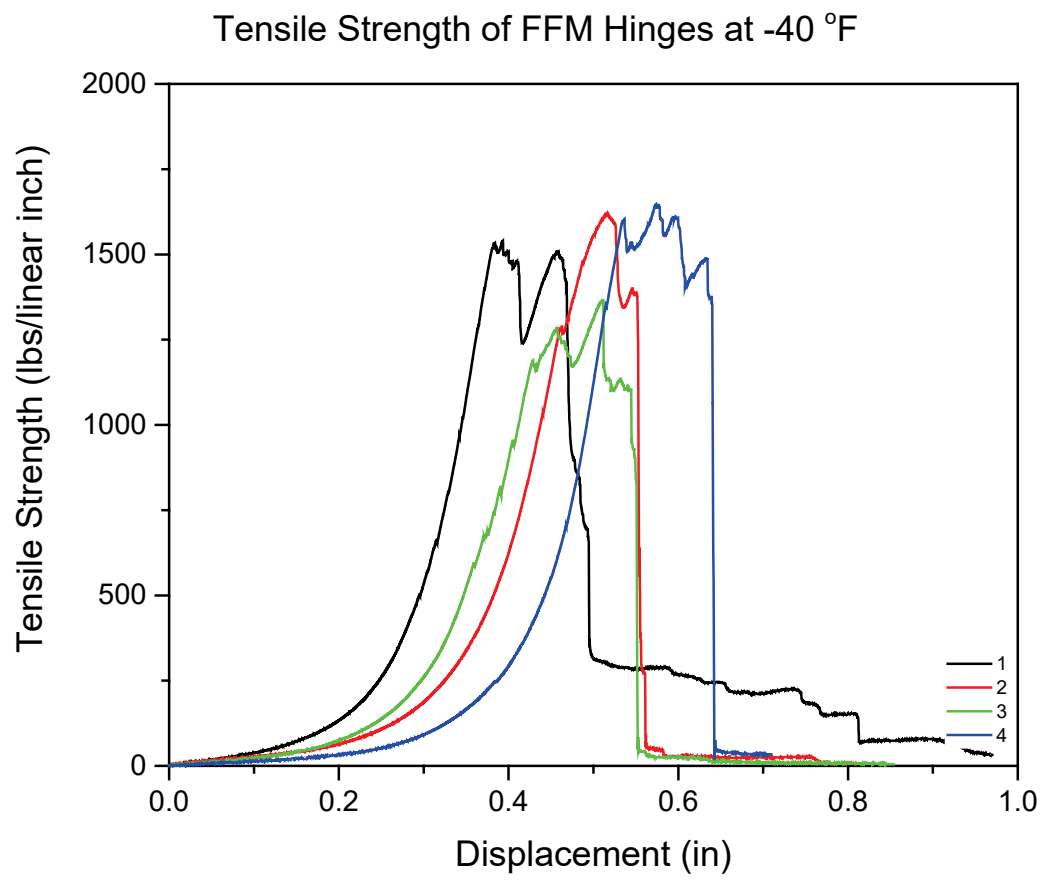

e) 
Figure A3. Individual force-displacement curves for tensile testing of FRP covers at various temperatures: a) 73 ; b) 25 ; c) 0 ; d) -25 ; e) $-40^{\circ} \mathrm{F}$.
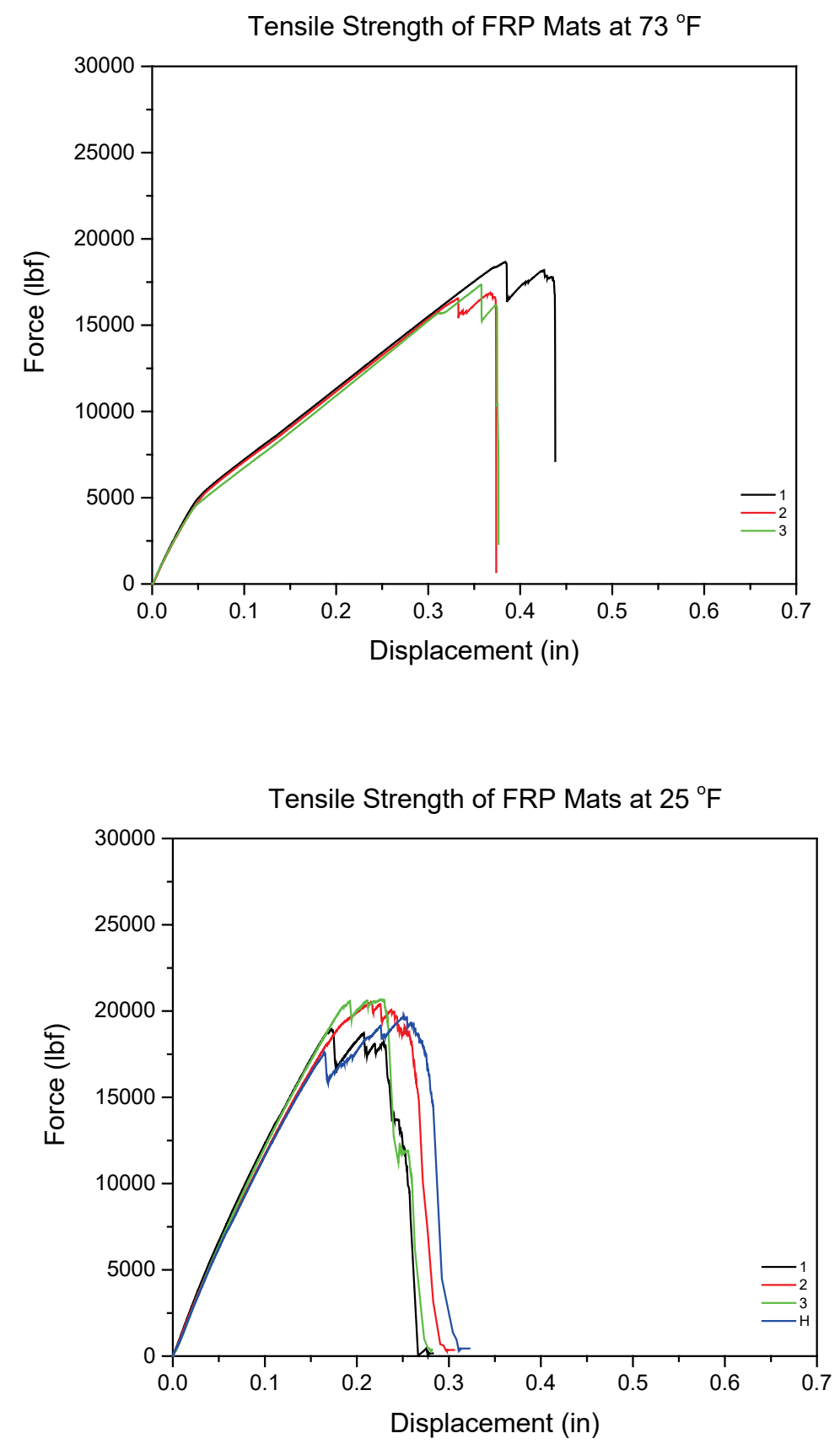

b) 


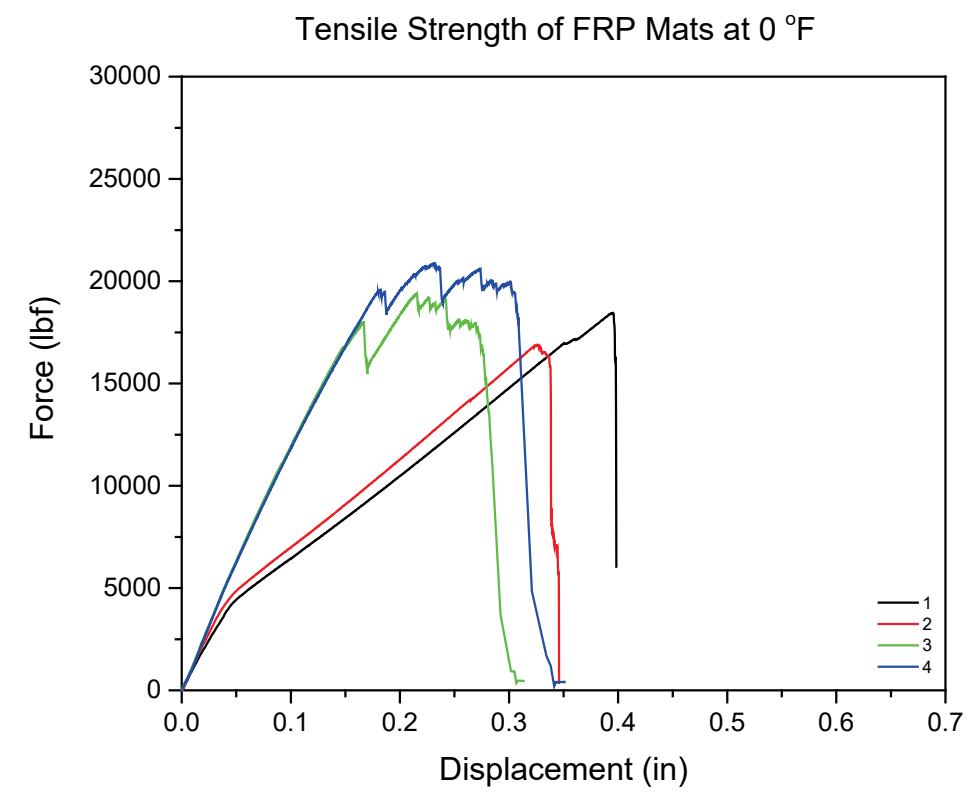

c)

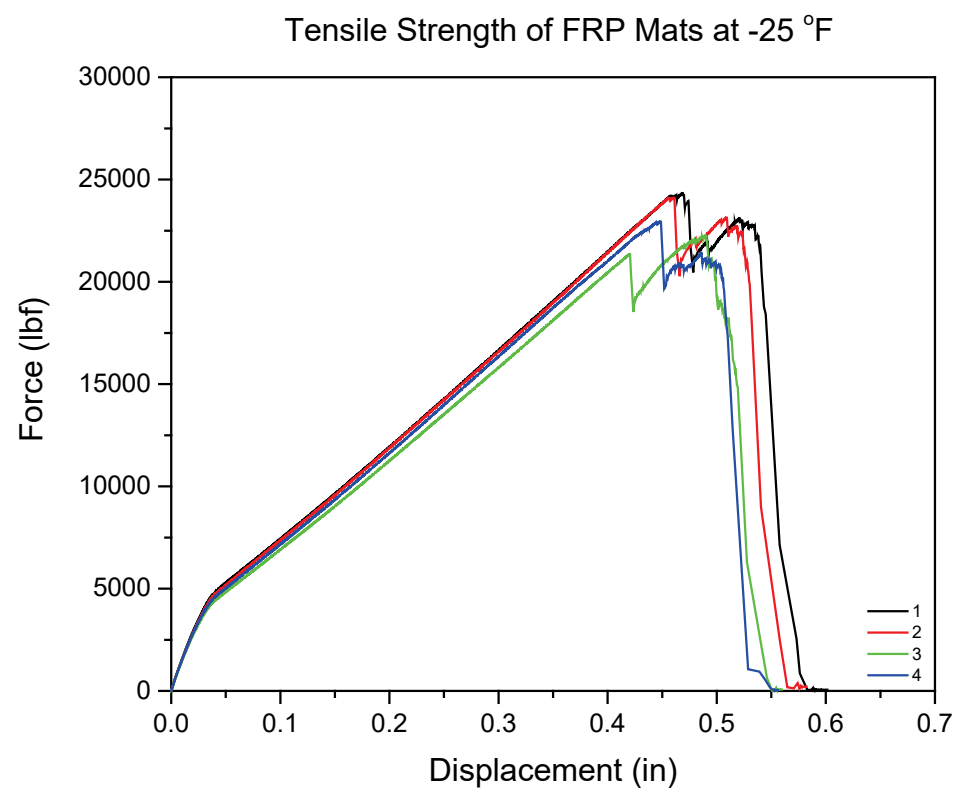

d) 


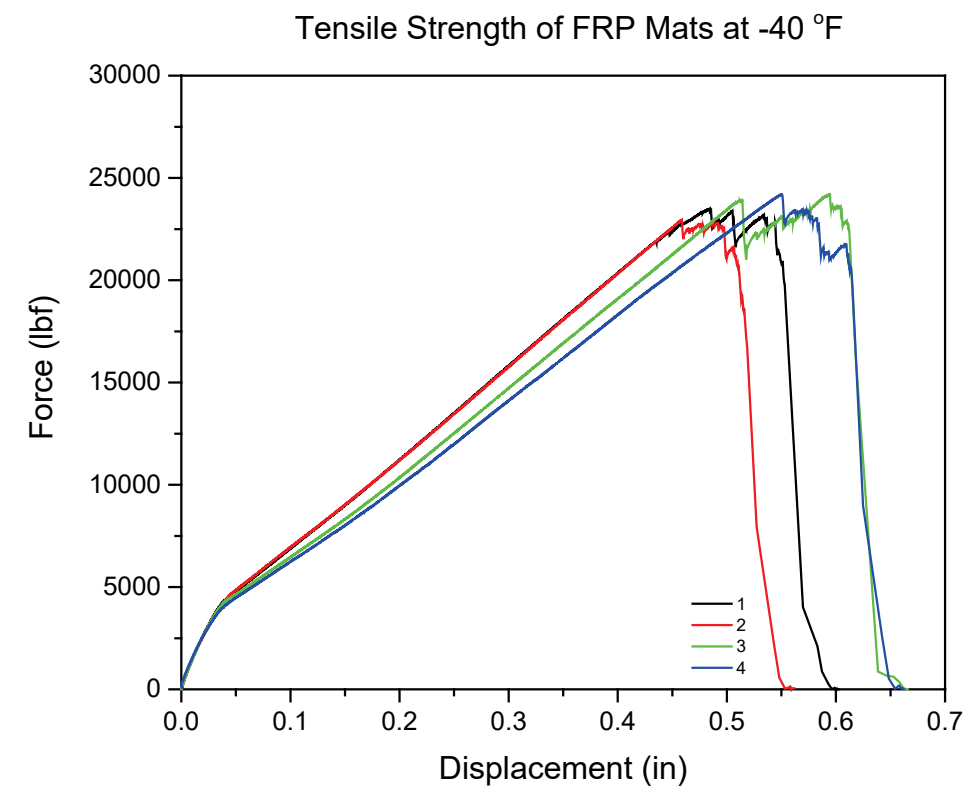

e)

Figure A4. Individual stress-deflection curves for flexural testing of FFM covers at various temperatures: a) 73 ; b) 25 ; c) 0 ; d) -25 ; e) $-40^{\circ} \mathrm{F}$.

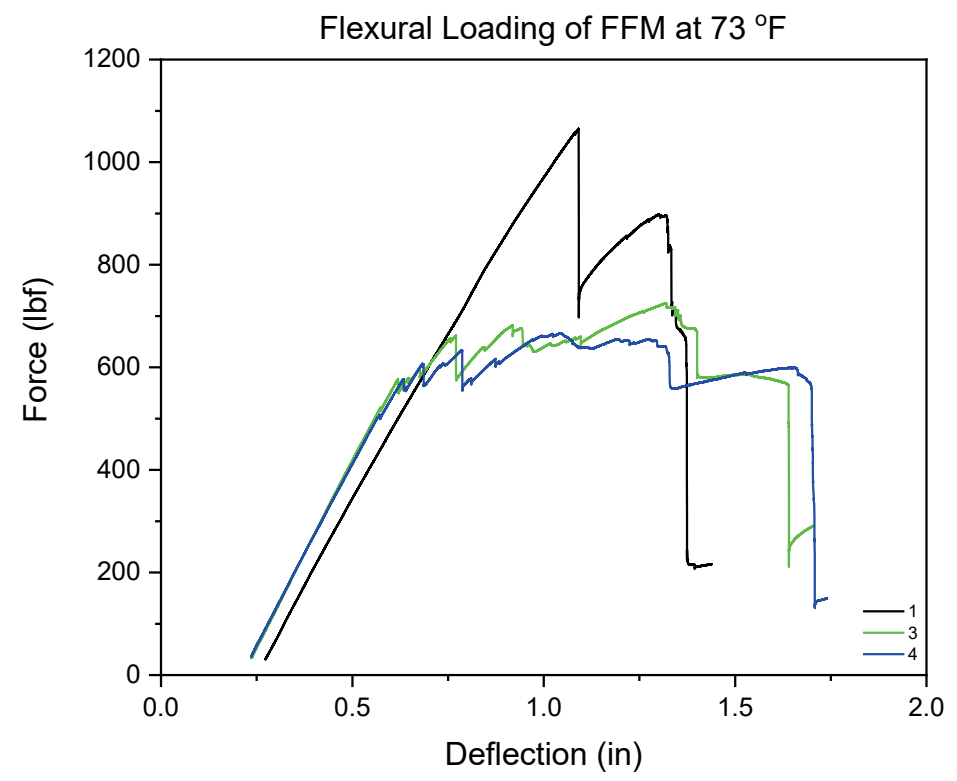

a) 


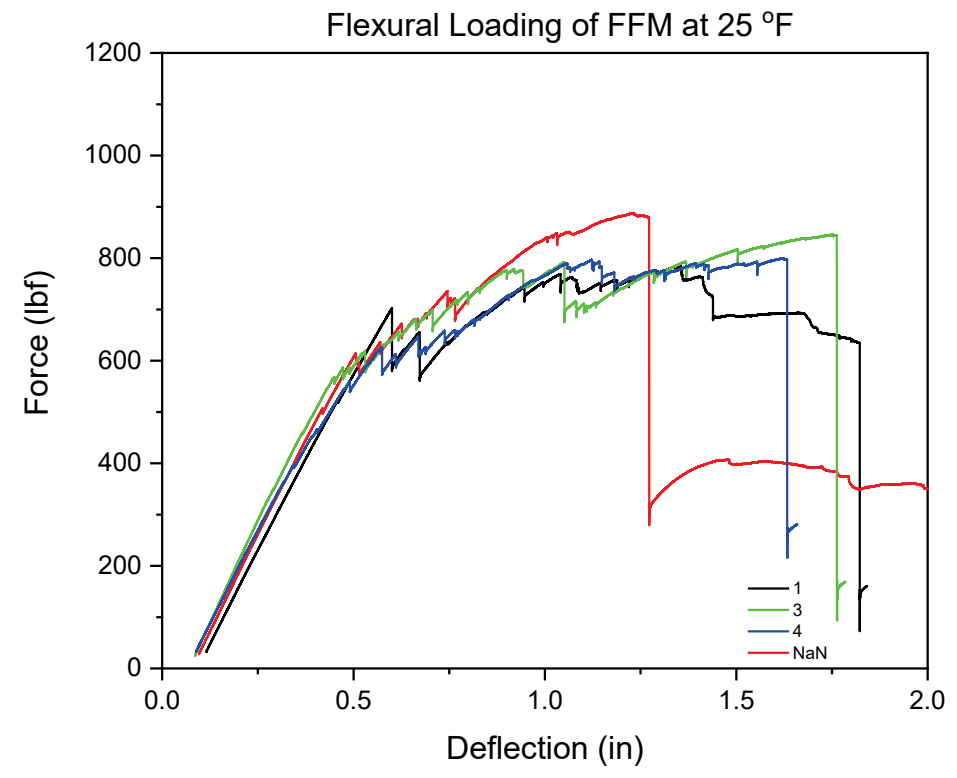

b)

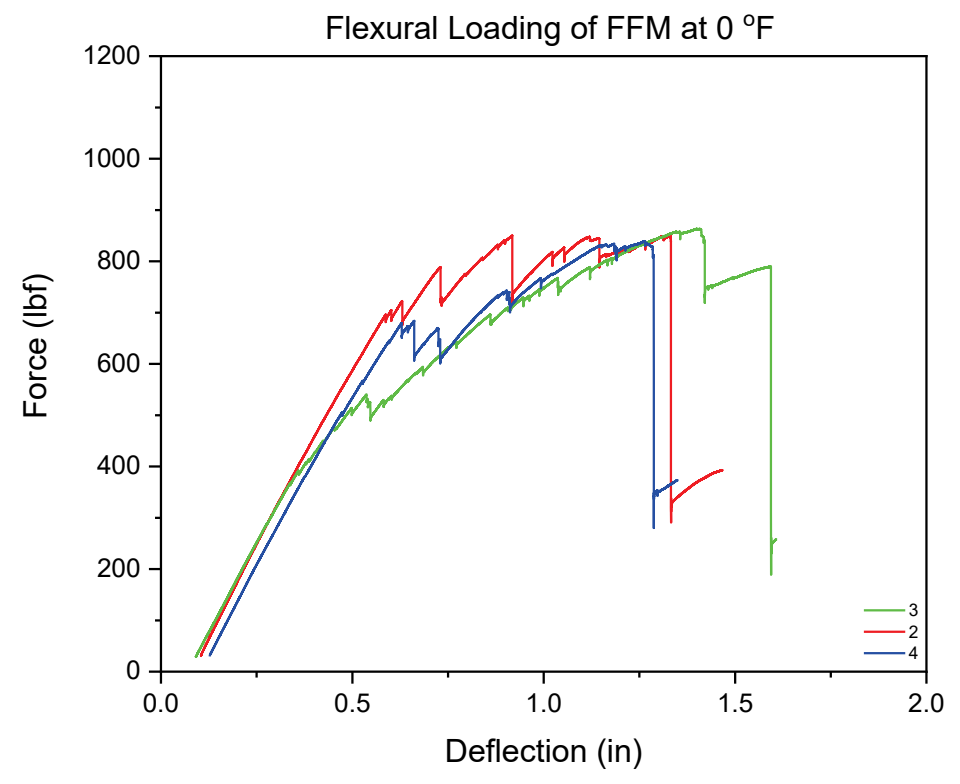

c) 


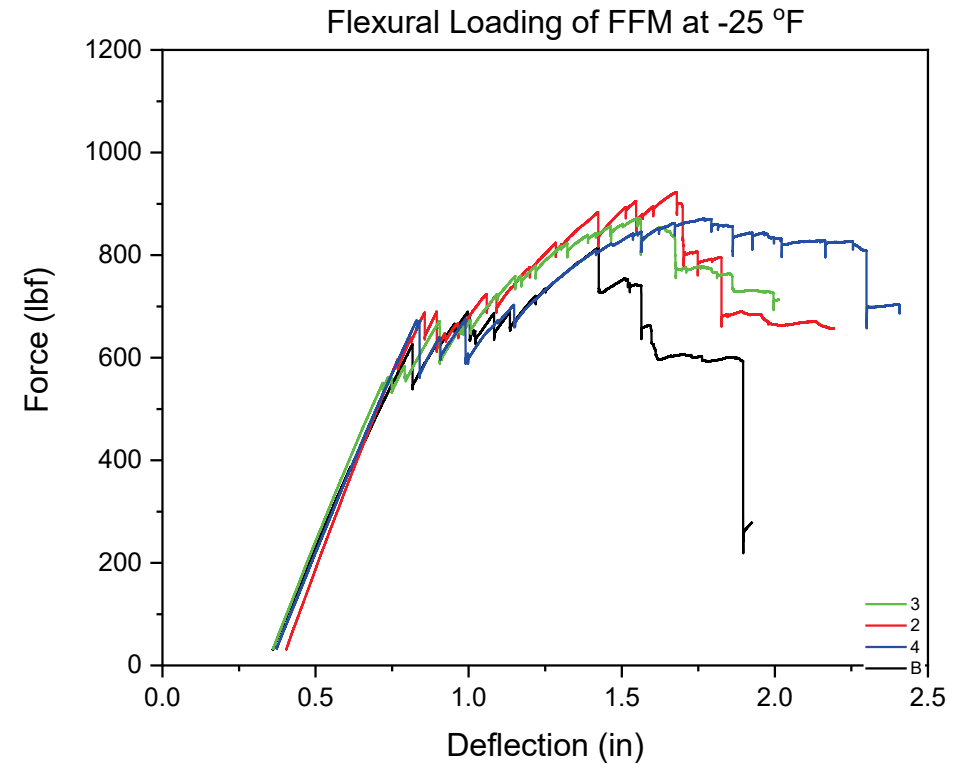

d)

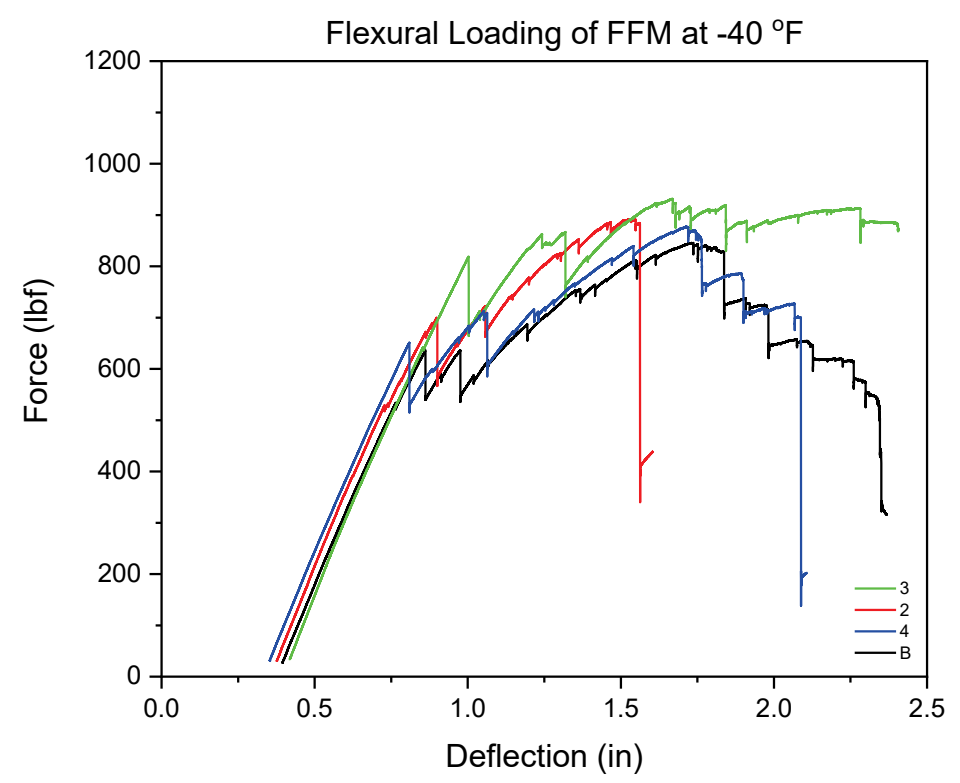

e) 
Figure A5. Individual stress-deflection curves for flexural testing of FRP covers at various temperatures: a) 73 ; b) 25 ; c) 0 ; d) -25 ; e) $-40^{\circ} \mathrm{F}$.

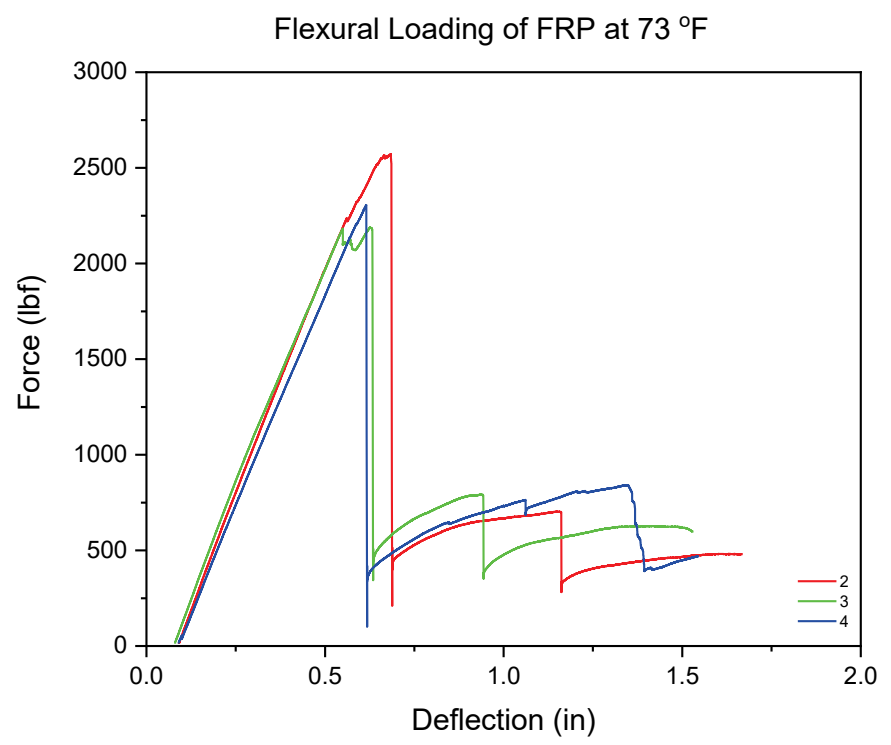

a)

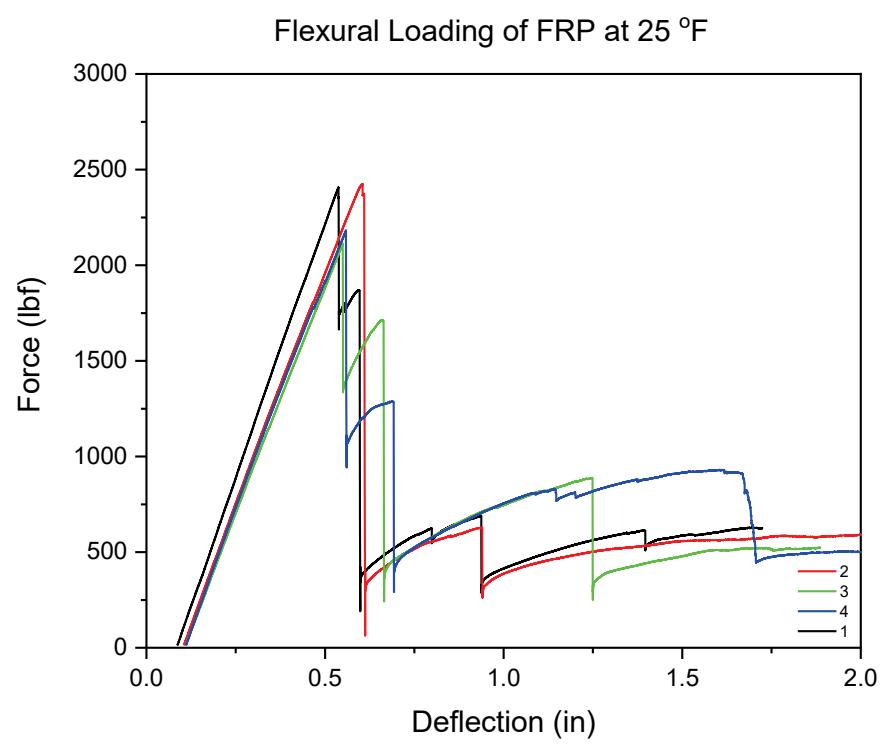

b) 


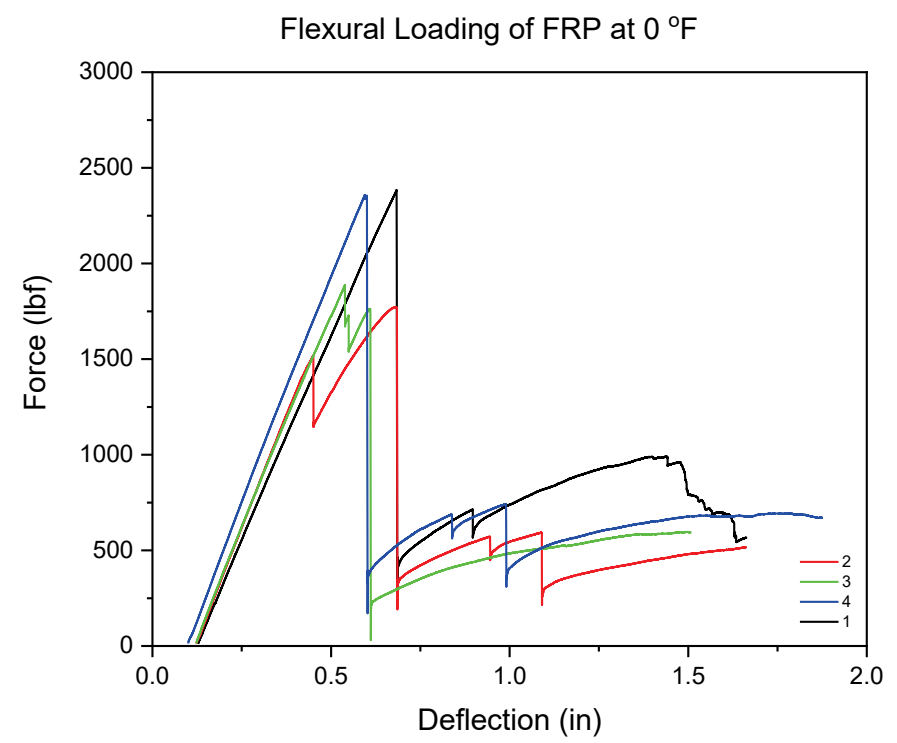

c)

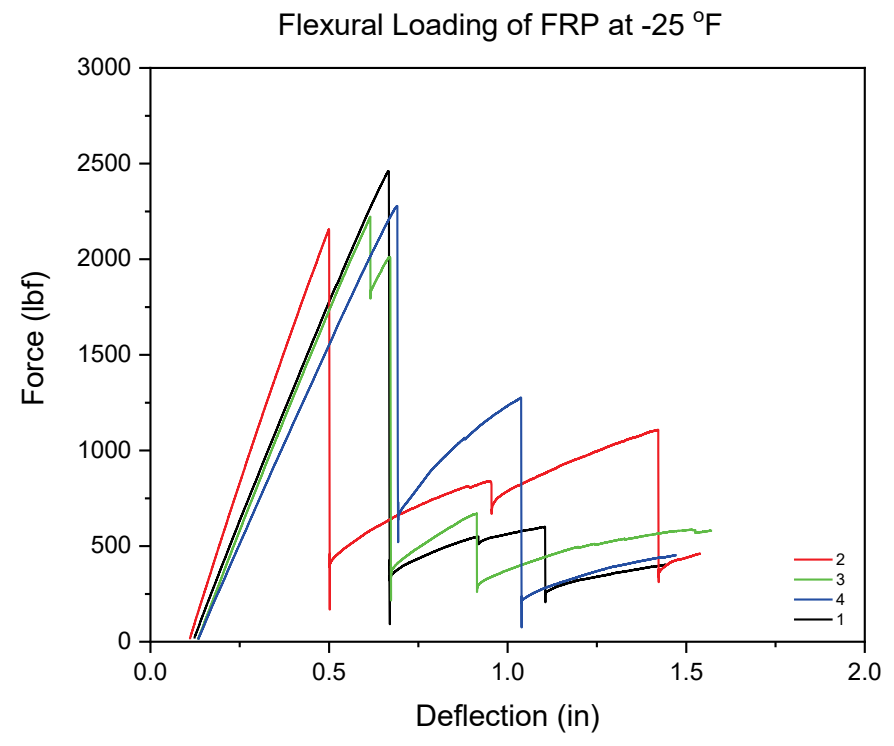

d) 


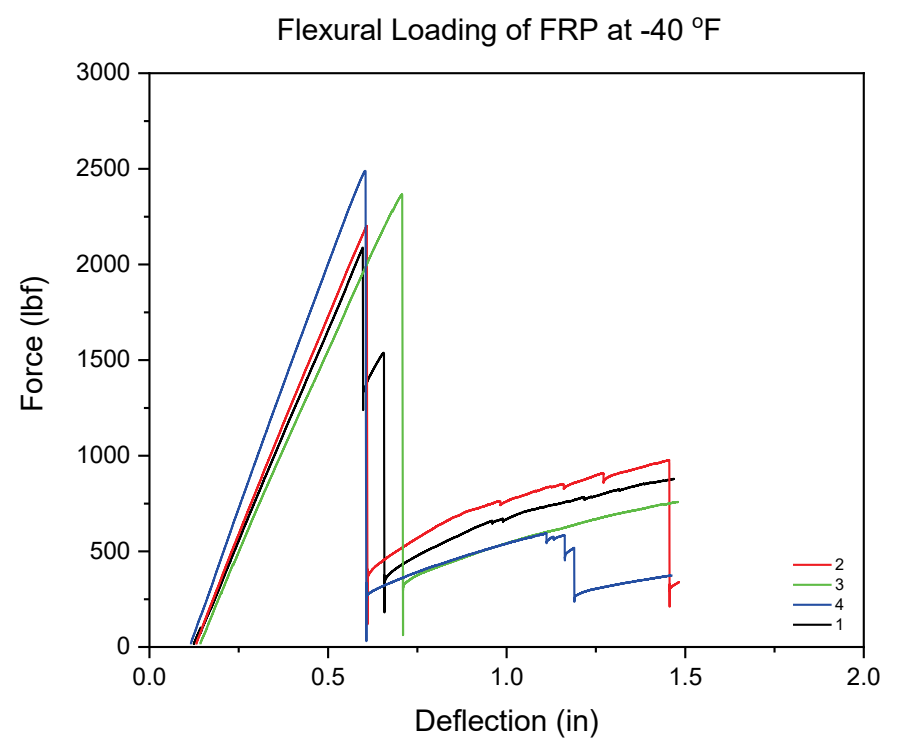

e)

Figure A6. Raw load vs. displacement curves for flexural fatigue testing of FRP covers at various temperatures: a) 73 ; b) 0 ; c) -25 ; d) $-40^{\circ} \mathrm{F}$.

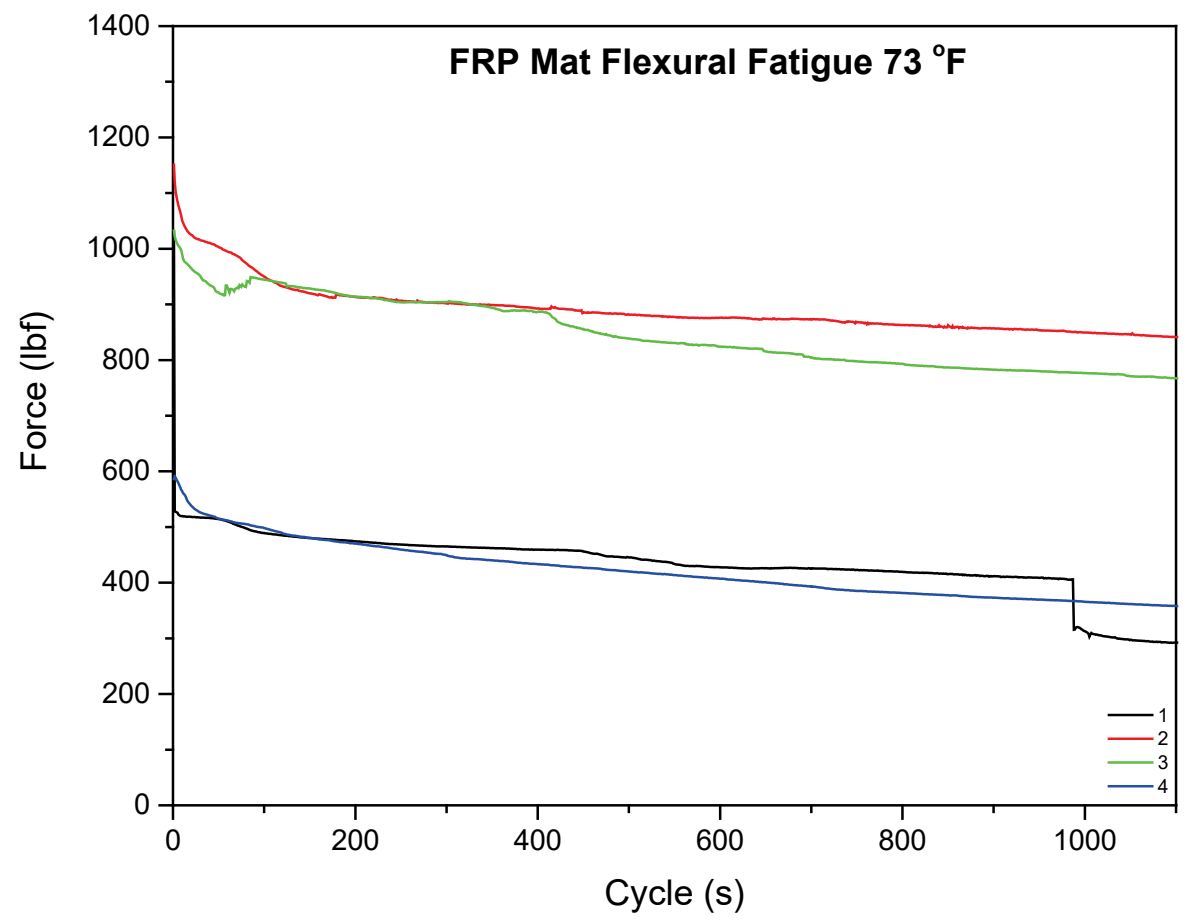

a) 


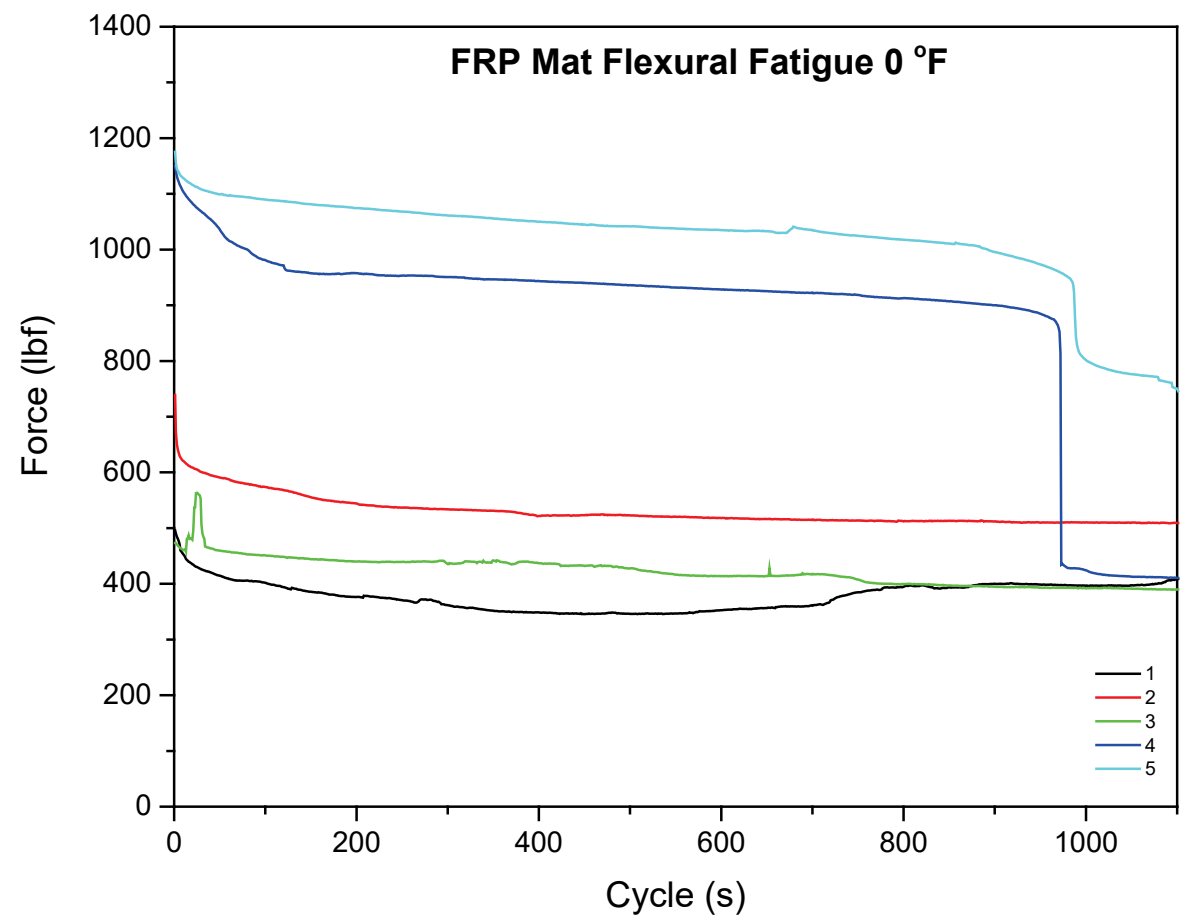

b)

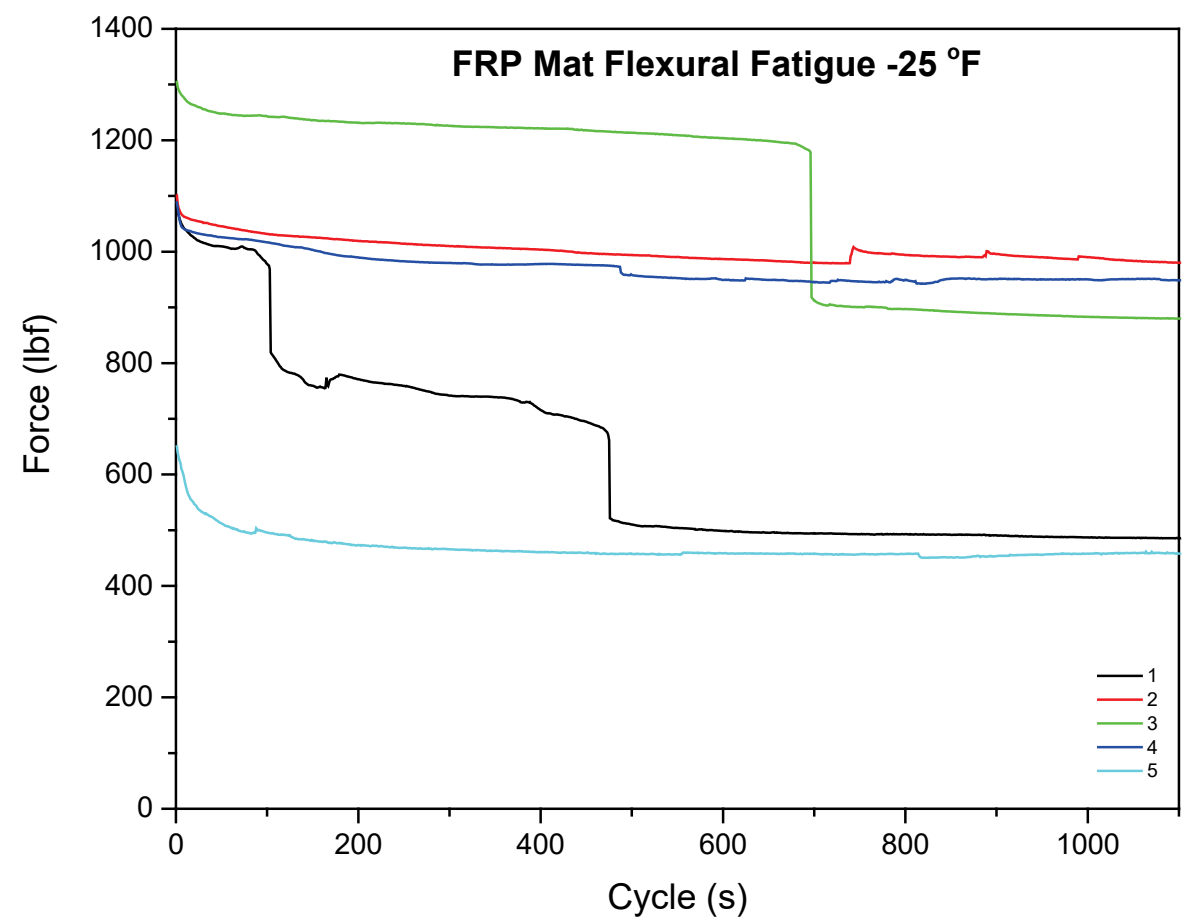

c) 


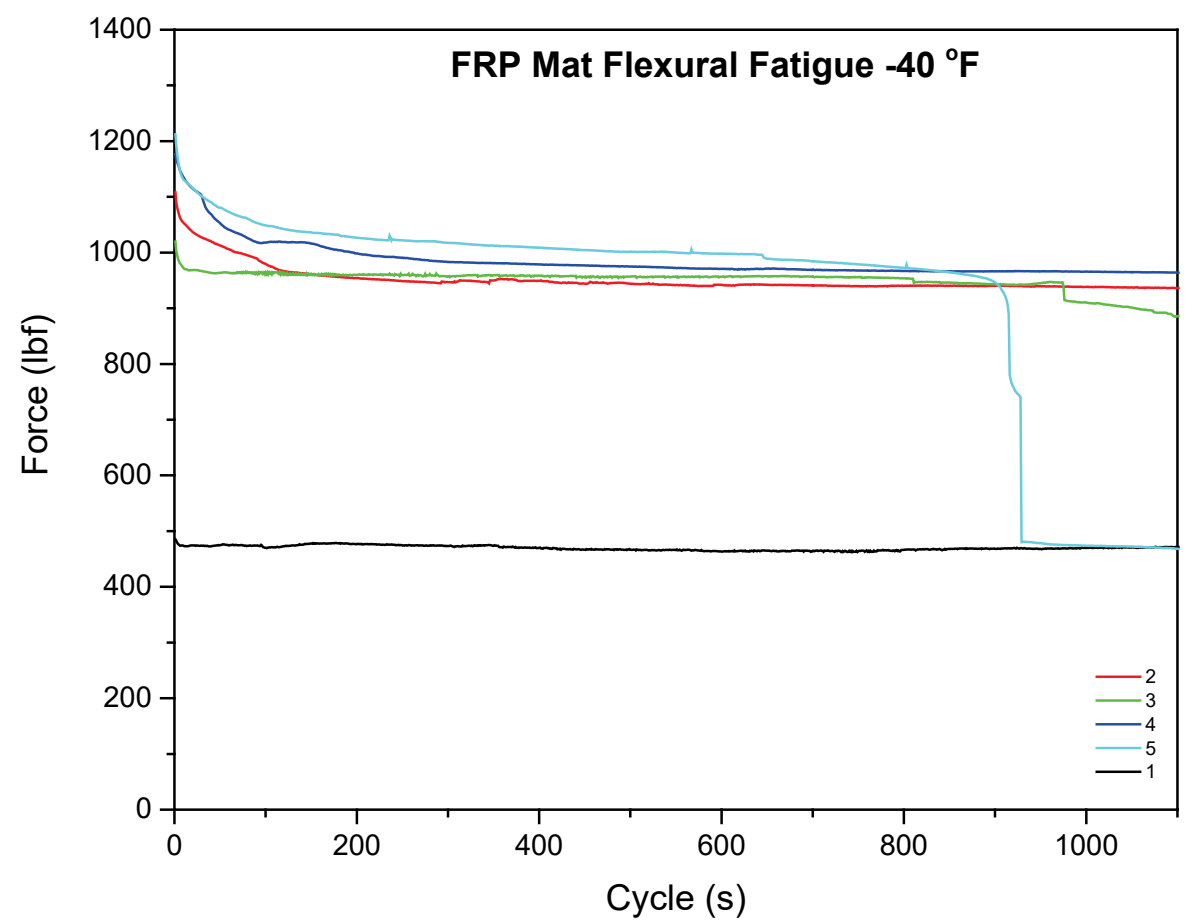

d)

Figure A7. Raw stress vs. deflection curves used to calculate the flexural strength of FRP mats after cyclic loading at various temperatures: a) 73 ; b) 0 ; c) -25 ; d) $-40^{\circ} \mathrm{F}$.

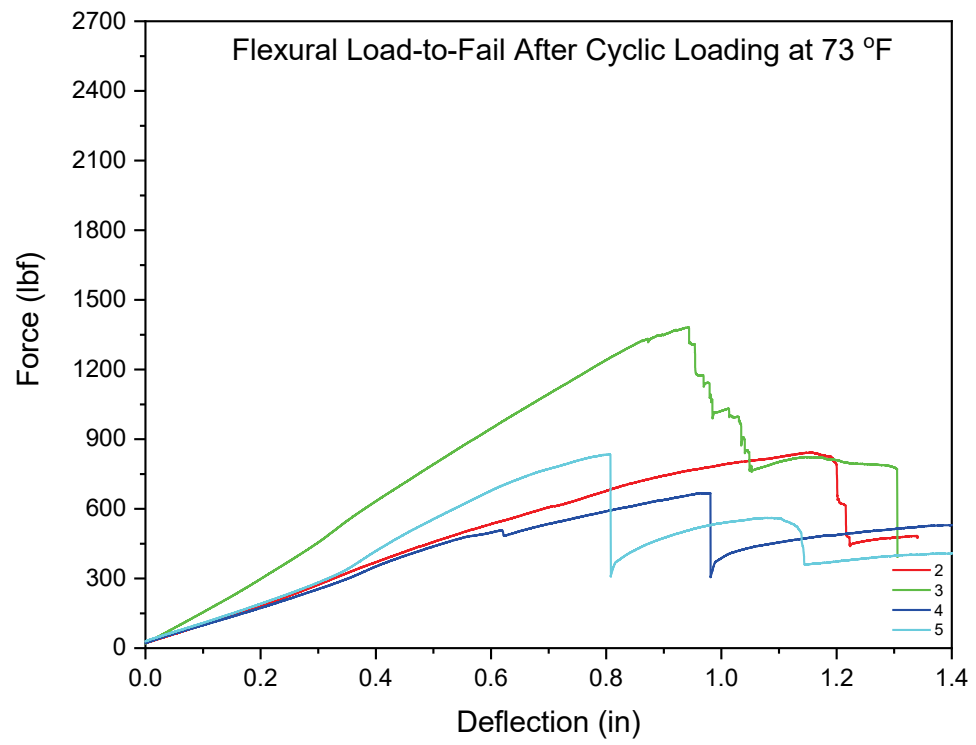

a) 


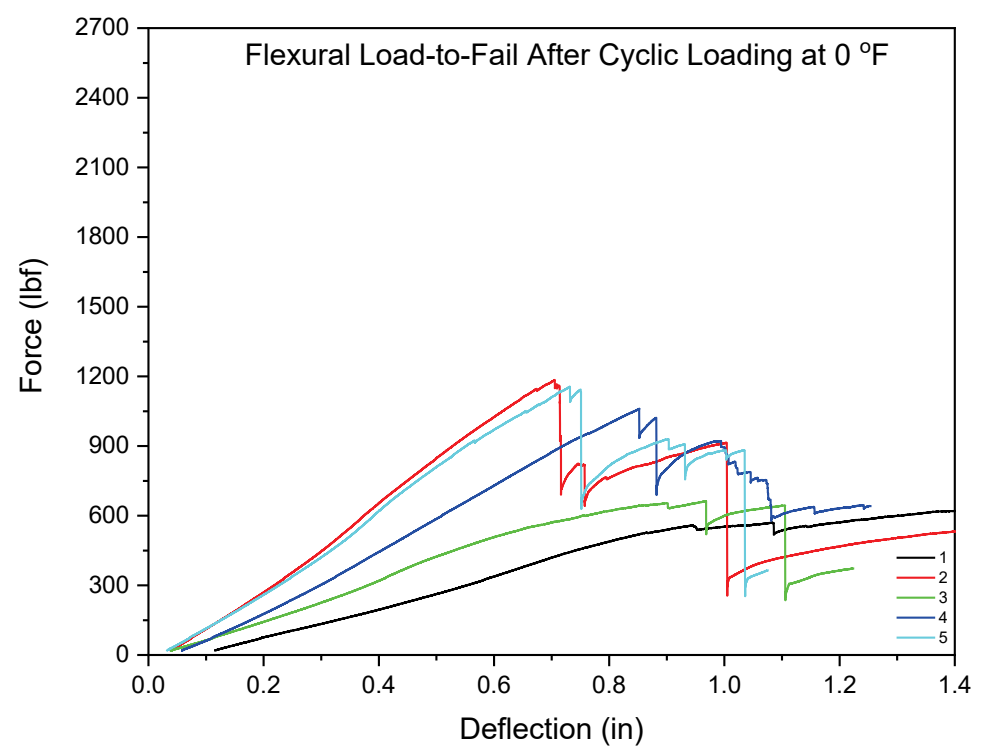

b)

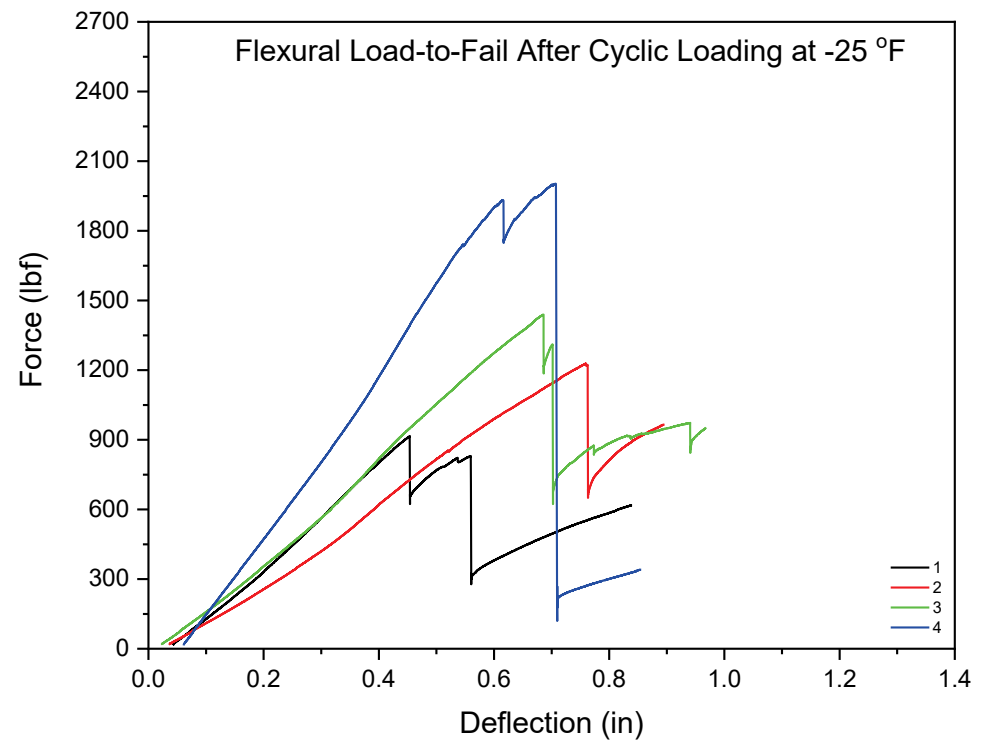

c) 


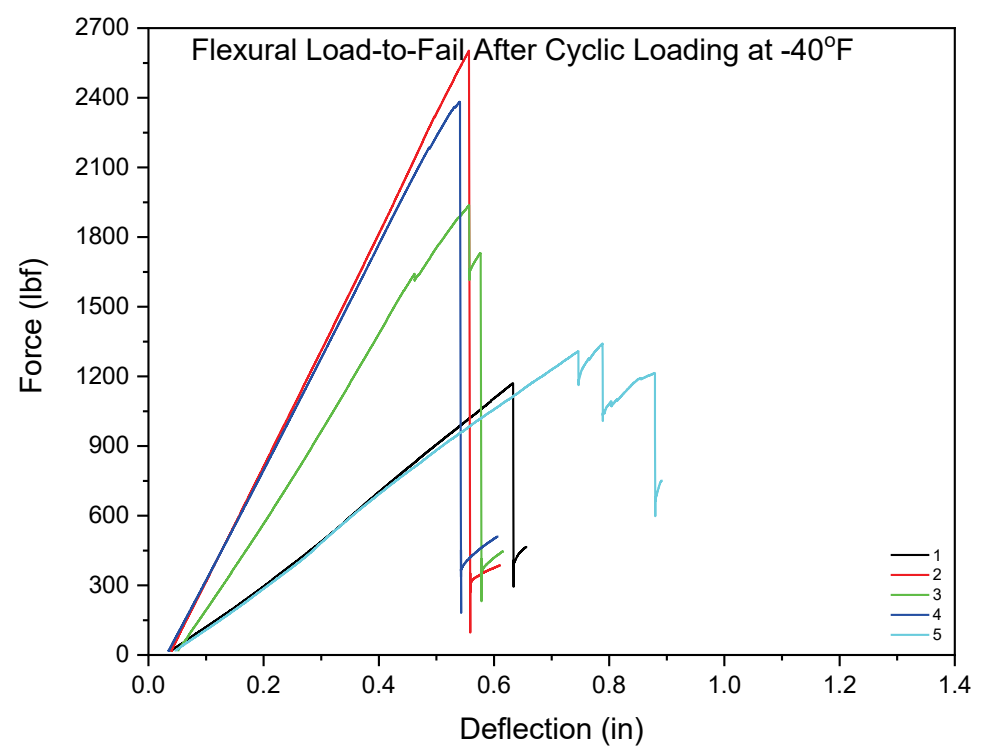

d) 


\section{Appendix B: Photographs of Polyurethane Foam Samples during Curing at $-\mathbf{4 0}^{\circ} \mathrm{F}$}

Figure B1. Polyurethane foam sample during curing at $-40 \mathrm{~F}$. While the foam was capable of expansion (a), it was extremely brittle after $2 \mathrm{hr}(\mathrm{b})$, making it impossible to form samples with an aspect ratio of 1 for uniaxial compression testing.

a)

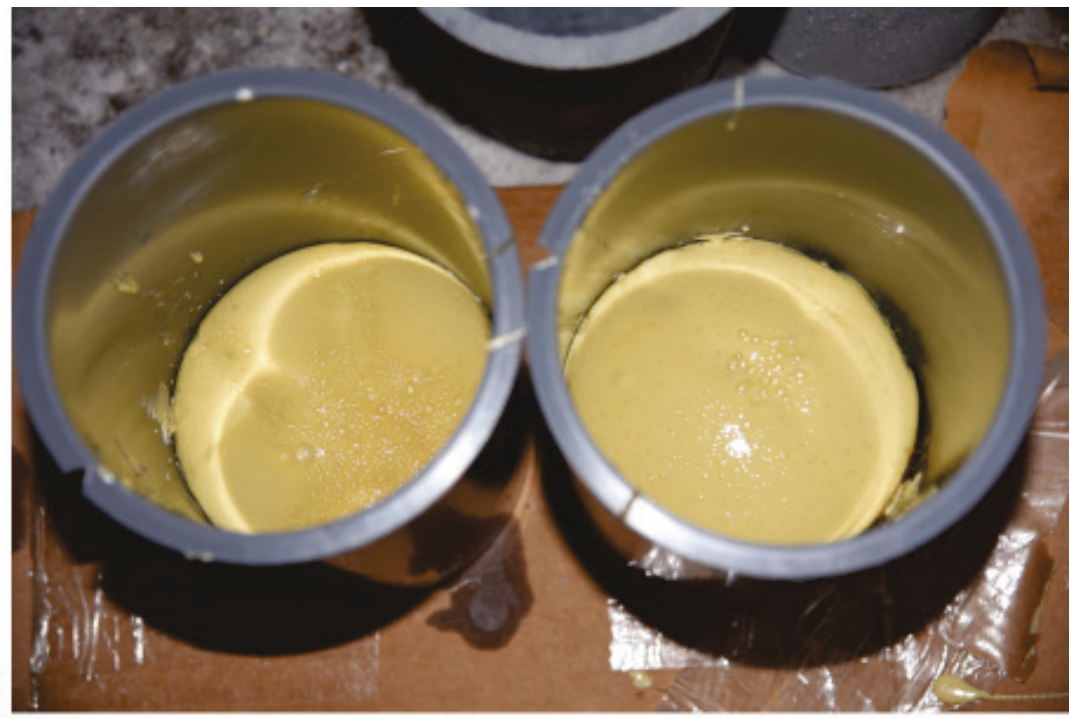

b)

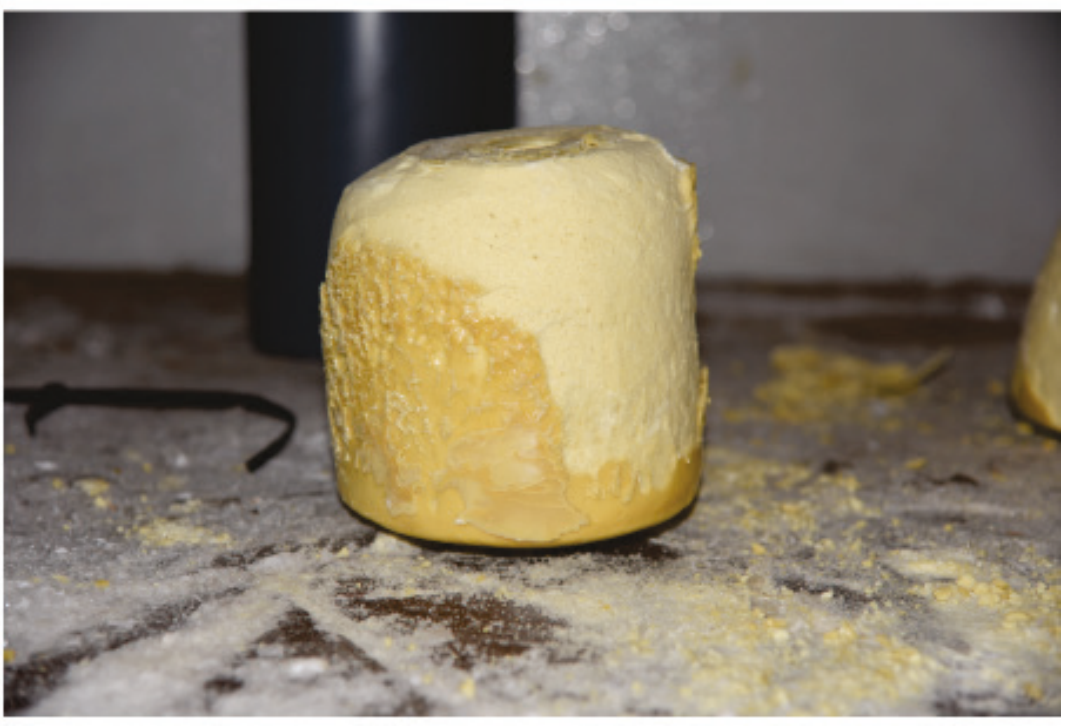




\section{Appendix C: Plots of Compressive Strength versus Temperature for Existing Cementitious Crater Fill Materials}

Figure C1. Compressive strength of Rapid Set concrete at different temperatures from uniaxial compressive testing.

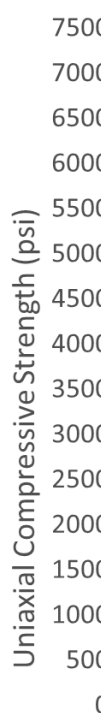

Average Compressive Strength of Rapid Set Concrete

500

7000

6500

6000

5500

5000

4500

4000

3500

3000

2500

2000

1500

1000

0

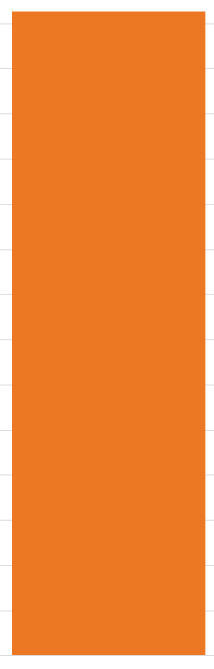

$73^{\circ} \mathrm{F}$

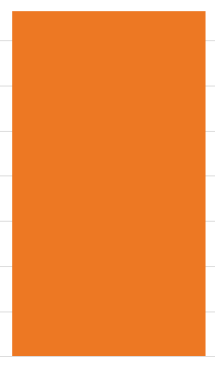

$23^{\circ} \mathrm{F}$

Temperature

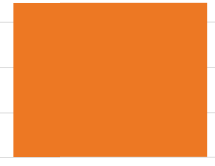

$0^{\circ} \mathrm{F}$ 
Figure C2. Compressive strength of rapid set flowable fill at different temperatures from uniaxial compressive testing.

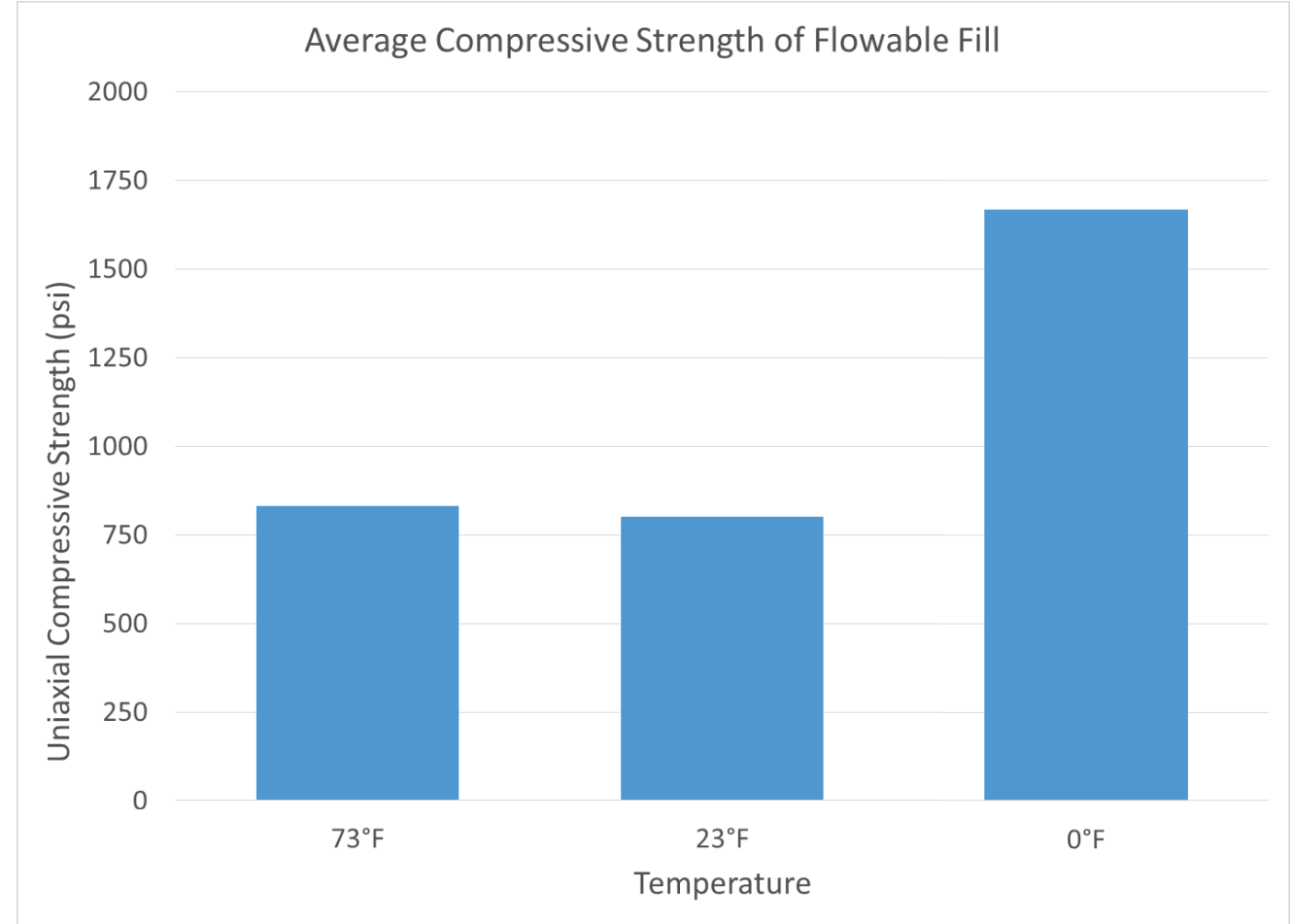




\section{Appendix D: Plots of Compressive Strength versus Temperature for New Crater Fill Materials for use Below Freezing}

Figure D1. Compressive strength of frozen slush from uniaxial compressive testing. Average Compressive Strength of Frozen Slush at $0^{\circ} \mathrm{F}$

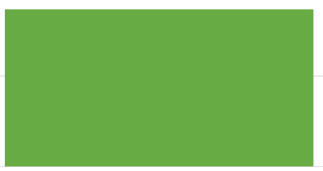

Snow Slurry (2 Parts)

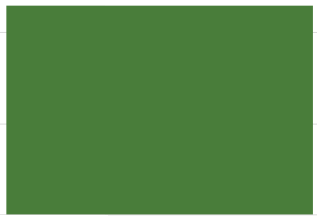

Snow Slurry (3 Parts) 
Figure D2. Compressive strength of ice composite at different temperatures from uniaxial compressive testing.

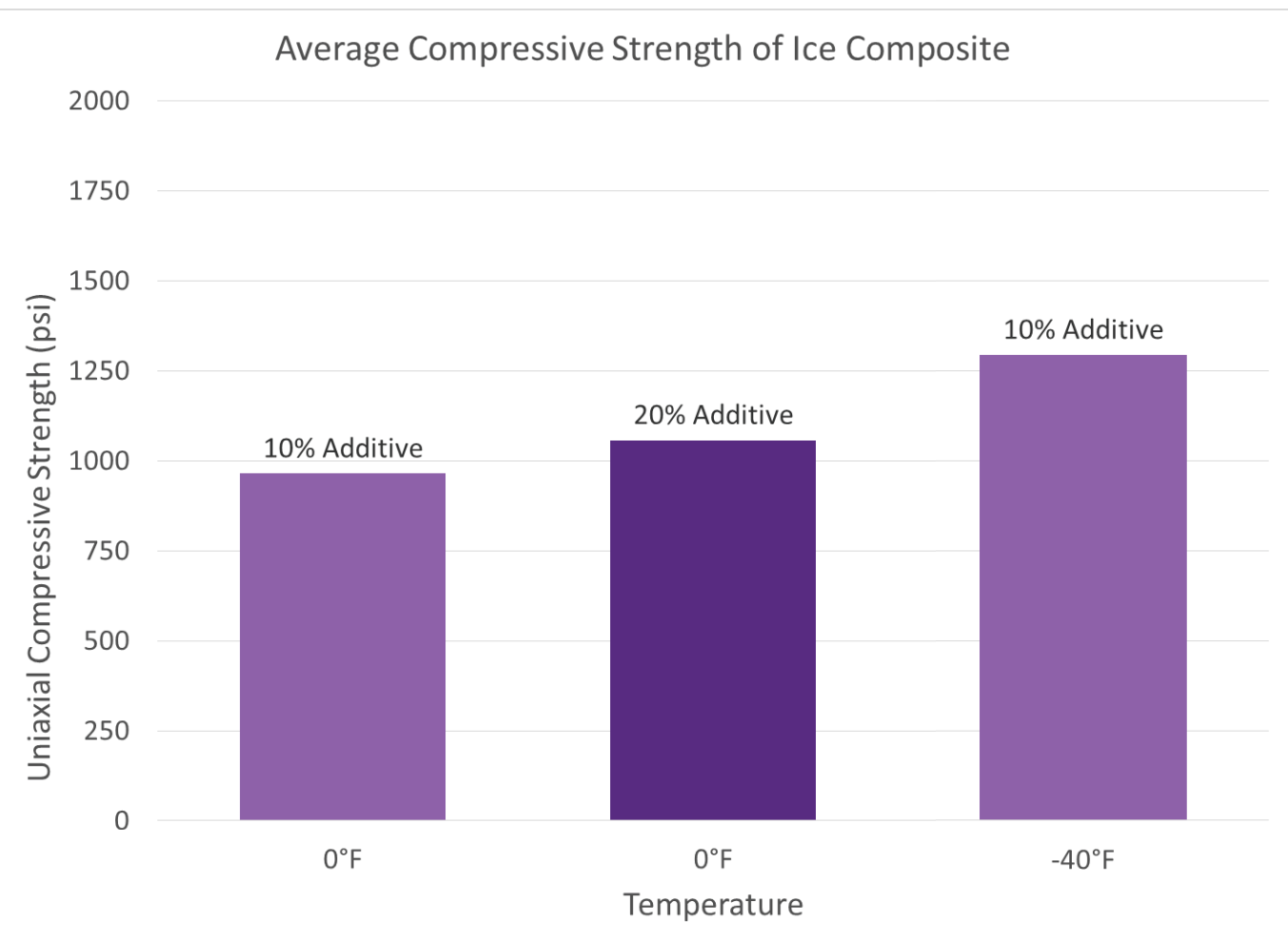

Figure D3. Compressive strength of ice with debris at different temperatures from uniaxial compressive testing.

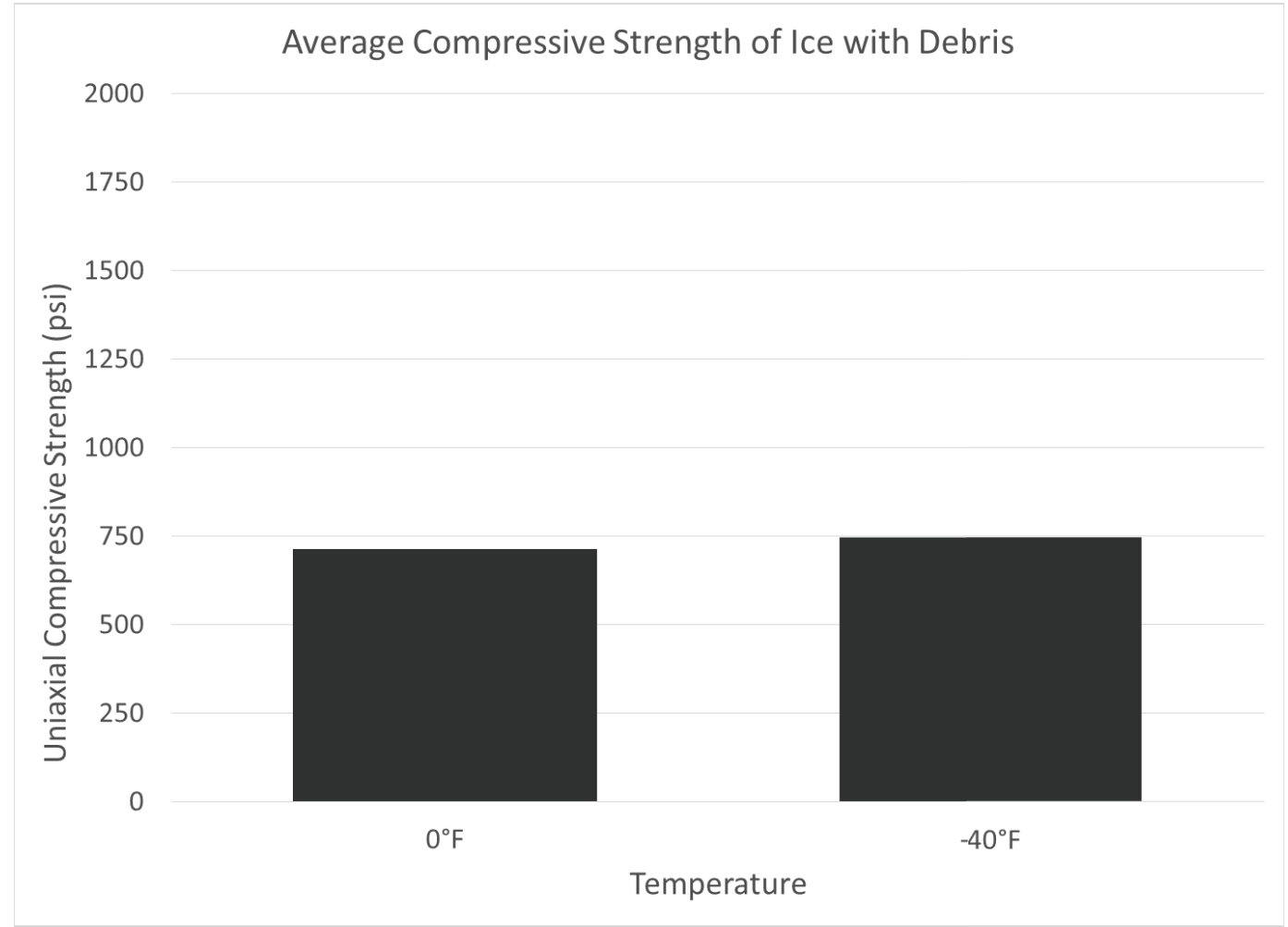




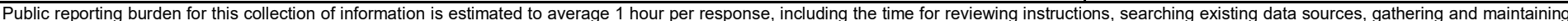

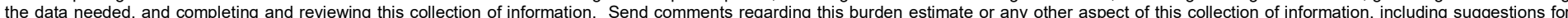

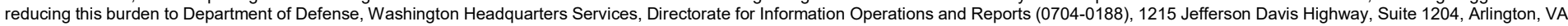

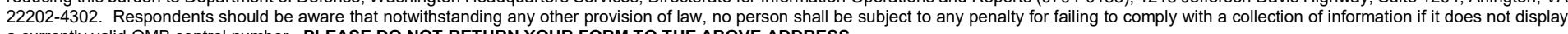
a currently valid OMB control number. PLEASE DO NOT RETURN YOUR FORM TO THE ABOVE ADDRESS.
1. REPORT DATE $(D D-M M-Y Y Y Y)$
2. REPORT TYPE
February 2019

\section{TITLE AND SUBTITLE}

3. DATES COVERED (From - To)

5a. CONTRACT NUMBER

Evaluation of Airfield Damage Repair Methods for Extreme Cold Temperatures

5b. GRANT NUMBER

5c. PROGRAM ELEMENT NUMBER

\section{AUTHOR(S)}

Emily Asenath-Smith, Terry D. Melendy, Jr., Amelia M. Menke, Andrew P. Bernier, and George L. Blaisdell

5d. PROJECT NUMBER

463347

5e. TASK NUMBER

4036

5f. WORK UNIT NUMBER

$842 \mathrm{~L} 1 \mathrm{G}$

\section{PERFORMING ORGANIZATION NAME(S) AND ADDRESS(ES)}

8. PERFORMING ORGANIZATION REPORT NUMBER

Cold Regions Research and Engineering Laboratory

US Army Engineer Research and Development Center

ERDC/CRREL TR-19-2

72 Lyme Road

Hanover, NH 03755

\section{SPONSORING / MONITORING AGENCY NAME(S) AND ADDRESS(ES)}

Headquarters, Air Force Civil Engineer Center

Tyndall Air Force Base, FL 32403-5319

10. SPONSOR/MONITOR'S ACRONYM(S)

AFCEC

11. SPONSOR/MONITOR'S REPORT NUMBER(S)

\section{DISTRIBUTION / AVAILABILITY STATEMENT}

Approved for public release; distribution is unlimited.

\section{SUPPLEMENTARY NOTES}

14. ABSTRACT To address the need for expedient repair solutions for paved runways in cold environments, airfield damage repair (ADR) materials were tested at temperatures down to $-40^{\circ} \mathrm{F}$. New materials and methods were developed to fill the identified performance gaps for conventional ADR materials. Simulated crater repairs were performed at -20 and $-40^{\circ} \mathrm{F}$. Folded fiber glass panels and hinges met the published tensile strength, but did not meet the required flexural strength. Fiberglass-reinforced polyester panels retained their $73{ }^{\circ} \mathrm{F}$ tensile and flexural strengths down to $-40{ }^{\circ} \mathrm{F}$. If required, foreign object debris covers can be used at temperatures below freezing, but further experimentation is needed to fully assess matting candidates at temperatures below $0{ }^{\circ} \mathrm{F}$. Geocell sidewalls and junctions showed an increased maximum force, with a ten-fold decrease in the displacement before failure. Rapid setting flowable fill and polyurethane foam, prepared conventionally, were demonstrated as backfill materials at temperatures as low as $0{ }^{\circ} \mathrm{F}$. As a cap material, Rapid-Set ${ }^{\circledR}$ concrete can be placed using conventional techniques down to $17^{\circ} \mathrm{F}$. Snow and ice materials were demonstrated as backfill materials below freezing and met the strength requirements for capping applications at temperatures down to $-40{ }^{\circ} \mathrm{F}$.

\section{SUBJECT TERMS}

ADR, Runway, Snow, Ice, Pavements, Compo-

sites, Concrete, Mechanical properties,
Concrete-Additives, Geocells, Matting, Runways (Aeronautics)-Maintenance and repair, Runways (Aeronautics)-Cold weather conditions,
16. SECURITY CLASSIFICATION OF:

\begin{tabular}{|l|l|}
\hline a. REPORT & b. ABSTRACT \\
UNCLASSIFIED & UNCLASSIFIED
\end{tabular}

17. LIMITATION OF ABSTRACT

c. THIS PAGE

UNCLASSIFIED
18. NUMBER OF PAGES

SAR
Controlled low-strength materials,

Fills (Earthwork), Composite materials, 